\title{
COMPUTATIONAL MODELING OF FIRE SAFETY IN METRO-STATIONS
}

\author{
By \\ Philip McKeen \\ Bachelor of Architectural Science, Ryerson University, 2009 \\ A thesis \\ Presented to Ryerson University \\ In partial fulfillment of the \\ Requirements for the degree of Master of Applied Science \\ In the Program of \\ Building Science
}

Toronto, Ontario, Canada, 2016

(C) Philip McKeen 2016 


\section{Author's Declaration}

I hereby declare that I am the sole author of this thesis. This is a true copy of the thesis, including any required final revisions, as accepted by my examiners.

I authorize Ryerson University to lend this thesis to other institutions or individuals for the purpose of scholarly research.

I further authorize Ryerson University to reproduce this thesis by photocopying or by other means, in total or in part, at the request of other institutions or individuals for the purpose of scholarly research.

I understand that my thesis may be made electronically available to the public. 


\title{
COMPUTATIONAL MODELING OF FIRE SAFETY IN METRO-STATIONS
}

\author{
Philip McKeen \\ Masters of Applied Science in Building Science, 2016 \\ Ryerson University, Toronto
}

\begin{abstract}
This research investigates and attempts to quantify the hazards associated with fire in metrostations. The use of numerical simulations for the analysis of fire safety within metro-stations allows for the prediction and analysis of hazards within the built environment. Such approaches form the growing basis of performance based design (PBD), which can optimize design solutions. The simulations utilize Fire Dynamics Simulator (FDS), a Computational Fluid Dynamics (CFD) model and Pathfinder, an evacuation modeling software.
\end{abstract}

The safety of underground metro-stations is analyzed through the simulation of smoke spread and egress modelling. CFD models of TTC's Union Station and TransLink's Yaletown Station are developed to allow for simulations of smoke spread scenarios. These models are evaluated in regards to the preservation of tenability and influence on the Available Safe Egress Time (ASET). The egress of metro-stations is modelled and analyzed to determine the Required Safe Egress Time (RSET). 


\section{Acknowledgements}

The development of this research was made possible through support from friends, faculty and family. Tremendous assistance was provided by Dr. Ramani Ramakrishnan of Ryerson University, who provided access to powerful computer processors. This allowed for detailed simulations which would otherwise have been impractical. I would like to extend thanks to my supervisor, Dr. Zaiyi Liao for his tremendous support and to the faculty of the graduate program in building science at Ryerson University.

A noted thanks to the developers of FDS, the National Institute of Standards and Technology (NIST) and VTT Technical Research Centre of Finland. The availability of this software made this research possible. Many thanks are given to Thunderhead Engineering, whom provided educational licenses for PyroSim and Pathfinder software which proved extremely valuable.

The research for fire simulation of polyether polyurethane foam (see Appendix A) was reliant on experimental data provided by the National Research Council of Canada (NRC). The sharing of information and strategies in numerical simulations were critiqued through The Google Discussion Group for Fire Dynamics Simulator and Dr. Kuldeep Prasad of NIST amongst others. 


\section{Table of Contents}

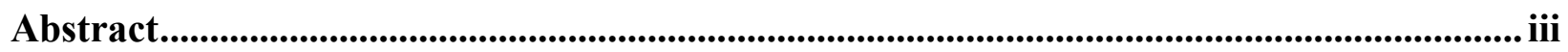

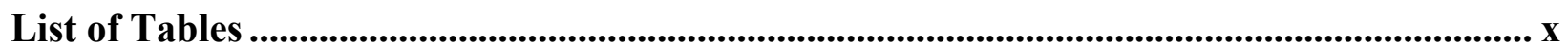

List of Figures......................................................................................................................................... xi

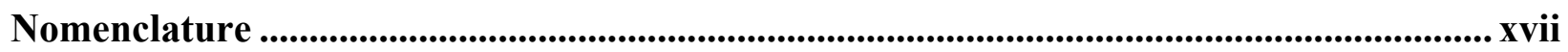

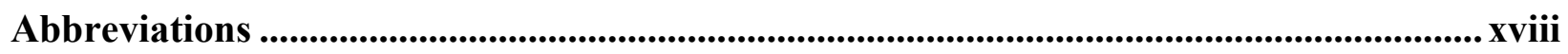

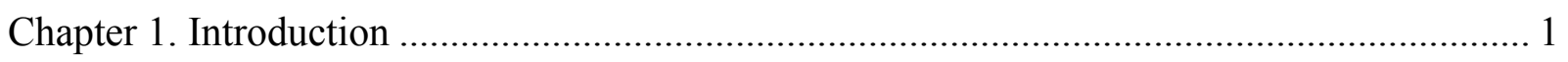

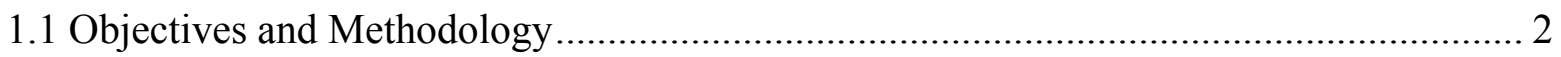

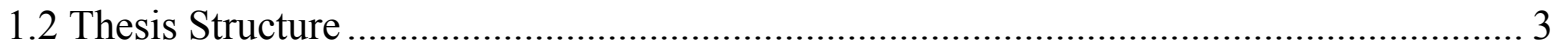

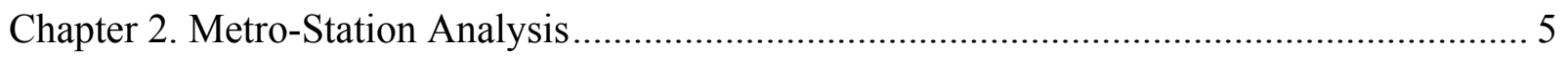

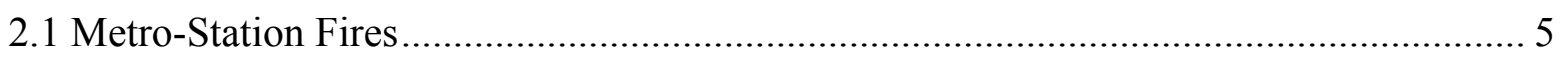

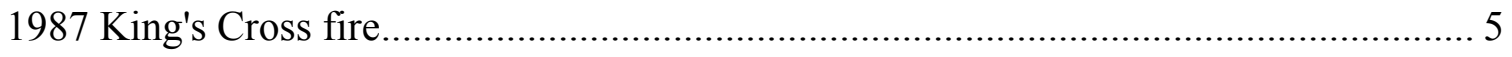

1995 Baku Metro Azerbaijan................................................................................... 5

Daegu, Korea Subway Fire metro train fire, Korea, 2003 ............................................... 5

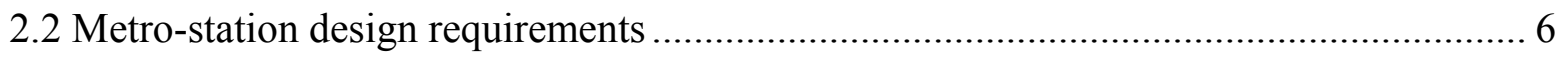

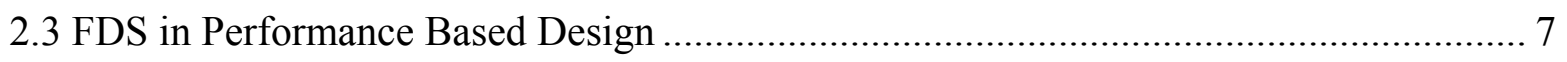

2.4 Determining the Design Fire Size for Simulations........................................................ 9

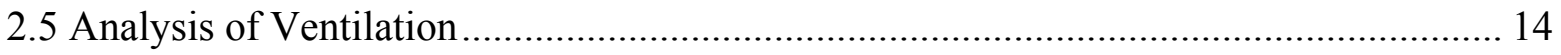

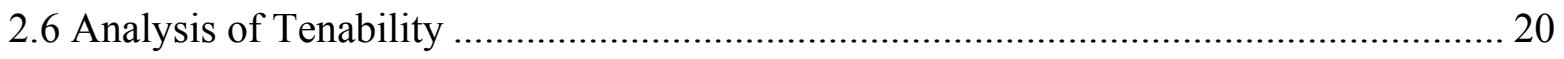


2.6.1 Smoke Spread Simulation Procedure

Chapter 3. Smoke Spread Analysis: TTC's Union Station Platform ......................................... 24

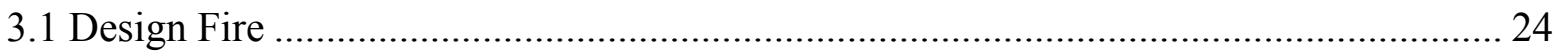

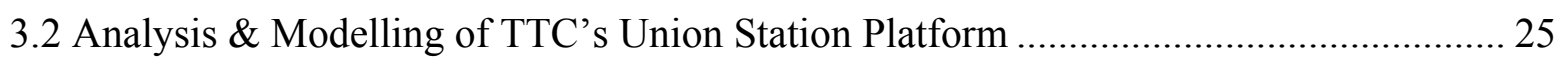

3.3 Developing the Model ................................................................................................ 27

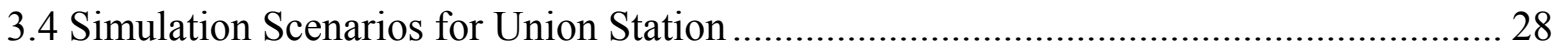

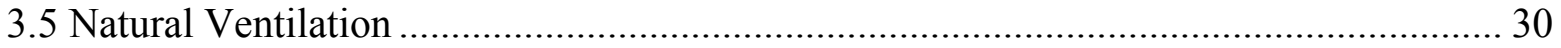

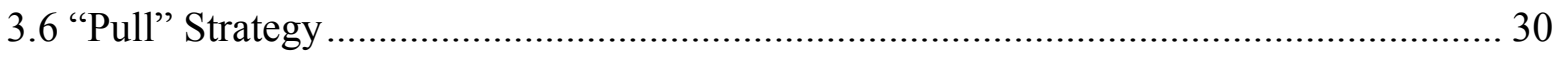

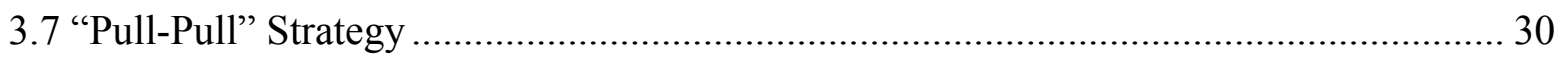

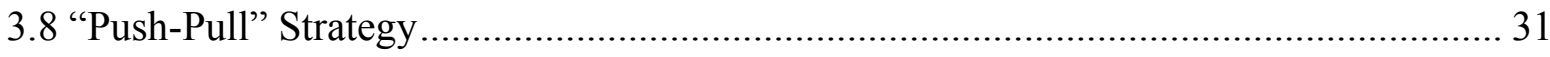

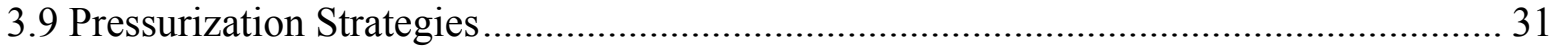

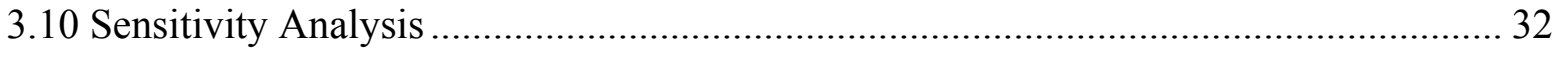

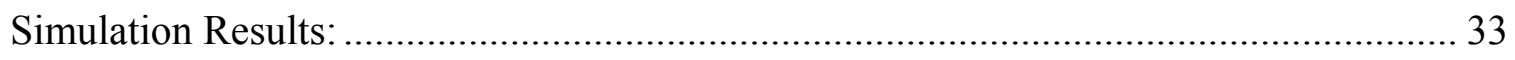

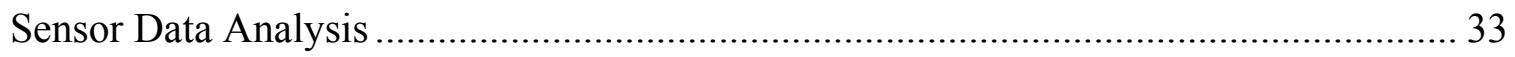

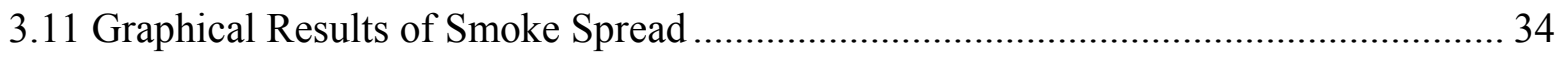

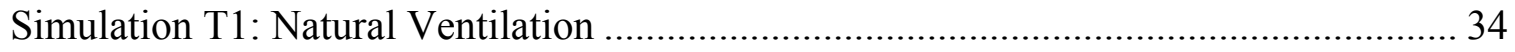

Simulation T2: "Pull" Strategy, Single Exhaust at $80 \mathrm{~m}^{3} / \mathrm{s}$ (E80s) ................................. 35

Simulation T3: "Pull” Strategy, Exhaust at 160m³/s (E160) ......................................... 35

Simulation T4: "Pull" Strategy, Exhaust at 240m³/s (E240) ……………………......... 35

Simulation T5: "Pull-Pull" Strategy, Exhaust 160 m³/s on east and west (E160 | E160). 36 
Simulation T6: "Push-Pull" Strategy, Supply $160 \mathrm{~m}^{3} / \mathrm{s}$ on east and exhaust $160 \mathrm{~m}^{3} / \mathrm{s}$ on

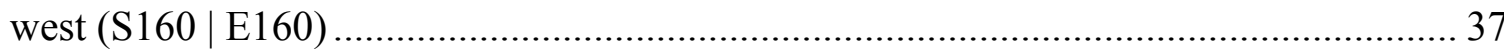

3.12 Analysis of tenability on Platform .......................................................................... 38

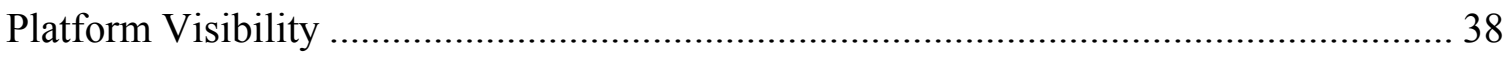

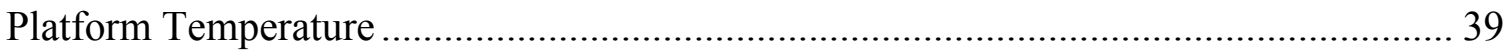

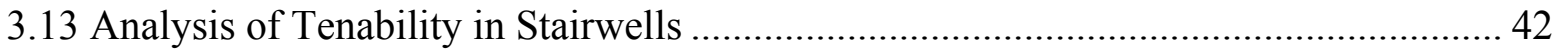

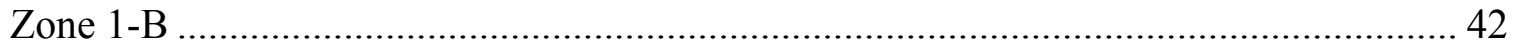

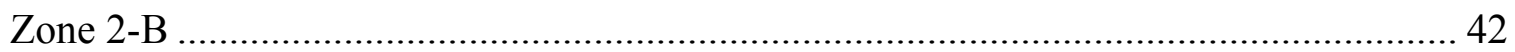

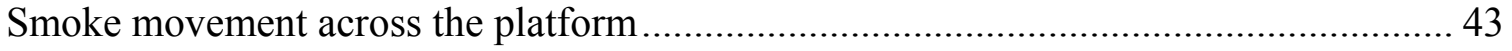

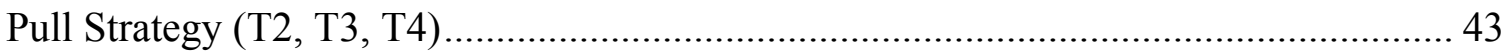

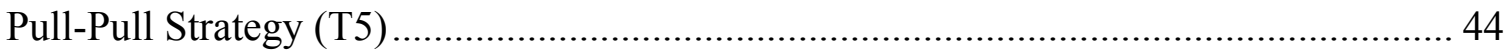

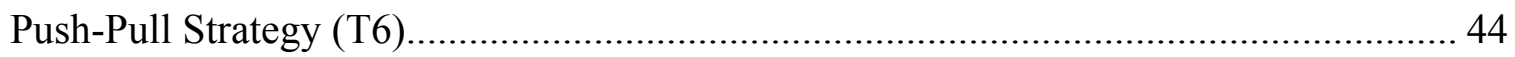

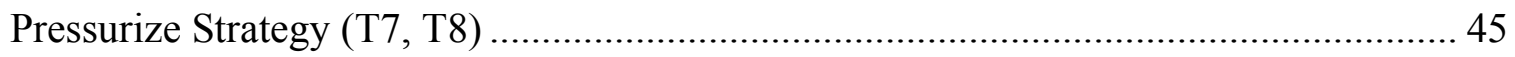

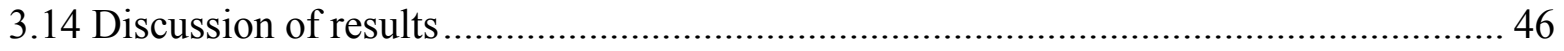

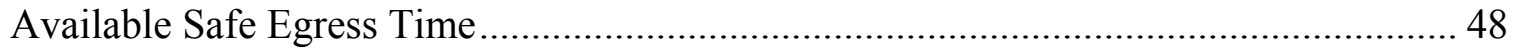

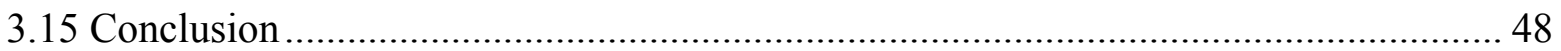

Chapter 4. Smoke Spread Analysis: TransLink's Yaletown Skytrain Station ........................ 49

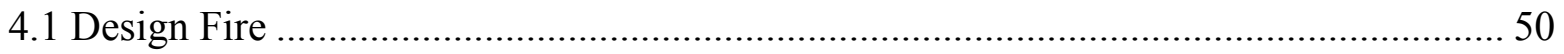

4.2 Analysis \& Modelling of Yaletown Station .......................................................... 51

4.3 Simulation Scenarios for Yaletown station ........................................................... 53 


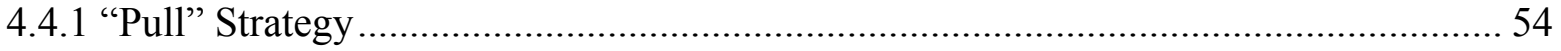

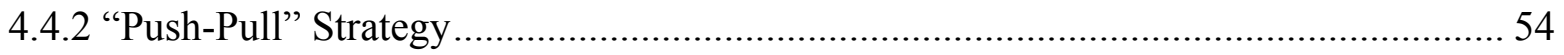

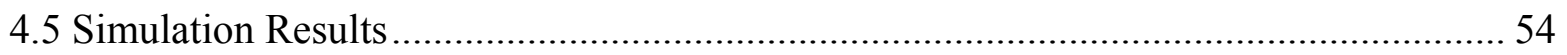

4.6 Simulation Results: Graphical .......................................................................... 55

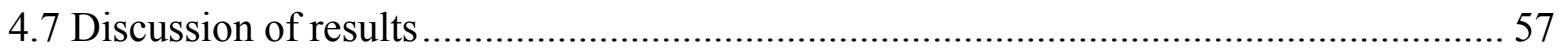

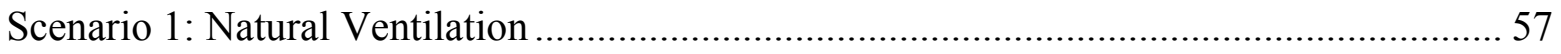

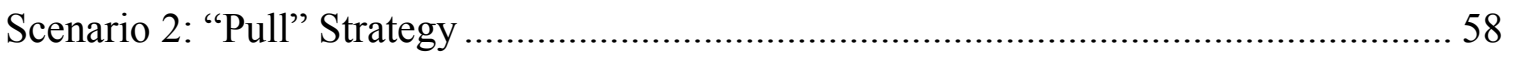

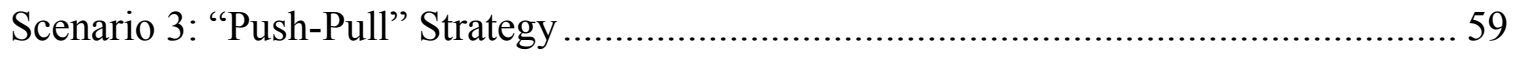

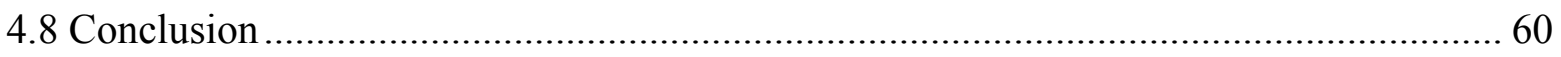

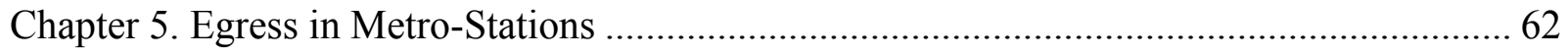

5.1 Analysis of Egress Characteristics in Metro-Stations .......................................... 62

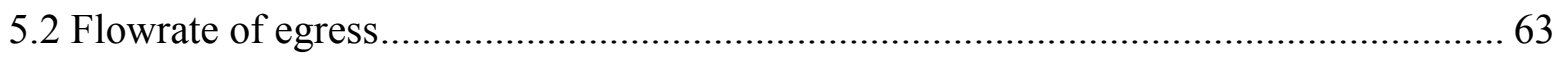

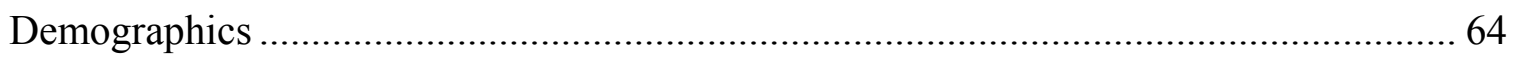

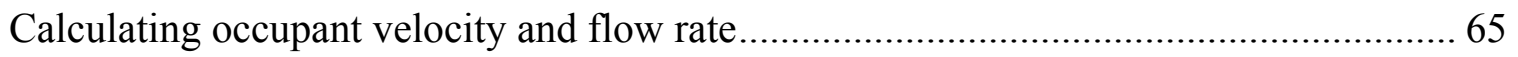

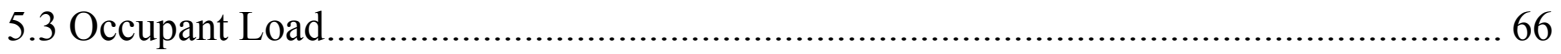

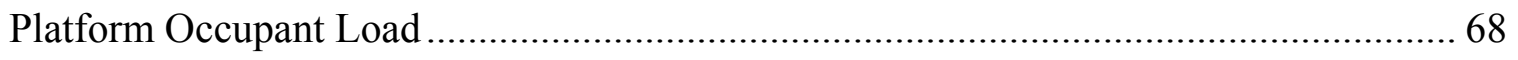

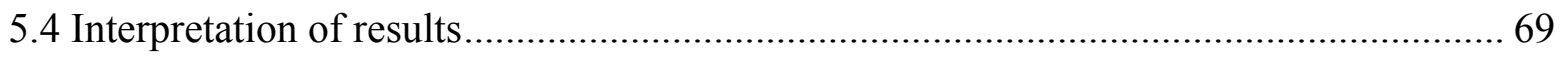

Chapter 6. Egress Analysis: TTC's Union Station Platform............................................. 70

6.1 Egress Scenarios Occupant Load Selection............................................................ 70 


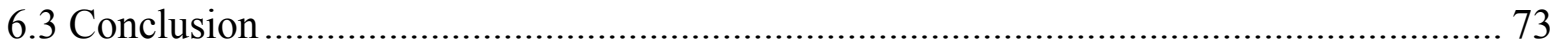

Chapter 7. Egress Analysis: TransLink’s Yaletown Station ............................................... 76

7.1 Egress Scenarios and Occupant Load Selection................................................. 78

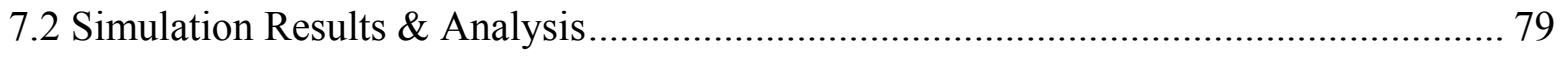

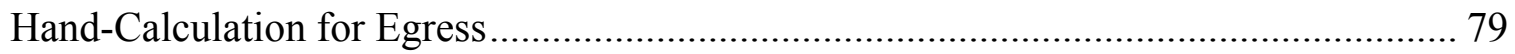

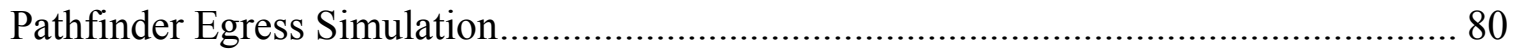

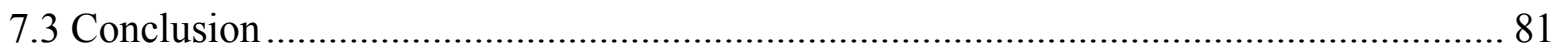

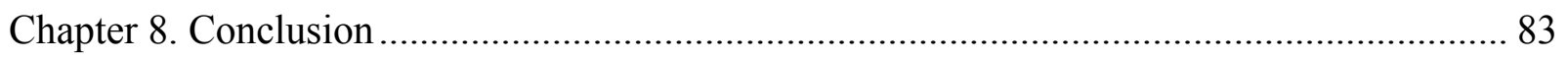

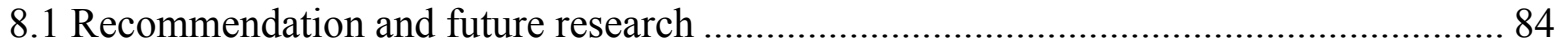

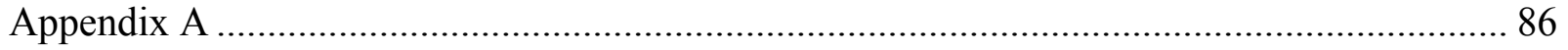

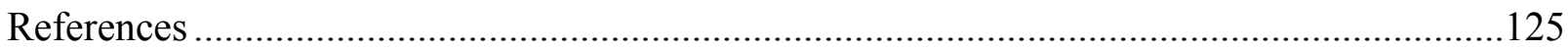




\section{List of Tables}

Table 1 Mechanical Ventilation of Simulation Scenarios ................................................... 29

Table 2 Simulation results summary............................................................................. 46

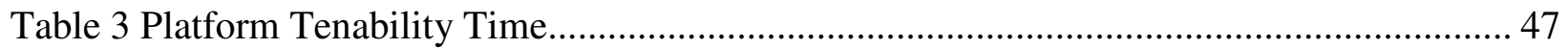

Table 4 Ventilation for Scenarios ................................................................................ 54

Table 5 Average Tenability Time for Zones in Simulation Scenarios ................................... 60

Table 6 Occupant Loads for Union Station ....................................................................... 71

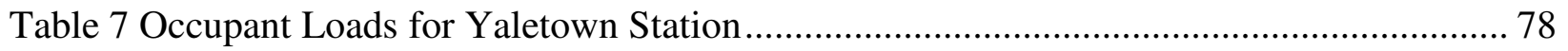

Table 8 Required Safe Egress Time from Pathfinder Simulation.......................................... 81 


\section{List of Figures}

Figure 1 Thesis outline overview

Figure 2 Burning of a metro rail car (White, Dowling, \& Barnett, 2005) and FDS simulation to

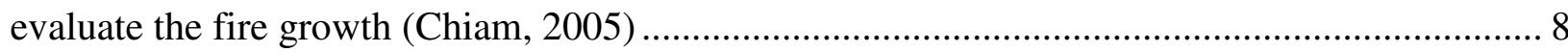

Figure 3 Schematic of TTC T-Series Hawker Sidley car (Bow, 2015) ........................................ 10

Figure 4 The HRR "T-Squared" curve for fires identified as Ultra-Fast, Fast and Medium........ 12

Figure 5 Interior view of Skytrain (left) and exterior view of the car skytrain (right). ............... 12

Figure 6 A ceiling jet is the horizontal movement of hot bouyant gases along the ceiling (Brewer

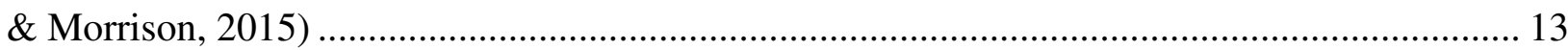

Figure 7 Natural ventilation and the longtitudinal ventilation strategy in tunnels (Li \& Ingason,

$2015)$

Figure 8 Ventilation shafts at the end of platform at TTC's Union Station ................................. 15

Figure 9 The effect on longitudinal tunnel velocity produced by fire and exhaust ventilation

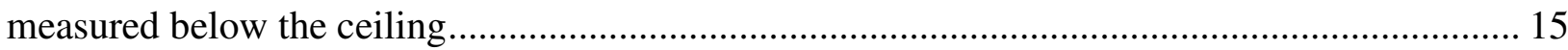

Figure 10 Geometry of the existing station (left), as modeled for smoke spread simulations

(middle) and simplified for critical velocity analysis (right)....................................................... 16

Figure 11 Calculated critical velocity from a growing fire and longitudinal velocity from

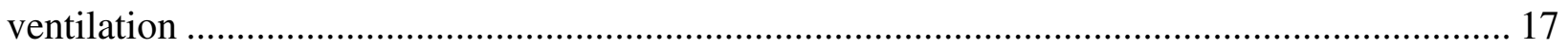

Figure 12 Back-layering occurs when the fire reaches $10 \mathrm{MW}$ despite exhaust ventilation of 400

$\mathrm{m}^{3} / \mathrm{s}$

Figure 13 The exhaust ventilation results in a large influx of fresh air from stairwells ............... 18

Figure 14 Longitudinal tunnel velocity for various exhaust rates located on the west side of the

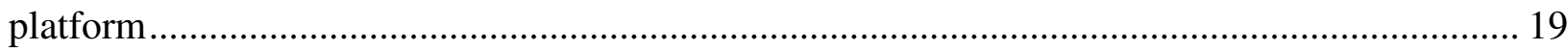


Figure 15 Air velocity measured at end of platform (left) and mid-platform (right) as exhaust rate

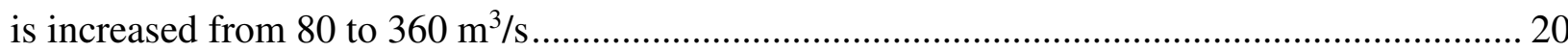

Figure 16 Temperature and visibility is measured and represented graphically. ..................... 22

Figure 17 Platform of Union Station and Yaletown Station................................................ 23

Figure 18 H-Series subway car (left) T-series subway car (middle) and fuel sources (right) (Bow,

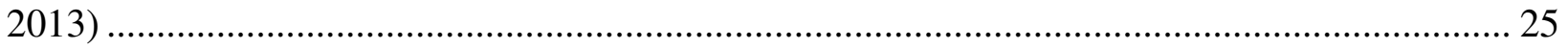

Figure 19 Union Station platform (Toronto Transit Commission, 2011) ................................ 26

Figure 20 Union Station tunnel and platform schematic .............................................. 26

Figure 21 Union Station TTC platform during renovation period...................................... 27

Figure 22 The simulation measures measure smoke, temperature and visibility with sensors at A,

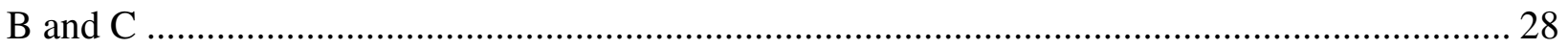

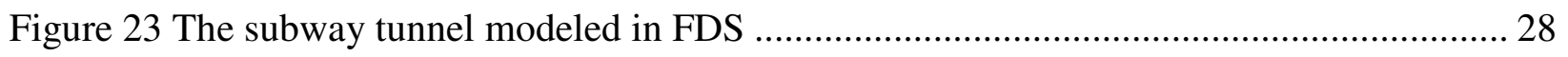

Figure 24 Ventilation shafts at both ends of the platform which can operate in supply or exhaust.

Figure 25 The longitudinal air velocity at stairwell location B1 for simulations of varying mesh

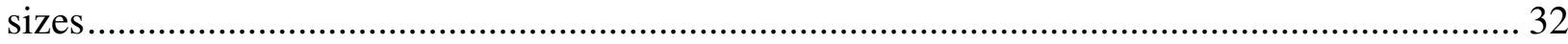

Figure 26 Temperature at platform location A4 for simulations of varying mesh sizes. ............ 33

Figure 27 Smoke spread and visibility on station platform for Natural Ventilaiton .................. 34

Figure 28 Results for smoke spread and visibility for "Pull" strategies ................................. 36

Figure 29 Results for smoke spread and visibility for "Pull-Pull" strategies ........................... 36

Figure 30 Results for smoke spread and visibility for "Push-Pull" strategies .......................... 37

Figure 31 Results for smoke spread and visibility for pressurization strategies....................... 38

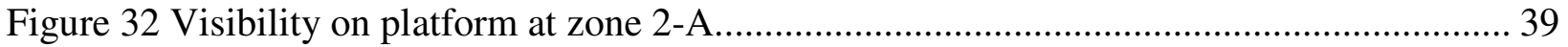




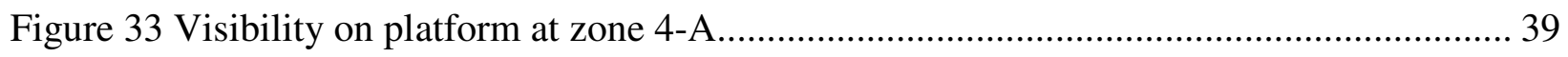

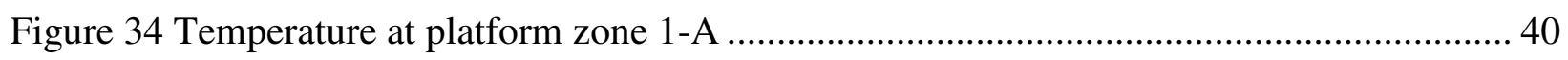

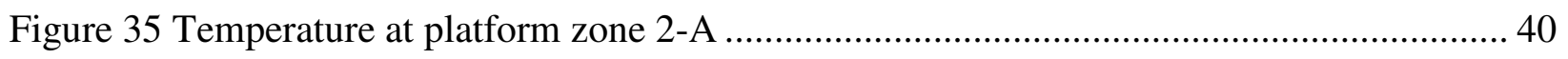

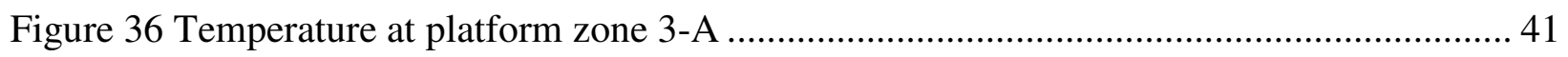

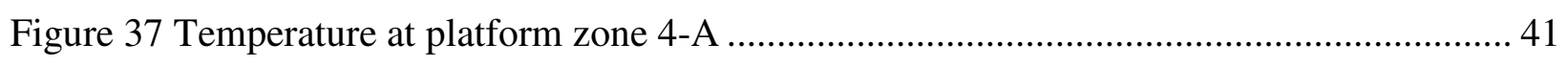

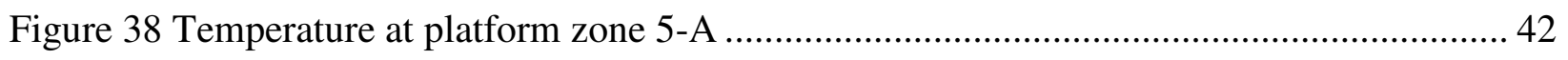

Figure 39 Ventilation strategies effect on smoke spread and the time smoke comprises the space

Figure 40 Duration of tenability for each zone location .................................................. 47

Figure 41 Egress from the Yaletown Station platform is served by one stairway, one escalator

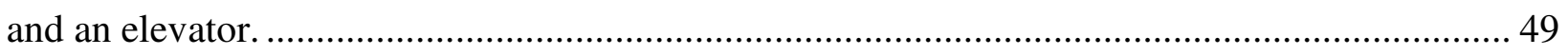

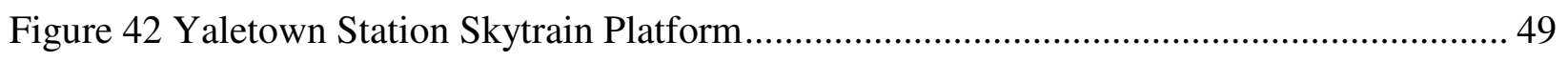

Figure 43 Interior view of Skytrain (TransLink, 2015) and exterior view of the car skytrain (Lo,

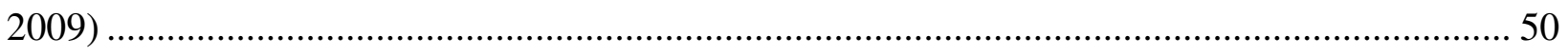

Figure 44 The TransLink Skytrain which serves the Yaletown platform (Translink, 2011)....... 51

Figure 45 Egress from the platform occurs through two stairs and 1 elevator......................... 52

Figure 46 Sectional schematic of Yaletown Station platform ............................................. 52

Figure 47 The subway tunnel modeled in FDS which includes open boundary conditions at

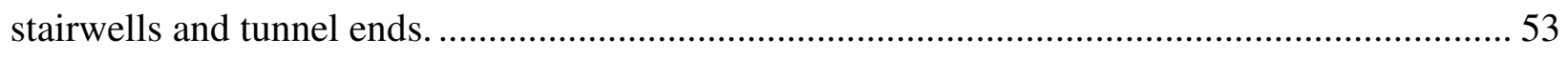

Figure 48 Ventilation shafts at both ends of the platform which can operate in supply or exhaust.

Figure 49 Smoke spread results for Natural Ventilation (left), "Pull" (middle) and "Push-Pull"

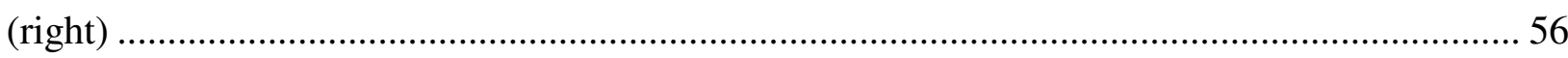


Figure 50 Visibility results for Natural Ventilation (left), "Pull" (middle) and "Push-Pull" (right)

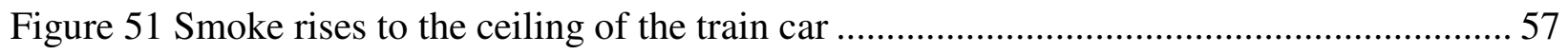

Figure 52 Smoke travels throughout the train and into the station after 50 seconds ................. 57

Figure 53 Visibility becomes untenable at the staging area of the North stairway at around 160

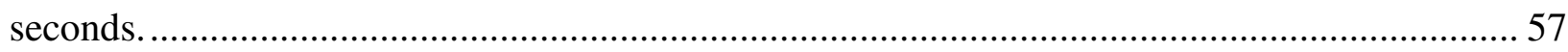

Figure 54 By 190 seconds, no safe paths of egress exist for remaining evacuees..................... 57

Figure 55 Smoke enters stairwell and escalator shaft by 160 seconds. ................................ 58

Figure 56 At 174 seconds, smoke completely engulfs escalator, making it untenable. ............. 58

Figure 57 By 160 seconds, visibility remains and allows access to both stairwells and staging

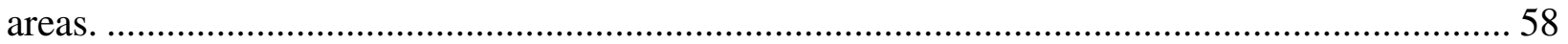

Figure 58 By 190 seconds access to the stairway is still fully tenable. ..................................5

Figure 59 By 220 seconds, the platform is untenable, except for the north end stairway........... 59

Figure 60 By 306 seconds, the north end stairway begins to be untenable as smoke enters....... 59

Figure 61 Station section demonstrating the movement and interaction of gases.................... 59

Figure 62 At 160 seconds, the majority of the platform, stairs and escalator remain tenable..... 60

Figure 63 The platform stabilizes and remains tenable past 565 seconds .............................. 60

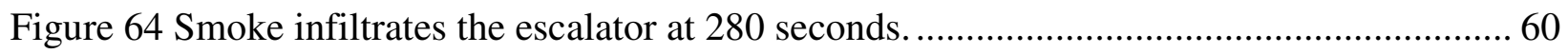

Figure 65- Stairwell width effect on egress in Pathfinder software (left) and anthropometric

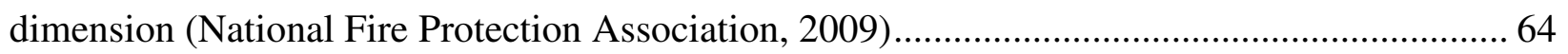

Figure 66 Relationship between speed and density on stairs during evacuation (Choi, Hwang, \&

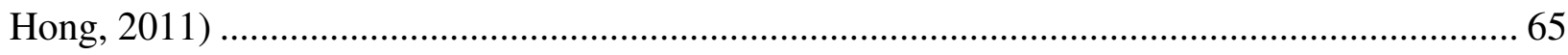


Figure 67 Egress speed (left) and specific flow (right) for corridors and stairs of varying inclinations 66

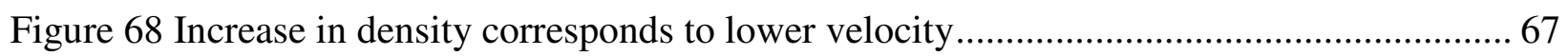

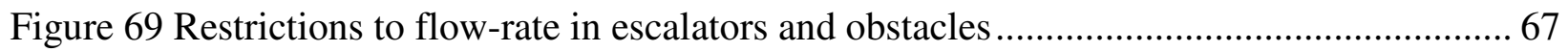

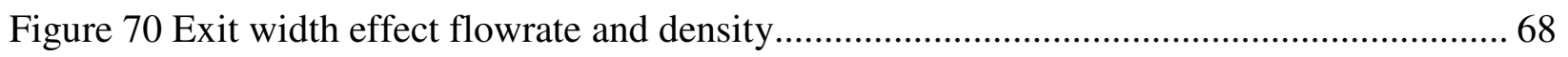

Figure 71 Comparison of evacuation results from train car experiments in Pathfinder (Yunlong,

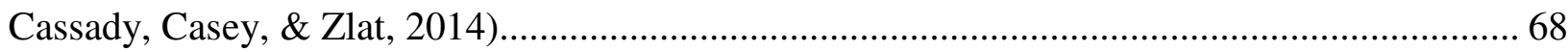

Figure 72 Hawker Sidley T-Series on busy platform (Toronto Transit, 2015) ........................ 70

Figure 73 Union Station platform with 4 different occupant loads and their pre-movement

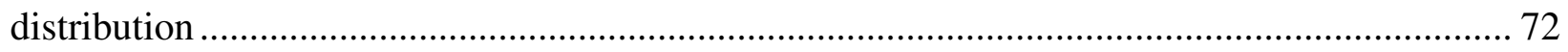

Figure 74 Calculated egress time for varying loads at Union Station .................................... 72

Figure 75 Egress simulation: Pedestrian models in Crush Load Scenario at 360 seconds .......... 74

Figure 76 Egress simulation: Platform Usage Heat Map in Crush Load Scenario..................... 74

Figure 77 Tenability on Platform at 360 seconds in T 6, "Push-Pull" scenario ........................ 74

Figure 78 East stairwell visualization at 415 s during the T6 "Push-Pull" strategy ................... 75

Figure 79 East stairwell egress progress during different loads at times specified................... 75

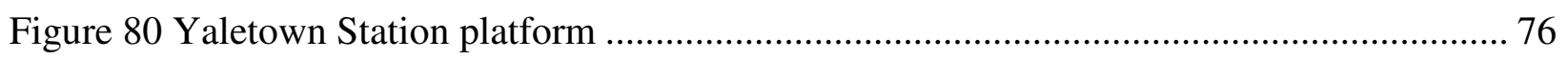

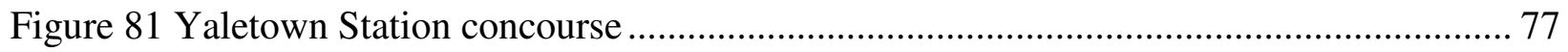

Figure 82 Yaletown station platform, stairs and escalator to the concourse ........................... 77

Figure 83 Schematic of Yaletown Station egress model .................................................. 77

Figure 84 Schematic showing the paths of egress from train to exterior................................. 79

Figure 85 The platform and concourse egress time was calculated cumulatively for each egress

path. 79 
Figure 86 Platform Density at $\mathrm{t}=0$ and $\mathrm{t}=23$ seconds in High Occupant Load Scenario ........... 80

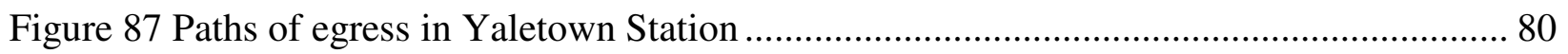

Figure 88 Occupant in simulation over time for High (left) and Medium occupant load (right). 81

Figure 89 Escalator smoke spread and egress simulation.............................................. 82 


\section{Nomenclature}

\begin{tabular}{|c|c|c|}
\hline$a$ & Constant & $\left(0.2666 \mathrm{~m}^{2} / \mathrm{s}\right)$ \\
\hline $\mathrm{A}_{\mathrm{f}}$ & Fuel surface Area & $\left(\mathrm{m}^{2}\right)$ \\
\hline $\mathrm{A}_{\mathrm{o}}$ & Area of opening, $\mathrm{m}^{2}$ & $\left(\mathrm{~m}^{2}\right)$ \\
\hline $\mathrm{H}_{\mathrm{c}}$ & Heat of Combustion & $(\mathrm{kJ} / \mathrm{kg})$ \\
\hline$A$ & Thermal degradation & (ratio) \\
\hline $\mathrm{D}$ & Occupant Flow Density & $\left(\right.$ persons $/ \mathrm{m}^{2}$ ) \\
\hline $\mathrm{D}$ & Diameter & $(\mathrm{m})$ \\
\hline $\mathrm{F}_{\mathrm{s}}$ & Specific Flow & (persons/s-m) \\
\hline $\mathrm{g}$ & Acceleration of gravity & $\left(\mathrm{m} / \mathrm{s}^{2}\right)$ \\
\hline $\mathrm{h}_{\mathrm{o}}$ & Height of opening & $(\mathrm{m})$ \\
\hline $\mathrm{H}^{\prime}$ & Hydraulic tunnel height & $(\mathrm{m})$ \\
\hline HR & Heat Release & $(\mathrm{MJ}$ or $\mathrm{kJ})$ \\
\hline HRR & Heat Release Rate & $(\mathrm{kW}$ or $\mathrm{MW})$ \\
\hline$k$ & Velocity factor & $(\mathrm{m} / \mathrm{s})$ \\
\hline $\mathrm{k}$ & Thermal Conductivity & $(\mathrm{W} / \mathrm{mk})$ \\
\hline $\mathrm{K}$ & Rate of reaction & $\left(\mathrm{s}^{-1}\right)$ \\
\hline $\mathrm{L}$ & Length & $(\mathrm{m})$ \\
\hline $\mathrm{m}$ & Mass & $(\mathrm{kg})$ \\
\hline$\dot{\mathrm{m}}_{\mathrm{f}}$ & Mass burning rate & $(\mathrm{kJ} / \mathrm{kg})$ \\
\hline$\dot{\mathrm{m}}_{\mathrm{f}}$ & Mass flow rate of air & $(\mathrm{kg} / \mathrm{s})$ \\
\hline$\rho$ & Density & $\left(\mathrm{kg} / \mathrm{m}^{3}\right)$ \\
\hline $\mathrm{q}$ & Heat release & $(\mathrm{kJ}$ or $\mathrm{MJ})$ \\
\hline Q & Heat Release Rate & $(\mathrm{kW}$ or $\mathrm{MW})$ \\
\hline Q” & Dimensionless heat release & \\
\hline$\dot{\mathrm{Q}}_{\max }$ & Maximum Heat Release Rate & $(\mathrm{kW}$ or $\mathrm{MW})$ \\
\hline $\mathrm{R}$ & Gas Constant & $\left(8.314 \mathrm{~J} \mathrm{~K}^{-1} \mathrm{~mol}^{-1}\right)$ \\
\hline $\mathrm{t}$ & Time & $(s)$ \\
\hline $\mathrm{T}$ & Temperature & $\left(\mathrm{K}\right.$ or $\left.{ }^{\circ} \mathrm{C}\right)$ \\
\hline $\mathrm{V}$ & Volume & $\left(\mathrm{m}^{3}\right)$ \\
\hline$V^{\prime \prime}$ & Critical Velocity & $(\mathrm{m} / \mathrm{s})$ \\
\hline$v$ & Occupant velocity & $(\mathrm{m} / \mathrm{s})$ \\
\hline
\end{tabular}




\section{Abbreviations}

$\begin{array}{cl}\text { ASET } & \text { Available Safe Egress Time } \\ \text { CFD } & \text { Computational Fluid Dynamics } \\ \text { FDS } & \text { Fire Dynamics Simulator } \\ \text { NFPA } & \text { National Fire Protection Agency } \\ \text { NIST } & \text { National Institute of Standards and Technology } \\ \text { PBD } & \text { Performance-Based Design } \\ \text { RSET } & \text { Required Safe Egress Time } \\ \text { SI } & \text { Safety Index } \\ \text { SM } & \text { Safety Margin }\end{array}$




\section{Chapter 1. Introduction}

The safety in metro-stations is of growing concern due to high population densities, confined space and the growing role they play in supporting the function of major cities. In metro-station fires, the immediate danger to passengers is rarely fire, but rather the smoke which accumulates quickly in the confined space. The application of fire safety in the design process has made substantial influence in the design of new metro-stations systems, influencing both mechanical systems and the architectural design to allow for efficient extraction of smoke. Yet smoke mitigation persist as a challenge for underground mass-transit stations due to the difficulty and cost in providing the necessary mechanical infrastructure. The ventilation system needs to be able to prevent the accumulation of heat, smoke and toxic gases from the egress routes long enough to allow passengers to get to a safe location (Schachenmayr, 1998).

For modern metro-stations, ventilation strategies are the principal method of mitigating the danger of smoke (Kayili, 2005). The onset of PBD and the use of CFD has allowed for accurate simulations of scenarios involving the effect of extraction and supply of air. While this recent tool is employed in the design of modern underground rail systems, many existing stations are of significant vintage and predate the fire safety and egress principles employed today. The information provided by CFD allows for a deeper understanding of the life safety implications passengers face and the improvements which can be made. The analysis of smoke spread and ventilation strategies in metro-stations is examined in this study. 
Metro-station fires do happen frequently, but there have been significant fires in modern city's world-wide that have caused catastrophic death and injury. Within Toronto Transit Commission (TTC) subway system, four tunnel fires have occurred from 1963 to 2000. Standards for fire safety in transit and rail systems have been adopted by many transit systems in the designs of new stations. The adoption of these standards is often not required or enforce. As of 2002, investigations revealed that "only $6.5 \%$ of the below-grade subway system has adequate ventilation in the event of a major fire" (Crean, 2012). Since this time, projects by the TTC to improve egress and ventilation systems has occurred to some metro-stations. Union Station did not receive any upgrades to its infrastructure, until the recent renovation in 2014. The use of primarily prescriptive codes remains common practice, although the opportunity to utilize PBD in validating designs has helped influence development of new stations world-wide.

\subsection{Objectives and Methodology}

The objective of this research is to investigate the hazard posed by fires in metro-stations and evaluate the effectiveness of ventilation strategies on maintaining life safety. The use of CFD and egress modelling has greatly enhanced our ability to analyze threats from fire and smoke through simulations. This is a new and valuable resource that has only become available and practical in recent years. The benefits they can provide are significant and allows us to:

- ascertain hazards from fire and smoke of existing metro-stations

- optimize strategies for mitigating the effects of fire and increasing tenability time

- evaluate the means of egress means available and determine the risk which occupants face

- develop goals for life safety that can become standardized in the development of future metro stations 
The dynamic nature of fires and the catastrophic consequence demands the use of PBD to evaluate existing and future metro-stations. Prescriptive codes cannot adapt to the complexity of metro-station designs and their level of safety can never be ascertained. PBD allows us to determine goals for a level of safety and qualify them through experimentation. Ensuring that passengers can evacuate a metro-station prior to conditions becoming untenable is a clear goal that PBD can address. Others goals can be defined as well, such as the protection of property.

Utilizing a PBD approach is an iterative process which attempts to determine a reasonable performance based on the life safety goals. This involves a detailed examination of metro-station characteristics, including the design geometry, fire load, mechanical ventilation, occupant loads and egress capacity. The maintenance of tenability within the egress paths is evaluated using CFD simulations. The study focuses on two Canadian metro-stations, TTC's Union Station platform in Toronto and TransLink's Yaletown Station. The principles applied in this study can be applied to other metro-stations worldwide.

\subsection{Thesis Structure}

The investigation of the characteristics of metro-stations and the fire consequences are determined in Chapter 2. This includes the reviewing the attributes of metro-stations such as geometry, fire load density and mechanical ventilation. Chapter 3 and 4 evaluate the spread of smoke in Toronto's Union Station TTC platform and Vancouver's Yaletown Station respectively. The ASET is assessed for each station for a number of ventilation strategies.

Chapter 5 investigates the egress of metro-stations and the methods of modeling. Chapter 6 and 7 
investigate the modelling of the Union Station platform and Yaletown Station to determine the RSET. This is compared to the ASET determined previously. Chapter 8 summarizes the conclusions gained through this research (Figure 1).

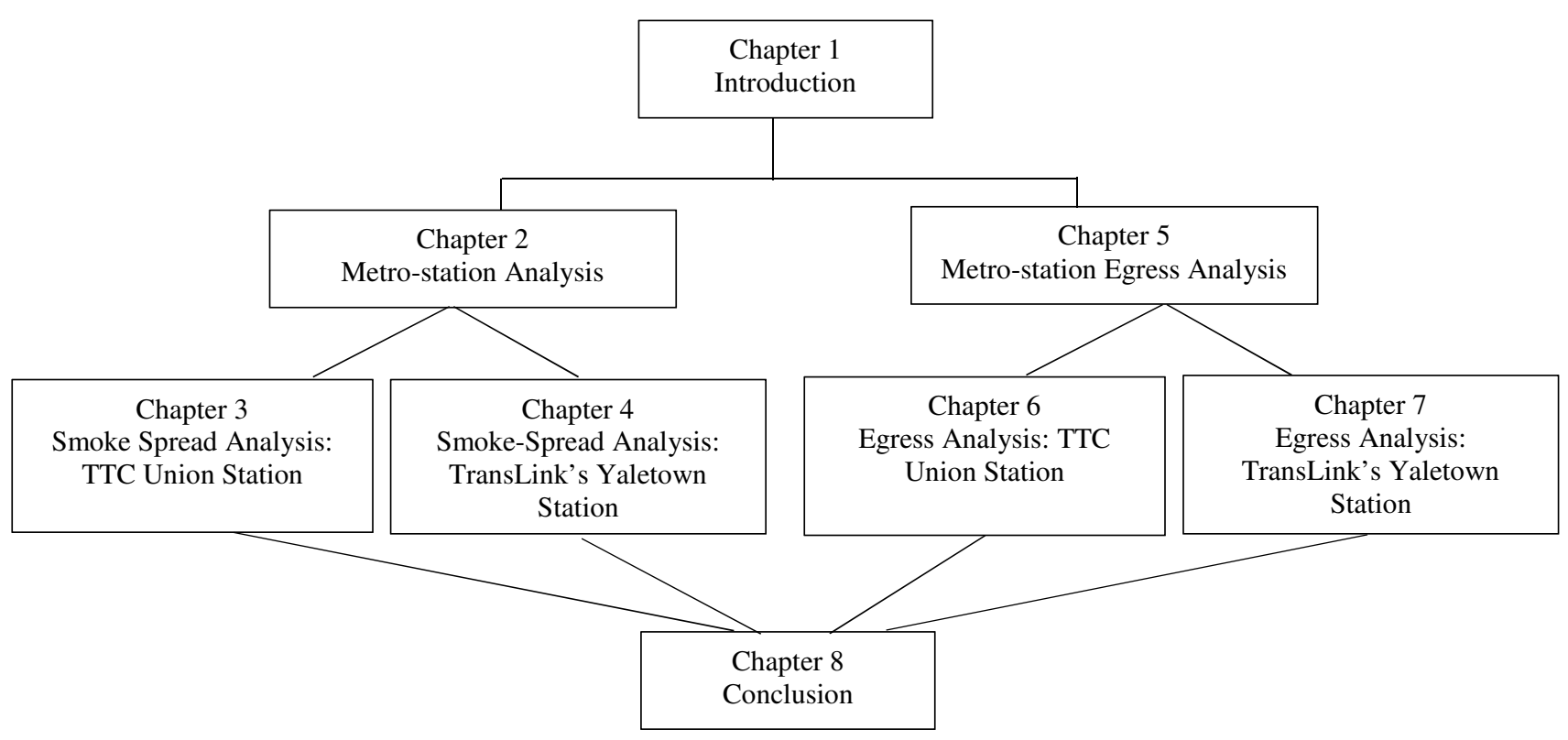

Figure 1 Thesis outline overview 


\section{Chapter 2. Metro-Station Analysis}

\subsection{Metro-Station Fires}

Several fires have occurred in metro-stations and prove that the potential for mass casualties is high. Over the past three decades, significant disasters have warranted increasing attention towards tunnel fires from fire safety engineers and building officials. In almost all cases, subway fire fatalities are caused by smoke inhalation. The effect of smoke, population density and panic make tunnel fires especially dangerous.

\section{King's Cross fire}

Fatalities: $18 \quad$ Injuries: 100

The King's Cross fire occurred in an escalator connecting the subway platform to the station concourse. The fire most likely originated from a passenger discarding a lit match while on the escalator. The burning match is believed to have fallen on the escalator running track and came in contact with grease. The fire and smoke filled the escalator shaft minutes later flashover occurred. This trapped hundreds of people below ground who were fortunate to escape on departing trains (Cox, Chitty, \& Kumar, 1989).

1995 Baku Metro Azerbaijan

Fatalities: $286 \quad$ Injuries: 270

The Baku Metro fire resulted from an electrical fault during evening rush hour. Smoke began to fill the train cars while on-route. The train stopped 200 meters from its nearest station. Some passengers were able to evacuate but the majority did not. The fire is believed to have been caused by outdated equipment and lack of maintenance (Chiam, 2005).

\section{Daegu, Korea Subway Fire metro train fire, Korea, 2003}

Fatalities: $192 \quad$ Injuries: 151

The fire was resulted from arson onboard a train arriving at Jungangno Station in Daegu. The 
homicidal fire started when a container of gasoline was spilled and ignited. The fire spread to all cars within two minutes. The incident occurred during late morning rush hour. Numerous points of failure occurred in the response, particularly with the train operator failing to notify officials. Minutes later a second train entered the station alongside the fire. The operator shut the train down, unintentionally locking all passengers inside (Hong, 2004).

\subsection{Metro-station design requirements}

The TTC has had three major fires over its history. These fires occurred at Union Station in 1963, Christie Station in 1976 and a tunnel fire in 1997 near Greenwood Station. The latest resulted in the TTC's decision to overhaul a number of stations in the Fire Ventilation Upgrade Project (Crean, 2012). The project consisted of an analysis of existing stations to evaluate smoke movement and proposed remedial action using mechanical ventilation to address shortcomings. As stated in the Commission report, "only 6.5\% of below grade subway systems had an adequate ventilation system to deal with a major fire" (Toronto Transit Commission, 2015). The study determined "the majority of existing TTC subway systems could not adequately ventilate smoke from small fires. At the time, TTC management held that "the deficiencies identified in the ventilation system capacity represent an unacceptable level of risk to the public safety in the event of a major fire" (Crean, 2012). Ventilation upgrades occurred at a number of stations determined by the TTC in regards to the severity of hazard vs. the economic impact and practicality of renovations (Toronto Transit Commission, 2015). Union Station did not receive any upgrades to its infrastructure, until the recent renovation of 2014.

Best practices and standards exist for the design and expectations of safety in underground platforms. National Fire Protection Agency (NFPA) 130 "Standard for Fixed Guideway Transit 
Systems" is widely used internationally and prescribes safety requirements train and station, along with criteria for the duration of evacuation. The standard is not enforceable, but many transit systems have elected to adopt its requirements (Chiam, 2005). Despite the widespread application of NFPA 130, which allows for provisions of Performance Based Design (PBD), the implementation of some of its criteria have been criticized by the TTC. Disagreement was voiced over the "4-minute rule" which NFPA 130 requires for full platform evacuation (Crean, 2012).

\subsection{FDS in Performance Based Design}

In order to investigate the spread of smoke throughout metro-stations, simulations were performed using FDS. Its use is employed in the fire research and safety consultants to evaluate fire growth, heat and smoke transport. It has been used to reconstruct many fire experiments and incidents successfully (Madrzykowski, Forney, \& Walton, 1999; McGrattan \& Hamins, 2006). It is utilized in the evaluation of smoke spread in tunnels, including the tenability of metro-station designs. Due to the enormous processing demands associated with large smoke spread models, the adoption of its use has only become practical for large scale simulations in recent years.

FDS is able to simulate fire, heat and smoke transport in a three-dimensional environment utilizing hydrodynamic, combustion and radiation models. The hydrodynamic model performs Navier-Stokes equations suitable for thermally driven flow. The model uses a large eddy simulation (LES) technique to solve turbulent motion. This is the default mode and used in simulations in this study. Under the LES approach, FDS uses a mixture fraction-based combustion model. This model approximates the combustion process over time, calculating combustion from the mixing rates of fuel and oxygen. A comprehensive overview of the numerical methods utilized in the FDS model is available from NIST (McGrattan, et al., 2010). 
Significant progress in the combustion and pyrolysis model of material fires was developed consecutively with this research. The creation of an accurate fire model for polyurethane foam presents promise for the expansion of larger models and applications (See Appendix A). The use of this approach can allow for the analysis of railcar fire simulations and prediction of the fire growth and smoke produced. Integration with multiple fuel types, fuel scenarios and verification and validation exercise are needed.

Train cars represent large fire loads with high heat release rates. It remains an area in need of further investigation regarding the growth of fire within railcars and stations (White, Dowling, \& Barnett, 2005). Significant problems exist merely for the burning of railway cars to gather data surrounding fire growth within the compartment. Field experiments of railcar fires are costly, particularly if current models are used, environmental damage and a limited ability to observe and manipulate variables. The FDS fire models can be employed in this regard, allowing for observable results of multiple scenarios (Figure 2).
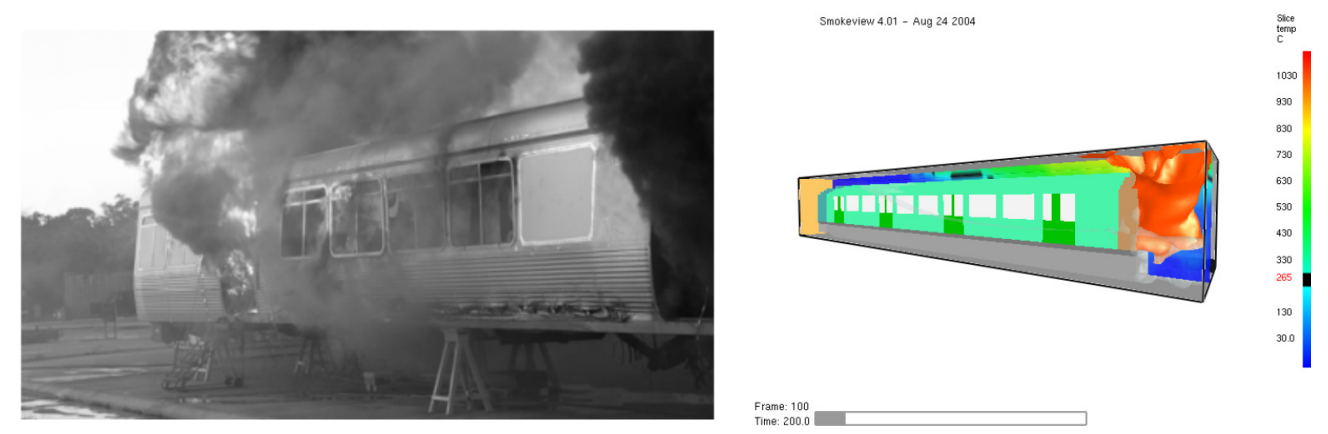

Figure 2 Burning of a metro rail car (White, Dowling, \& Barnett, 2005) and FDS simulation to evaluate the fire growth (Chiam, 2005) 
While FDS is capable of utilizing a full combustible model, where fuel sources are ignited and combusted based on radiation and heat transfer, the complexity and processing power required are overwhelming. However, development of the combustible fuel models is continually producing accurate recreations of fires. It is expected that the use of fuel combustion models will be integrated in safety analysis in the future.

For the purposes of producing a smoke spread simulation, the use of a design fire is implemented. The design fire replicates a desired fire through a formula describing its growth rate, size and smoke production. The design fire approach has become standardized in the analysis of life safety in buildings, with heat and smoke introduced at specific rates.

\subsection{Determining the Design Fire Size for Simulations}

Knowing the size of a possible train fire is critical in the design of a ventilation system. A fire can overwhelm a station if the ventilation is unable to exhaust sufficient quantities of smoke. Yet the fire load of a subway car can vary dramatically depending on the design, size, furnishing, finishes and miscellaneous items brought onboard (newspaper, luggage etc). In practice, it is common to find design fires used in smoke spread simulations to be remarkably low. Many design based projects utilize a maximum fire of $5 \mathrm{MW}$ and express concerns on the validity of fire sizes used in simulations (Chow, 2012). The fire sizes possible in subway fires are much larger and a review of various experiments and historical data suggest peak heat release rate to range between 7 and $43 \mathrm{MW}$ within 5 to 80 minutes (Chow, Lam, Fong, Li, \& Gao, 2011). A limited quantity of experiments exist due to the cost, size and emissions produced. The fatal Daegu subway fire in Korea was estimated to be at least 20 MW (Chow, 2004). 
The design fire simplifies the fire dynamics modeled, which would exist in real life. For instance, a fire in a subway car may initially confine smoke except openings such as doors. Inevitably, the windows will be compromised from heat and smoke will exit at windows locations (Figure 3). Thus, the HRR of the fire will also be subject fluctuation due to varying oxygen content during combustion. These details are important to consider for their impact. However, simplifying the subway car fire with a design fire is still the common method as less costly in calculation and les complex. The design fire can properly relied on as long as a suitable fire size and growth rate is determined. Modern subway cars contain far less combustible materials, less upholstery and more stringent flame spread requirements prescribed through NFPA 130. Determining a design fire is an integral part of utilizing the CFD simulation in this purpose.

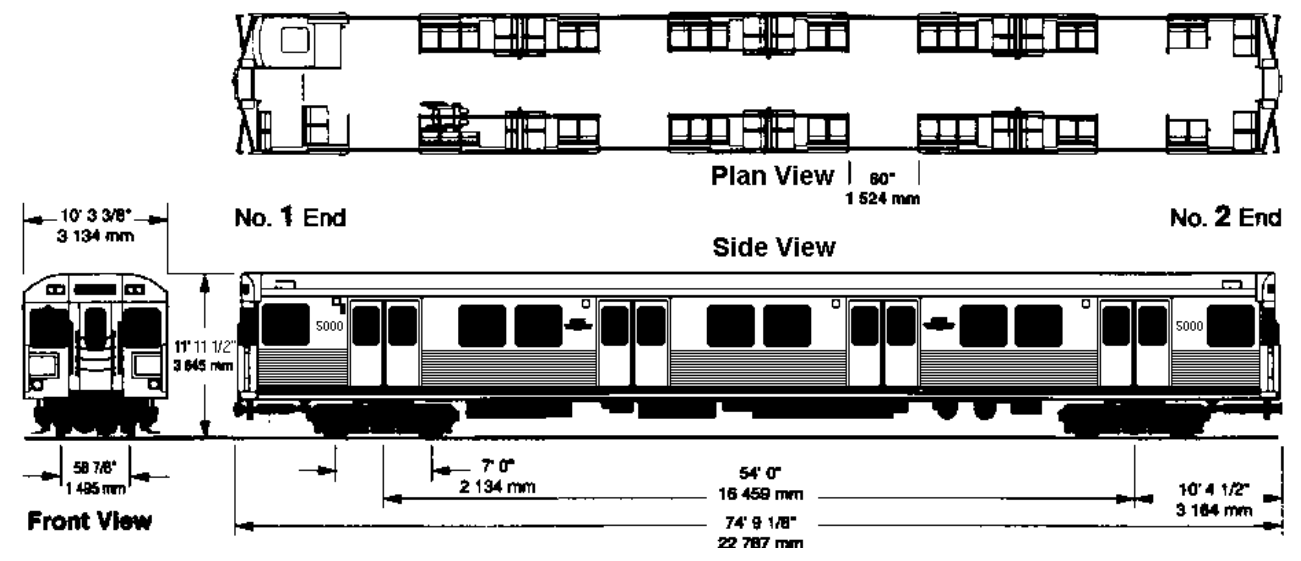

Figure 3 Schematic of TTC T-Series Hawker Sidley car (Bow, 2015)

Calculating the fire load is not a standard practice and its utilization exist within many different forms and assumptions. Some methods synthesize material properties and HRR curves from bench scale experiments and combine this with surface area. However, peak HRR will be vastly affected by the interaction within geometry, its radiation, convection and flashover. Utilizing CFD to determine fire loads in conjunction with bench scale material experiments promises to be an optimal solution, however, the application of this is not widespread, reliable or practical due 
to processing cost at the current time (Chow, 2012). While not optimal, simple rules of thumb do exist for calculating peak HRR, which closely resemble experiments and observations of actual burning train cars. The theoretic peak HRR, $\dot{\mathrm{Q}}_{\max }$, for the subway is the product of the effective heat of combustion, $H_{c}$, mass burning rate, $\dot{m}_{f}$, and total surface area of the material, $A_{f}(\mathrm{Li}$ Y. Z., 2014).

$$
\mathrm{Q}_{\max }=\sum \dot{\mathrm{m}}_{f, i} A_{f, i} \Delta H_{c, i}
$$

The theoretic peak HRR value represents all the combustible material at peak heat release rate simultaneously. However, in a subway fire this is not realistic as some fuels, such as seat fabric and lining would be depleted early on and other surfaces potentially charred. Most significantly, with fuel combusting in the compartment, oxygen levels will plummet forming a ventilation controlled fire (Li Y. Z., 2014). While windows near the fire may break relatively quickly, windows furthest from the fire may stay intake for quite some time. The degree to which windows ventilate the fire is a variable that would vastly affect the HRR. An estimation of the possible fire size, $Q_{\max }$, limited by the openings of a subway car can be obtained by the following (Li Y. Z., 2014):

$$
\begin{aligned}
& \dot{\mathrm{m}}_{\mathrm{a}}=0.5 \sum \mathrm{A}_{\mathrm{o}, \mathrm{i}}, \mathrm{h}_{\mathrm{o}, \mathrm{i}}^{1 / 2} \\
& \mathrm{Q}_{\max }=1.85 \dot{\mathrm{m}}_{\mathrm{a}}
\end{aligned}
$$

In this calculation, the potential peak HRR could range between 15 and $80 \mathrm{MW}$ depending on the amount of openings available for a fire on a typical subway car. The rate of fire growth within the subway car is dependent on flame spread and resistance of materials. Review of 
subway HRR demonstrates growth rates in accordance with "t-squared" formula seen in Figure 4. The standard HRR curves between are noted as medium $(\alpha=0.01172)$, fast $(\alpha=0.0469)$ and ultra-fast $(\alpha=0.1876)$. The fast growth curve was selected for all metro-station simulations. It is assumed that the modern train cabins generally have less flammable materials, but still contain significant quantities of combustible contents (Figure 5). Future studies should be conducted on different fire growth rates. The fire growth rate plays a significant role in the ASET. It can be noted that the fire growth rate can be above ultra-fast, due to arson (Liu, 2014).

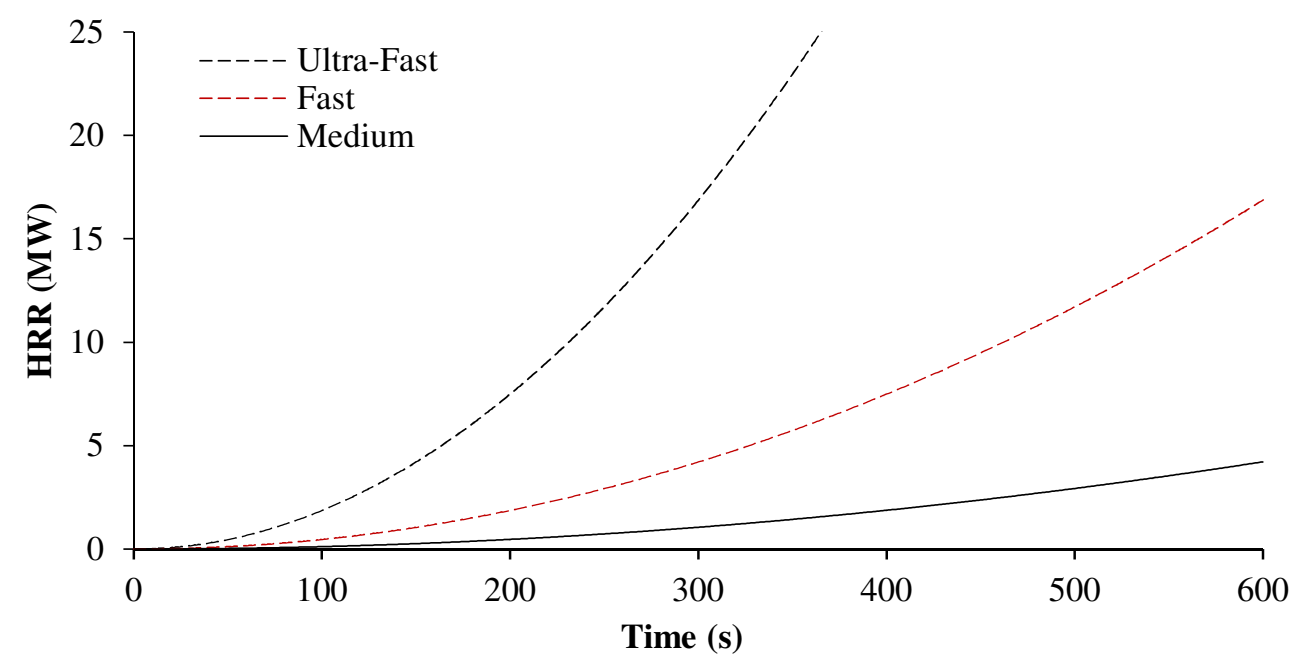

Figure 4 The HRR "T-Squared" curve for fires identified as Ultra-Fast, Fast and Medium.
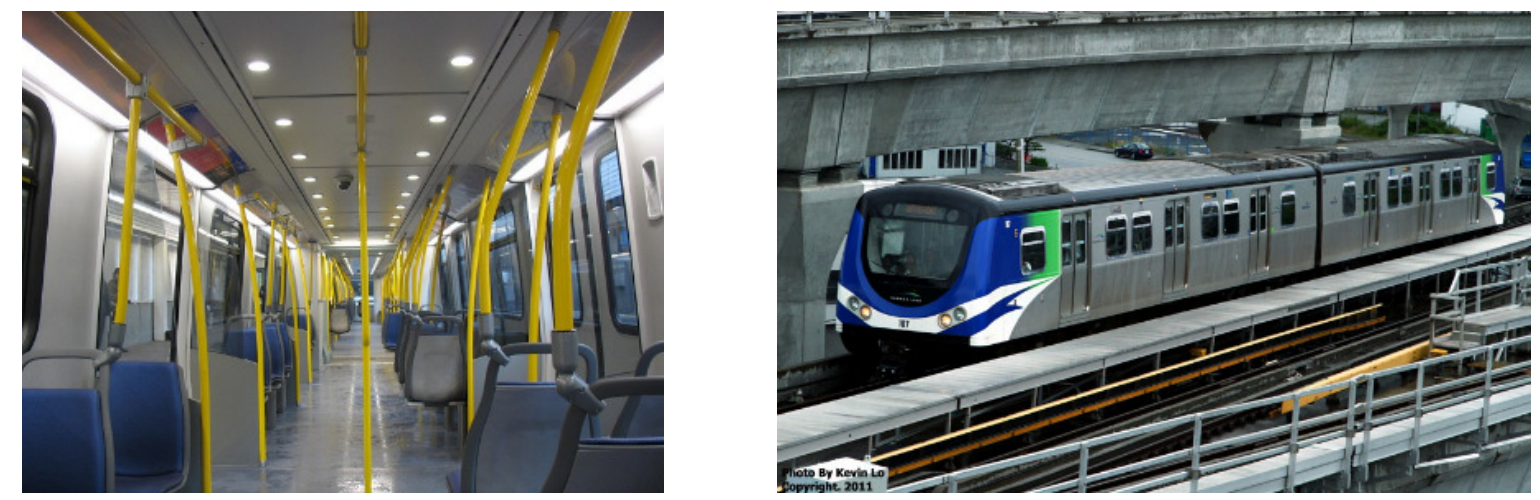

Figure 5 Interior view of Skytrain (left) and exterior view of the car skytrain (right). 
For a fire in a confined space, the hot buoyant rise towards the ceiling. Restricted from rising further, the buoyant gases expand radially outward along the ceiling in what is known as a ceiling jet (Figure 6). The hot gases lose energy as they travel away from the fire and the buoyancy become reduced as heat is exchanged with the ambient air and surfaces. The ceiling jet is primary means by which smoke travels quickly within a confined space.

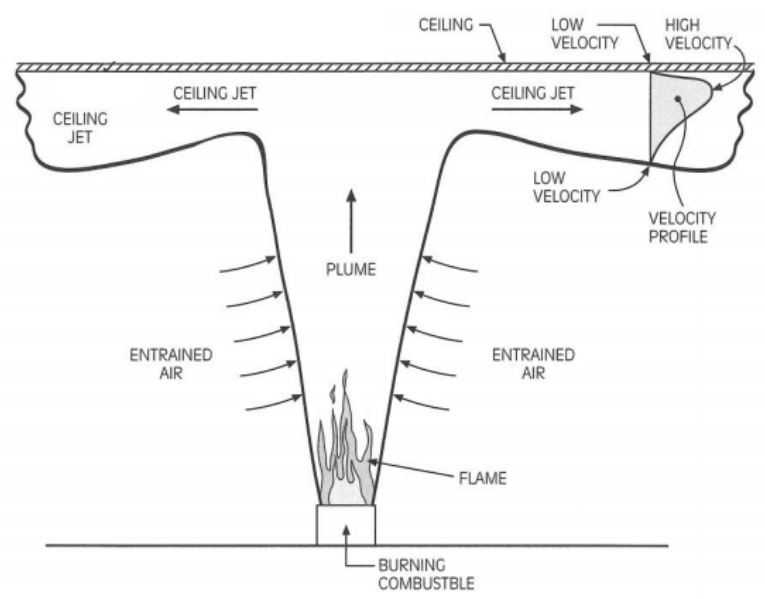

Figure 6 A ceiling jet is the horizontal movement of hot bouyant gases along the ceiling (Brewer \& Morrison, 2015)

The size of the fire and the geometry of the environment governs how smoke spreads in metro-stations. The ceiling jet velocity increases with heat release rate and decreases with increase of tunnel height (Li \& Ingason, 2015). Thus, the hazard posed by the spread of smoke throughout a metro-station is increased with larger fires.

Mechanical ventilation is often used in buildings and metro-stations to mitigate the spread of smoke and hot gases. In metro-stations, the extraction or supply of air at the end of platforms can create a directional flow of air longitudinally along the platform. The geometry of the metrostation platform is often similar to a tunnel or shaft, which allows for an efficient movement of 
air. This approach is often employed in metro-stations and tunnels to prevent the expansion of smoke in a particular direction (Figure 7).

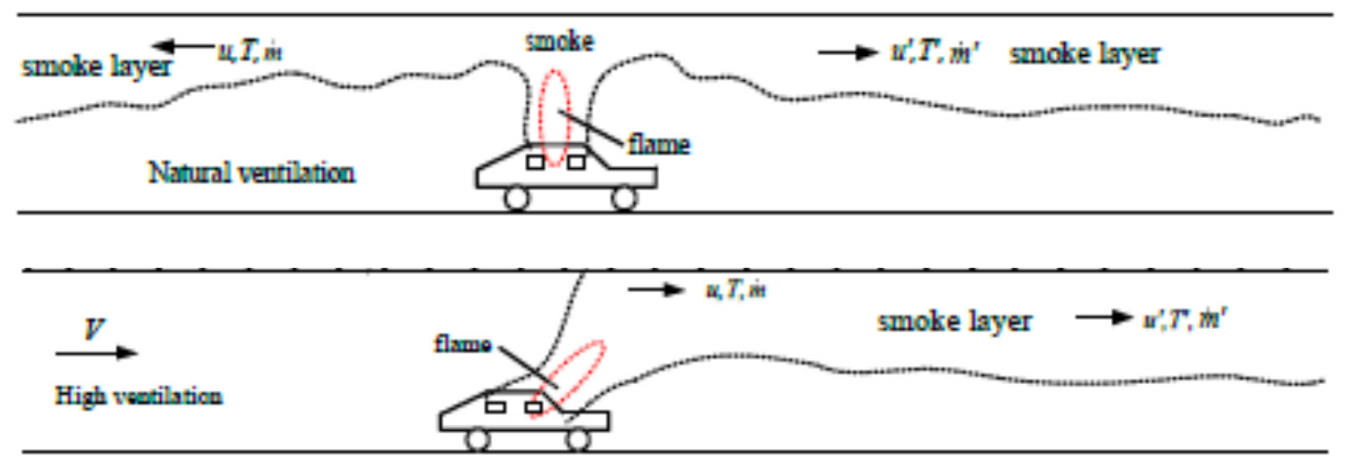

Figure 7 Natural ventilation and the longtitudinal ventilation strategy in tunnels (Li \& Ingason, 2015)

\subsection{Analysis of Ventilation}

A longitudinal ventilation system is used to extract smoke from the train platform tunnel. The forced movement of air longitudinally allows for the creation of an unimpeded evacuation route upstream of the fire. This strategy can have a negative impact on the areas adjacent to downstream path, so it is best employed when exhaust ventilation source is close to the fire source.

The use of mechanical ventilation fans in metro-stations varies dramatically for metro-stations. TTC's Museum Station contained exhaust fans rated for approximately $44 \mathrm{~m}^{3} / \mathrm{s}$ (Rhodes, McCulloch, \& Wong, 2008). Ventilation fans of $80 \mathrm{~m}^{3} / \mathrm{s}$ are used in Krakow Fast Tram station in Poland (Kayili, 2005). In Switzerland, multiple stations are noted to have a total ventilation capacity of up to $300 \mathrm{~m}^{3} / \mathrm{s}$, however some stations do not have ventilation fans and rely on passive ventilation (Ferrazzini, Busslinger, \& Reinke, 2011). Ventilation fans TTC station ventilation systems have been criticized in the past for having ventilation systems which are not fire rated and incapable of controlling smoke in even moderate fires (Rhodes, McCulloch, \& 
Wong, 2008). The four large ventilation shafts in the station schematic are represented in the model (Figure 8).

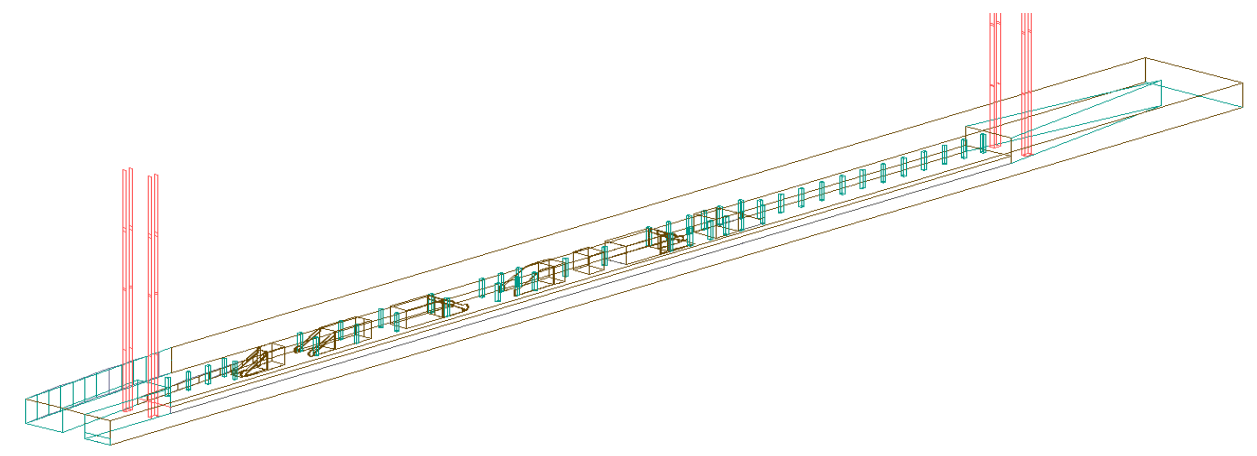

Figure 8 Ventilation shafts at the end of platform at TTC's Union Station

A CFD simulation was conducted to examine the effect of air velocity near the ceiling produced by fire and by mechanical ventilation (Figure 9). Ideally, the ceiling jet velocity generated from a fire is able to be matched by ventilation. The influence of geometry, openings and turbulence can result in uneven distribution of velocities not experienced in this simple simulation.
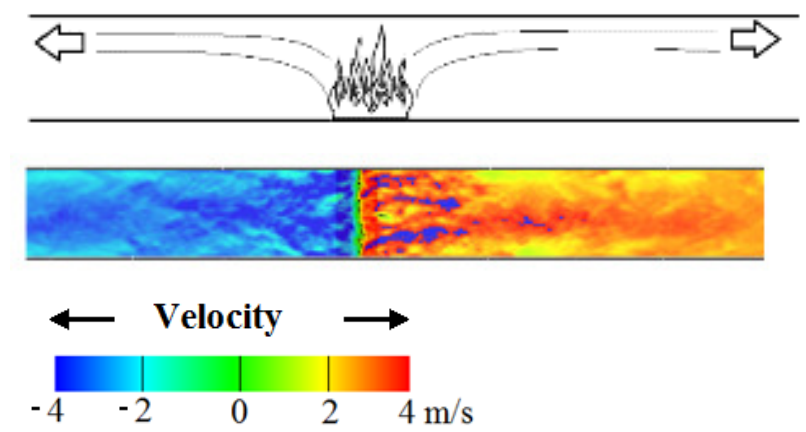
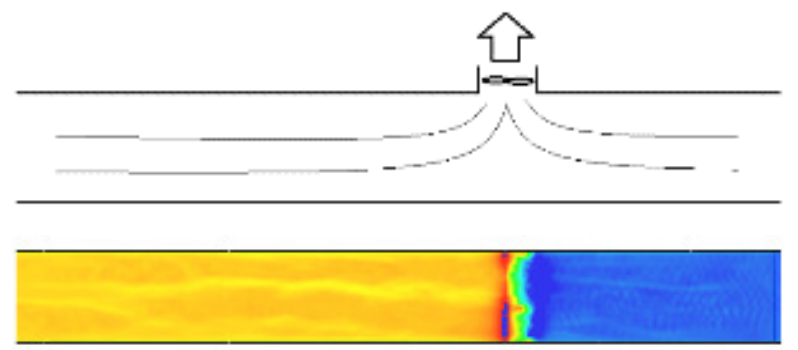

Figure 9 The effect on longitudinal tunnel velocity produced by fire and exhaust ventilation measured below the ceiling

The velocity of air inside the tunnel resulting from mechanical ventilation must be significant to counteract the convective forces of hot gas produced from the fire. If the velocity is not sufficient, the smoke will begin to travel upstream, against the direction of mechanical 
ventilation. The change in this direction is known as back-layering. Back-layering is a significant hazard as it defines the point where the fire has become more powerful than mechanical ventilation can handle. Preventing back-layering requires a sufficient air velocity for a fire size. This velocity is known as the critical velocity and is important for sizing of mechanical ventilation in tunnels. A relationship exists between critical velocity, fire size and tunnel geometry. Much effort has been put towards defining these relationships. The critical velocity, V”, can be determined from the equations below (Lee \& Hong, 2006; Wu \& Bakar, 2000).

$$
\begin{gathered}
\mathrm{Q}^{\prime \prime}=\frac{\mathrm{Q}}{\rho_{0} \mathrm{C}_{\mathrm{p}} \mathrm{T}_{0} \sqrt{\mathrm{gH}^{5}}} \\
\mathrm{~V}^{\prime \prime}=\frac{\mathrm{V}}{\sqrt{\mathrm{gH} /}}
\end{gathered}
$$

Where

$$
\begin{aligned}
& \mathrm{V}^{\prime \prime}=0.40[0.20]^{-\frac{1}{3}}\left[\mathrm{Q}^{\prime \prime}\right]^{\frac{1}{3}} \text { for } \mathrm{Q}^{\prime \prime} \leq 0.20, \\
& \mathrm{~V}^{\prime \prime}=0.40 \text { for } \mathrm{Q}^{\prime \prime}>0.20
\end{aligned}
$$

Examination of the critical velocity was conducted for the TTC's Union Station platform utilizing its dimensions. The cross sectional area is simplified for a CFD simulation and for calculations, with a coarse geometry of $15.0 \mathrm{~m}$ in width and $4.5 \mathrm{~m}$ in height (Figure 10).
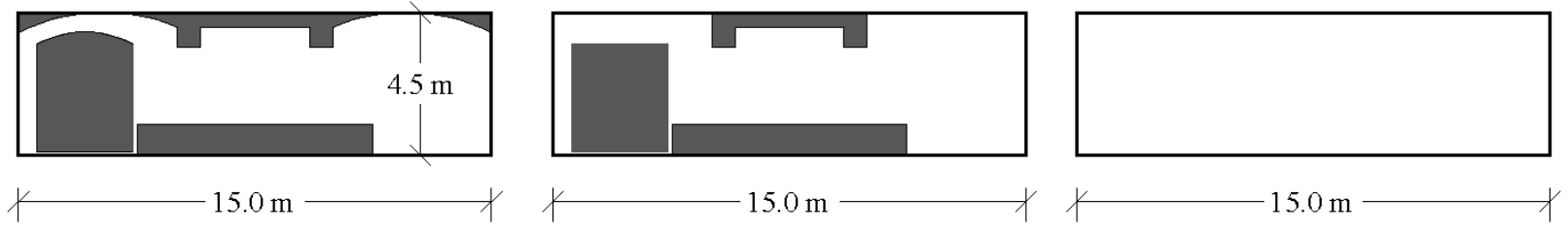

Figure 10 Geometry of the existing station (left), as modeled for smoke spread simulations (middle) and simplified for critical velocity analysis (right).

Calculations and CFD simulations demonstrate that mechanical ventilation is only capable of preventing back-layering for small fire sizes. Figure 11 demonstrates the critical velocity from a 
fires that grows incrementally from $3 \mathrm{MW}, 6 \mathrm{MW}, 10 \mathrm{MW}, 20 \mathrm{MW}$ to $30 \mathrm{MW}$ at 100 second increments. The critical velocity calculated through Equation 4, 5, 6, 7 and as measured in the CFD simulation were very similar. The critical velocity was determined to be approximately 2.3 $\mathrm{m} / \mathrm{s}$ for a fire of $10 \mathrm{MW}$. The longitudinal velocity for multiple exhaust rates were simulated in CFD. An exhaust rate of $320 \mathrm{~m}^{3} / \mathrm{s}$ achieved a longitudinal velocity of approximately $1.7 \mathrm{~m} / \mathrm{s}$.
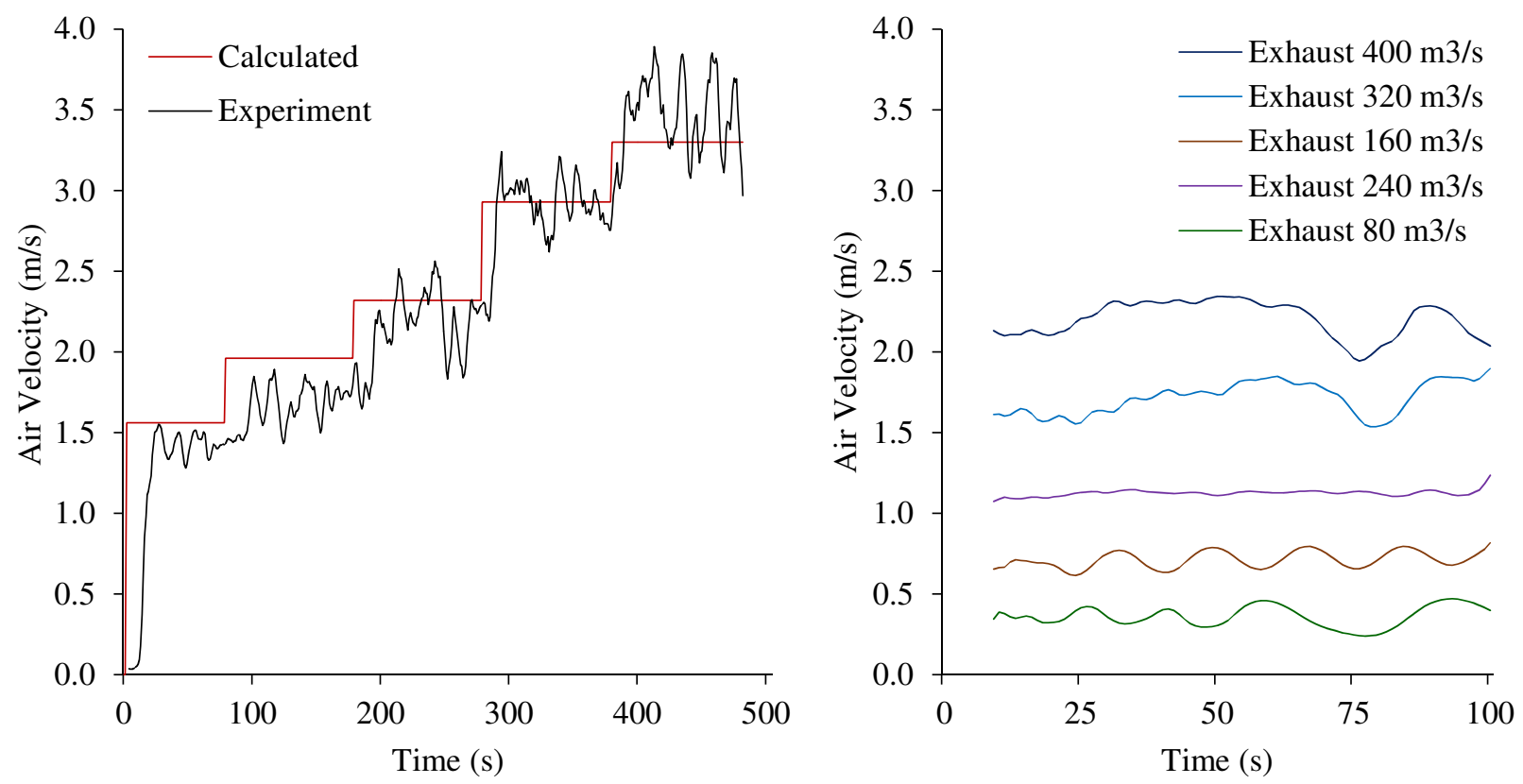

Figure 11 Calculated critical velocity from a growing fire and longitudinal velocity from ventilation

To prevent back-layering in a $10 \mathrm{MW}$ fire seen in Figure 11, an increase in ventilation rate would be required. However, many metro-stations are limited in the fans and shafts needed to facilitate this. Few metro-station investigated had ventilation capacities above $300 \mathrm{~m}^{3} / \mathrm{s}$. Thus it can be anticipated that fires larger than $10 \mathrm{MW}$ present a serious concern for safety. Figure 12 demonstrates the effect of a $3 \mathrm{MW}, 6 \mathrm{MW}$ and $10 \mathrm{MW}$ fire with mechanical ventilation of 400 $\mathrm{m}^{3} / \mathrm{s}$. Back-layering does not occur for fires sizes of $3 \mathrm{MW}$ or $6 \mathrm{MW}$, however it begins to occur at $10 \mathrm{MW}$. When back-layering begins, smoke can quickly travel into previously tenable areas 
increasing risk to evacuees. This emphasizes the importance of ventilation capacity is extremely important in subway platforms.

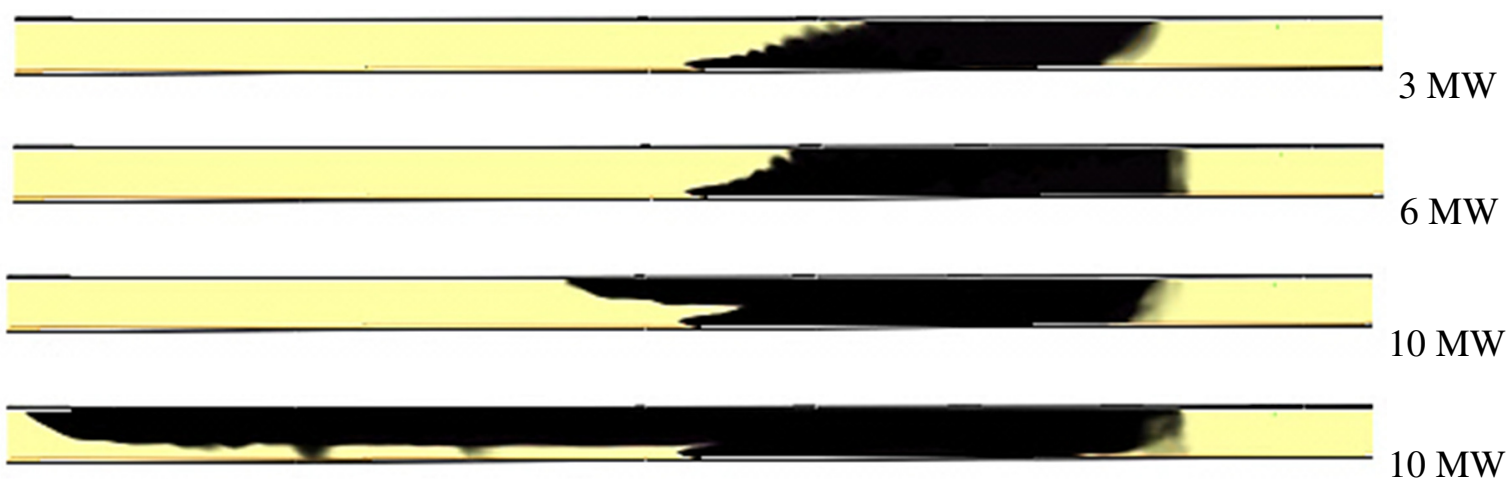

Figure 12 Back-layering occurs when the fire reaches $10 \mathrm{MW}$ despite exhaust ventilation of $400 \mathrm{~m}^{3} / \mathrm{s}$ The examination of longitudinal ventilation reveals the influence of geometry on the critical velocity. However, the complexity of the geometry of a subway platform is quite complex and is best done with the use of CFD simulations. The platform introduces multiple variables that affect the ventilation capacity. The geometry, obstructions and surface friction all affect the velocity of air. However, most significant is the presence of openings for stairways and escalators. These openings decrease the efficiency of the exhaust system and result in an unequal distribution of velocities along the platform tunnel (Figure 13).
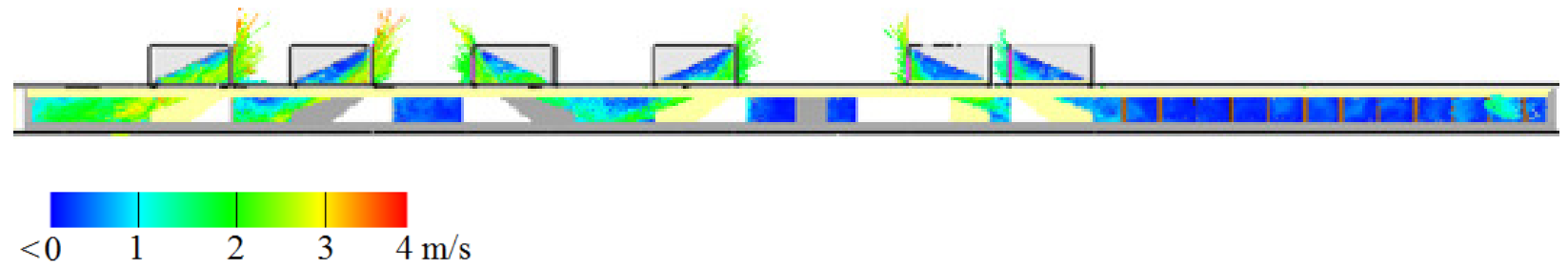

Figure 13 The exhaust ventilation results in a large influx of fresh air from stairwells A simulation using exhaust ventilation at the ends of TTC's Union Station platform shows the velocity of air traveling longitudinally through the tunnel (Figure 14). It is noted that the longitudinal velocity decreases with distance from the exhaust vent. However, this is most pronounced for lower ventilation rates which have little impact on air velocity on the other end 
of the platform. This decrease in efficiency could be problematic for fires located in the middle of the platform, as they are furthest from the end of platform exhaust vents.

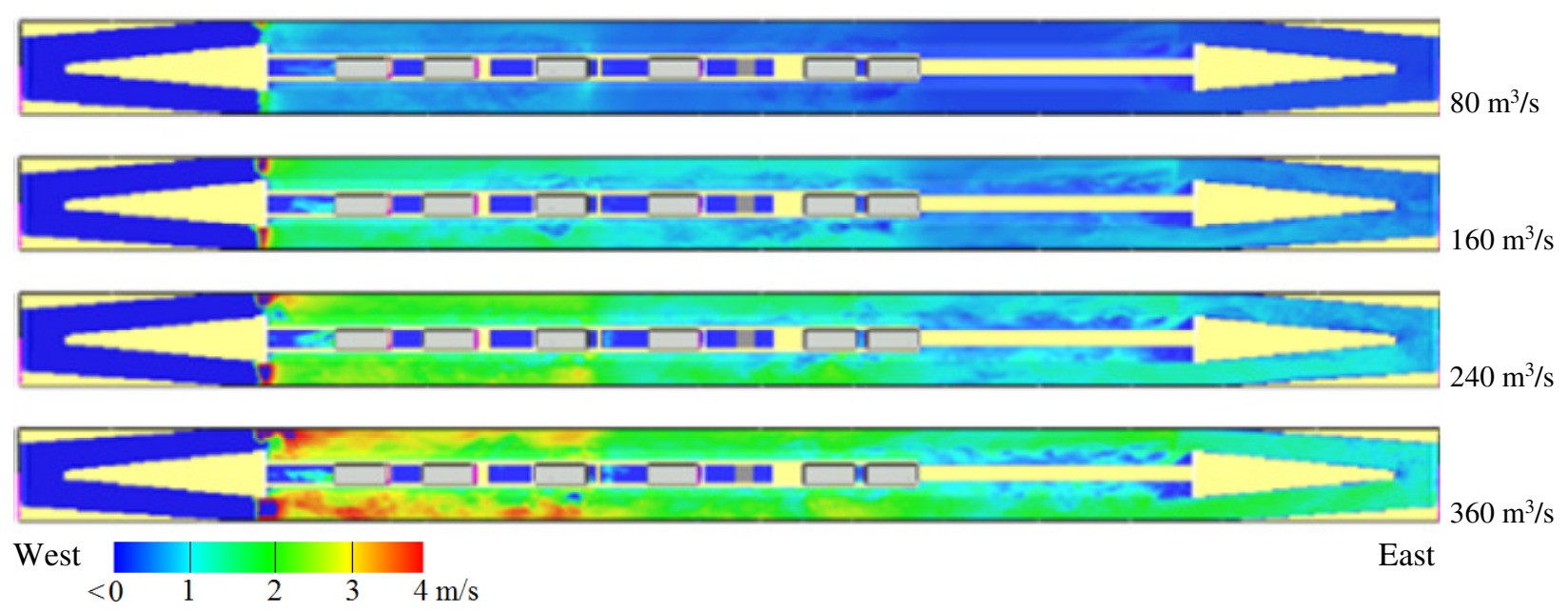

Figure 14 Longitudinal tunnel velocity for various exhaust rates located on the west side of the platform

Figure 14 demonstrates the average velocity along the platform changes from approximately 0.9 $\mathrm{m} / \mathrm{s}$ at to $0.3 \mathrm{~m} / \mathrm{s}$ under an exhaust rate of $80 \mathrm{~m}^{3} / \mathrm{s}$. However increasing the exhaust rate to 360 $\mathrm{m}^{3} / \mathrm{s}$, velocity is approximately $3.9 \mathrm{~m} / \mathrm{s}$ and $2.0 \mathrm{~m} / \mathrm{s}$ for the same locations. Sensitivity to these measurements is apparent because of the effect of geometry and openings from stairwells. Sensor data from CFD simulations in Figure 15 demonstrates the observed difference between air velocity at end of platform and mid-platform as exhaust rates are increased from $80 \mathrm{~m}^{3} / \mathrm{s}$ to 360 $\mathrm{m}^{3} / \mathrm{s}$. 

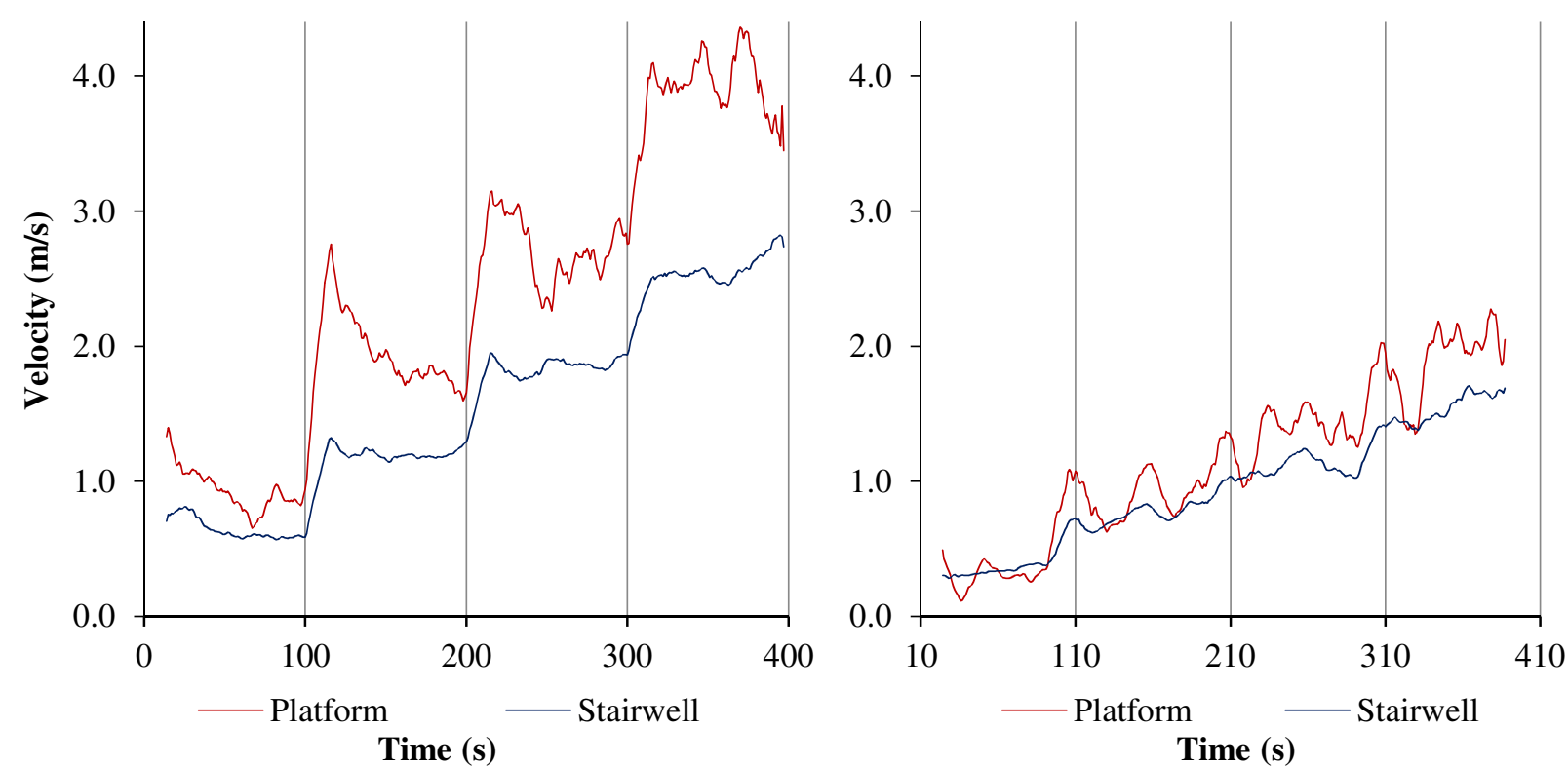

Figure 15 Air velocity measured at end of platform (left) and mid-platform (right) as exhaust rate is increased from 80 to $360 \mathrm{~m}^{3} / \mathrm{s}$

\subsection{Analysis of Tenability}

Tenability of egress paths is required to ensure timely evacuations. The duration of tenability is referred to as the ASET. While the fatalities from smoke are due to asphyxiation and toxicity, they are not the sole criteria for determining tenability during egress. In fact, smoke can reduce visibility, emit heat and irritants, which can reduce the mobility of evacuees. These issues must be considered, as they can increase the time required for a safe evacuation.

The duration and intensity of exposure to hazards are significant factors during egress. People can withstand short durations of intense heat for instance, but will succumb to prolonged exposure. Similarly, exposure to a toxic environment may not prove lethal if duration is not prolonged. Visibility, does not have any negative affect on health, but will prevent people from finding exits. Thus, judgments must be made in evaluating the threats to occupants. Multiple 
standards for these criteria exist from various studies. NFPA 101 Life Safety Code outlines many of these tenability criterions (National Fire Protection Association, 2009).

The critical limiting factor, is the hazard which eliminates the tenability of a space first. This hazard can differ depending on the environment. For instance, observations have indicated that visibility is often the limiting tenability criteria in atriums. Atriums have large volumes of space, temperatures are low due to entraining air and the toxicity of smoke is often diluted (National Fire Protection Association, 2008). Many experts have identified the first compromise to tenability to be visibility. Visibility is typically compromised before toxicity becomes a survival threat, except for long durations of exposure (Hirschler, 2005).

CFD modeling of smoke spread provides data which can be used to graphically represent the environment throughout the model. Criteria for tenability, in regards to temperature and visibility were analyzed within each simulation. The results allow for slices of temperature and visibility profiles throughout the model. For horizontal slices, measurements are generally taken at 2 meters above floor level, just above the heads of most people (Figure 16). This gives a clear overview of temperatures or visibility which will be encountered simultaneously throughout the model. For vertical slices, the measurements are taken along a path of travel. They identify the temperature of gas masses from floor to ceiling or the density of smoke encountered simultaneously. Each simulation was analyzed on its performance in maintaining a tenable environment. While tenability criteria varies greatly amongst people and its very definition, standard tenable criteria have been utilized as rules of thumb or comparison standard. This 
included maintaining a temperature below $100^{\circ} \mathrm{C}$ and a visibility above $10.0 \mathrm{~m}$, taken at the height of 2 meters above the floor (Society of Fire Safety, 2014).
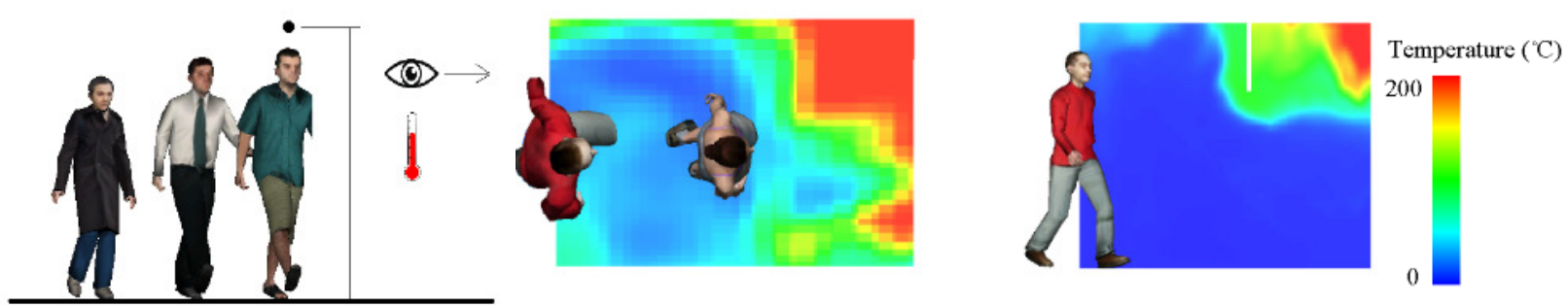

Figure 16 Temperature and visibility is measured and represented graphically.

The amount of time where space is tenable was determined for key locations of egress. Much of the focus is on exit locations where evacuee population density will be highest as they queue to the stairs. For instance in many fires, like the King's Cross subway fire, buoyant smoke entered the stairwells blocking channels where passengers would typically egress (Zhou, Zhang, Zhu, \& Zhao, 2013). Even diffused smoke traveling in these areas has implications on egress. A relationship exist between the density of smoke and a resulting decrease in the speed of egress (Poh, 2010).

Areas within the platform vary in their value for egress. For instance, the far end portion of a train platform that does not serve stairs or means of escape, has less significance. However, maintaining a tenable zone where stairs are located will allow egress to occur. In the simulations, focus was given to stairwell (or escalator) and pre-loading areas. To analyze the tenability, these areas of the CFD model is was examined visually and through sensor data.

Stairwells: The available egress time was determined visually by determining when smoke entered the stairwells. 
Pre-Stairwells or Stairwell staging: This area is of key importance because it is where a large density of people queue to access the stairs. The tenability of this area was done by comparing temperature at $2.0 \mathrm{~m}$ above platform floor in front of the stairway.

\subsubsection{Smoke Spread Simulation Procedure}

Determining the danger of fire and smoke in metro stations was done utilizing CFD simulation in FDS. The spread of smoke is predicted and analyzed for its impact on tenability which is derived using the following steps:

- Creation of the Design Fire

- Station Analysis \& Modelling

- Creation of the Scenarios

- Sensitivity Analysis

- Simulation Results \& Analysis

The study was conducted on two Canadian metro-stations: Toronto Transit Commission's Union Station in Toronto and Translink's Yaletown Station in Vancouver (Figure 17). The results highlight optimal strategies as well as areas of concern in the subway station. The results were analyzed based on tenability criteria including temperature and visibility, which impact the evacuee's safety.
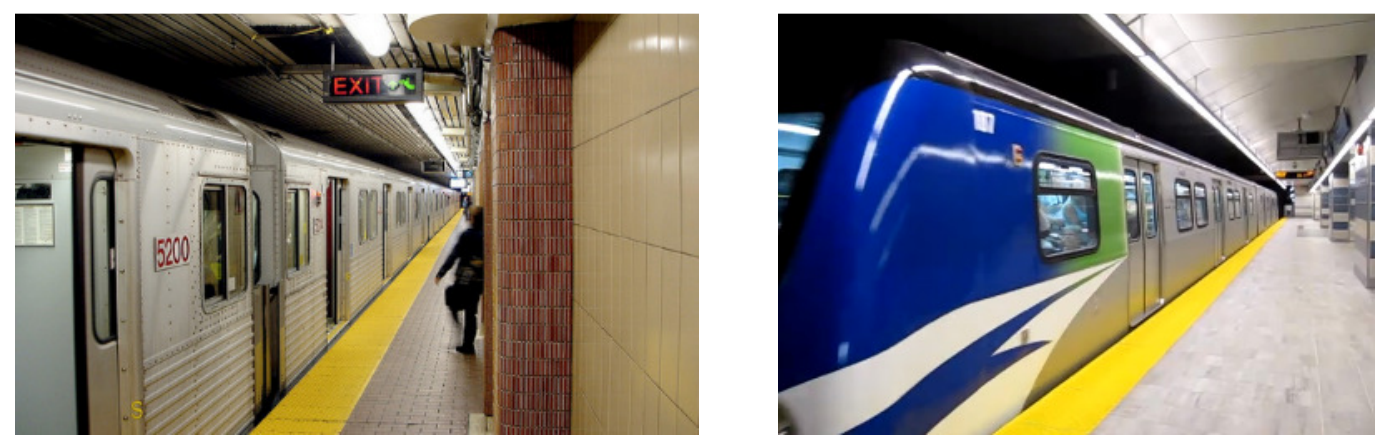

Figure 17 Platform of Union Station and Yaletown Station 


\section{Chapter 3. Smoke Spread Analysis: TTC's Union Station Platform}

The TTC Union Station platform is part of the Union Station transportation facility, which opened in 1927. The TTC station, which serves the underground subway system was added in 1954. In 2013 , the platform ridership was 114,800 people per average weekday, making it the $2^{\text {nd }}$ busiest subway train platform in Canada, behind the Yonge-Bloor station further north. The station went through few modifications over the years, but recently during 2014-2015 was renovated to expand the platform to address overcrowding and passenger circulation (TTC). At the time of this study, the subway was under an extensive renovation/addition. The study investigates the station prior to this renovation.

\subsection{Design Fire}

The design fire size was modelled off experiments and observations for similarly sized train cars. Burning characteristics of the TTC T-Series subway car materials were not readily available and thus a study of similar surfaces and furnishing materials were reviewed. A fast growth rate was assumed and the simulation was run for 600 seconds, by which time the fire reaches $16.9 \mathrm{MW}$ (growth rate "fast"). Smoke production is simulated to be a function of fire size. A number of fuel sources exist within the subway train, some of which are high soot yielding. An assumed soot yield of $10 \%$ was used, based on reviewing fuel soot yield estimations for built environments (Butler \& Mulholland, 2004; Society of Fire Protection Engineers, 1998).

A large variation of railcars are in use throughout the world. Even within the TTC, a number of different railcars have been used with vastly different construction. The interior of an older $\mathrm{H}-$ Series subway car operational until 2012 is seen in Figure 18. The interior of the T-series subway 
car had notable enhancements in materials with a lower fire load. However, additional fuel sources are readily introduced by passengers including newspapers, luggage and flammable objects.

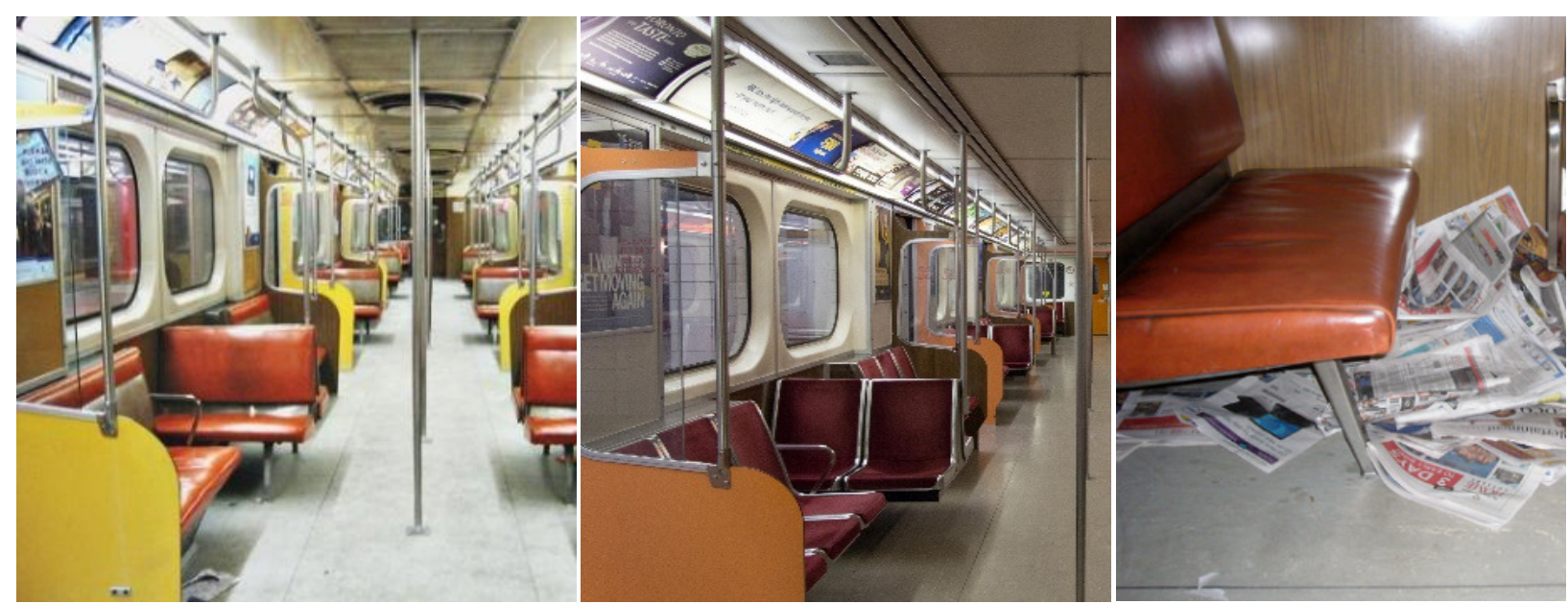

Figure 18 H-Series subway car (left) T-series subway car (middle) and fuel sources (right) (Bow, 2013)

\subsection{Analysis \& Modelling of TTC's Union Station Platform}

The TTC's Fire Ventilation Upgrade study determined that station platforms had safety concerns due to the distance between the ends of the platform and exit stairs. Many locations along the platforms were described as dead-ends, with only one viable exit available. Dead-end platform areas are hazardous as evacuees could be trapped during emergencies if the exit is blocked. Additionally, these dead-end platforms often had a longer distance of travel from the furthest point from the exits. The Second Exit Project initiated by the TTC, modified existing station with additional exits to eliminate dead-end areas on the subway platform. The commission determined that a maximum distance of 23 meters is acceptable for station platforms (Crean, 2012). The Union Station TTC platform had a dead-end platform, with a travel distance of over 40 meters to 
the nearest stairs (Figure 19). It remained unaddressed until the 2014 renovation.

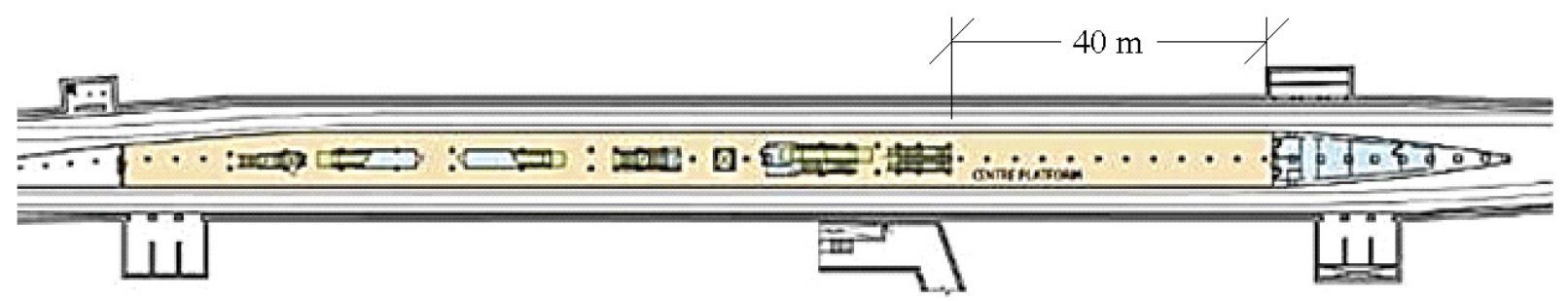

Figure 19 Union Station platform (Toronto Transit Commission, 2011)

The way in which fires develop and their placement can significantly affect the level of danger present to passengers. For instance, a fire which begins at the end of the platform will not be as problematic as a fire is located at mid-platform. For this reason, the fire scenario studied involves a fire on the $2^{\text {nd }}$ car of the platform. This location in the most concentrated in regards to egress paths through stairs and escalators, off the platform.

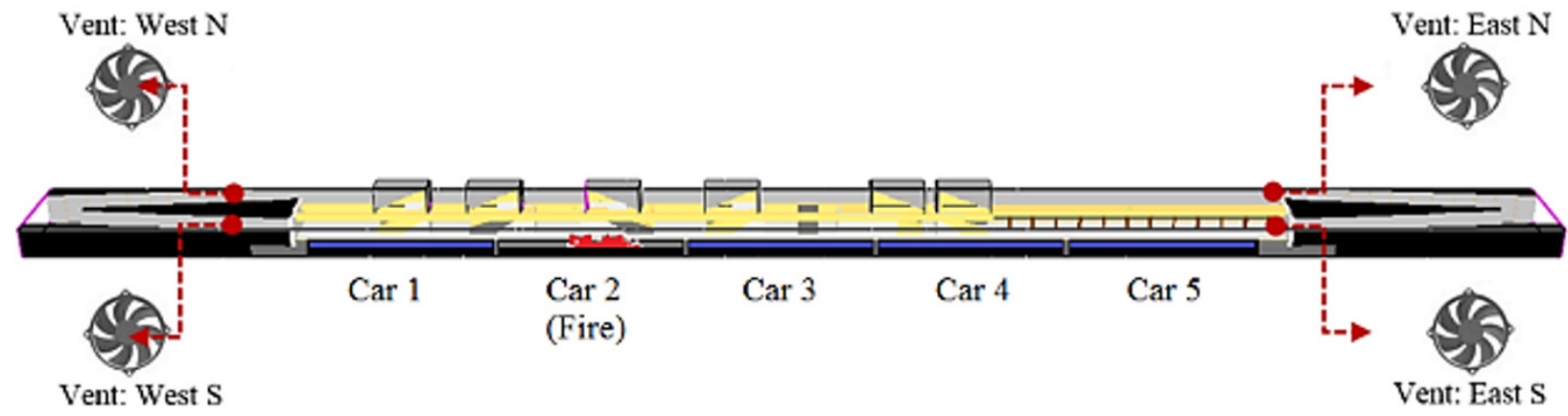

Figure 20 Union Station tunnel and platform schematic

As with many TTC subway stations, the exhaust ventilation relies on ventilation shafts at both ends of the platform. These can operate in exhaust or supply, allowing for different ventilation strategies/configurations to exist. A ventilation fan can be used to exhaust smoke, referred to as a "Pull" strategy. Alternatively ventilation fans can supply air. Supplying air can aiding the movement of smoke toward the exhaust vent as well as provide tenable air to evacuees. 
Combining exhaust and supply at opposite ends of the platform is known as the "Push-Pull" strategy, and results in an increase in air velocity to better control smoke. However, directing the smoke in either direction has the potential to create hazard for those in egress downwind of the fire. A "Pull-Pull" strategy, uses ventilation to extract the smoke from both ends with air being drawn from stairwells. The use of CFD simulations allows for analysis of tenability and determination if ventilation can sustain a tenable environment for evacuating passengers.

\subsection{Developing the Model}

The model for the Union Station platform was derived from drawings and photographs to accurately represent station. As the station was undergoing a major renovation, many of these features were revealed (Figure 21). This included the shape of the concrete ceiling, typically concealed by a metal fascia. Areas which formed obstructions to smoke were modelled. Specific attention to ceiling obstructions and stairwells perimeters was given. The ceiling attributes and detail can affect the spread and containment of smoke.
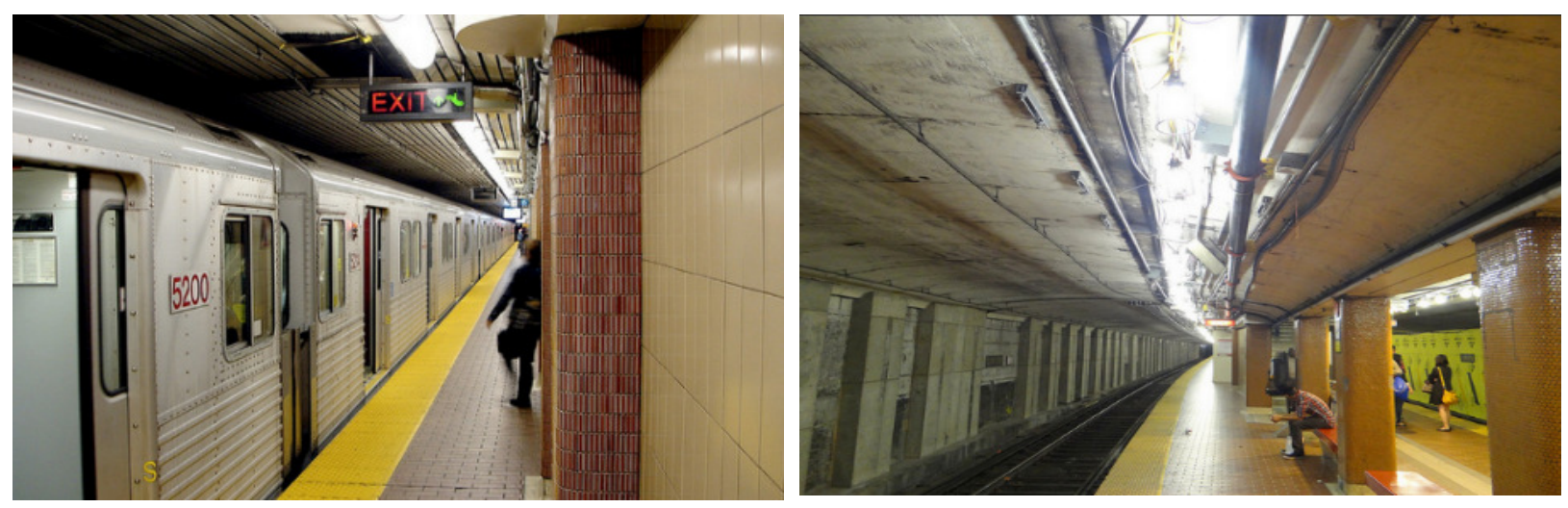

Figure 21 Union Station TTC platform during renovation period 
For analysis purposes, the platform was divided into different zones to measure tenability criteria. Sensors within the model and visualizations provide information on concentration of smoke, temperature and visibility. These zones give indication of zone tenability, with floor to ceiling sensors located the platform (A), stairwells (B) and stair queue area (C) seen in Figure 22.

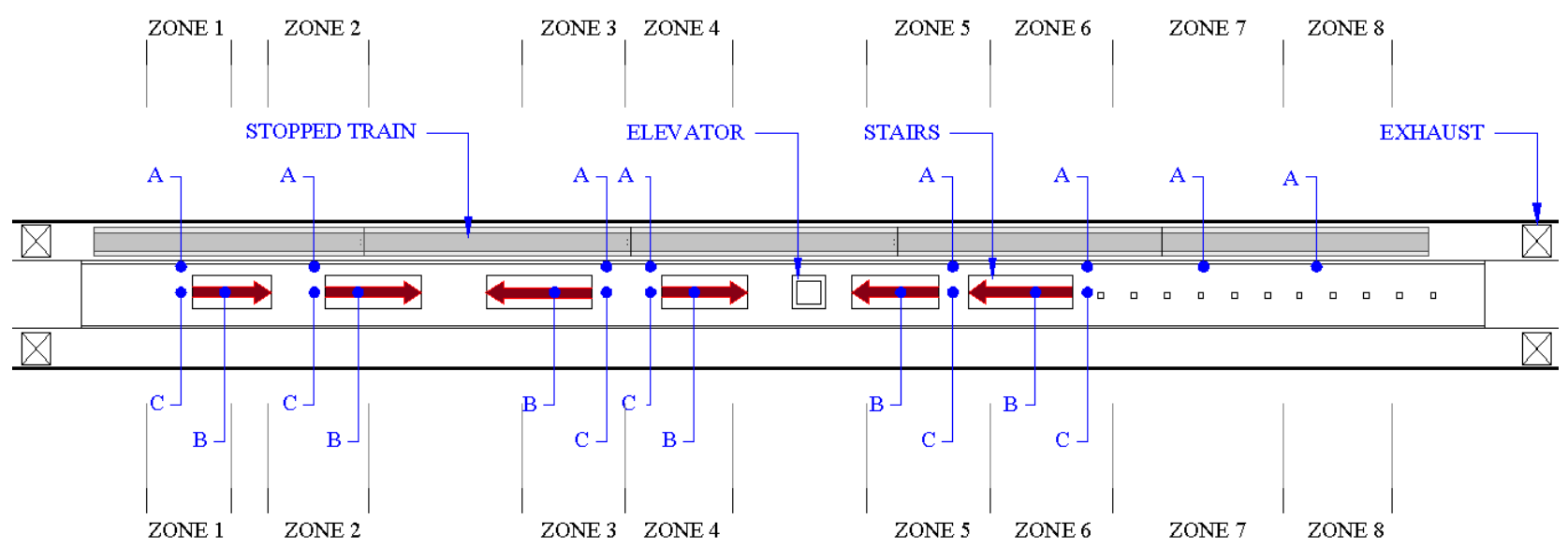

Figure 22 The simulation measures measure smoke, temperature and visibility with sensors at A, B and C

\subsection{Simulation Scenarios for Union Station}

The fire scenario assumes the ignition of a fire on a T-Series train which has just arrived at the Union Station platform. The fire location was selected to occur on the $2^{\text {nd }}$ car on the platform (Figure 23). This location chosen is near the concentration of stairwell exits. This is a high risk area due to the closeness of the fire to principal egress paths.

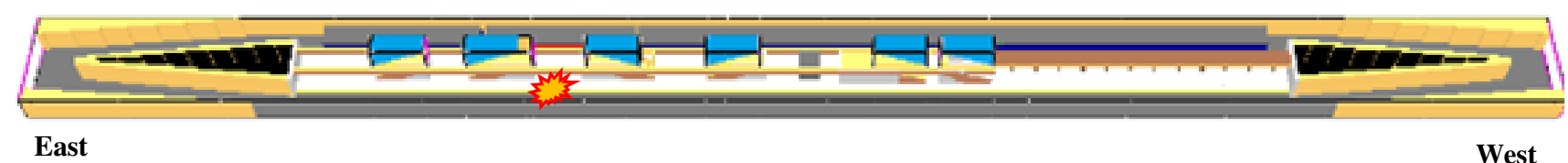

Figure 23 The subway tunnel modeled in FDS

The design fire begins to grow along a fast HRR growth curve. The simulation is run with a natural ventilation base case and several scenarios of various ventilation strategies commencing 60 seconds into the fire. The model records temperature, visibility and gas velocity in multiple 
locations, primarily along egress axis and exit locations. Limited information was available regarding the specific exhaust and supply capabilities of the ventilation system. Based on data from comparable TTC platforms, end of tunnel exhaust are assumed to be capable of supplying or exhausting air at a rate of $80 \mathrm{~m}^{3} / \mathrm{s}$ each. For this simulation, the four ventilation shafts were utilized with different strategies to limit smoke spread (Figure 24). A series of eight simulations were run to determine the optimal strategies. This included natural ventilation, "pull", "pullpull”, "push-pull" and zone pressurization approaches. The details of ventilation rates are provided in Table 1 and a schematic of the operation is seen in Figure 24.

\section{Table 1 Mechanical Ventilation of Simulation Scenarios}

\begin{tabular}{|c|c|c|c|c|c|c|}
\hline \multirow{3}{*}{ Sim } & \multirow{3}{*}{ Strategy } & \multicolumn{5}{|c|}{ Ventilation $\left(\mathrm{m}^{3} / \mathrm{s}\right)$} \\
\hline & & \multicolumn{2}{|c|}{ West } & \multicolumn{2}{|c|}{ East } & \multirow{2}{*}{$\begin{array}{c}\text { Total } \\
\text { Ventilation rate }\end{array}$} \\
\hline & & North & South & North & South & \\
\hline T1 & Natural & - & - & - & - & 0 \\
\hline T2 & Pull & 80 & - & - & - & 80 \\
\hline T3 & Pull & 80 & 80 & - & - & 160 \\
\hline T4 & Pull & 120 & 120 & - & - & 240 \\
\hline T5 & Pull-Pull & 80 & 80 & 80 & 80 & 360 \\
\hline T6 & Push-Pull & 80 & 80 & -80 & -80 & 360 \\
\hline $\mathbf{T 7}$ & Pressurize & 80 & -80 & -80 & -80 & 360 \\
\hline T8 & Pressurize & 80 & -80 & 80 & -80 & 360 \\
\hline
\end{tabular}

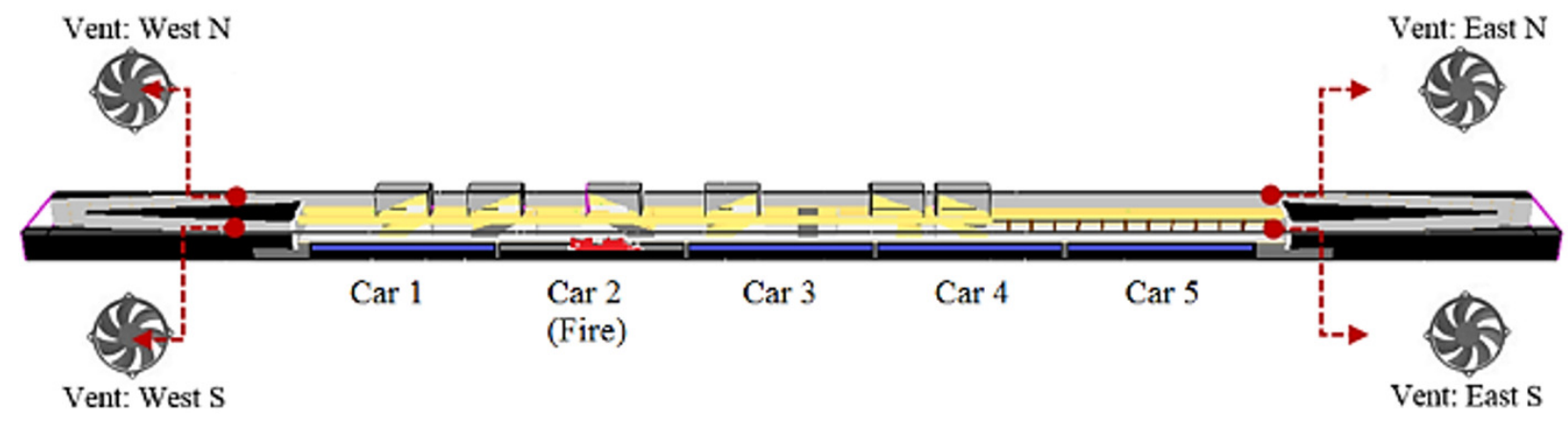


Figure 24 Ventilation shafts at both ends of the platform which can operate in supply or exhaust.

\subsection{Natural Ventilation}

The smoke produced travels naturally through the underground station with no mechanical extraction or supply of air.

- T1 No ventilation

\section{6 "Pull" Strategy}

The pull ventilation strategy utilizes fans working in exhaust at one end of the station. In this scenario, the exhaust ventilation occurs on the west vents operating as follows:

- $\mathrm{T} 2$ [West] A single fan operating in exhaust at $80 \mathrm{~m}^{3} / \mathrm{s}$

- T3 [West] Two fans operating, providing a combined $160 \mathrm{~m}^{3} / \mathrm{s}$ in exhaust.

- T4 [West] Two fans operating, providing a combined $240 \mathrm{~m}^{3} / \mathrm{s}$ in exhaust.

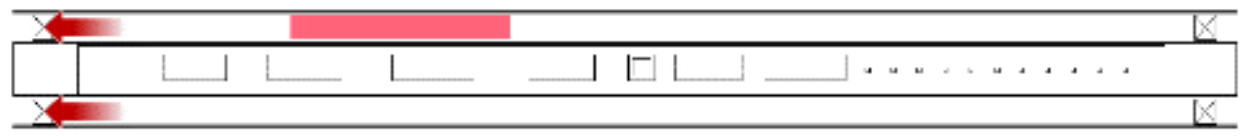

\section{7 'Pull-Pull” Strategy}

The vents operate in exhaust on both ends of the tunnel. This is effective for utilizing all ventilation sources and drawing air down through the stairwells, however, it can aid the spread of smoke along the platform.

- T5 [West] Two fans operating, providing a combined $160 \mathrm{~m} 3 / \mathrm{s}$ in exhaust [East] Two fans operating, providing a combined $160 \mathrm{~m} 3 / \mathrm{s}$ in exhaust

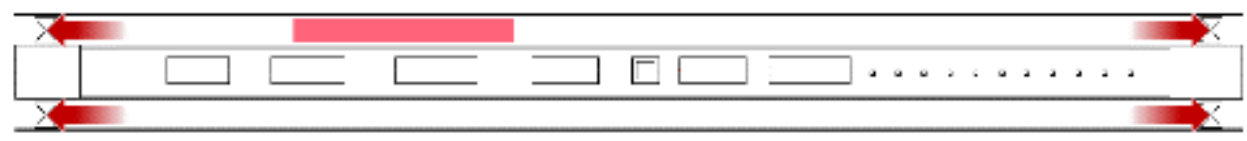




\section{8 "Push-Pull” Strategy}

This method operates vents in exhaust at one end of the platform and supplies air from the opposite end. This utilizes all ventilation sources and makes up for the loss in longitudinal air velocity along the platform due to boundary openings (stairwells).

- T6 [West] Two fans operating, providing a combined $160 \mathrm{~m}^{3} / \mathrm{s}$ in exhaust [East] Two fans operating, providing a combined $160 \mathrm{~m}^{3} / \mathrm{s}$ in supply

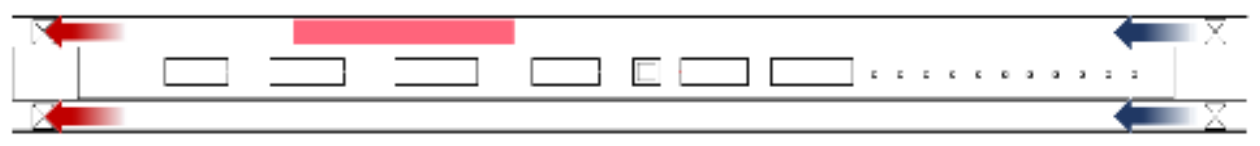

\subsection{Pressurization Strategies}

Other strategies investigated involve using ventilation to pressurize areas of the tunnel in order to maintain a smoke free area along the platform. T7 - This unique strategy exhaust air in the vent nearest to the fire source while all other vents supply air, attempting to pressurize the environment around the fire. T8 utilizes the exhaust at each end of the station above the rail with the fire. It operates supply at each end of the station above the rail which does not have the fire. This extracts smoke directly along the path of the fire and create a buffer zone of supply air to maintain tenability.

- T7 [West] One fan (nearest to fire) exhaust at $80 \mathrm{~m}^{3} / \mathrm{s}$. One fan supply at $80 \mathrm{~m}^{3} / \mathrm{s}$. [East] Two fans operating, providing a combined $160 \mathrm{~m}^{3} / \mathrm{s}$ in supply

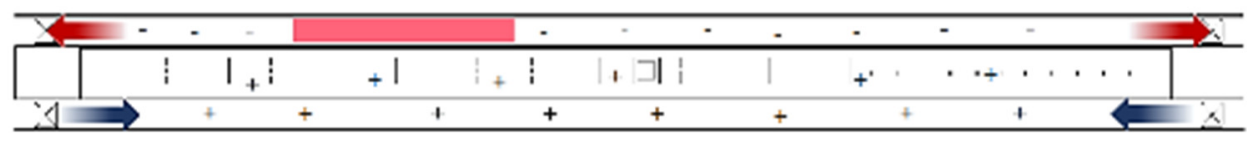

- T8 [West] One fan (nearest to fire) exhaust at $80 \mathrm{~m}^{3} / \mathrm{s}$. One fan supply at $80 \mathrm{~m}^{3} / \mathrm{s}$. [East] One fan operating in exhaust at $80 \mathrm{~m}^{3} / \mathrm{s}$. One fan acts in supply at $80 \mathrm{~m}^{3} / \mathrm{s}$.

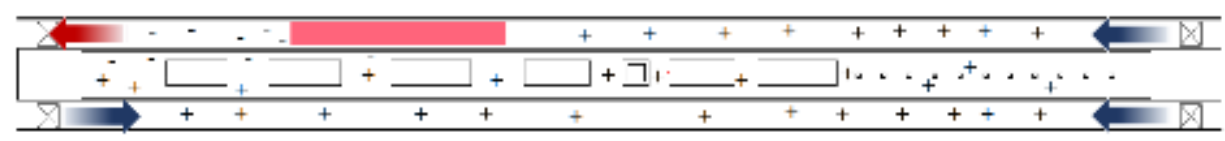




\subsection{Sensitivity Analysis}

The grid sizing selected was based on comparative analysis of varying grid sizes. This included coarse to fine grid spacing of $50 \mathrm{~cm}, 30 \mathrm{~cm}, 25 \mathrm{~cm}, 20 \mathrm{~cm}, 15 \mathrm{~cm}, 12.5 \mathrm{~cm}$. The mesh size of 25 $\mathrm{cm}$ was chosen based on precision of results in regard to smoke movement and gas velocities (Figure 25 and Figure 26). The selected mesh size model was composed of just over 1 million cells compared to the finest mesh of over 8.2 million cells. The model was processed on a Xeon CPU $2.6 \mathrm{GHz}$ with 32 threads, $64 \mathrm{~GB}$ of RAM. Processing time required between 36-48 hours each for the more demanding simulations.

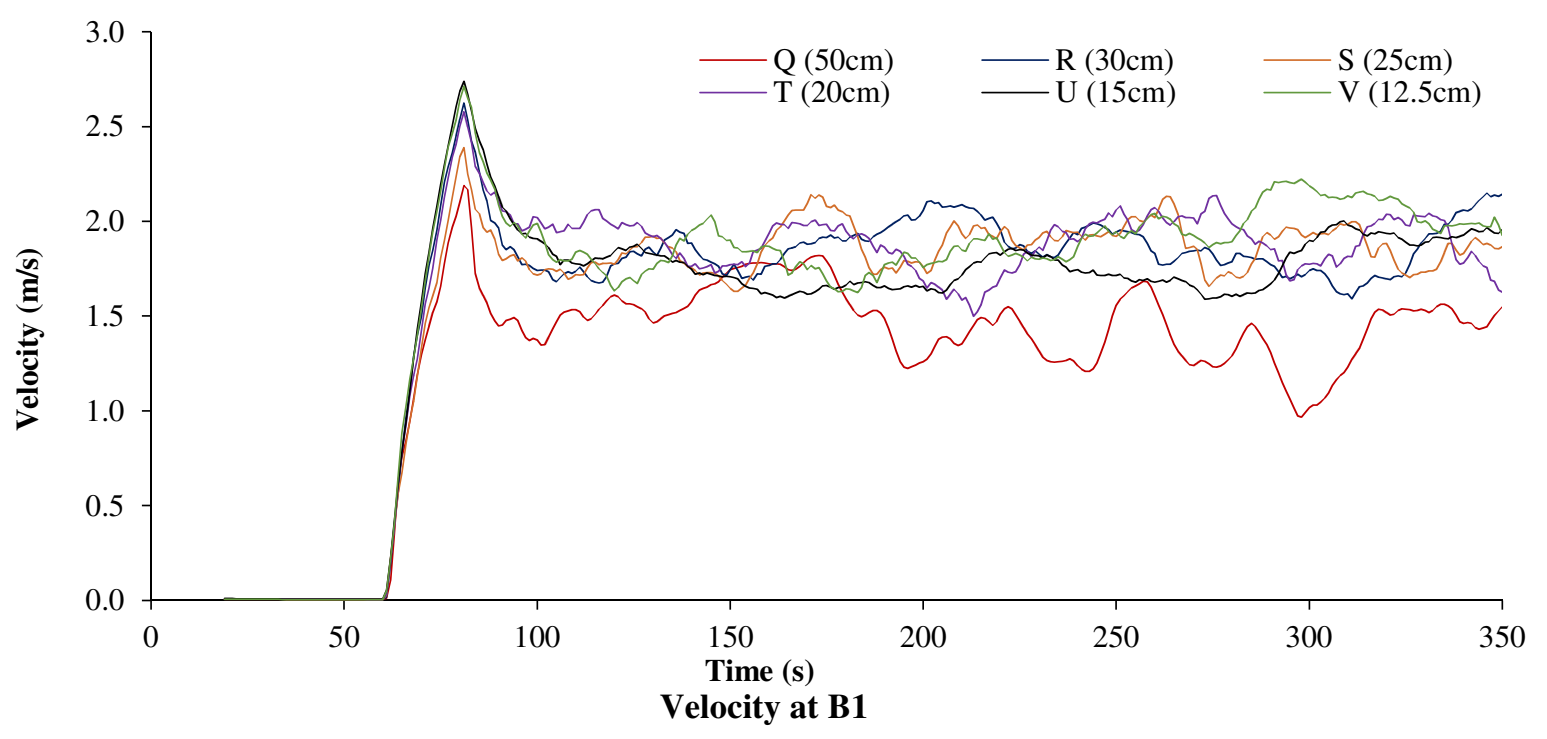

Figure 25 The longitudinal air velocity at stairwell location B1 for simulations of varying mesh sizes 


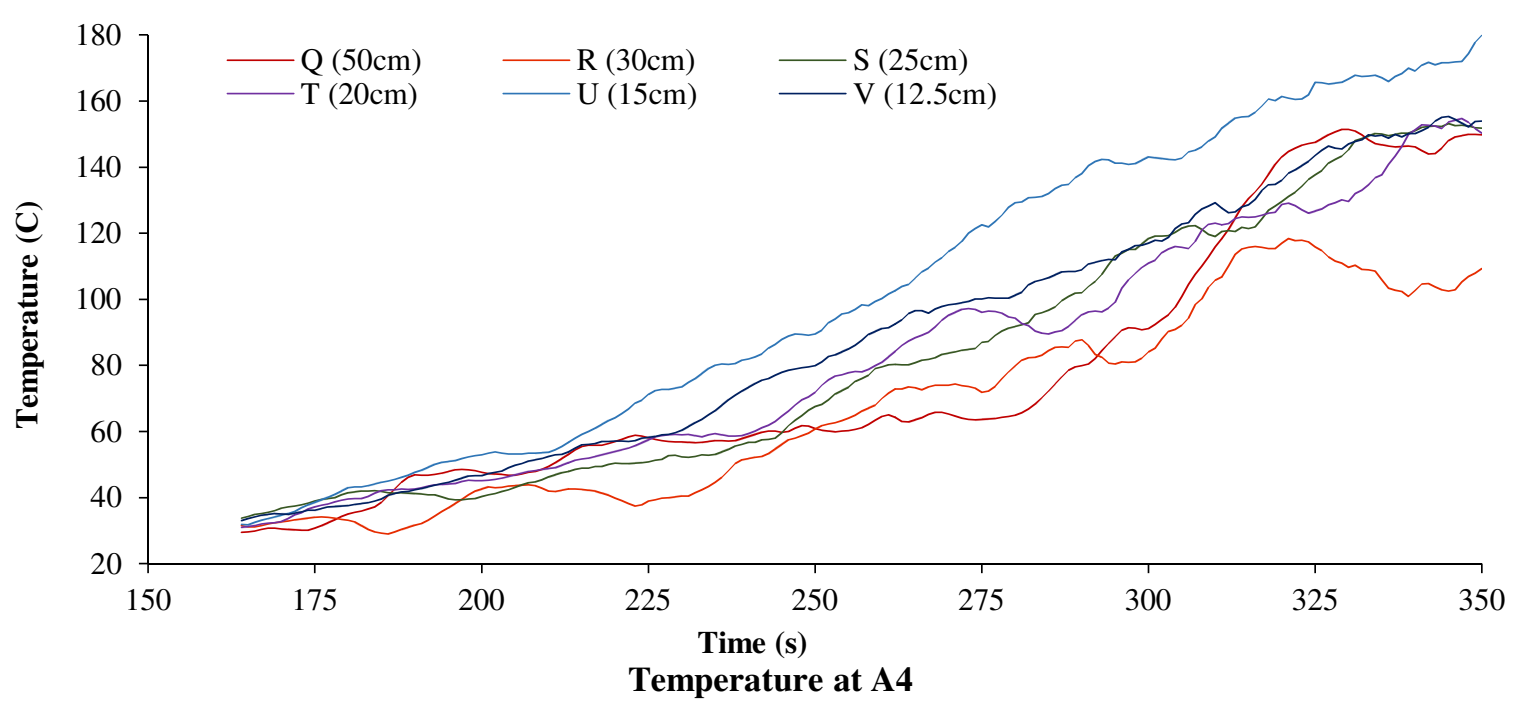

Figure 26 Temperature at platform location A4 for simulations of varying mesh sizes.

\section{Simulation Results:}

The simulation results were analyzed through visualizations of smoke movement and graphical slices of the CFD model. The use of graphical slices were used to reveal smoke concentration, visibility, gas velocity and temperature profiles.

\section{Sensor Data Analysis}

The sensor data was utilized to provide detailed comparison of tenability of specific zones and locations, such as stairwells. Each zone consisted a stairwell (or escalator) and a pre-loading area. Areas within the platform vary in their value for egress. The west end of the platform where stairs are located is of high importance for maintaining tenability as it contains the majority of the exit stairs. However, the east end of the platform is a "dead-end", served by only one exit stairwell. Maintaining the integrity of this exit is critical as it is the only exit serving a significant portion of the platform.

\subsection{Graphical Results of Smoke Spread}

The simulation results were analyzed through visualizations of smoke movement and graphical representation of smoke concentration and visibility. Results at 240 seconds and 360 seconds 
provides a comparison between different strategies and the duration of tenability they provide.

The visibility on the platform is graphically represented through a plan view, taken at a height of 2.0 meters above the platform and a sectional view taken longitudinally at the center of the platform. The graphical results for simulations including Natural Ventilation and strategies "Pull", "Pull-Pull", "Push-Pull" and pressurization indicate the significant changes in tenability obtained by each.

\section{Simulation T1: Natural Ventilation}

The smoke spread rapidly throughout the platform, reaching both ends by 240 seconds. The smoke entered all exit stairwells by 360 seconds (Figure 27).

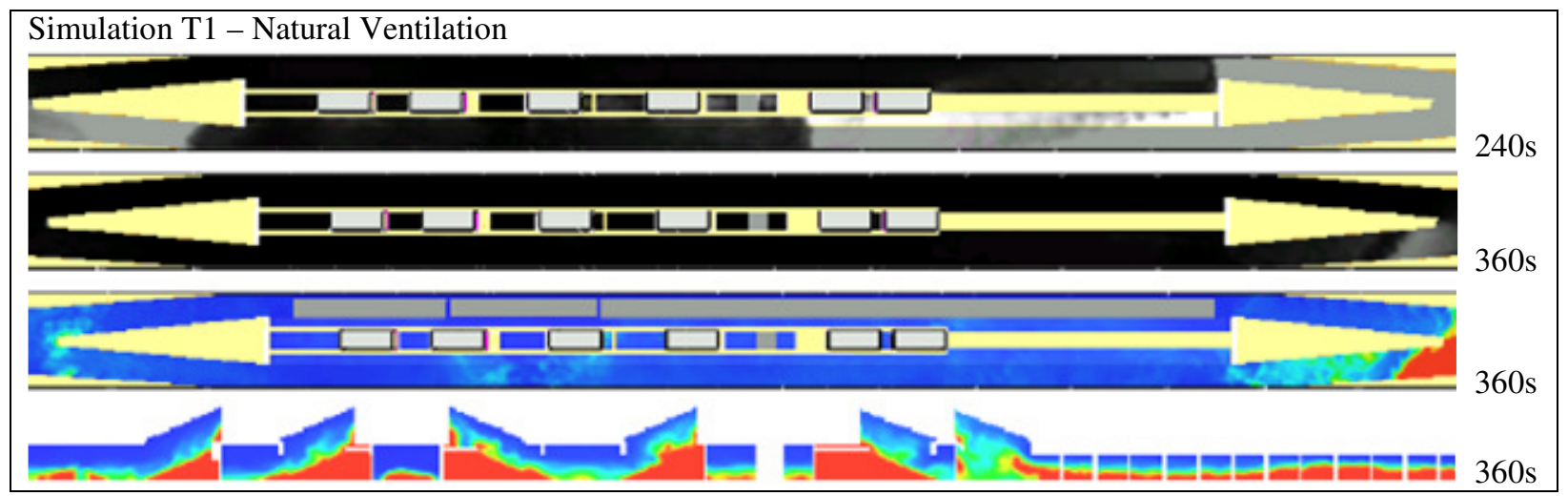

Figure 27 Smoke spread and visibility on station platform for Natural Ventilaiton

\section{Simulation T2: “Pull” Strategy, Single Exhaust at $80 \mathrm{~m}^{3} / \mathrm{s}$ (E80s)}

The smoke spread was mitigated in comparison to simulation T1. Tenability duration throughout the platform is increased, however, smoke had spread throughout the platform by 360 seconds. At 360 seconds, all stairwells had been infiltrated with smoke and were no longer tenable (Figure 28).

\section{Simulation T3: “Pull” Strategy, Exhaust at 160m³/s (E160)}

The smoke spread was significantly reduced compared to prior scenarios. Smoke does not spread throughout the platform by 360 seconds. While a large portion of the platform is untenable by 
360 seconds, the east platform remain tenable. Exits remain tenable except for a single stairwell at 360 seconds (Figure 28).

\section{Simulation T4: “Pull” Strategy, Exhaust at 240m³ (E240)}

The increase of ventilation to $240 \mathrm{~m}^{3} / \mathrm{s}$ prevents the back layering of smoke as demonstrated in

(Figure 2-24). This provides significant unimpeded area of the platform. The smoke drawn

backwards does impact the visibility at the west end. The platform west of the incident fire is untenable by 360 seconds. However, the density of the smoke is less than T3 due to the rapid rate of exhaust and influx of fresh air. By 360 seconds, one stairwell is untenable and the far-west stairwell is being compromised (Figure 28).

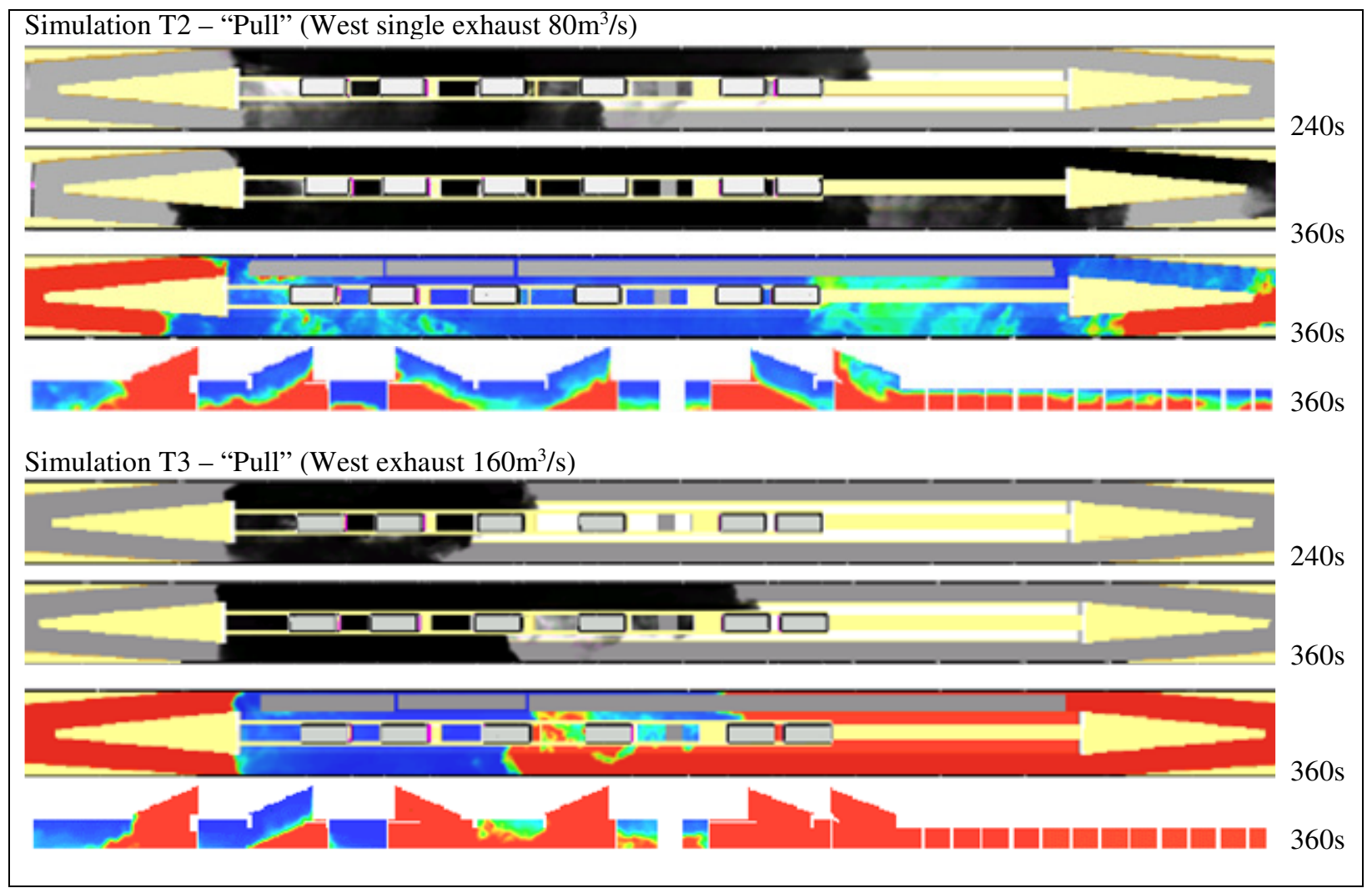




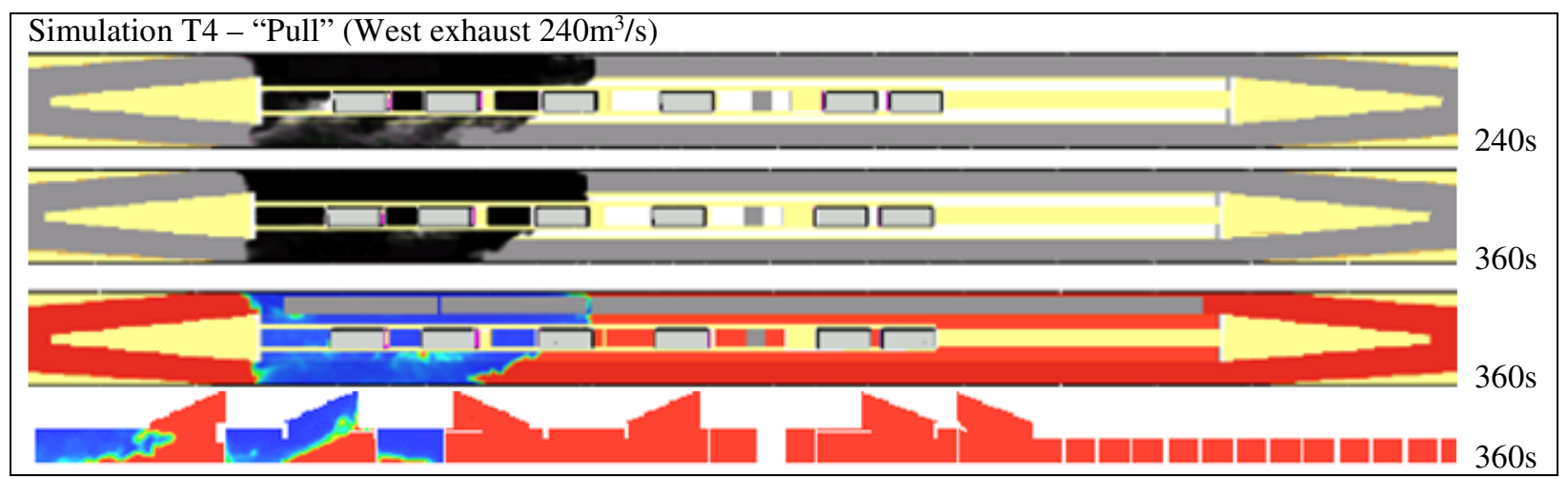

Figure 28 Results for smoke spread and visibility for "Pull" strategies

Simulation T5: “Pull-Pull” Strategy, Exhaust $160 \mathrm{~m}^{3} / \mathrm{s}$ on east and west (E160 | E160)

The exhaust from both sides rapidly spreads smoke across the platform. This has a prompt negative affect on visibility. Despite this, the concentration of smoke is reduced and tenability is maintained in marginal conditions. The effect of extracting air from both ends of the platform draws fresh air into the platform from the stairwells. This also increases the tenability of the stairwells with only one being untenable at 360 seconds (Figure 29).

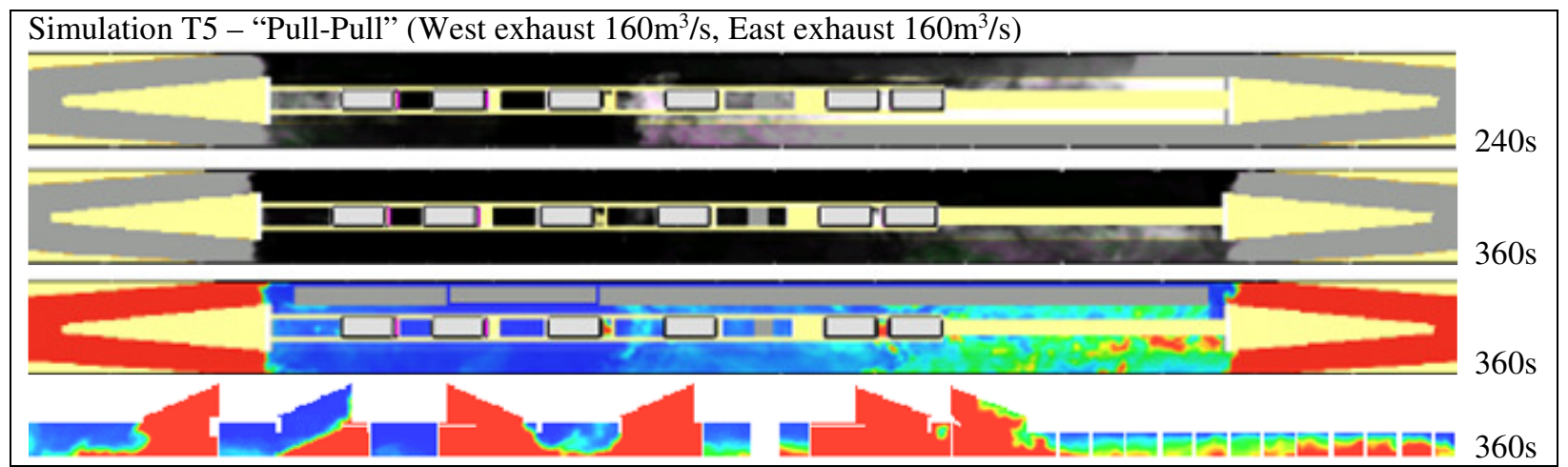

Figure 29 Results for smoke spread and visibility for "Pull-Pull" strategies

Simulation T6: “Push-Pull” Strategy, Supply $160 \mathrm{~m}^{3} / \mathrm{s}$ on east and exhaust $160 \mathrm{~m}^{3} / \mathrm{s}$ on west (S160 | E160)

The Push-Pull Strategy produced results similar T4. It provided significantly high air velocities and able to contain the smoke, preventing back layering. However, tenability in several stairs was reduced with only two stairwells unaffected by smoke at 360 seconds. The effect of pushing 
results in the turbulent mixing of fresh air and smoke which lowers visibility compared to T4

(Figure 30).

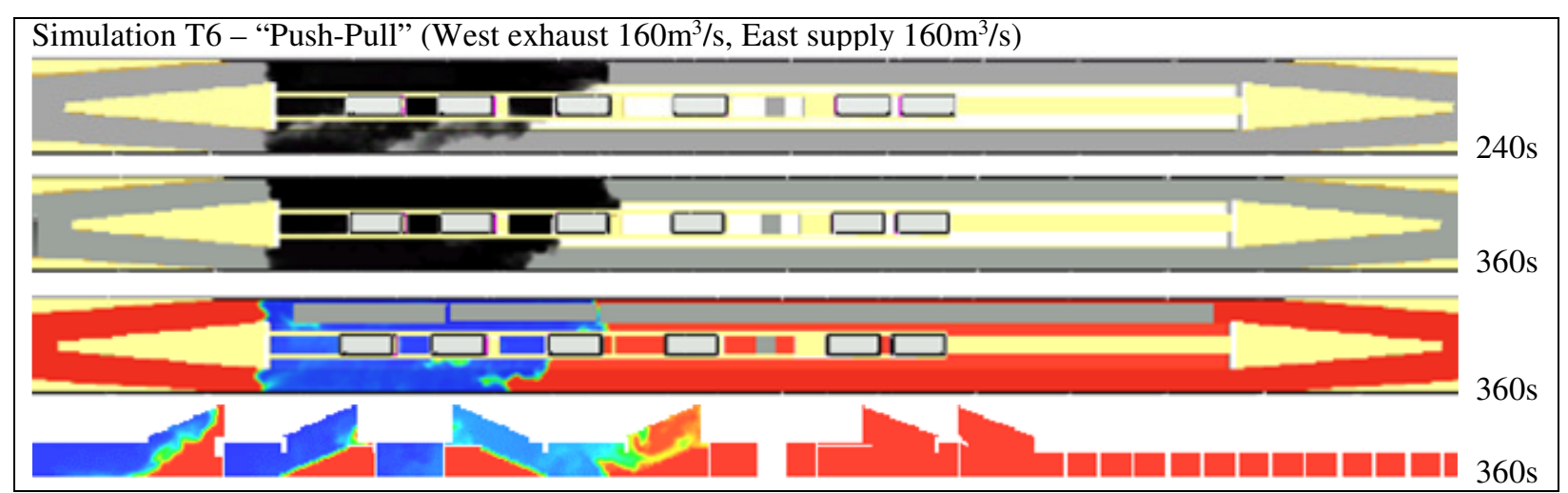

Figure 30 Results for smoke spread and visibility for "Push-Pull" strategies

\section{Simulation T7: Pressurize Strategy, (E80 S3x80)}

The results of pressurizing the platform to contain smoke did not prove overly effective. The smoke was contained to some degree on the west side of the platform. However, the tenability of this area was quickly compromised (Figure 31).

\section{T8: Pressurize Strategy, (ES80 I ES80)}

The exhaust and supply of smoke at both ends of the platform was not successful in protecting the platform from the expansion of smoke. The mix of the smoke layer was a result of increased turbulence. While this spread smoke throughout the platform the concentrations were lower due to the supply air. Thus while visibility is reduced throughout, it remains tenable for many locations (Figure 31).

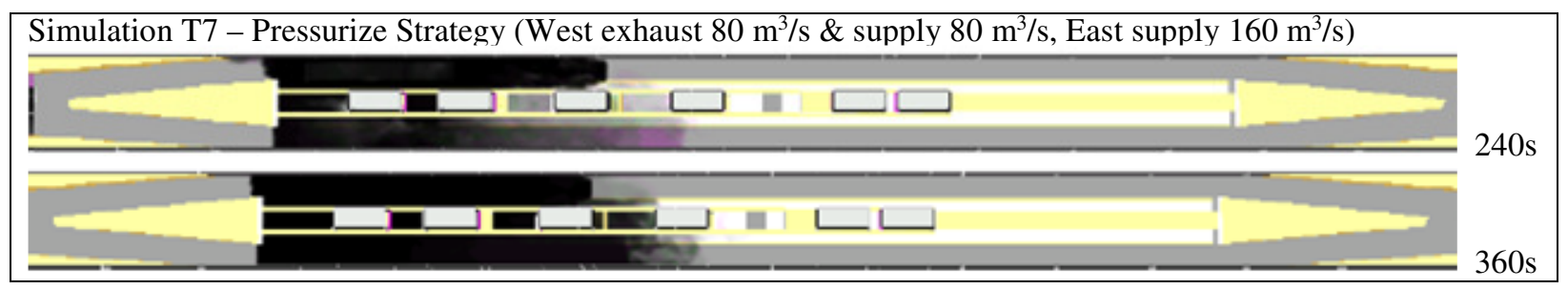




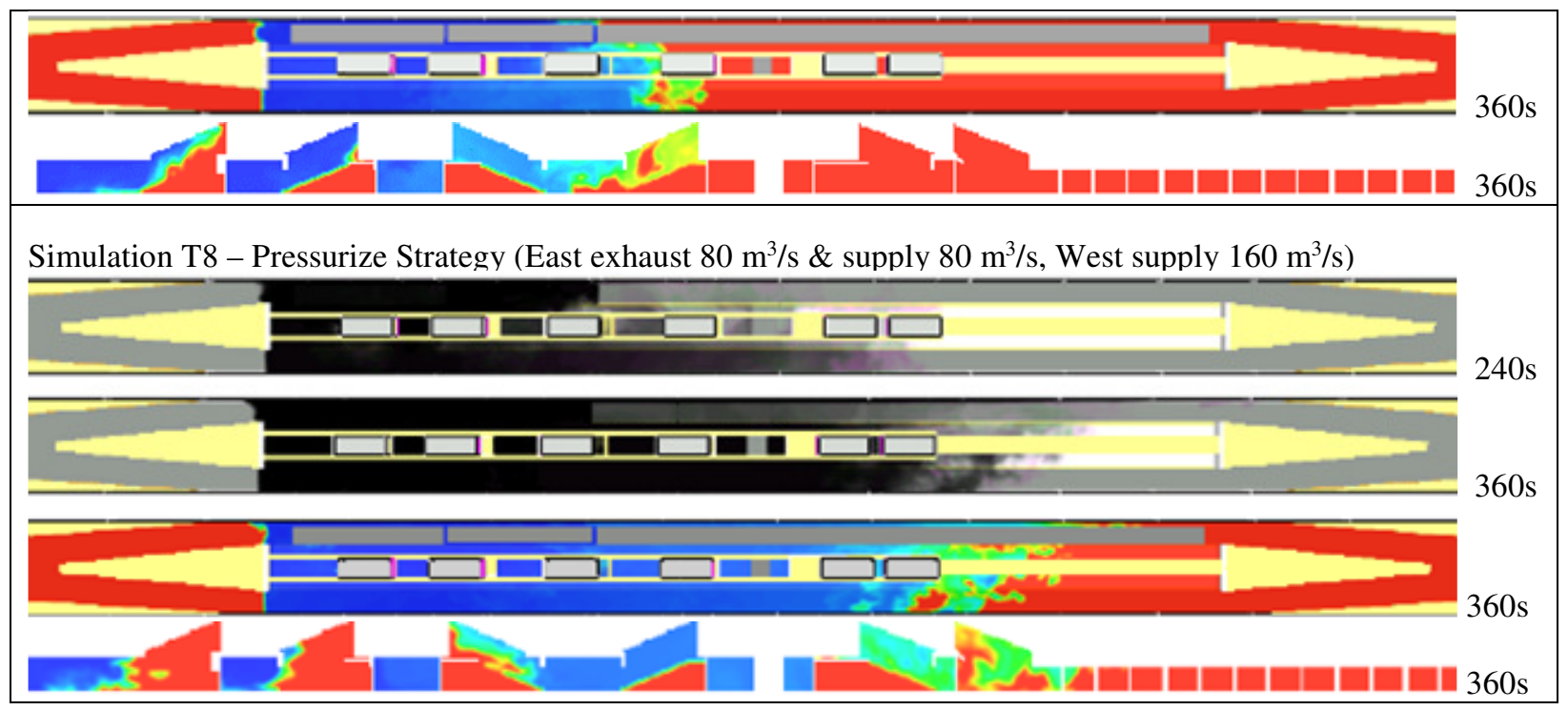

Figure 31 Results for smoke spread and visibility for pressurization strategies

\subsection{Analysis of tenability on Platform}

\section{Platform Visibility}

The movement of smoke had significant impact on the visibility around the platform. While the confinement of smoke was best established in simulation T6 "Push-Pull", the effect of the air movement negatively affected the visibility of the platform downstream. The visibility at Zone 2A, located downstream of the incident car, is seen to rapidly drop below tenable criteria approximately 90 seconds into the simulation (Figure 32). The natural ventilation provided better tenability for the platform location. However, this is to be expected, as the platform adjacent to the train will become untenable quickly as smoke is extracted from the incident car. The evacuees will find tenable conditions on the other side of the platform.

Visibility at Zone 4-A, upstream of the incident car, is seen to best be maintained by simulation T-4 "Pull" (Figure 33). The exhaust at the west end of the platform severely limits the migration of smoke to the other end of the platform. The simulation T6 "Push-Pull" was able to limit 
smoke migration to these areas 480 seconds. Natural ventilation resulted in the worst tenability with visibility compromised at 160 seconds.

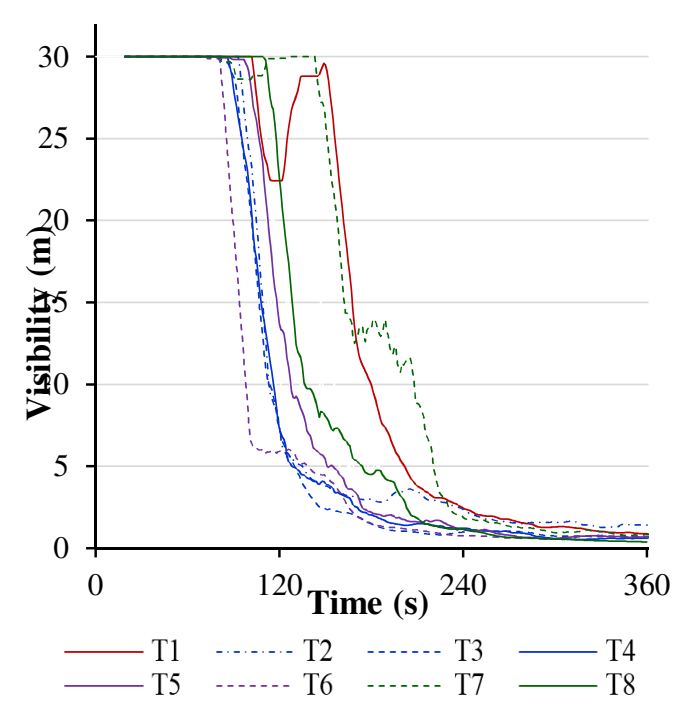

Figure 32 Visibility on platform at zone 2-A.

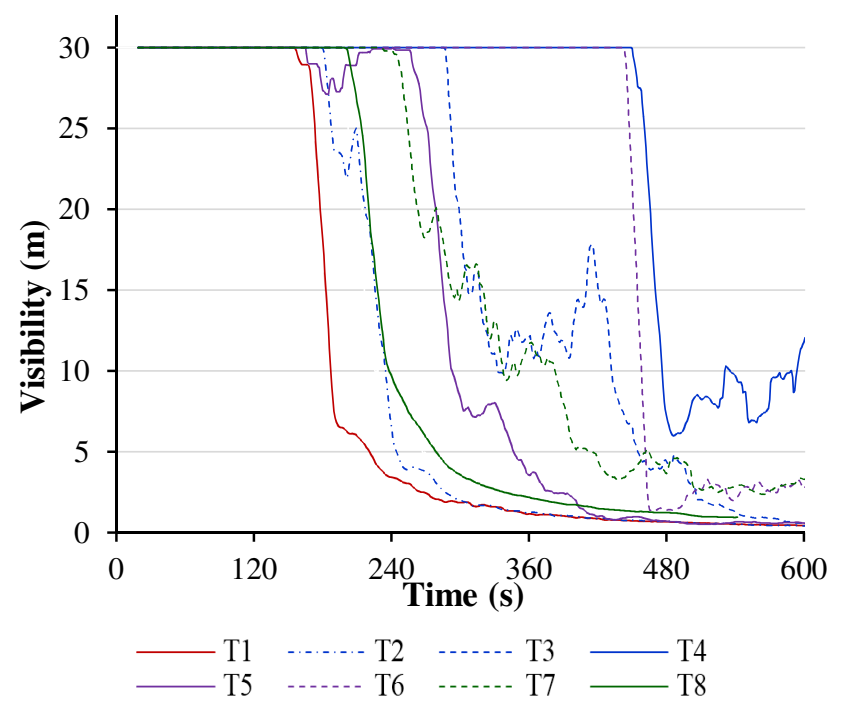

Figure 33 Visibility on platform at zone 4-A

\section{Platform Temperature}

The temperature around the platform greatly affected by mechanical ventilation. For the most part, temperature on the platform improved with ventilation. However, the extraction of smoke does result in drawings smoke across some areas of the platform. Under natural ventilation, Zone 1-A temperature remained tenable for 420 seconds. This duration was greatly improved upon with all "Pull" and "Push-Pull" scenarios remaining tenable for over 600 seconds (Figure 34).

Mechanical ventilation did not offer improvement to temperature tenability in Zone 2-A, except for simulation T2, which exhaust air through only one vent. Due to this, smoke is not pulled across the platform, it is extracted in a vector parallel to the platform. This resulted in substantially longer tenability of nearly 600 seconds compared to 460 seconds for natural ventilation (Figure 35). 


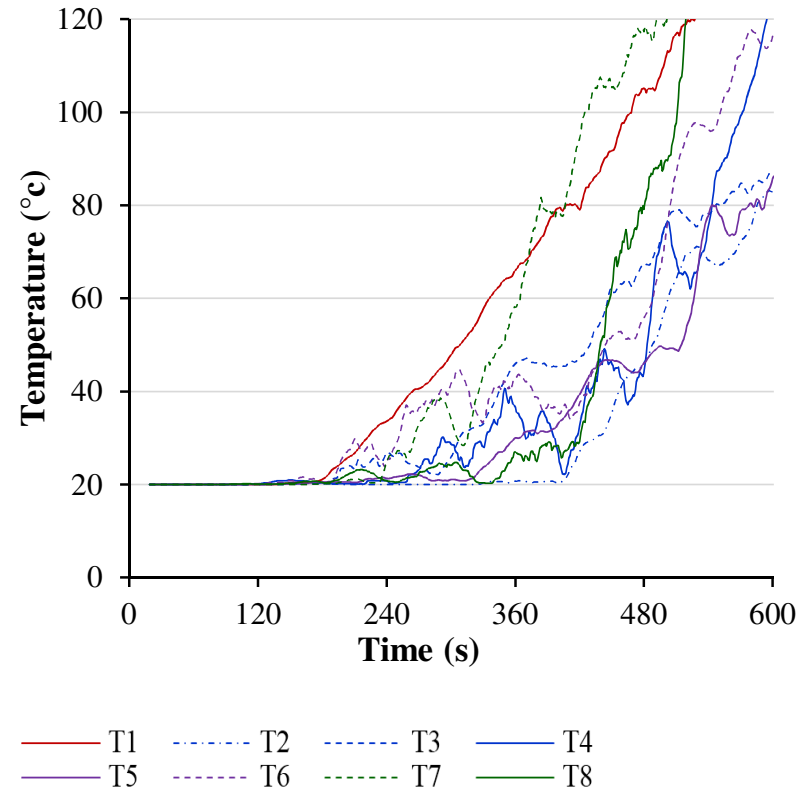

Figure 34 Temperature at platform zone 1-A

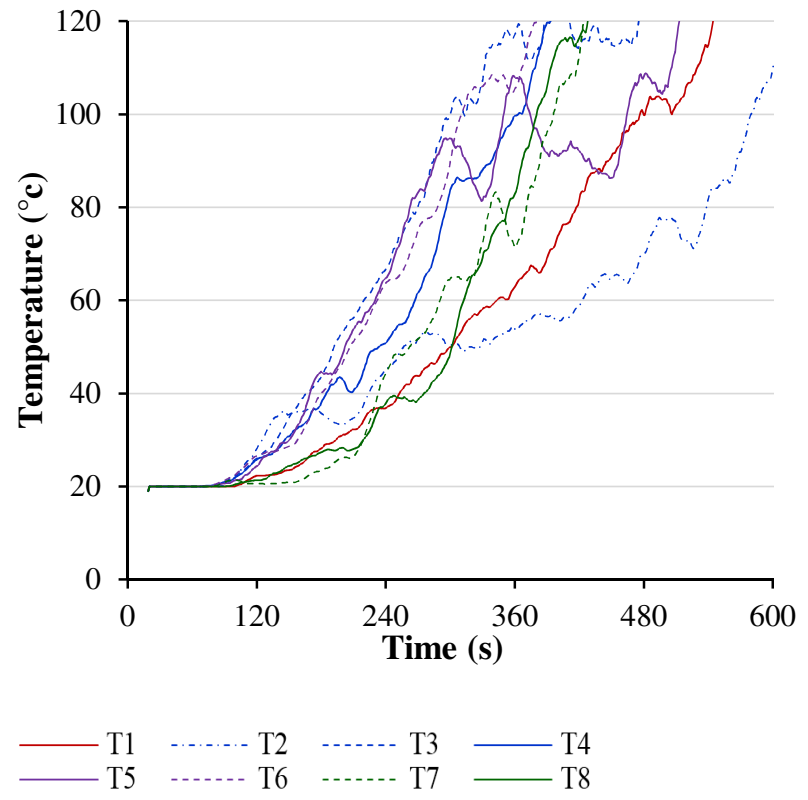

Figure 35 Temperature at platform zone 2-A

Zone 3-A was directly adjacent to the incident fire and as a result, temperatures rise significantly. Many ventilation strategies did not improve tenability from the natural ventilation base case which reached $100^{\circ} \mathrm{C}$ at 300 seconds (Figure 36). Simulation T4 and T6 were able to improve this duration to over 360 seconds. Interestingly, the pressurization strategies T7 and T8 appeared to have benefitted the mid platform with significantly longer tenability. It is likely that the use of supply air in these strategies was able to circulate sufficient cool air throughout the midplatform.

Zone 4-A remained tenable in regards to temperature for the 600 second duration (Figure 37). Simulation T5 resulted in higher temperatures late into the simulation. T2 had minimal impact on the temperature and suggest that the effectiveness of the single exhaust fan is limited at further distances. 

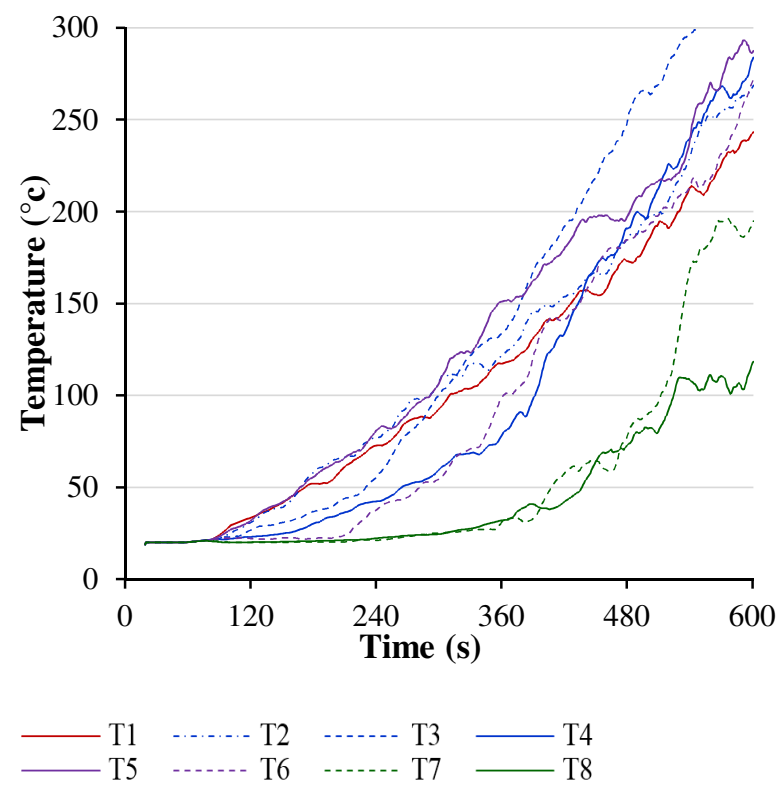

Figure 36 Temperature at platform zone 3-A

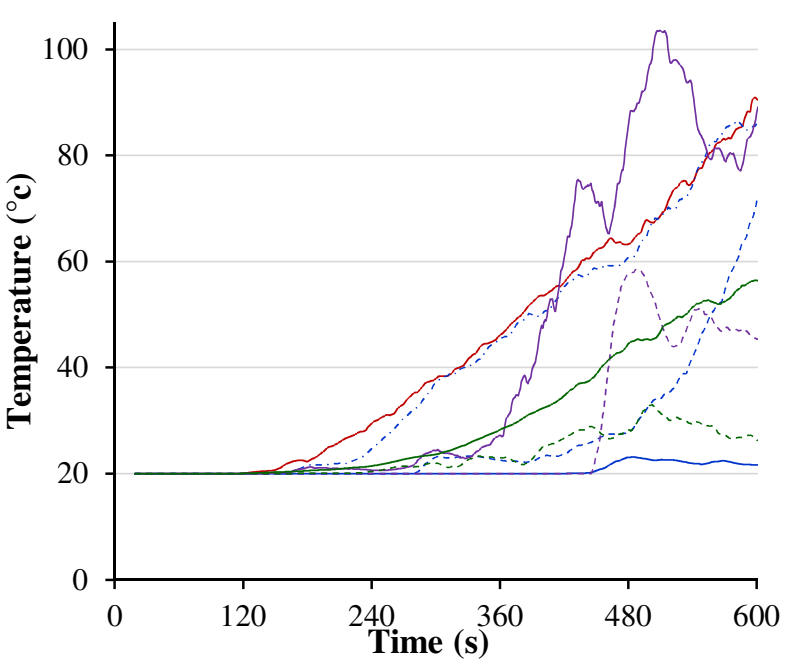

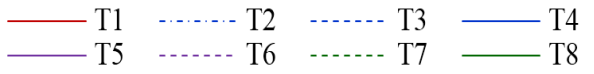

Figure 37 Temperature at platform zone 4-A

Zone 5-A maintained tenability in regards to temperature for the duration of the simulations

(Figure 38). Similar observations are noted regarding the effectiveness of ventilation strategies as in Zone 4-A.

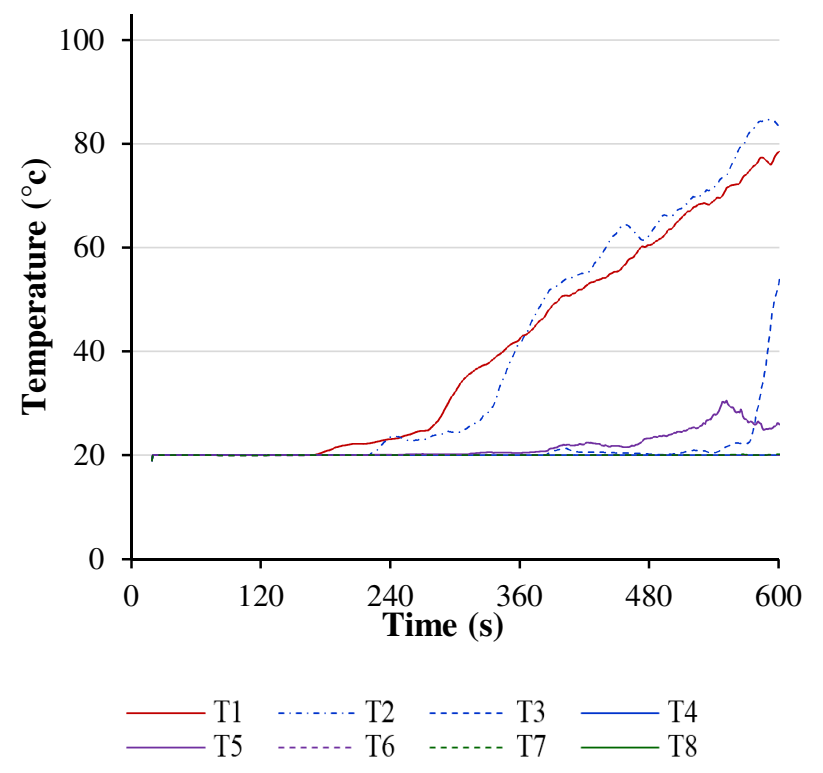


Figure 38 Temperature at platform zone 5-A

\subsection{Analysis of Tenability in Stairwells}

\section{Zone 1-B}

In Natural Ventilation T1, smoke enters the east stairwell (Zone 1-B) eliminating tenability at 189 seconds. The effects of exhausting $160 \mathrm{~m}^{3} / \mathrm{s}$ in simulation T3, increases the tenability of the space to 415 seconds. Increasing the exhaust to $240 \mathrm{~m}^{3} / \mathrm{s}$ in T4 maintains tenability for 580 seconds.

\section{Zone 2-B}

Nearest to fire source, Zone 2-B was tenable for the shortest amount of time. Natural ventilation was tenable until 135 seconds. Simulation T2, a single $80 \mathrm{~m}^{3} / \mathrm{s}$ exhaust, provided slightly worse results of 130 seconds. This is a result of drawing smoke across the platform. This is a problem encountered with the movement of air by mechanical ventilation. However, increasing the strength of extraction limits the spread of smoke into the zone 2-B. The other "Pull" strategies, T3 and T4, provide for improved tenability.

\section{Smoke movement across the platform}

The result of exhausting at the end of a platform unavoidably brings smoke concentrations across the platform. Evacuees between the fire and exhaust will may experience worse tenability conditions. This is seen in zone 2-C, where the influence of exhaust decreases tenability for all except T2. Due to only a single exhaust vent, T2 pulls less smoke across the platform.

\section{Pull Strategy (T2, T3, T4)}

With an increase in exhaust power, an increase in total tenability was observed. The single exhaust vent at $80 \mathrm{~m}^{3} / \mathrm{s}$ marinated a tenable environment for just $115 \mathrm{~s}$ (at zone $2-\mathrm{B}$ ). The improvement in platform environment from with a single exhaust is notable, but not obvious. In 
fact in zone 2-B (stairwell), tenability is maintained for only 115 seconds compared to 120 seconds in natural ventilation. Yet it maintains tenability in zone 2-C, in front of the stairs, longer than all other scenarios. T3, T4 decreased tenability in zone 2-C as they draw simple across the platform. Due to only a single exhaust vent, T2 does not pull smoke across the platform. Most notably, it also helps maintain egress in zone 1 tenable for 458 seconds compared to 189 seconds. This offers a means of egress to those evacuating on the west side of the platform.

Using two exhaust for a total of $160 \mathrm{~m}^{3} / \mathrm{s}$ lead to a substantial increase in ASET. Zone 2-B is maintained tenable for 174 seconds, a $45 \%$ increase over natural ventilation. The majority of the platform remains free of smoke and back layering occurs at 250s. Increasing the exhaust to a total of $240 \mathrm{~m}^{3} / \mathrm{s}$ results in vastly improved tenability amongst all zones. Zone 2-B is maintained tenable for 280 s, a $230 \%$ increase over natural ventilation. The majority of the platform remains free of smoke and back layering occurs at 400 seconds (Figure 39).

\section{Pull-Pull Strategy (T5)}

The use of east and west fans operating in exhaust resulted in the quick spread of smoke longitudinally and consequentially amongst the platform. While smoke is spread along the platform, the smoke density is more diffuse due to it being pulled. In Figure 29, this is observed in the decline of visibility amongst much of the east end of the platform, yet the visibility is still mostly tenable conditions. While the tenability is compromised quickly in this scenario, tenable conditions are still maintained for some time due to the influx of fresh air from stairwells.

Furthermore, running all exhaust increases the air velocity in stairwell shafts as they become the only "open" boundary for air to enter. It is noted that general platform tenability is decreased but stairwells are maintained tenable comparable to "Pull" strategy T2. 


\section{Push-Pull Strategy (T6)}

With fans working in exhaust at $160 \mathrm{~m}^{3} / \mathrm{s}$ and east fans working in supply at $160 \mathrm{~m}^{3} / \mathrm{s}$, the pushpull strategy resulted in similar results to T3. It did however pose a few benefits and drawbacks. The tenability in the east of the platform, upwind of the fire, was maintained tenable for the duration of the simulation. Back layering occurred 387 seconds. The supply of air does positively impact the prevention of back layering, demonstrated by the decreased spread of smoke compared to T3. A major consequence of utilizing supply air to push smoke is the disruption of the buoyant layer. The geometry of the stairwells is also significant where they act like valves, effected depending on their orientation to the ventilation direction. After back layering occurs, smoke is seen to be pushed into the stairwell in the visibility profile in Figure 30. This can pose a serious threat to those evacuees on the stairwell and in the concourse above. The west end of the platform also experience a decrease in tenability compared to T3.

\section{Pressurize Strategy $(T 7, T 8)$}

With a single fan working in exhaust at $80 \mathrm{~m}^{3} / \mathrm{s}$ and all other fans working in supply at $80 \mathrm{~m}^{3} / \mathrm{s}$ each, a zone of pressure around the train fire limits the spread of smoke. As with the push-pull strategy, the effect of fans operating in supply at the east end of the platform resulted in a tenable environment in zones 5 and 6 . The strategy works well to contain a small fire. However, when smoke becomes abundant its' expansion reaches into the stream from the supply vent and this gets spread around quickly.

With two vents working in exhaust at either end and two working in supply the smoke is extracted along the subway tracks and supply air fills the platform. In general, this strategy failed to maintain a tenable environment along the platform. This is likely due to the aspect ratio of the platform. Producing a pressurized southern half through ventilation is not practical. However, it did result in fresh air being driven towards the center of the platform and maintained platform 
tenability at zone 4-C for the longest duration. The protection offered in the stairwells was minimal and comparable to the natural ventilation results.
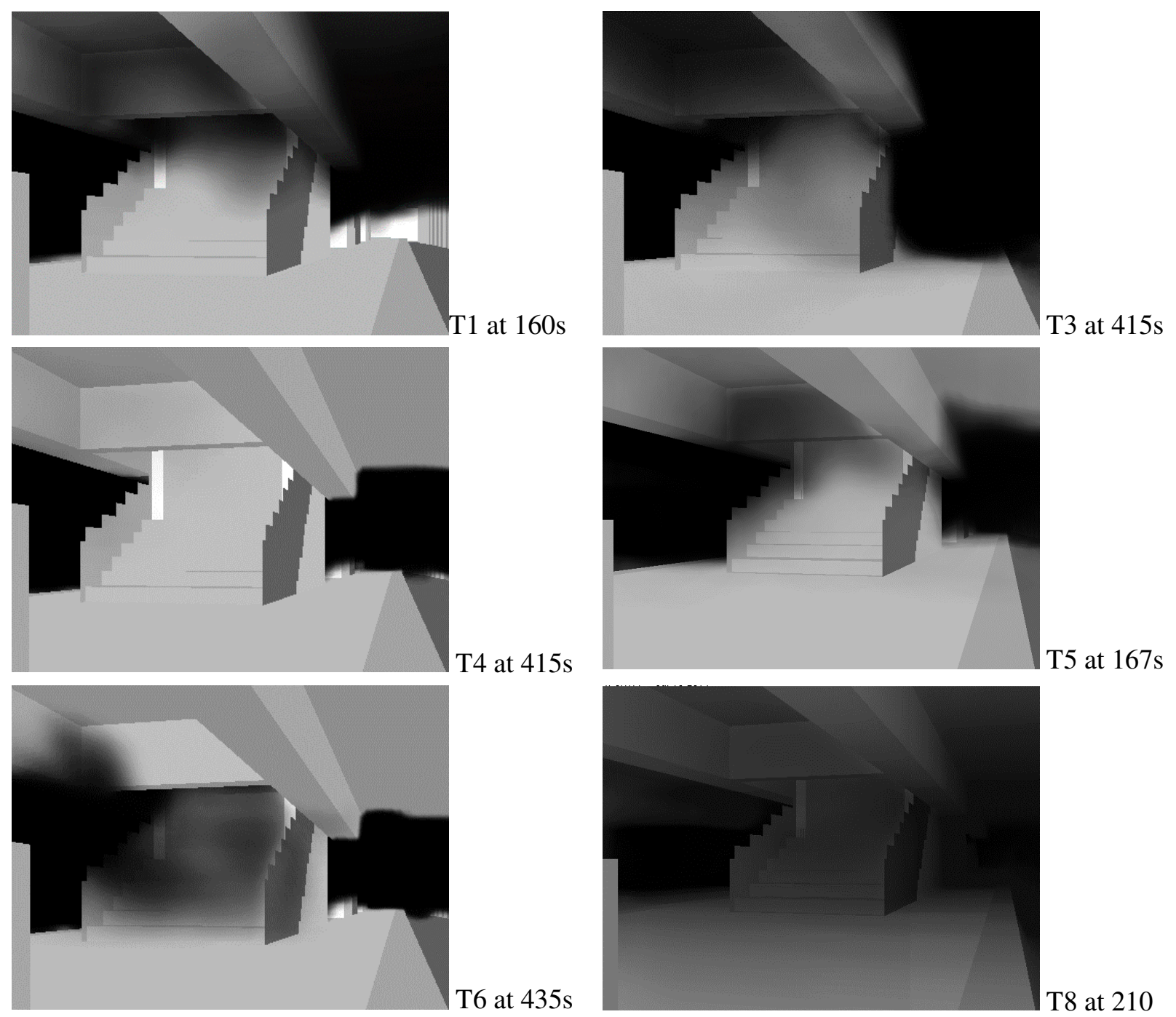

Figure 39 Ventilation strategies effect on smoke spread and the time smoke comprises the space

The influence of mechanical ventilation on the tenability of the subway platform is significant. The simulations demonstrate the absence of mechanical ventilation cannot provide enough time for egress during a large subway fire occurring mid-platform according to NFPA 130.

The maintenance of tenability in stairwells is identified as a priority as it threatens those evacuating and results in the spread of smoke to other occupied space above the platform. The improvement realized through ventilation varied in each zone. However, almost all ventilation 
strategies resulted in a dramatic improvement compared to natural ventilation. In some zones, improvements to the duration of tenability ranged between $82 \%$ to $285 \%$ for the mechanical ventilation strategies (Table 2). The importance of station design and geometry is evident in this paper. The location, size and quantity of stairwells, for instance, can be optimized based on CFD simulations to ensure that they stay tenable for increased duration.

\subsection{Discussion of results}

A general overview is provided through the simulation visualizations, heat map of zone tenability duration and measurement of temperature and visibility. The results were synthesized into a heat map showing the performance of each strategy in maintaining tenability at specific locations (Table 2). The time was determined through measurements and visualization in CFD. Where tenability exceeded simulation length of 600 seconds, the value of 700 seconds is used. Figure 40 demonstrates the tenability from sensor data for each location noted.

Table 2 Simulation results summary

\begin{tabular}{|c|c|c|c|c|c|c|c|c|c|c|c|c|c|c|c|}
\hline \multirow{3}{*}{ Sim } & \multirow{3}{*}{ Strategy } & \multirow{2}{*}{\multicolumn{2}{|c|}{ Ventilation }} & \multicolumn{2}{|c|}{ Zone 1} & \multicolumn{2}{|c|}{ Zone 2} & \multicolumn{2}{|c|}{ Zone 3} & \multicolumn{2}{|c|}{ Zone 4} & \multicolumn{2}{|c|}{ Zone 5} & \multicolumn{2}{|c|}{ Zone 6} \\
\hline & & & & \multirow{2}{*}{$\begin{array}{l}\text { Stage } \\
1-\mathrm{C}\end{array}$} & \multirow{2}{*}{$\begin{array}{l}\text { Stair } \\
1-B\end{array}$} & \multirow{2}{*}{$\begin{array}{l}\text { Stage } \\
2-\mathrm{C} \\
\end{array}$} & \multirow{2}{*}{$\begin{array}{l}\text { Stair } \\
2-B \\
\end{array}$} & \multirow{2}{*}{$\begin{array}{l}\text { Stage } \\
3-\mathrm{C} \\
\end{array}$} & \multirow{2}{*}{$\begin{array}{l}\text { Stair } \\
3-B\end{array}$} & \multirow{2}{*}{$\begin{array}{l}\text { Stage } \\
4-\mathrm{C} \\
\end{array}$} & \multirow{2}{*}{$\begin{array}{l}\text { Stair } \\
4-B\end{array}$} & \multirow{2}{*}{$\begin{array}{l}\text { Stage } \\
5-\mathrm{C}\end{array}$} & \multirow{2}{*}{$\begin{array}{l}\text { Stair } \\
5-B\end{array}$} & \multirow{2}{*}{$\begin{array}{l}\text { Stage } \\
6-\mathrm{C} \\
\end{array}$} & \multirow{2}{*}{$\begin{array}{l}\text { Stair } \\
6-B\end{array}$} \\
\hline & & West & East & & & & & & & & & & & & \\
\hline \multirow[t]{2}{*}{ T1 } & Natural & & & 460 & 189 & 480 & 120 & 310 & 135 & 274 & 196 & 230 & 700 & 265 & 700 \\
\hline & & & & & & & & & & & & $\wedge$ & & $\wedge$ & \\
\hline \multirow[t]{2}{*}{$\mathbf{T 2}$} & Pull & E80s & & 700 & 458 & 580 & 115 & 290 & 200 & 289 & 255 & 255 & 700 & 310 & 700 \\
\hline & & & & & $\wedge$ & & & & & & & & & $\wedge$ & \\
\hline \multirow[t]{2}{*}{ T3 } & Pull & E160 & & 700 & 404 & 300 & 174 & 300 & 516 & 374 & 540 & 540 & 700 & 516 & 700 \\
\hline & & & & & & & & & & & & $\wedge$ & & $\wedge$ & \\
\hline \multirow[t]{2}{*}{ T4 } & Pull & E240 & & 570 & 540 & 360 & 280 & 390 & 700 & 511 & 700 & 700 & 700 & 700 & 700 \\
\hline & & & & & & & & & & & & $\wedge$ & & $\wedge$ & \\
\hline \multirow[t]{2}{*}{ T5 } & Pull-Pull & E160 & E160 & 700 & 515 & 350 & 195 & 290 & 480 & 325 & 700 & 700 & 700 & 430 & 700 \\
\hline & & & & & & & & & & & & $\wedge$ & & $\wedge$ & \\
\hline \multirow[t]{2}{*}{ T6 } & Push-Pull & E160 & S160 & 550 & 445 & 310 & 189 & 360 & 165 & 459 & 466 & 700 & 700 & 700 & 700 \\
\hline & & & & & & & & & & & & $\wedge$ & & $\wedge$ & \\
\hline \multirow[t]{2}{*}{ T7 } & Pressurize & E80 & S80x3 & 420 & 345 & 400 & 210 & 510 & 260 & 545 & 400 & 700 & 700 & 700 & 700 \\
\hline & & & & & & & & & & & & $\wedge$ & & $\wedge$ & \\
\hline \multirow[t]{2}{*}{ T8 } & Pressurize & ES80 & ES80 & 510 & 388 & 380 & 245 & 525 & 380 & 700 & 220 & 300 & 700 & 440 & 700 \\
\hline & & & & & $\wedge$ & & & & & & & & & $\wedge$ & \\
\hline
\end{tabular}




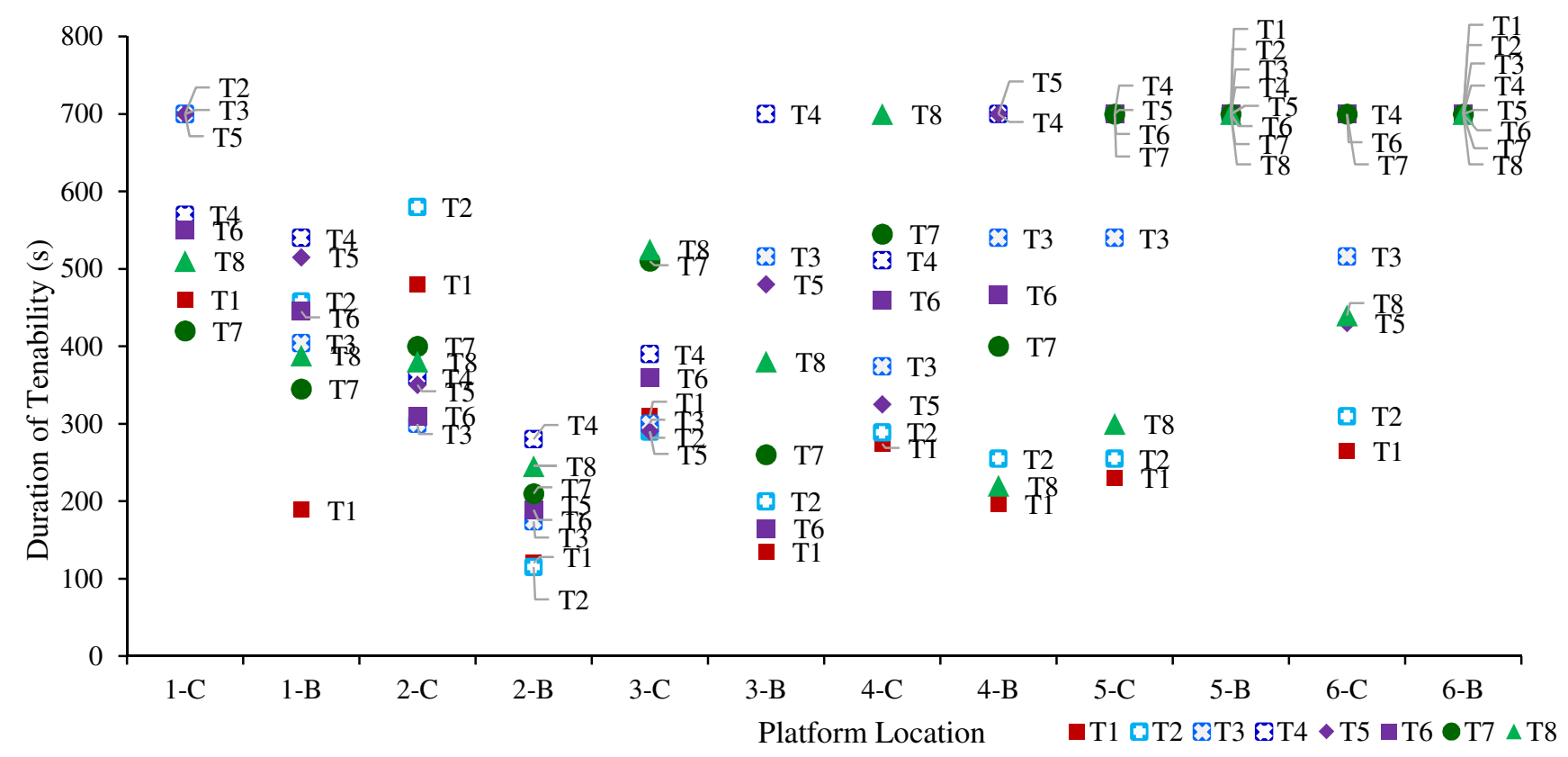

Figure 40 Duration of tenability for each zone location

\section{Available Safe Egress Time}

The results were further compiled to assess the average tenability time throughout the platform locations measured (Table 3). However, care must be given to interpret the results because many benefits and drawbacks occur with each strategy. Thus, the ranking only provides an overview and is not meant to endorse a strategy over another. While the average tenability time gives an indication of the performance of each strategy, it does not give a true indication of ASET. Tenability must held along an entire egress path.

Table 3 Platform Tenability Time

\begin{tabular}{|c|c|c|c|c|c|c|c|c|}
\hline \multirow[t]{2}{*}{ Sim } & \multirow[t]{2}{*}{ Strategy } & \multicolumn{2}{|c|}{ Vent } & \multirow{2}{*}{$\begin{array}{l}\text { Average Tenability Time } \\
\text { (average of stairwell exits) }\end{array}$} & \multirow{2}{*}{$\begin{array}{c}\text { Increase in } \\
\text { Tenability }\end{array}$} & \multirow[t]{2}{*}{ Rank } & \multirow[t]{2}{*}{ ASET } & \multirow[t]{2}{*}{ Rank } \\
\hline & & West & East & & & & & \\
\hline T1 & Natural & - & - & 338 & - & $8^{\text {th }}$ & 230 & $8^{\text {th }}$ \\
\hline T2 & Pull & E80s & - & 404 & $20 \%$ & $7^{\text {th }}$ & 310 & $7^{\text {th }}$ \\
\hline T3 & Pull & E160 & - & 480 & $42 \%$ & $5^{\text {th }}$ & 516 & $4^{\text {th }}$ \\
\hline T4 & $\mathbf{P}_{\mathrm{u}}$ & F240 & 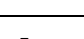 & 571 & $69 \%$ & $1^{\text {st }}$ & 700 & $1^{\text {st }}$ \\
\hline & & & & & & & & \\
\hline T5 & Pull-Pull & E160 & E160 & 507 & $50 \%$ & $2^{\text {nd }}$ & 430 & $5^{\text {th }}$ \\
\hline
\end{tabular}




\begin{tabular}{|l|l|l|l|l|l|l|l|l|} 
& & & & & & & \\
\hline T6 & Push-Pull & E160 & S160 & 479 & $42 \%$ & $4^{\text {th }}$ & 700 & $1^{\text {st }}$ \\
\hline & & & & & & & & \\
\hline T7 & Pressurize & E80 & S80x3 & 491 & $45 \%$ & $3^{\text {rd }}$ & 700 & $1^{\text {st }}$ \\
\hline & & & & & & & & $6^{\text {th }}$ \\
\hline T8 & Pressurize & ES80 & ES80 & 457 & $35 \%$ & $6^{\text {th }}$ & 388 & ${ }^{\text {th }}$ \\
\hline
\end{tabular}

\subsection{Conclusion}

The simulations showed significantly longer durations of tenability can be maintained through mechanical ventilation. However, the effectiveness of ventilation strategies varies greatly between strategies employed and can both positively and negatively affect tenability at specific locations. The best performing ventilation strategies in regards to the maintenance of overall tenability were T4-Pull, T6-Push-Pull and T7-Pressurize. 


\section{Chapter 4. Smoke Spread Analysis: TransLink's Yaletown Skytrain Station}

The Skytrain Yaletown station was completed in 2009 and is located in downtown Vancouver. It serves approximately 13,500 passengers on a typical weekday (Translink, 2011). The station is located 17 meters below ground and is comprised of a central platform and concourse level. The central platform is served by a stairway, escalator and elevator (Figure 41). The concourse directs passengers through the payment area turnstiles. The fire location selected was the $1^{\text {st }}$ car on train 1 seen in Figure 42.
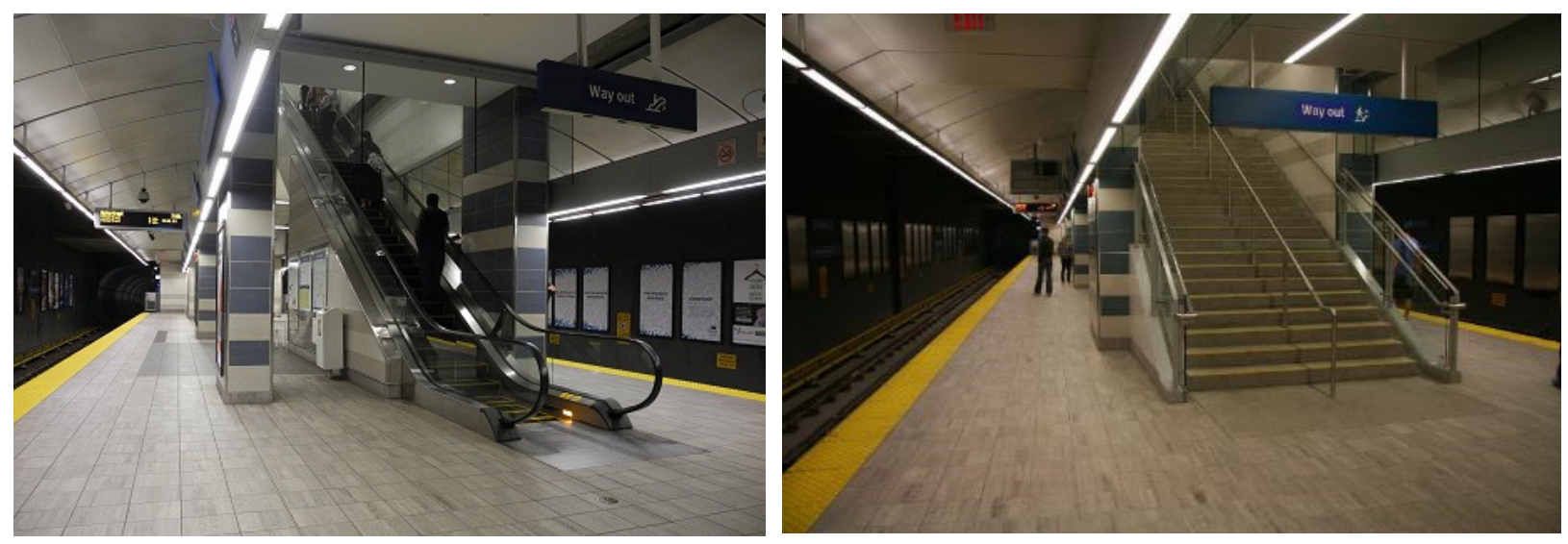

Figure 41 Egress from the Yaletown Station platform is served by one stairway, one escalator and an elevator.

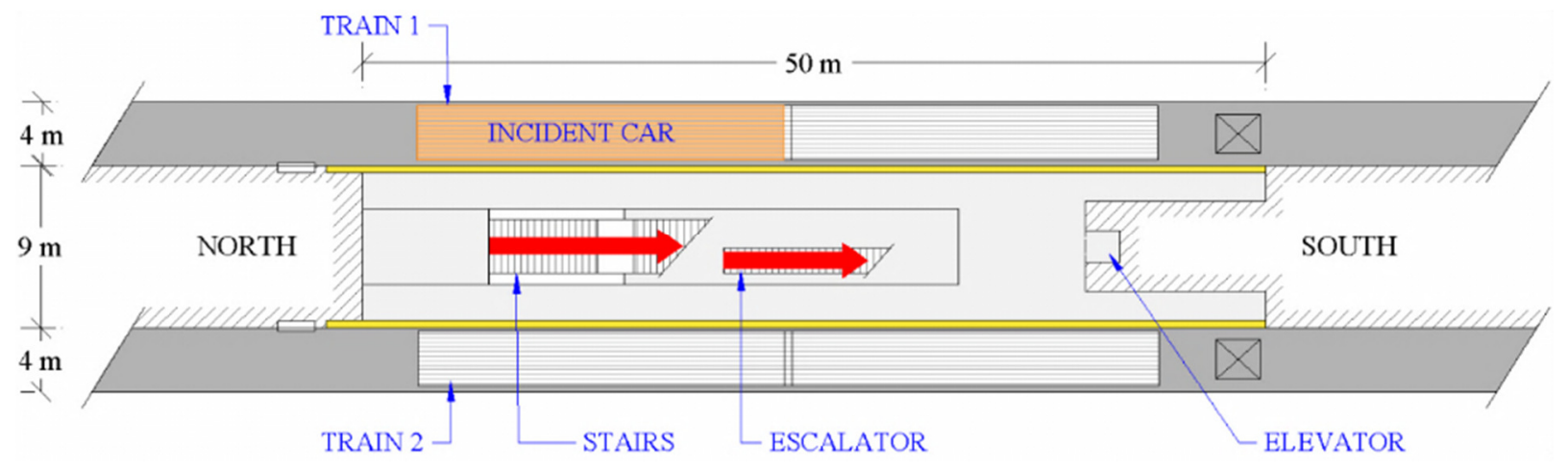

Figure 42 Yaletown Station Skytrain Platform 
The Skytrain platform is served by two joined Hyundai-Rotem rail cars which carry a maximum passenger load of 334 people (Figure 43). In comparison to the TTC subway, the Skytrain and platform is significantly smaller, carrying only about one third the amount of passengers.
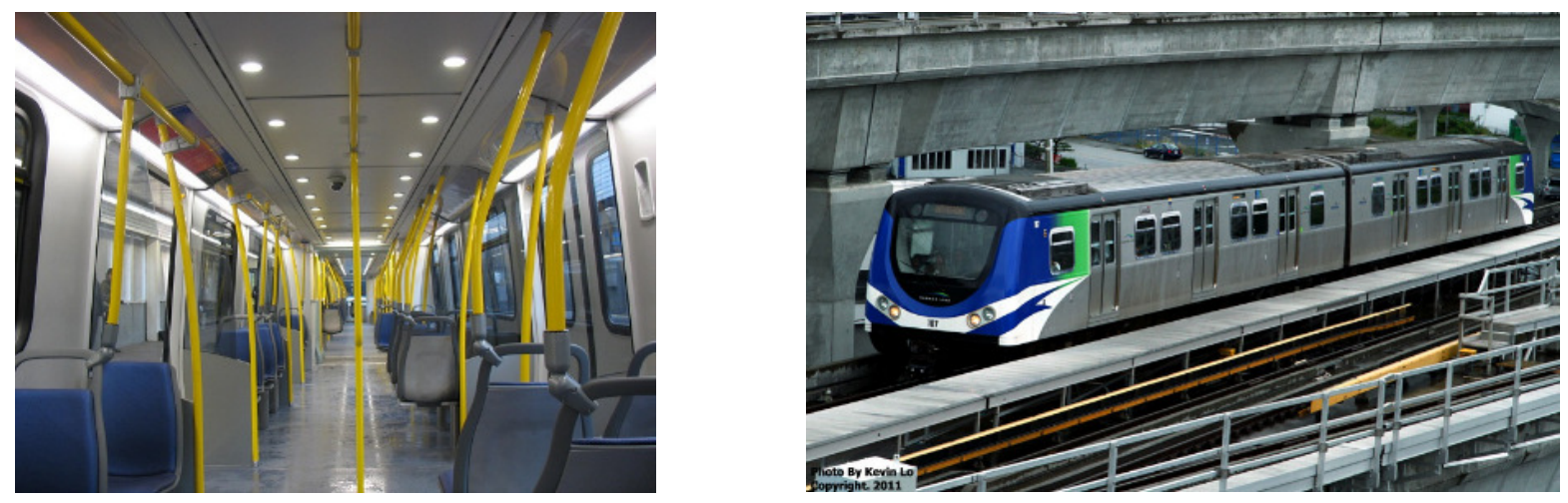

Figure 43 Interior view of Skytrain (TransLink, 2015) and exterior view of the car skytrain (Lo, 2009)

\subsection{Design Fire}

Similarly to the Union Station simulation, the design fire's HRR growth rate was modeled as "fast". In comparison to the TTC subway, the Skytrain and platform is significantly smaller, carrying only about one third the amount of passengers. The simulations was run for approximately 360 seconds, by which time the fire reaches its maximum prescribed size of 13.0 MW. Smoke production is simulated to be a function of fire size. A number of fuel sources exist within the train, some of which are high soot yielding. An assumed soot yield of $10 \%$ was used as with the TTC T-Series car (Figure 44). 


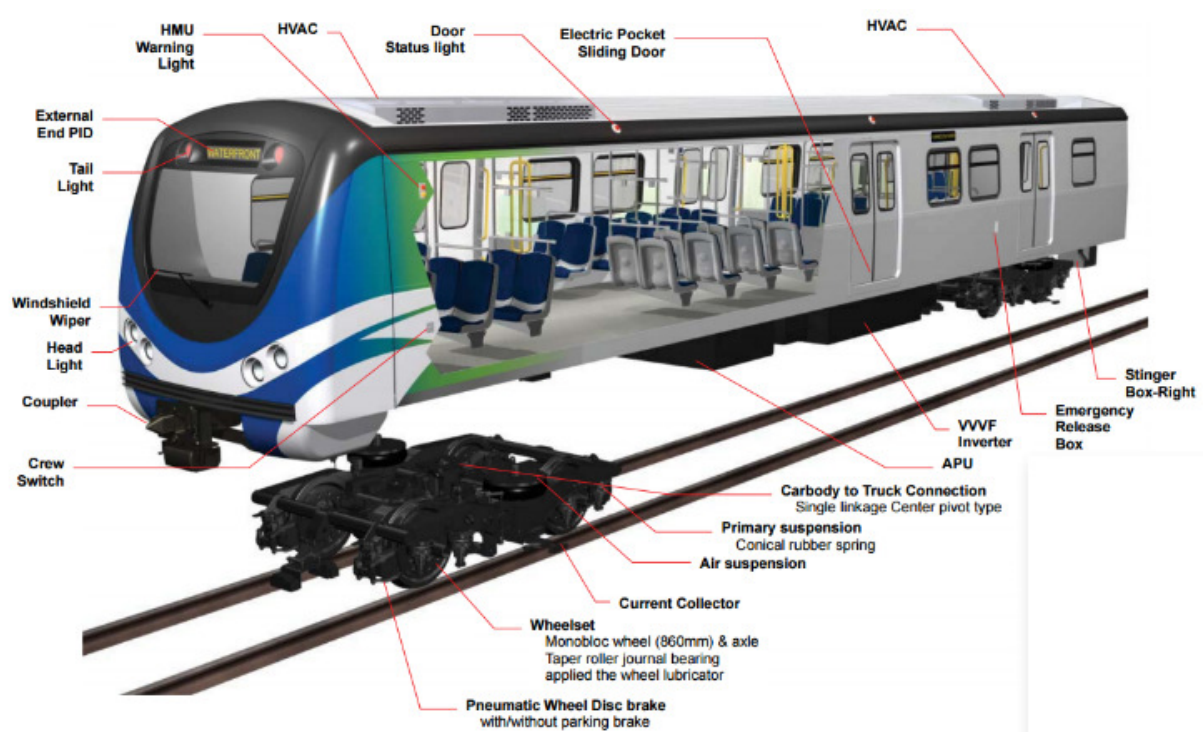

Figure 44 The TransLink Skytrain which serves the Yaletown platform (Translink, 2011)

\subsection{Analysis \& Modelling of Yaletown Station}

The platform vents are located at North and South ends of the platform (Figure 45 and Figure 46). These can function in exhaust or supply, allowing for different ventilation strategies/configurations to exist. Limitations on the disclosure of the exhaust and supply capabilities of the ventilation fans prevent modeling the exact smoke removal potential. The use of the common ventilation capacities for smoke removal in similarly sized stations was used. The model for Yaletown Station platform was derived from drawings and photographs to capture the unique design features. 


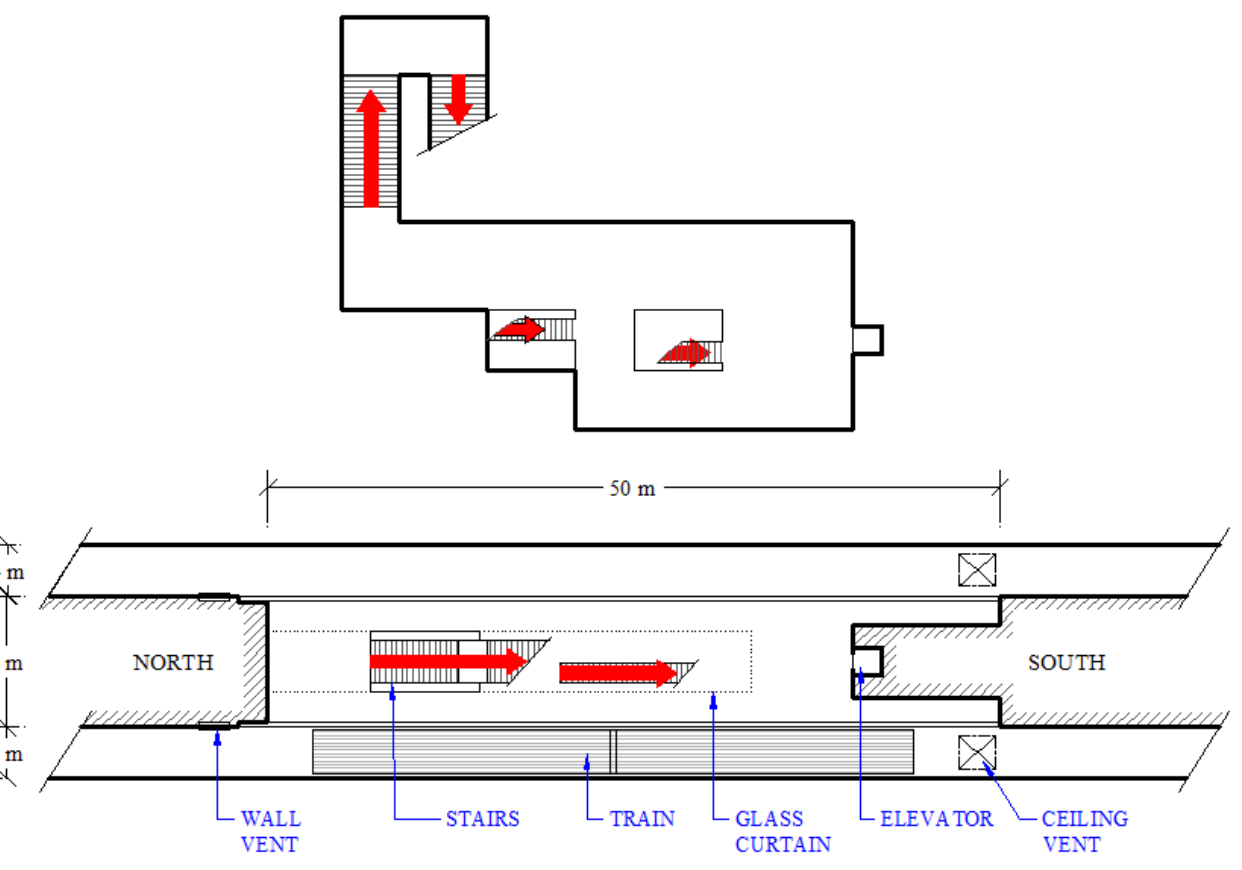

Figure 45 Egress from the platform occurs through two stairs and 1 elevator.

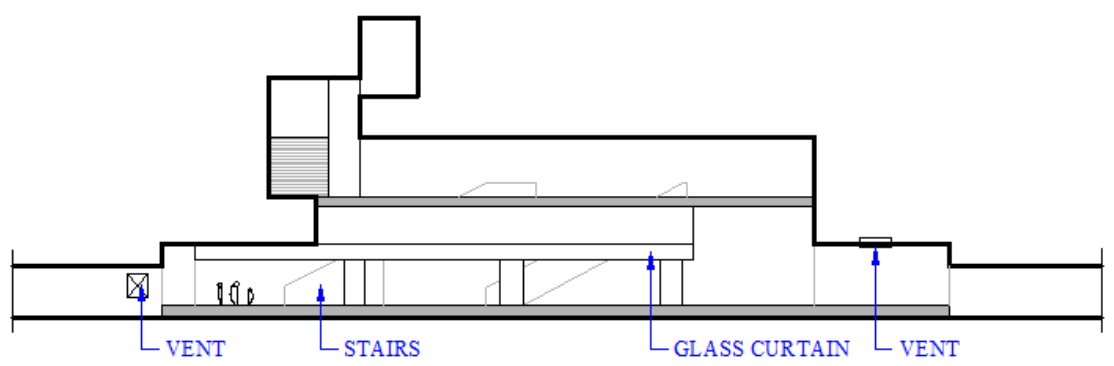

Figure 46 Sectional schematic of Yaletown Station platform

The grid sizing selected was based on comparative analysis of varying grid sizes. A grid spacing of $10 \mathrm{~cm}$ was used. The grid size used was able to be reduced greatly from the previous Union Station simulation due to its smaller station size, without enduring vastly increased simulation times. The processing time required was approximately 72-98 hours for the simulations with ventilation scenarios (Figure 47). 

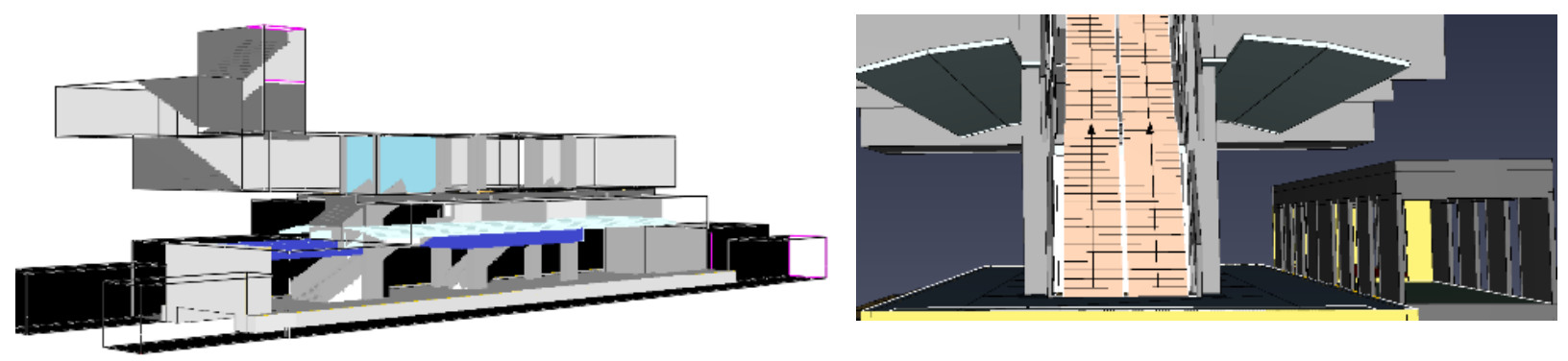

Figure 47 The subway tunnel modeled in FDS which includes open boundary conditions at stairwells and tunnel ends.

\subsection{Simulation Scenarios for Yaletown station}

The fire scenario assumes a fire occurs when the train is stopped at the station platform. The design fire occurs on the South train car and grows following a fast HRR growth curve. The location of the fire is in direct vicinity to the vertical egress. It is assumed that the fire commences while the train is stopped (Figure 48). The simulations run for 360 seconds, by which time the fire reaches its maximum prescribed size of 13.0 MW. The model records temperature, visibility and gas velocity in multiple locations, primarily along egress axis and exit locations. The simulation is run with a natural ventilation base case and two simulations of ventilation strategies commencing 60 seconds after the fire begins.

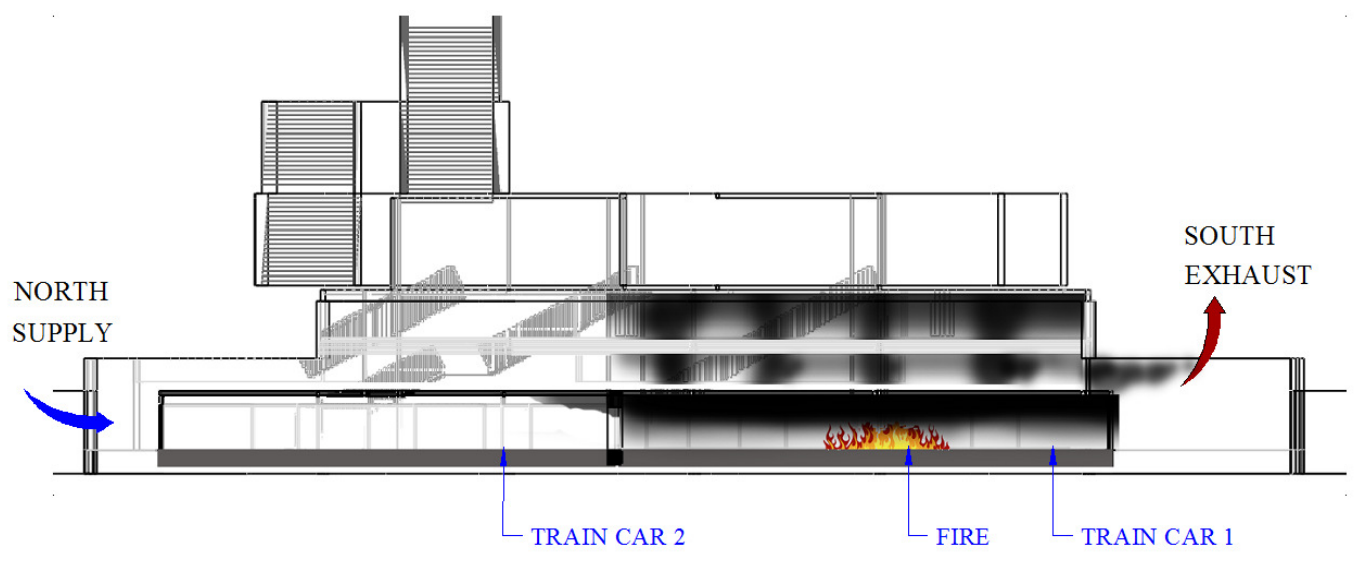

Figure 48 Ventilation shafts at both ends of the platform which can operate in supply or exhaust.

The platform's four vents are assumed to be capable of supplying or exhausting air at a rate of 80 $\mathrm{m}^{3} / \mathrm{s}$ each. To determine the effect of ventilation strategies on smoke spread, three scenarios 
were run which included natural ventilation, "pull", "push-pull". The details of operation are provided below and in Table 4.

Table 4 Ventilation for Scenarios

\begin{tabular}{|l|l|c|c|c|}
\cline { 3 - 5 } \multicolumn{2}{c|}{} & \multicolumn{3}{c|}{ Ventilation $\left(\mathrm{m}^{3} / \mathrm{s}\right)$} \\
\hline Sim & Strategy & North & South & Total Ventilation Rate \\
\hline T1 & Natural & - & - & 0 \\
\hline T2 & Pull & - & -80 & 80 \\
\hline T3 & Push-Pull & 80 & -80 & 160 \\
\hline
\end{tabular}

\subsection{Natural Ventilation}

The smoke produced travels naturally through the underground station.

- T1 No ventilation

\subsection{1 "Pull" Strategy}

The pull ventilation strategy utilizes fans working in exhaust the East end of the platform.

- T2 [East] Two fans operating, providing a combined $160 \mathrm{~m}^{3} / \mathrm{s}$ in exhaust

\subsection{2 "Push-Pull" Strategy}

This method operates vents in exhaust at one end of the platform and supplies air from the opposite end. This utilizes all ventilation sources and makes up for the loss in longitudinal air velocity along the platform due to boundary openings (stairwells).

- T3 [East] Two fans operating, providing a combined $160 \mathrm{~m}^{3} / \mathrm{s}$ in exhaust [West] Two fans operating, providing a combined $160 \mathrm{~m}^{3} / \mathrm{s}$ in supply

\subsection{Simulation Results}

Each simulation was analyzed on its performance in maintaining a tenable environment. While tenability criteria varies greatly amongst people and its very definition, standard tenable criteria 
have been utilized as rules of thumb or comparison standard. This included maintaining a temperature below $100^{\circ} \mathrm{C}$ and a visibility above $10.0 \mathrm{~m}$. The analysis of the three scenarios was done visual analysis of graphical data from the CFD simulations. First, a visual review of smoke spread was compared amongst scenarios. Secondly, a comparison of visibility determined above the platform and concourse floor was done. Special attention is given to paths of egress, stairwells and their staging areas and the maintenance of two paths of egress.

\subsection{Simulation Results: Graphical}

The simulation results were analyzed through visualizations of smoke movement, graphical data regarding smoke concentration and visibility seen in Figure 49 and Figure 50. The visibility on the platform is graphically represented through a plan view, taken at a height of 2.0 meters above the platform and concourse floor. Sectional views were taken longitudinally at the center of the platform.

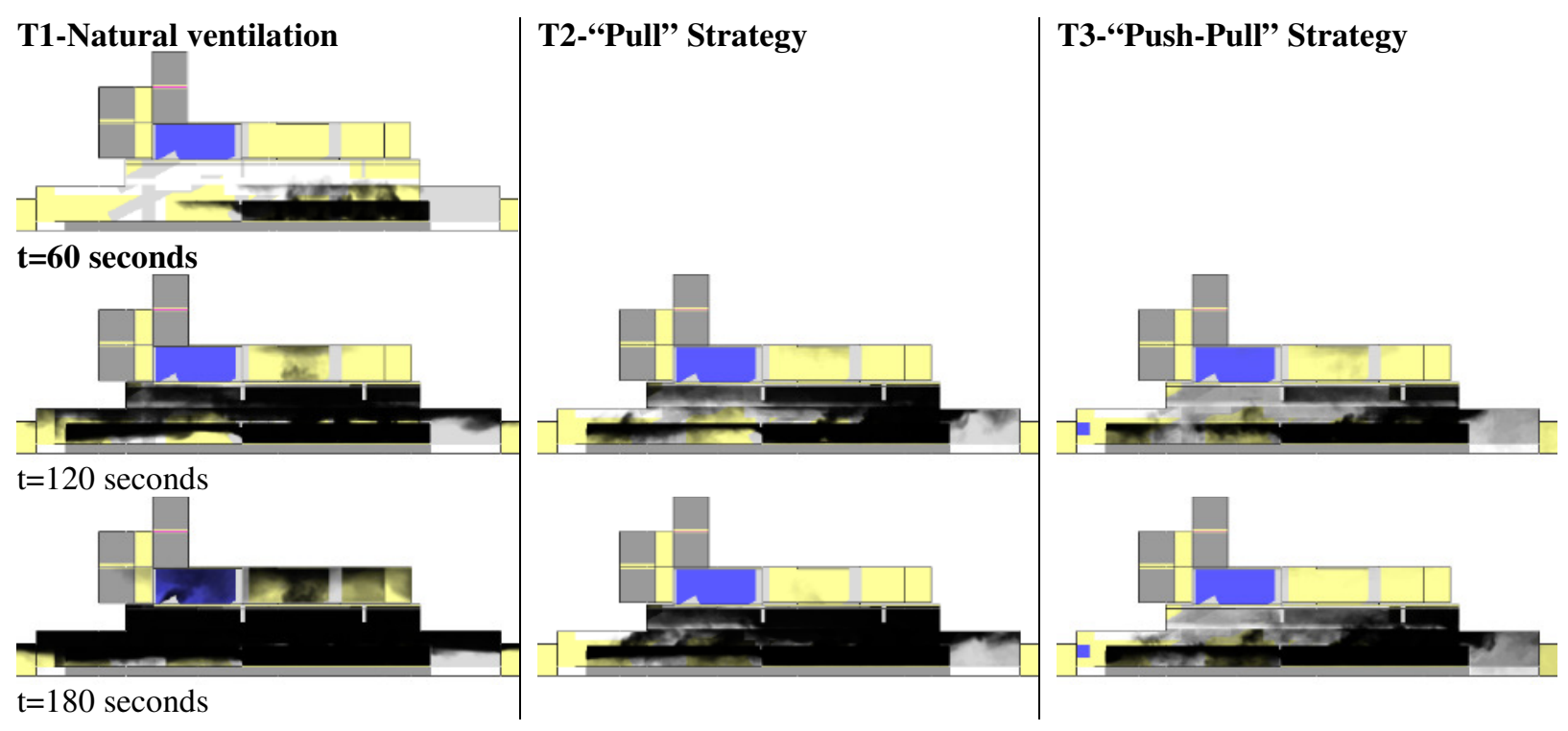




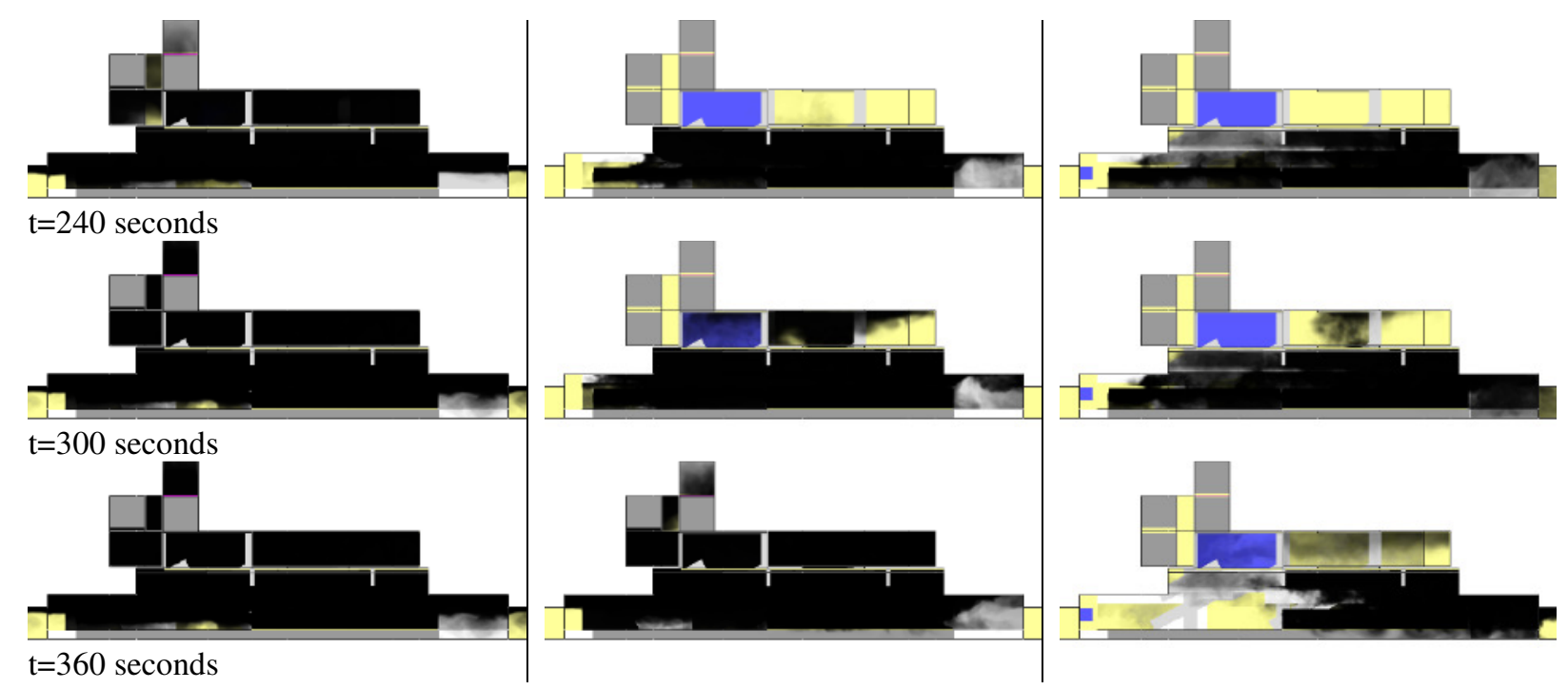

Figure 49 Smoke spread results for Natural Ventilation (left), "Pull" (middle) and "Push-Pull" (right)

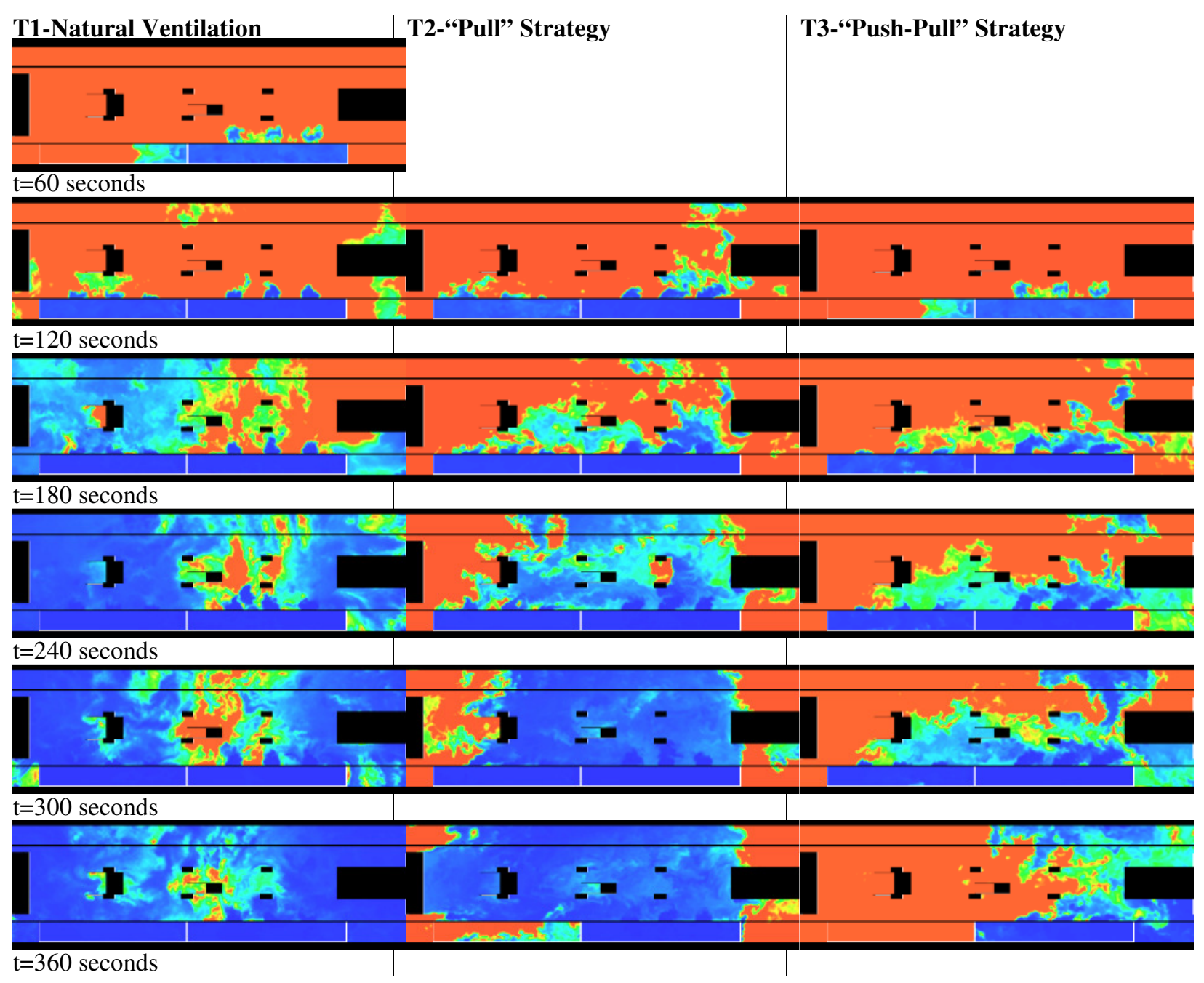




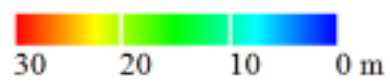

Figure 50 Visibility results for Natural Ventilation (left), "Pull" (middle) and "Push-Pull" (right)

\subsection{Discussion of results}

The fire begins at 0 seconds and begins to fill the train car with smoke (Figure 51). Smoke spreads into the remainder of the train by 50 seconds and begins to flow through doors and into the station (Figure 52).

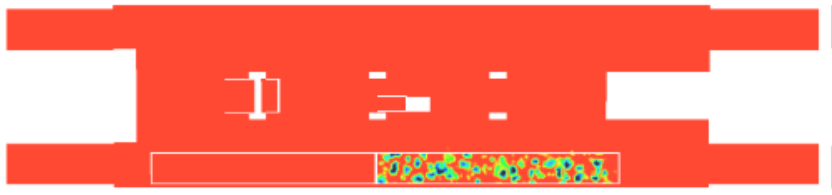

Figure 51 Smoke rises to the ceiling of the train car

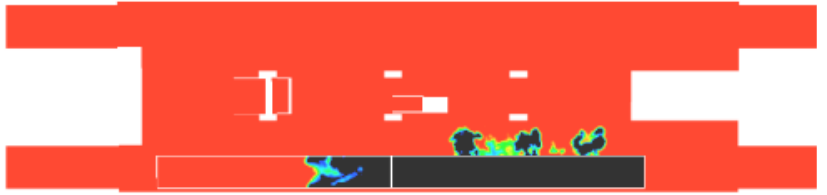

Figure 52 Smoke travels throughout the train and into the station after 50 seconds

\section{Scenario 1: Natural Ventilation}

The smoke spewing out of the train doors rises to form a smoke layer at the ceiling of the platform. Due to the vast height of the platform atrium, smoke is kept away from the platform level for significant time. Glass curtains prevent the entrance of smoke into the stair wells. The smoke layer builds and by 160 seconds, smoke begins to infiltrate the platform and stair/escalator shafts (Figure 53). By 190 seconds, the entire North half of the platform is filled with smoke and access to stairs/escalators is eliminated (Figure 54).

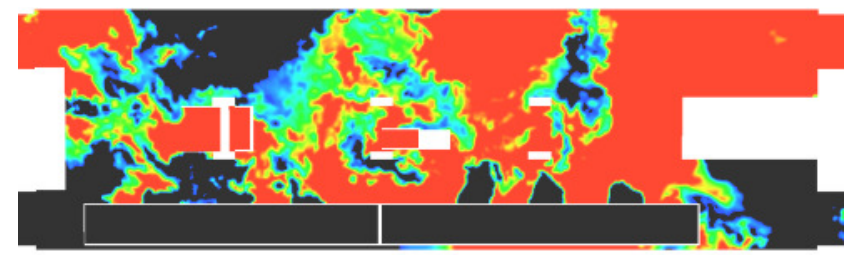

Figure 53 Visibility becomes untenable at the staging area of the North stairway at around 160 seconds.

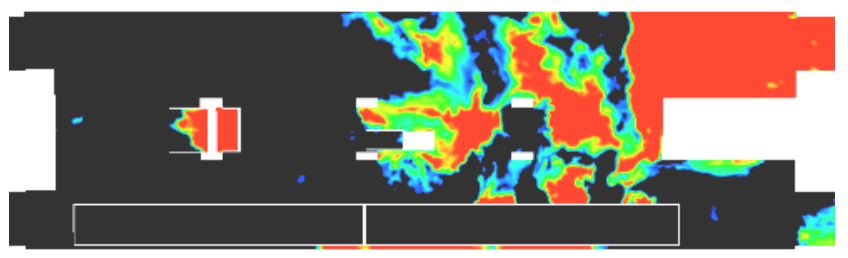

Figure 54 By 190 seconds, no safe paths of egress exist for remaining evacuees.

The concourse level is quickly infiltrated with smoke, which begins to occur at around 160 seconds (Figure 55). The amount of smoke entering the stairways to the concourse rapidly 
increases (Figure 56). By 210 seconds, the concourse is filled with smoke and untenable. The concourse stairways to the exit begins to become untenable at 220 seconds.

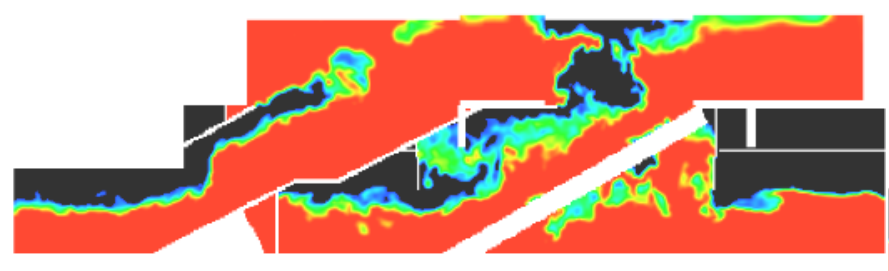

Figure 55 Smoke enters stairwell and escalator shaft by 160 seconds.

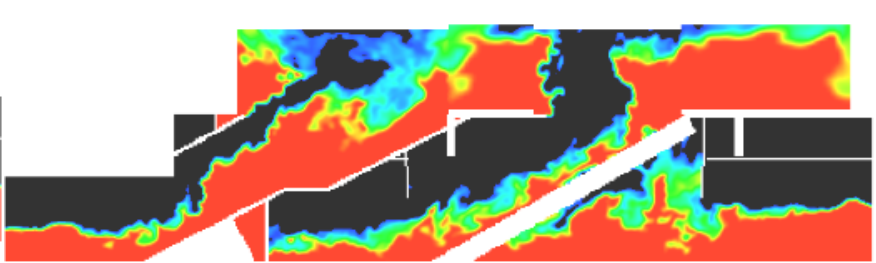

Figure 56 At 174 seconds, smoke completely engulfs escalator, making it untenable.

\section{Scenario 2: "Pull" Strategy}

After 100 seconds from the fire ignition, the south exhaust vents are opened and begin extracting air at a rate of $80 \mathrm{~m}^{3} / \mathrm{s}$. As a result, smoke is pulled from train and ceiling to the exhaust vents which causes some mixing. This has an immediate negative impact on visibility adjacent to the train. However, the benefit of the exhaust is apparent as it is able to maintain tenable conditions far exceeding natural ventilation. By 160 seconds, visibility remains high enough to allow access to both stairwells and staging areas (Figure 57). Tenable conditions are maintained until 190 seconds for the majority of the platform. The platform becomes untenable adjacent to the train (Figure 58). The queuing of people to access the stairwell will be forced to relocate to side of the platform opposite from the train fire. By 220 seconds, only the north end remains tenable, but allows the staging area to remain tenable until 318 seconds (Figure 59 and Figure 60).

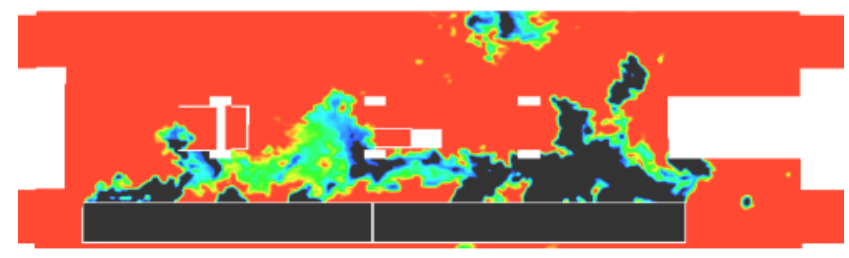

Figure 57 By 160 seconds, visibility remains and allows access to both stairwells and staging areas.

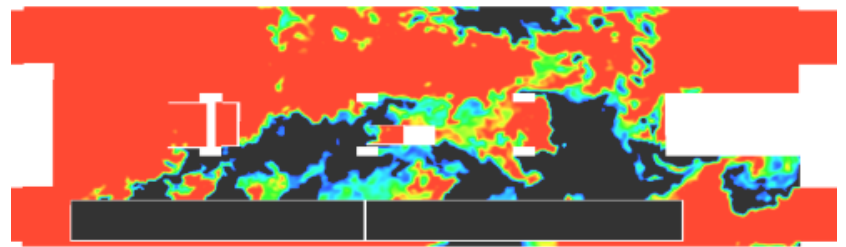

Figure 58 By 190 seconds access to the stairway is still fully tenable. 


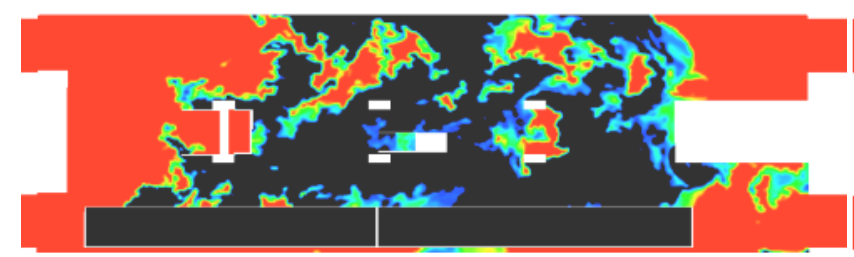

Figure 59 By 220 seconds, the platform is untenable, except for the north end stairway.

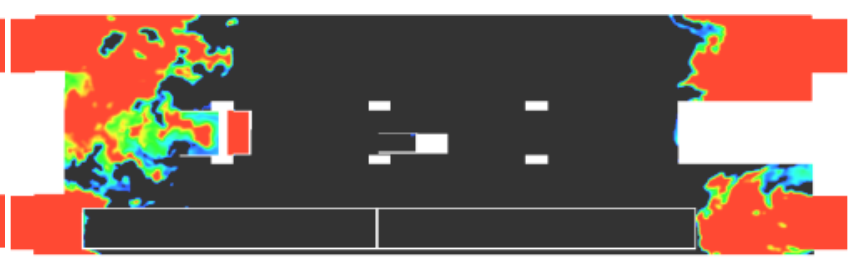

Figure 60 By 306 seconds, the north end stairway begins to be untenable as smoke enters.

The concourse remains smoke free until 260 seconds, when smoke enters from the escalator shaft. The stairs to grade level remain free of smoke until 330 seconds. Since the concourse begins to fill with smoke sooner than the platform stairs, occupants could become trapped in egress. As a result of the exhaust fan, air from the concourse is pulled back down the stairway (Figure 61). This could significantly impede egress.

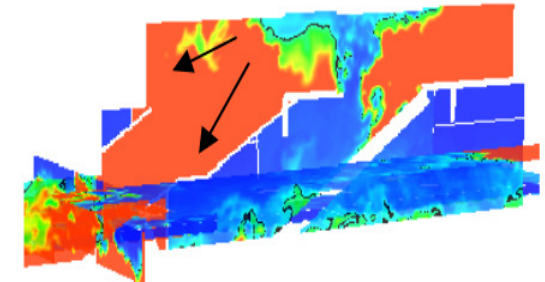

$\mathrm{t}=315 \mathrm{~s}$

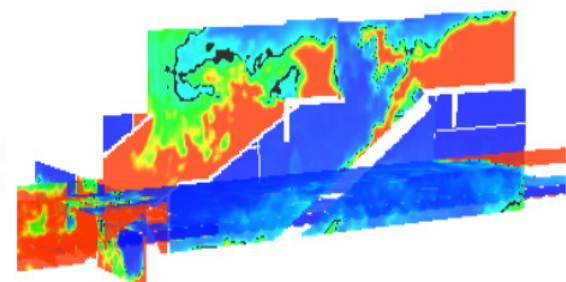

$\mathrm{t}=345 \mathrm{~s}$

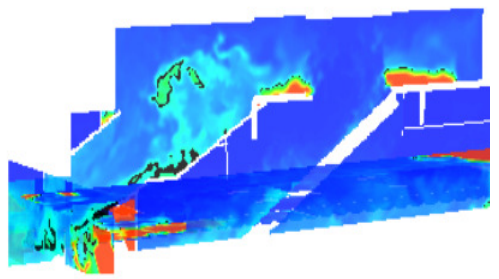

$\mathrm{t}=330 \mathrm{~s}$

Figure 61 Station section demonstrating the movement and interaction of gases.

\section{Scenario 3: "Push-Pull" Strategy}

The Push-Pull strategy utilizes $80 \mathrm{~m}^{3} / \mathrm{s}$ exhaust and $80 \mathrm{~m}^{3} / \mathrm{s}$ supply ventilation. These activate 100 seconds after the fire begins. As with the Pull strategy, smoke is pulled from the ceiling and as it exits the train to the South end of the platform. This causes some mixing of smoke onto the platform adjacent to the incident train car (Figure 62). However, the smoke on the platform is confined to this general area and even at 300 seconds, tenable conditions exist on enough of the platform for egress to occur (Figure 63). Smoke does infiltrate the escalator shaft at 280 seconds (Figure 64). 


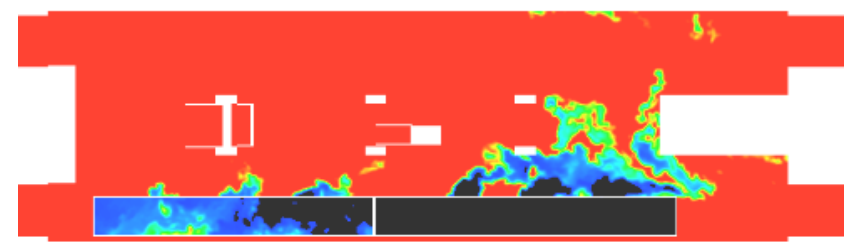

Figure 62 At 160 seconds, the majority of the platform, stairs and escalator remain tenable.

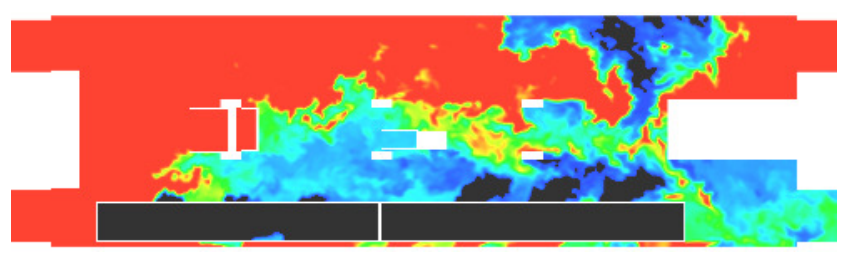

Figure 63 The platform stabilizes and remains tenable past 565 seconds

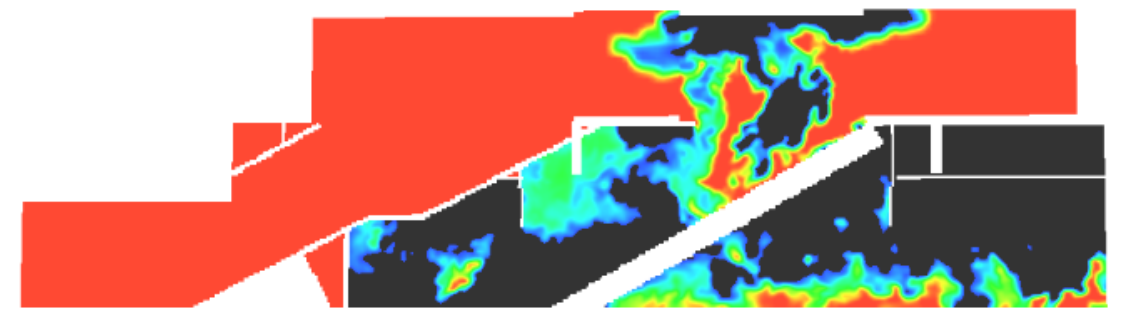

Figure 64 Smoke infiltrates the escalator at 280 seconds.

\subsection{Conclusion}

The simulations provided insight to the tenability throughout the platform. The average tenable time of important locations are identified in Table 5. The ASET is calculated based on the amount of time a single path of egress remains tenable due to the platforms small size. The simulation suggest that an ASET of only 160 seconds under natural ventilation circumstances. The use of exhaust ventilation provides an ASET of 316, nearly double the duration in the base case. The Push-Pull scenario maintained tenability for the duration of the simulation.

Table 5 Average Tenability Time for Zones in Simulation Scenarios

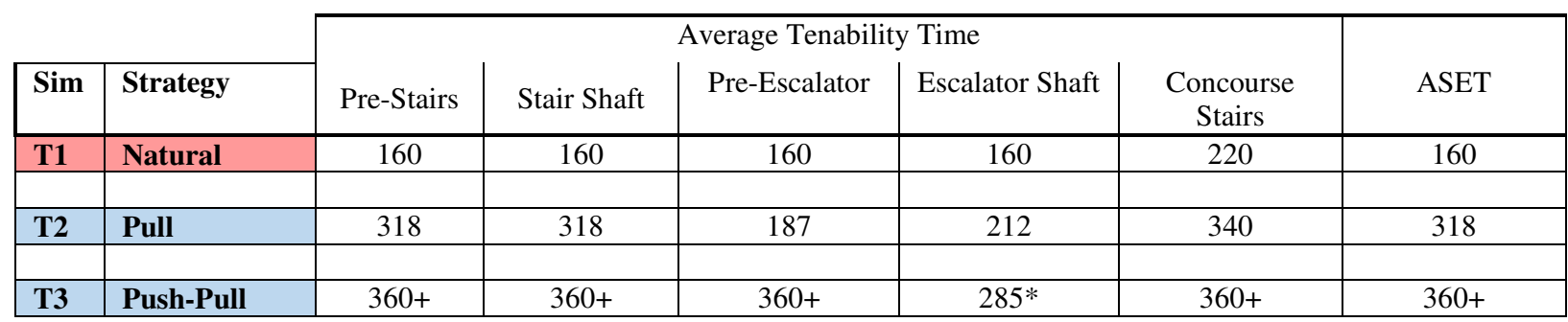

The influence of mechanical ventilation on the tenability of the Skytrain platform allowed for a significant increase in ASET. Without ventilation, the platform's ASET was limited to 160 
seconds. The Pull strategy, allowed protection of stairways until 212 seconds. The use of PushPull strategy allowed for the duration of a tenable egress path beyond 360 seconds. 


\section{Chapter 5. Egress in Metro-Stations}

Metro-stations face significant challenges in the assurance of the life safety during a fire. The use of active fire protection systems, such as ventilation and suppression, are used to provide tenable conditions along the evacuation path (Singapore Civil Defence Force, 2012; Blison \& Marsico, 2014). Yet the task of maintaining tenable conditions in sizable fires is not practical and often not physically possible. Fires that develop within train cars can reach enormous magnitudes that overwhelm any active fire protection systems available.

Evacuating passengers quickly is the primary method of preserving life and the use of ventilation attempts to extend this duration. Passengers travelling in underground metro systems are often separated from the outside by minutes of travel. The RSET is scrutinized when attempting to ensure an appropriate level of safety exist. Ideally, this is compared to the ASET, which can be estimated by conducting numerous smoke spread simulation scenarios as outlined previously. To ensure life safety, an ASET larger than the RSET is necessary. The Safety Margin (SM) is the difference between the two. The Safety Index (SI) allows for a quantifiable comparison between stations.

$$
\begin{aligned}
& \mathrm{SM}=\mathrm{ASET}-\mathrm{RSET} \\
& \mathrm{SI}=\frac{\mathrm{SM}}{\mathrm{RSET}}
\end{aligned}
$$

\subsection{Analysis of Egress Characteristics in Metro-Stations}

Determining how long evacuation will take in a metro station is extremely complex. In fact, the evacuation process draws not only on the physical form of the building, but also the demographics, physical fitness and psychology of the evacuees themselves. All evacuations will 
be unique and could differ greatly ranging from success to failure. Knowing the time required allows us to determine the hazards that exist with an emergency scenario. The comparison of smoke spread simulations can give valuable insight and allows for a performance base design and analysis. Hazardous areas can be identified, such as at the base of stairs where evacuee flow is restricted and forms queues.

\subsection{Flowrate of egress}

The flow rate is the measure of the amount of people able to pass through a specified location at a time. This rate is affected by the clearance dimension between obstacles, walls or door frames. The dimensions have long been established in building codes, utilizing antiquated rules of thumb (Bukowski, 2008). The origins of the 22 inch clearance dimension originates from a 1914 military standard for the dimensions of a person. However, the adequacy of 22 inches presents challenges for egress as people tend to sway when in motion and human body profiles vary over place and time. As early as 1935, the National Bureau of Standards (now NIST) surveyed the flow of evacuees in stairs and through doors at metro-stations during rush hours. The data collected identified a direct correlation between egress width and the flow rate. Flow rate estimates for a stairway with a 22 inch clear width were estimated to be 45 persons per minute. However, issues with the flow rate were observed to coincide with change in occupant density. Japanese research indicated that densities above 1 person per square meter decreased the flow rates significantly. It concluded flow rates of 26 persons per minute for 22 inch of clear width were more reasonable (Bukowski, 2008). The exit width of 44 inches (1100 mm) commonly found in exit stairs, was intended to support two occupants moving side by side, or for the passage of firefighters. The effect of width is illustrated in Figure 65. 

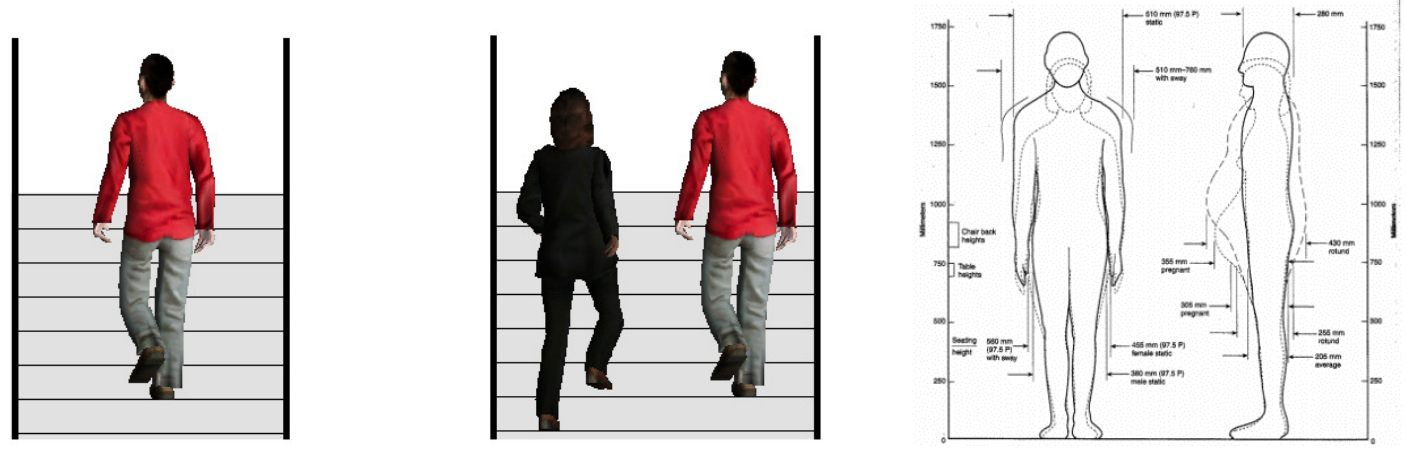

Figure 65- Stairwell width effect on egress in Pathfinder software (left) and anthropometric dimension (National Fire Protection Association, 2009)

\section{Demographics}

Describing the egress mathematically can be quite difficult due to the dynamic nature of people. The general population in North America is comparably larger than many decades ago when egress rules of thumb were formed. Thus, differences will be encountered depending on the occupant size and characteristics. Factors can be implemented to reduce the mobility within models. There is not a clear rule to follow regarding use of factors for specific building types or populations.

Logical assumptions of the demographics expected should be established when conducting an egress analysis when possible (Choi, Hwang, \& Hong, 2011). For instance, metro-train platforms have passengers that range in age, from children to seniors. However, during peak times, the ages will be confined to mostly working professionals and students. This group has less mobility restrictions than a population high in seniors or children. Psychology also effects the speed and reaction of passengers. Many passengers are reluctant to react to safety protocol which may delay their commute. Passengers on platforms may be aware of safety issues which are not observable to those on the train. 


\section{Calculating occupant velocity and flow rate}

Research in pedestrian and evacuation dynamics has provided dependable findings. The development of formula to predict the speed and flow rate of occupants through corridors and obstacles are used to provide an expectation of reasonable egress time expectations (Figure 66).
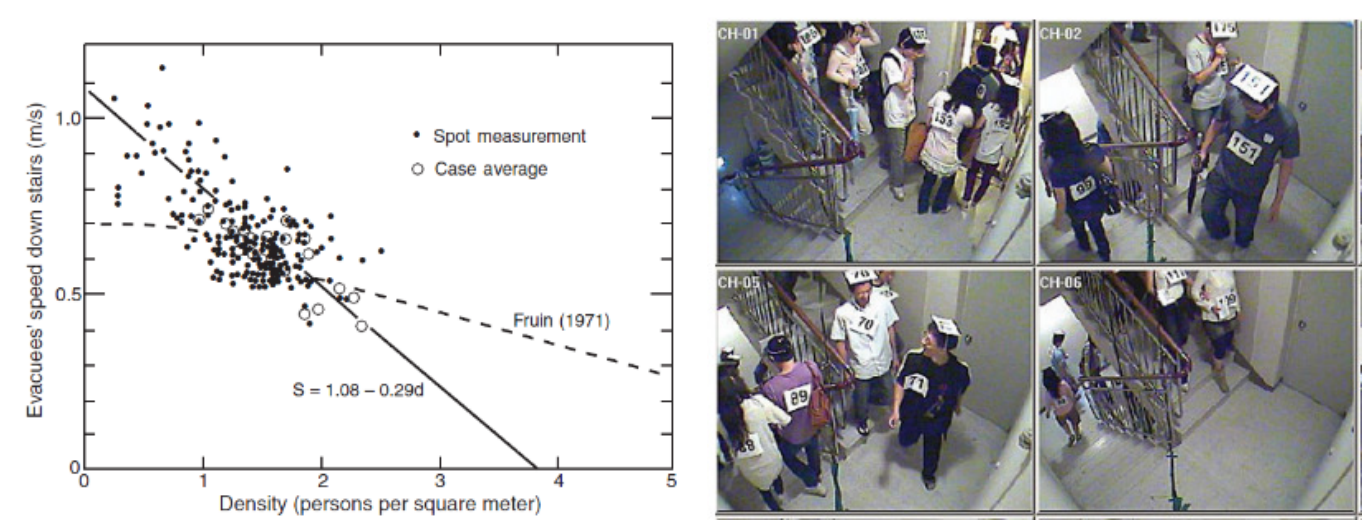

Figure 66 Relationship between speed and density on stairs during evacuation (Choi, Hwang, \& Hong, 2011)

Occupant travel speed is derived from the average measured walking speed of people. It can be expressed as a function of the density of the occupant flow, the type of egress method (ie. flat surface or stairs). The occupant speed, $v$, can be calculated as follows.

For densities of 0.55 pers $/ \mathrm{m}^{2}$ or less:

$$
v=0.85 k
$$

For densities greater than $0.55 \mathrm{pers} / \mathrm{m}^{2}$

$$
v=k-a k D
$$

The specific flow rate, $F_{S}$, is the product of the occupant density and speed.

$$
F_{s}=(1-a D) k D
$$


An efficient egress path is one which allows people to evacuate quickly. Maximum specific flow is found to occur at the optimal density, $\mathrm{D}_{\max }$. The specific flow is often is ideal approaching a density of two people per square meter.

$$
D_{\max }=\frac{1}{2 a}
$$

Figure 67 illustrates the effect of density on occupant speed and flow rate. The values are determined from the equations above with an additional modifier for the stairs of various inclinations.
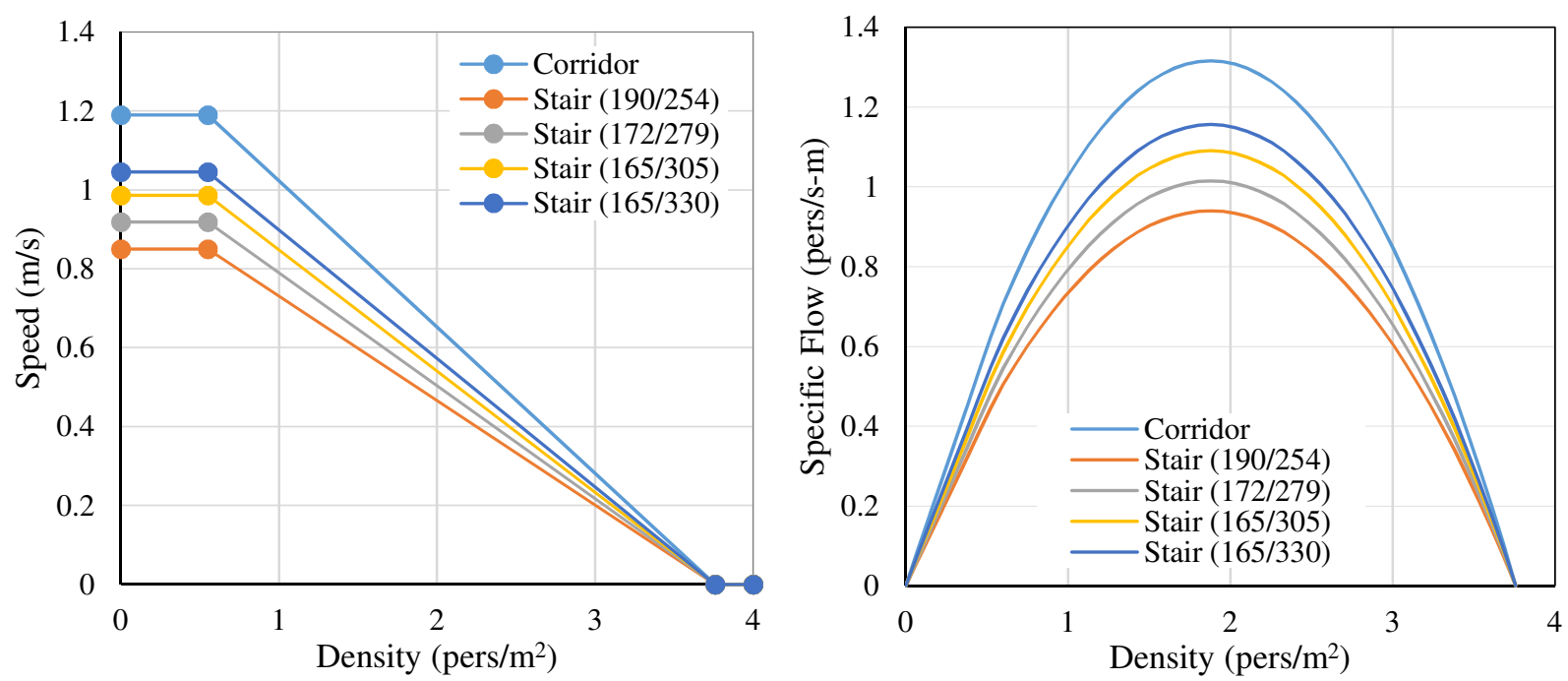

Figure 67 Egress speed (left) and specific flow (right) for corridors and stairs of varying inclinations

\subsection{Occupant Load}

The greatest impact to egress time is often the occupant load. A large occupant load results in a longer evacuation time. As there is limited space to travel in an underground metro-station, the density will rise. Egress inefficiencies can become pronounced when a high density situation occurs. A high density may reduce occupant travel speed (Figure 68). The effects can be compounded by resulting in a bottleneck where additional evacuees continue accumulate sending 
the density even higher. These effects are often seen at stairs, corridors or obstacles (Figure $69 \&$ Figure 70).

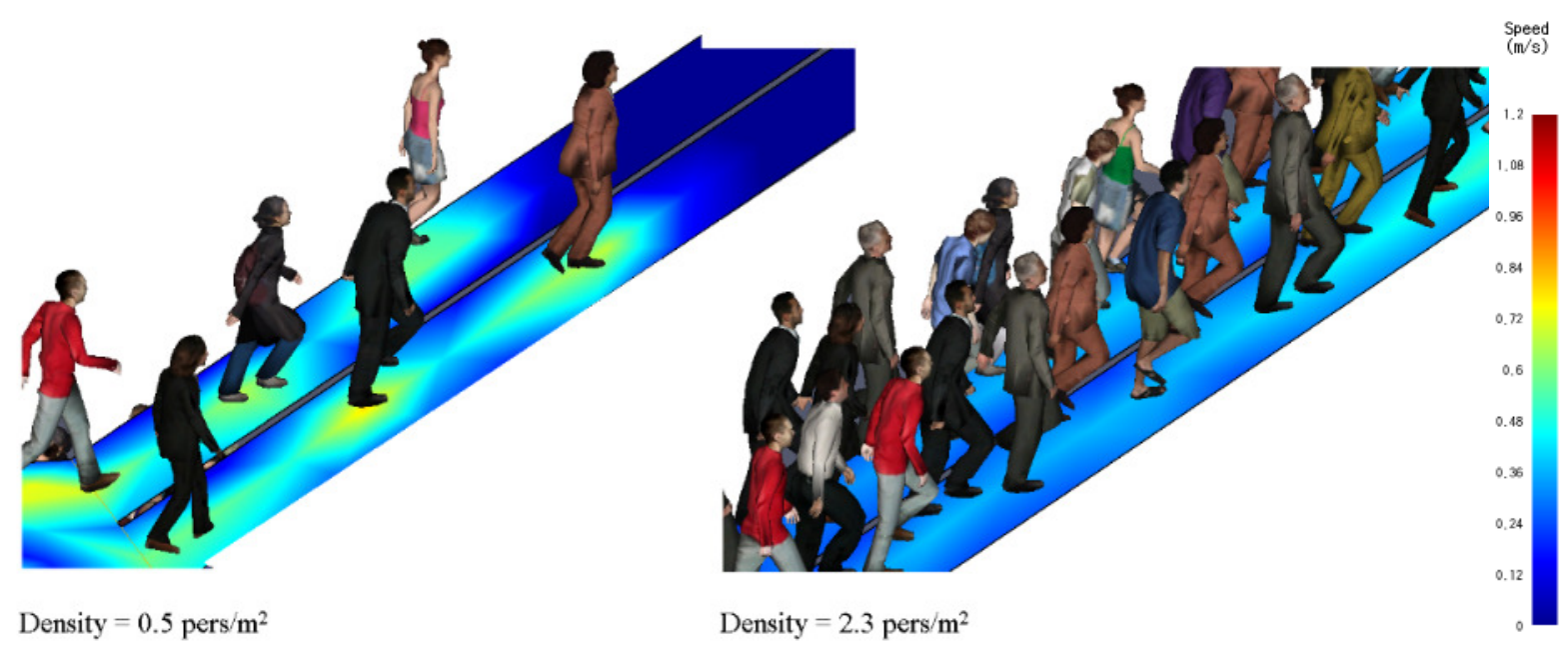

Figure 68 Increase in density corresponds to lower velocity
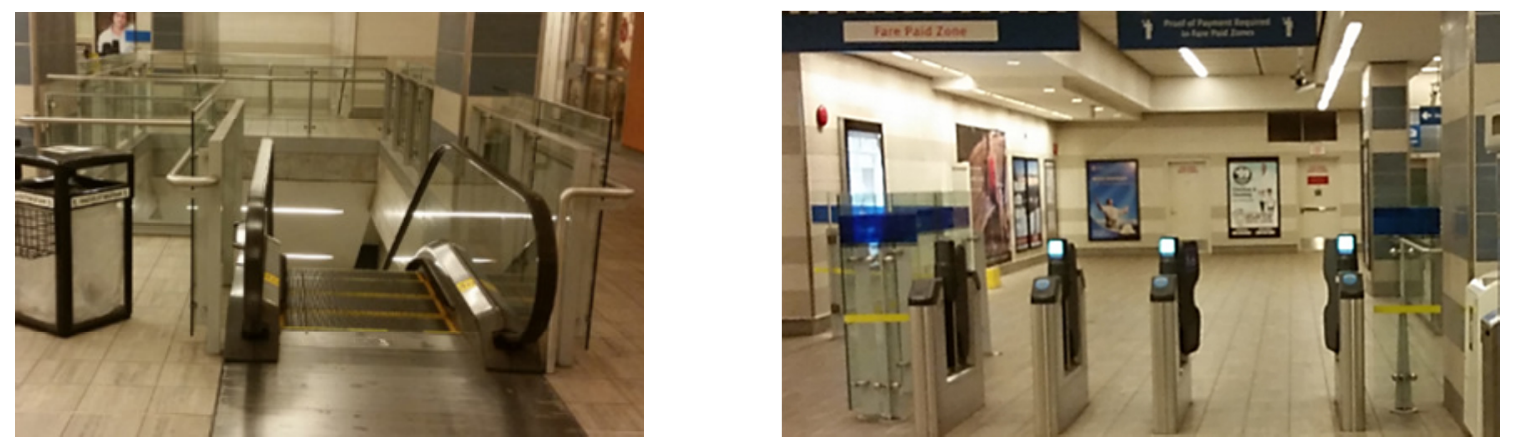

Figure 69 Restrictions to flow-rate in escalators and obstacles

In the area of a queue, the occupants are trapped within the building and closer to the smoke and fire. The effect of smoke can further reduce the speed of occupants, due to irritation, trouble breathing, confusion and panic.
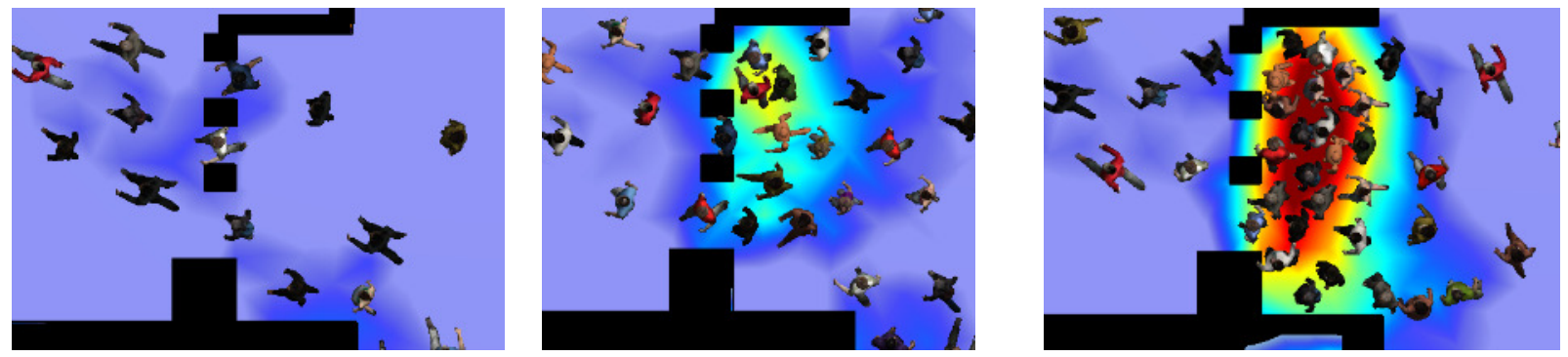
Figure 70 Exit width effect flowrate and density

\section{Platform Occupant Load}

The egress of metro-stations is vastly different than typical buildings due to its rapidly

fluctuating occupant load. The occupant load can change by thousands of people in just minutes. Additionally, trains may arrive at station platforms simultaneously, which can double the amount of evacuees. However, when analyzed over time, the occupant load and its fluctuations are predictable and recurring. Data regarding the occupant platform is routinely collected and monitored by mass transit officials. Ideally, the highest occupant load scenario should be used for evaluating egress. However, a study of multiple occupant loads is useful for determining the likely scenarios which may occur at given times. Figure 71 demonstrates an egress simulation for a metro-station with varying occupant loads (Yunlong, Cassady, Casey, \& Zlat, 2014).

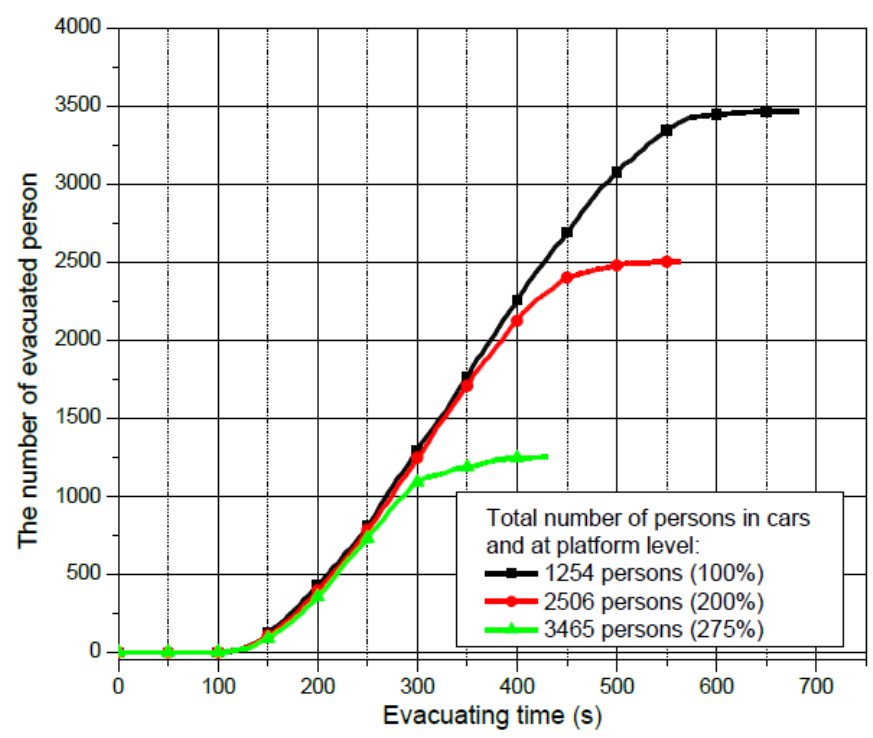

Figure 71 Comparison of evacuation results from train car experiments in Pathfinder (Yunlong, Cassady, Casey, \& Zlat, 2014)

This amounts to the maximum number of platform occupants and train capacity, known as the “crush" load. However, there are situations where utilizing crush capacity would represent over- 
engineering, such as for end of the line stations which cannot realistically expect a load as high as central stations. Thus, NFPA 130 determines criteria for occupant loading based station and train capacity forecast during the station's "peak hour". This can occur in the morning of afternoon depending on the station.

To ensure that a degree of safety from fire is achieved, the NFPA 130 guideline require that the egress capacity of the platform should guarantee to evacuate the platform occupant load in 4 minutes or less and 6 minutes for the completion of evacuation. Through performance based design, if engineers can convince officials to deviate from the requirement, exceptions can be permitted. This represents resent progress against the prescriptive codes, offering more design flexibility and potentially optimization of safety (Schachenmayr, 1998).

\subsection{Interpretation of results}

The comparison of RSET from evacuation modeling and ASET from smoke spread simulations can be difficult to evaluate when the simulations are independent of each other. The influence of smoke spread is not taken into account in the egress simulation. Thus, influence of environmental conditions do not alter the egress patterns developed in simulations. To mitigate this, significant time must be spent to review tenability criteria in occupant paths of travel to determine if egress would be impeded or not. 


\section{Chapter 6. Egress Analysis: TTC's Union Station Platform}

The TTC Union Station platform can become dangerously crowded during rush hour. The platform ridership was 114,800 people per average weekday in 2013 . Overcrowding was a common problem on the platform, particularly because of its use as a central transportation hub. During the weekdays, a large local working population and commuters throughout the city channel through Union Station. During rush hour, the platform often had two trains at crush load capacity arriving to full platforms. Conductors of arriving trains would sometimes wait for platforms to clear before proceeding to enter the station to unload. High density results in a reduction in egress speed, visual observations easily identify the significant hazards present (Figure 72).

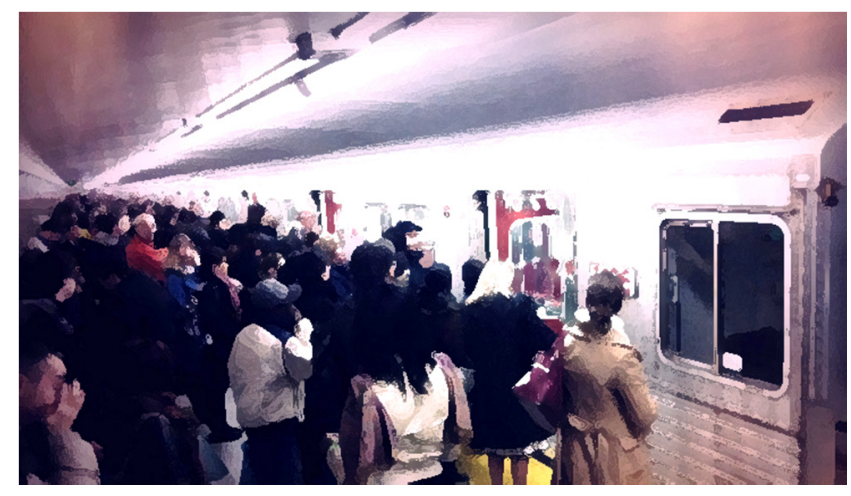

Figure 72 Hawker Sidley T-Series on busy platform (Toronto Transit, 2015)

\subsection{Egress Scenarios Occupant Load Selection}

The egress simulations accounts for the arrival of two trains at a crowded Union Station platform. Train 1 is discovered to be on fire. Passengers begin to discharge immediately and evacuate. The Hawker Sidley T-Series cars which access the station have a crush capacity of 315 passengers each. The trains are six cars in length and can bring 1890 passengers into the station when fully occupied. All passengers begin to evacuate immediately upon ignition of the fire. The simulation evaluates the egress of the platform into the above concourse. 
The egress simulations were conducted for varying occupant loads. The occupant loads for the simulations are described in Table 6. The pre-movement distribution of occupants is seen in Figure 73.

\section{Table 6 Occupant Loads for Union Station}

\begin{tabular}{|c|c|c|c|c|c|}
\cline { 2 - 6 } \multicolumn{1}{c|}{} & \multicolumn{4}{c|}{ Occupant Load (people) } & Occupant Load \\
\hline Simulation & Train 1 & Train 2 & Platform & Total & "Crush" \\
\hline 1 & 1890 & 1890 & 1200 & 4980 & High \\
\hline 2 & 1200 & 1200 & 1000 & 3400 & Medium \\
\hline 3 & 1000 & 1000 & 254 & 2254 & Low \\
\hline 4 & 800 & 800 & 203 & 1803 & \\
\hline
\end{tabular}

- “Crush" load scenario

The "crush" load represents a rare but possible scenario of two fully loaded trains arriving to a busy platform at Union Station. This represents a load of 4980 people for which egress occurs through the platform exit stairs.

- High occupant load scenario

The high load represents a more common scenario with two crowded trains arriving to a busy platform at Union Station. This represents a load of 3400 people for which egress occurs through the platform exit stairs.

- Medium occupant load scenario

The medium load represents a load of 2254 people for which egress occurs through the platform exit stairs.

- Low occupant load scenario

The low load represents a load of 1803 people for which egress occurs through the platform exit stairs.

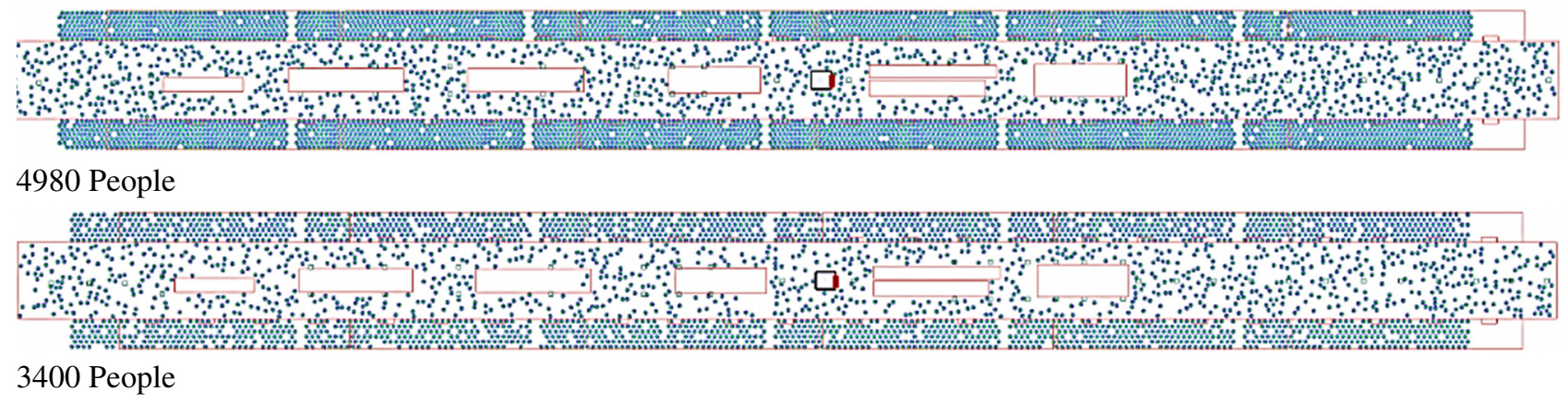




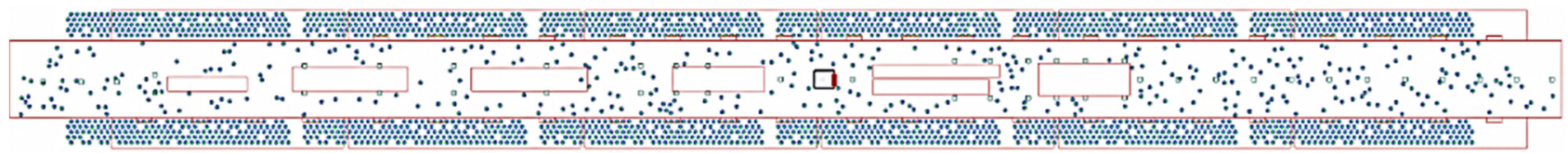

2254 People

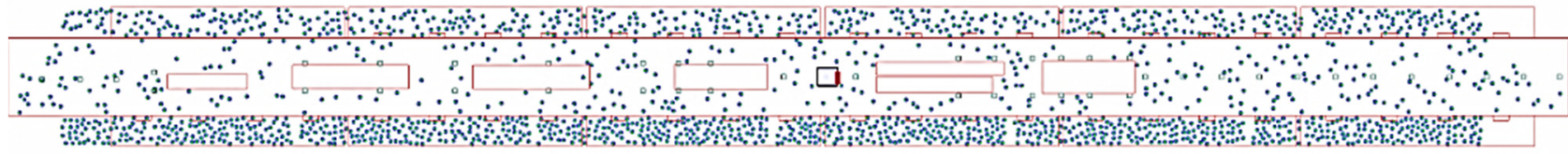

1803 People

Figure 73 Union Station platform with 4 different occupant loads and their pre-movement distribution

\subsection{Simulation Results}

Pathfinder simulations determined the RSET for the occupant loads in TTC's Union Station. The occupant load was seen to proportionally effect the RSET as seen in Figure 74. The crush, high, medium and low occupant loads had a RSET of 690, 509, 347, and 274 seconds respectively. This is significantly higher than the NFPA 130 guidelines which requires complete evacuation of the platform in 240 seconds or 4 minutes.

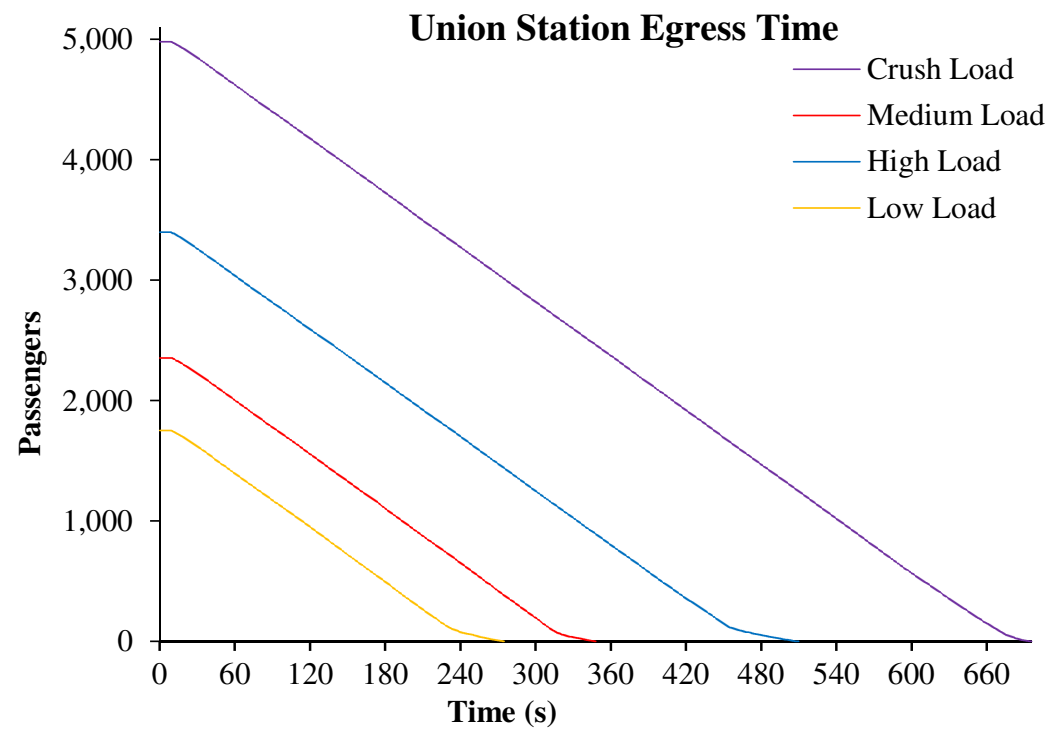

Figure 74 Calculated egress time for varying loads at Union Station

The selection of the crush load of 4980 occupants is not a commonly expected scenario.

However, it represents the physical limit of the train capacity. Though the crush load scenario is not likely to occur, it is a possibility. It does emphasizes the dilemma in the selection of 
performance criteria. Choosing to high of an occupant load may not be practical. Too low will compromise safety. Regardless, the simulation results for the lower, more conceivable occupant loads also exceed the NFPA 130 platform requirements.

The results from the simulation indicate that egress concerns are warranted at the 2013 Union Station TTC platform. However, this specific NFPA 130 requirement is prescriptive in nature and does not give a true RSET. Utilization of CFD simulations can allow a deeper realization of the risk present. Previous simulations on smoke spread (Section 2: Numerical Simulation of Smoke Spread and Ventilation Strategies in Metro-Stations) indicate the ASET for a given scenario. Ideally, an array of scenarios would be evaluated.

\subsection{Conclusion}

Under natural ventilation, the ASET for the TTC simulation was determined to be approximately 230 seconds previously. This would only allow for $25 \%$ of evacuation in a "crush" load scenario. At 360 seconds, approximately half of the occupants have evacuated the platform. Evacuating occupants form queues for the stairs, effectively bottlenecking egress (Figure 75). The duration of time spent at locations indicates the vulnerable areas of the platform where tenability effects the greatest number of lives (Figure 76).

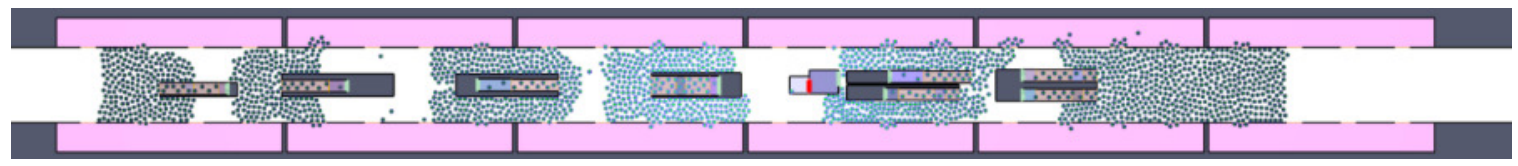


Figure 75 Egress simulation: Pedestrian models in Crush Load Scenario at 360 seconds

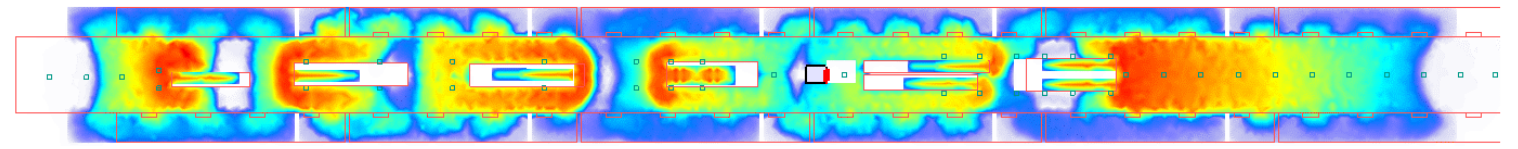

Figure 76 Egress simulation: Platform Usage Heat Map in Crush Load Scenario

The best performing ventilation strategies (conducted in Section 2) allowed for an ASET of approximately 700 seconds while maintaining at least two egress paths (T4-“Pull”, T6-“PushPull" and T7-Pressurize). These strategies could provide a sufficient ASET for egress for all of the occupant loading scenarios. However, the effect of smoke spread into some of the stairwells and platforms would have reduce the egress speed. In the "Push-Pull" ventilation strategy, a portion of the platform becomes untenable by 360 seconds (Figure 77).

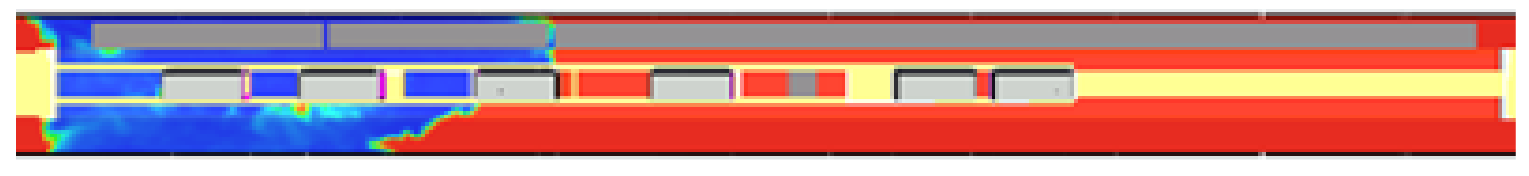

Figure 77 Tenability on Platform at 360 seconds in T 6, "Push-Pull" scenario In the "Push-Pull" simulation indicates smoke entering the east-most stairwell at 415 seconds (Figure 78). In this location, significant evacuees are expected to be queued for stair access (Figure 79). The evacuees would be forced to utilize other stairwells which would increase evacuation times. 


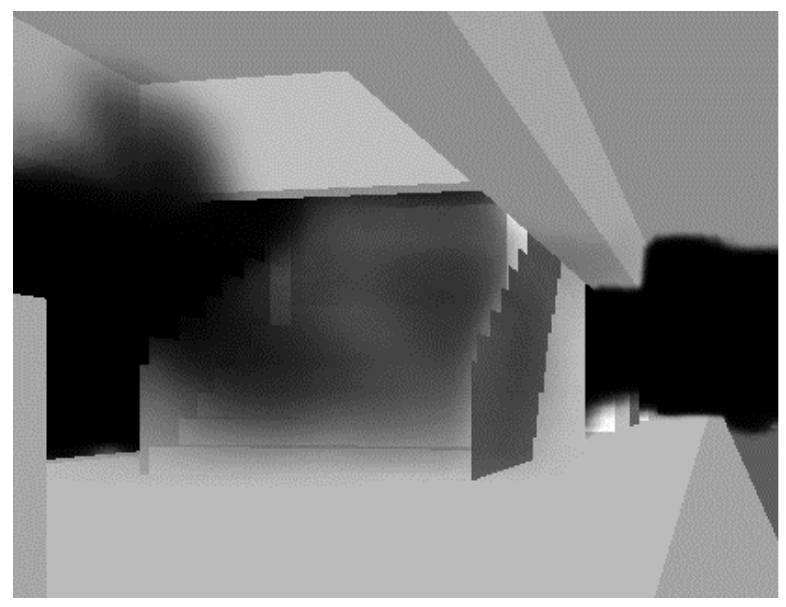

Figure 78 East stairwell visualization at $415 \mathrm{~s}$ during the T6 "Push-Pull" strategy

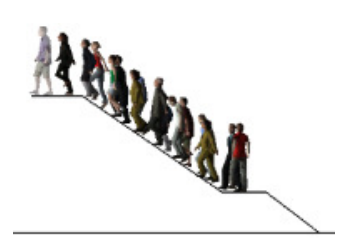

S1"Low" t=260 s

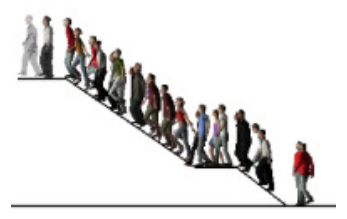

S2 "Medium" t=330 s

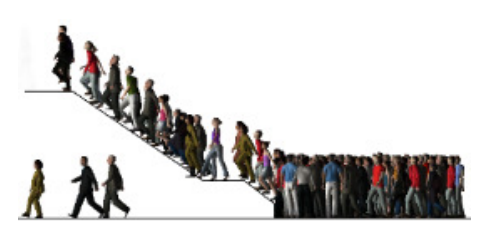

S3 "High" t=360 s

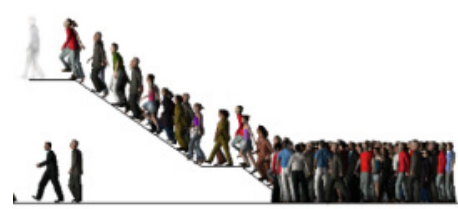

S4 "Crush" t=360 s

Figure 79 East stairwell egress progress during different loads at times specified.

Other ventilation strategies conducted previously would fail to provide tenable conditions at all egress locations for this duration. The stairwells at the east side of the platform lose tenability prior to egress being completed. The evacuees will be required to make their way to other remaining stairways. A consequence of this is the reduction in exits which decreases in flow rates. Thus, increase to the evacuation time is would likely result. 


\section{Chapter 7. Egress Analysis: TransLink's Yaletown Station}

The Skytrain Yaletown station serves approximately 13,500 passengers on a typical weekday (Translink, 2011). The station is comprised of a lower central platform (Figure 80) and upper concourse level (Figure 81). The platform is located 17 meters below grade and is served by a stairway, escalator and elevator connecting to the concourse (Figure 82). The concourse directs passengers through the payment area turnstiles. The station is equipped with a fire exit stairway on the concourse which provides an alternate path of egress. The entire station was modelled and utilized in Pathfinder (Figure 83). The paths of egress were measured as to ensure calculations regarding flow rates were representative of the station.
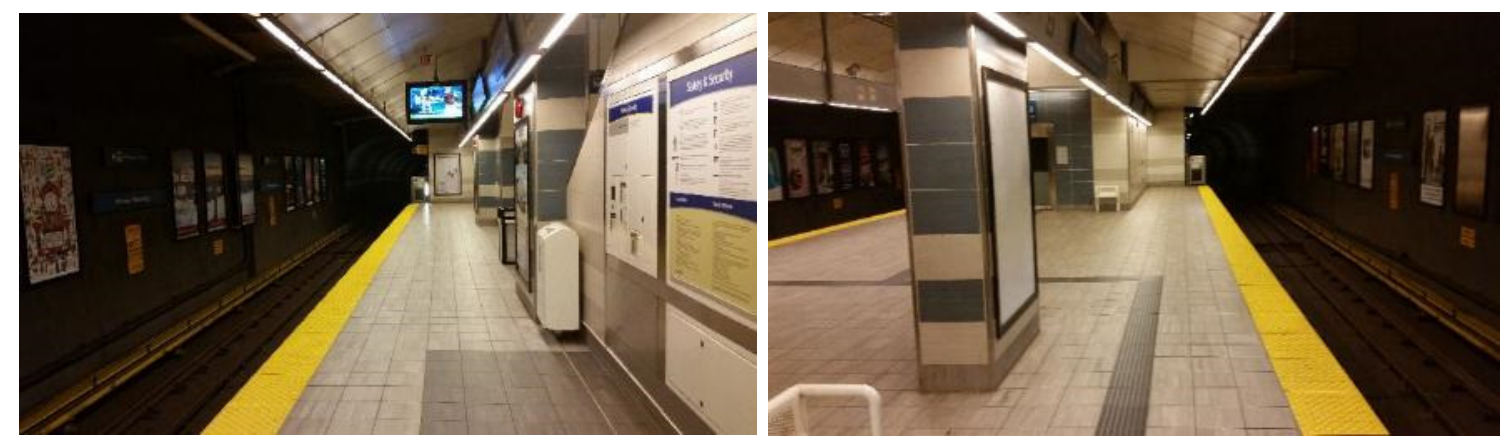

Figure 80 Yaletown Station platform 

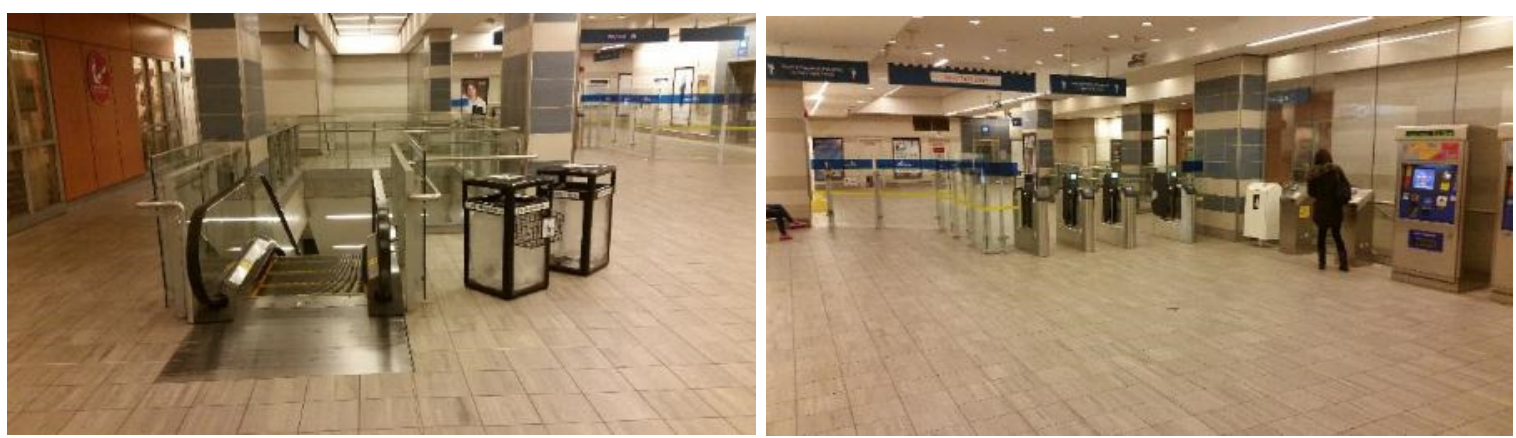

Figure 81 Yaletown Station concourse
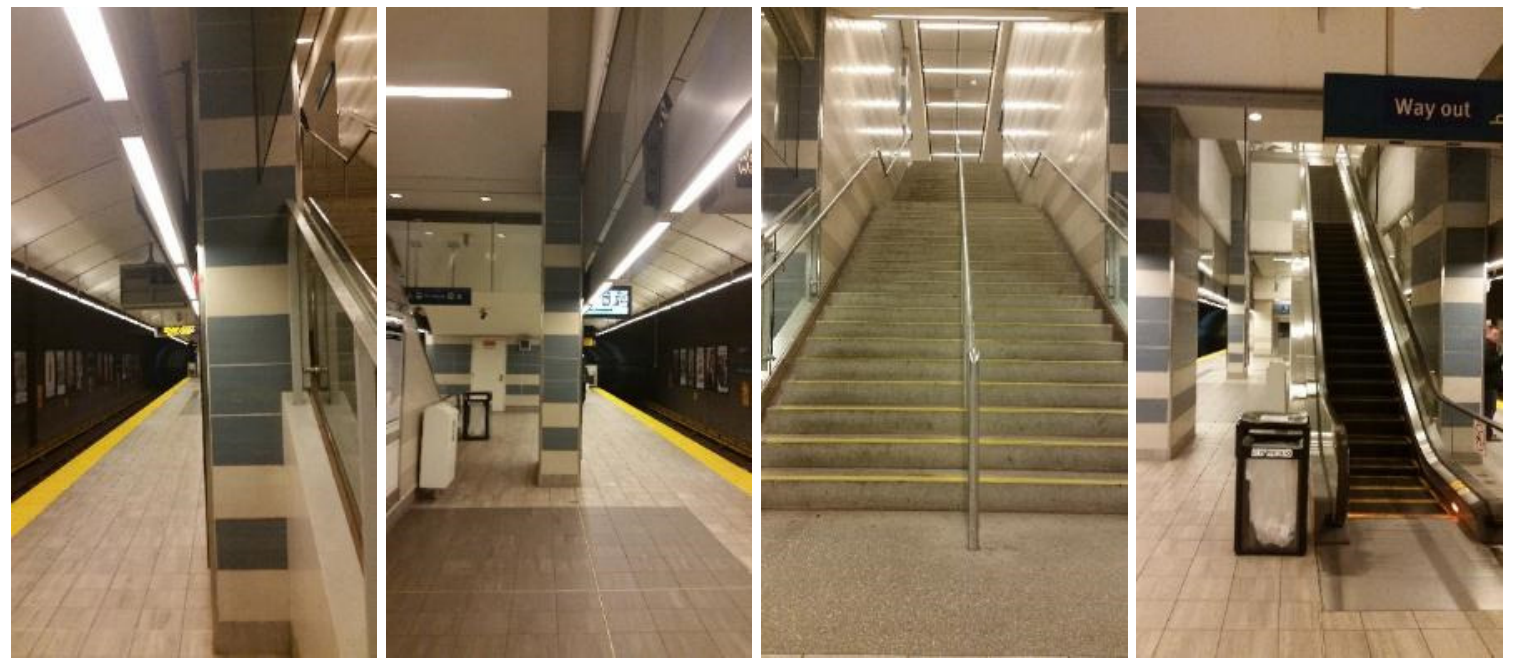

Figure 82 Yaletown station platform, stairs and escalator to the concourse

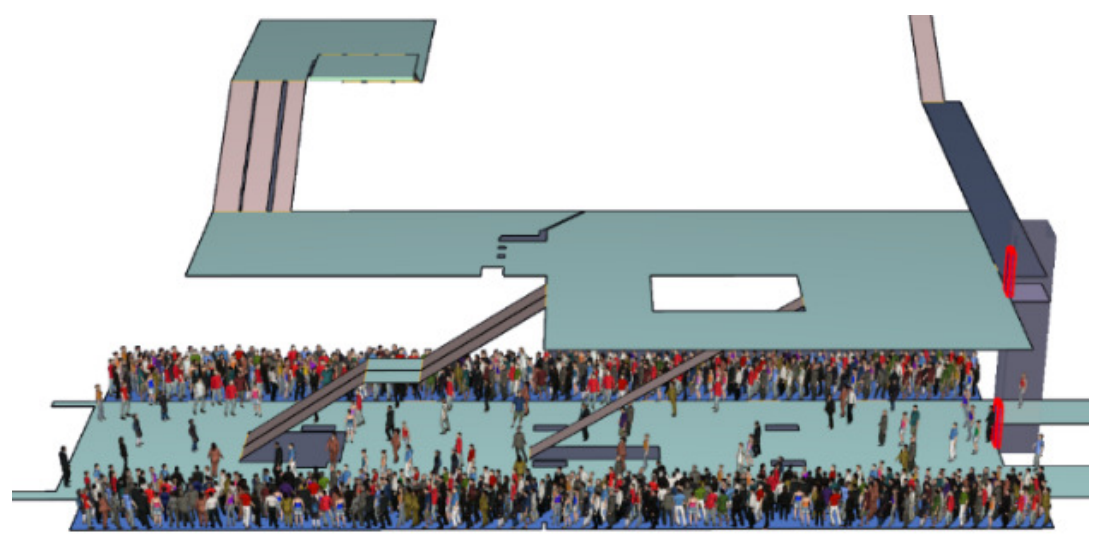

Figure 83 Schematic of Yaletown Station egress model 


\subsection{Egress Scenarios and Occupant Load Selection}

The egress simulation accounts for the arrival of two trains at a crowded Yaletown platform.

Train 1 is discovered to be on fire. Passengers begin to discharge immediately and evacuate. The Skytrain Canada Line cars which access the station have a standard capacity of 167 people and a crush load of 200 passengers. The trains are two cars in length and can bring 400 passengers into the station. The egress simulation accounts for the arrival of two trains at a crowded Yaletown Station platform. With a train discovered to be on fire and all passengers begin to evacuate immediately.

The occupant loads for the simulations were selected based on observations of the stations operation. The station peak loads occur during morning and evening rush hours. Despite being a popular station, the traffic in the rush hour generally much less than crush load scenarios. While trains on route to downtown can be full capacity, trains in the opposite direction are rarely at full capacity. As a result of being very close to the downtown, most of the commuters using the station are traveling away from the city. This predominantly one-way travel reduces the queue and counter flow that is experienced in central stations. High, medium and low occupant loads were simulated to evaluate egress times Table 7.

\section{Table 7 Occupant Loads for Yaletown Station}

\begin{tabular}{|c|c|c|c|c|c|}
\cline { 2 - 6 } \multicolumn{1}{c|}{} & \multicolumn{4}{c|}{ Occupant Load (people) } & \\
\hline Simulation & Train 1 & Train 2 & Platform & Total & Load \\
\hline 1 & 400 & 250 & 98 & 748 & High \\
\hline 2 & 250 & 250 & 61 & 561 & Medium \\
\hline 3 & 167 & 167 & 40 & 374 & Low \\
\hline
\end{tabular}




\subsection{Simulation Results \& Analysis}

The evacuation of passengers from the station to exterior occurs through the stair and escalator paths along the platform. The amount of people accounted for on the platform proportionally effects the time for egress as demonstrated in the results. Egress was estimated using hand calculations based on flow rates and Pathfinder egress simulation software (Thunderhead Engineering, 2012).

\section{Hand-Calculation for Egress}

The paths of travel for egress from platform/train location to exterior exit are identified in Figure 3-19. Hand calculations utilize SPFE equations for flow rate as the speed of egress is affected by obstacles, width of stairs etc. The length of travel also effects the duration of the egress. A simplified model demonstrating the egress time for platform and concourse, flow rate, velocity and queue times Figure 85. The hand calculations determined the RSET of high, medium and low occupant loads to be 324,243 and 162 seconds respectively.

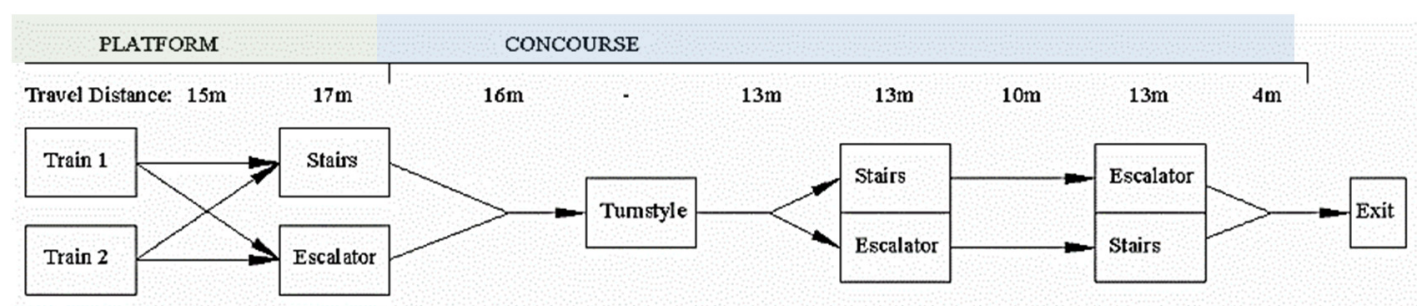

Figure 84 Schematic showing the paths of egress from train to exterior

Travel Surface D (person $\left./ \mathrm{m}^{2}\right)$ $\mathrm{v}(\mathrm{m} / \mathrm{s})$

Time (s)

\begin{tabular}{|cc|ccccccc|}
\hline \multicolumn{2}{|c|}{ Platform } & \multicolumn{9}{c|}{ Concourse } \\
\hline Flat & Stairs & Fla & Turnstyle & Flat & Stairs & Flat & Stairs & Flat \\
2 & 2 & 2 & - & 2 & 2 & 2 & 2 & 2 \\
0.7 & 0.54 & 0.7 & - & 0.7 & 0.54 & 0.7 & 0.54 & 0.7 \\
21 & 31 & 23 & - & 19 & 24 & 14 & 24 & 6
\end{tabular}

$\begin{array}{rrcc}\text { Load } & \text { People } & \begin{array}{l}\text { RSET } \\ \text { Platform }\end{array} & \text { Concourse } \\ \text { High } & 748 & 272 \mathrm{~s} & 324 \mathrm{~s} \\ \text { Medium } & 561 & 204 \mathrm{~s} & 243 \mathrm{~s} \\ \text { Low } & 374 & 136 \mathrm{~s} & 162 \mathrm{~s}\end{array}$

Figure 85 The platform and concourse egress time was calculated cumulatively for each egress path 


\section{Pathfinder Egress Simulation}

The modeling simulation provides a great deal of insight to the location of occupant queues and the paths of egress taken. For instance, the amount of time an area is occupied during a simulation can be observed (Figure 86). This identifies critical areas where maintaining tenable conditions is a priority. The movement and choice of paths by occupants is governed by Pathfinder's behavioral model (Figure 87).
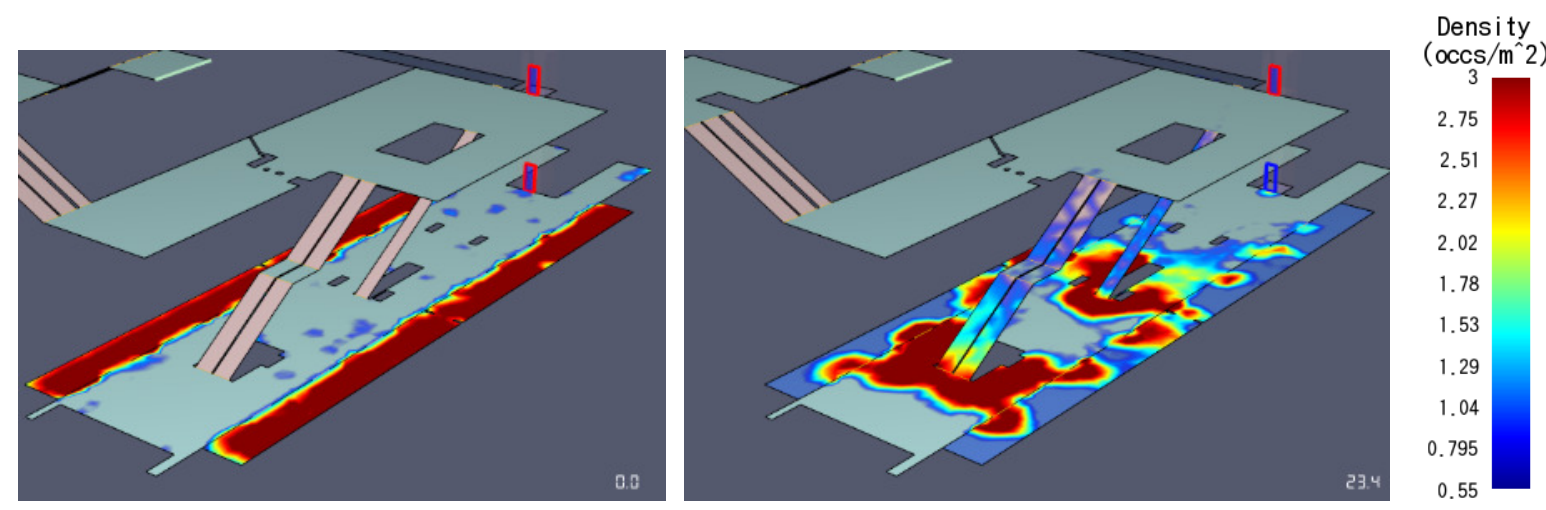

Figure 86 Platform Density at $\mathrm{t}=0$ and $\mathrm{t}=23$ seconds in High Occupant Load Scenario

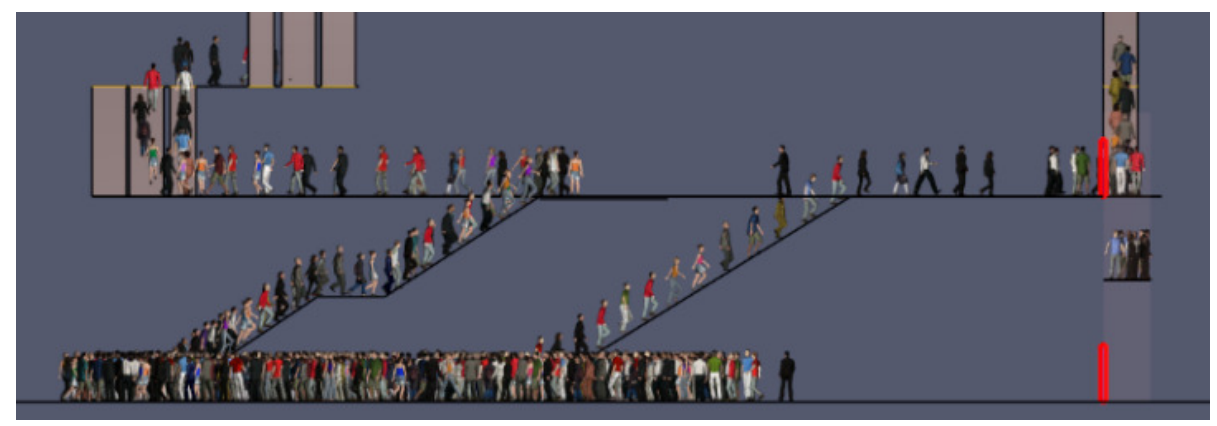

Figure 87 Paths of egress in Yaletown Station

The egress of occupants can be tracked throughout the simulation (Figure 88). The amount of occupants on the platform begins to decrease as egress proceeds up stairs. The concourse population increases due to this. The concourse remains populated until the last evacuee reaches the exit. This information is useful in determining the amount of time areas should remain tenable. 

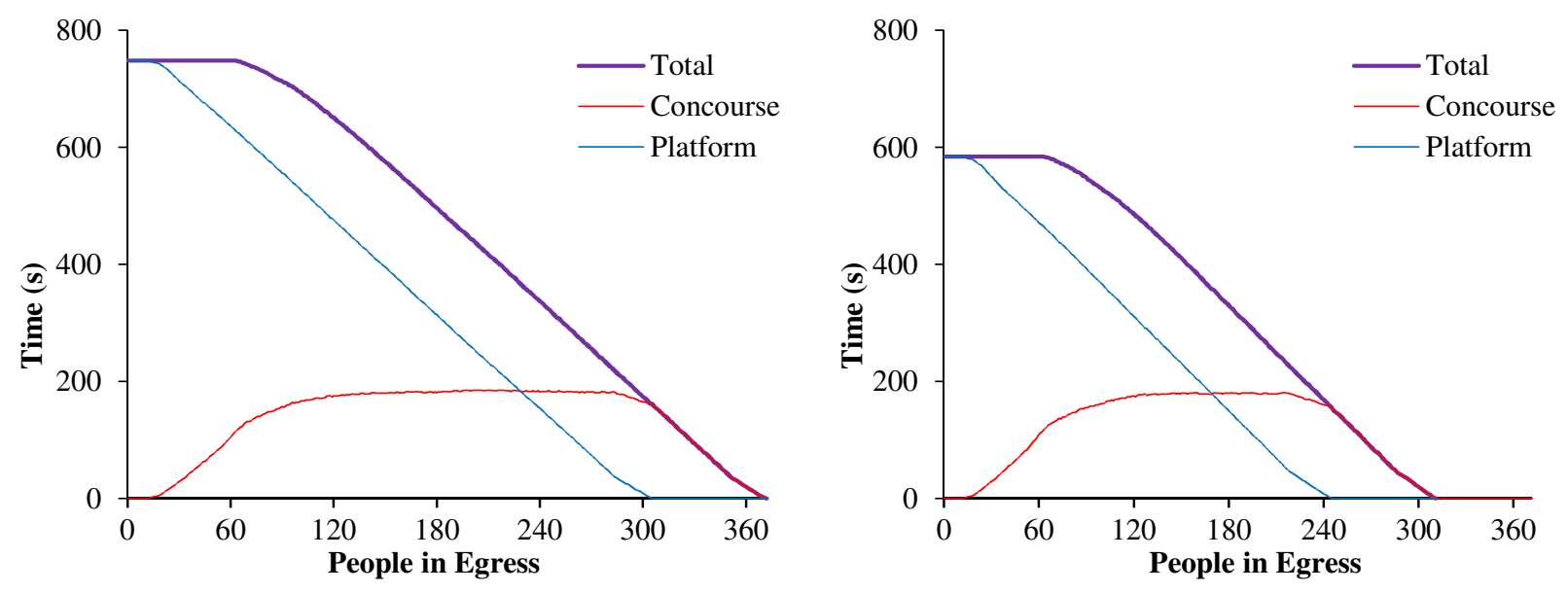

Figure 88 Occupant in simulation over time for High (left) and Medium occupant load (right)

Pathfinder simulations determined the RSET for the various occupant loads. The high, medium and low occupant loads had a RSET of 372, 311 and 260 seconds respectively. The results for all simulations are seen in Table 8 . The results from the egress simulation are within reason of the hand calculations.

Table 8 Required Safe Egress Time from Pathfinder Simulation

\begin{tabular}{|l|c|c|}
\hline Occupant Load & Platform Egress (s) & Total Egress Time (s) \\
\hline 748 People & 301 & 372 \\
\hline 561 People & 242 & 311 \\
\hline 374 People & 189 & 260 \\
\hline
\end{tabular}

\subsection{Conclusion}

The evacuation simulations indicate a time of 301 seconds would be required to evacuate a 748 people from the train and platform into the concourse. A total of RSET of 372 seconds would be required for full egress to the exterior to occur. 
Natural ventilation provided an ASET of only 160 seconds. The "Pull" strategy provided ASET of 318 seconds. The "Push-Pull" scenario was able to provide an ASET of over 360 seconds, the length of the simulation. It is assumed to be sufficient to meet the RSET of 372 seconds.

A detailed look at the escalator reveals the importance smoke extraction can play in maintaining tenable egress paths (Figure 89). Smoke enters the stairwell at 160 seconds under natural ventilation. The "Pull" strategy delays this until 240 seconds and the "Push-Pull" strategy delays smoke until 283 seconds. The last remaining occupant under the high load is seen approaching the concourse at 283 seconds. Thus, the RSET for a high occupant load is seen to be within the ASET for this ventilation strategy.

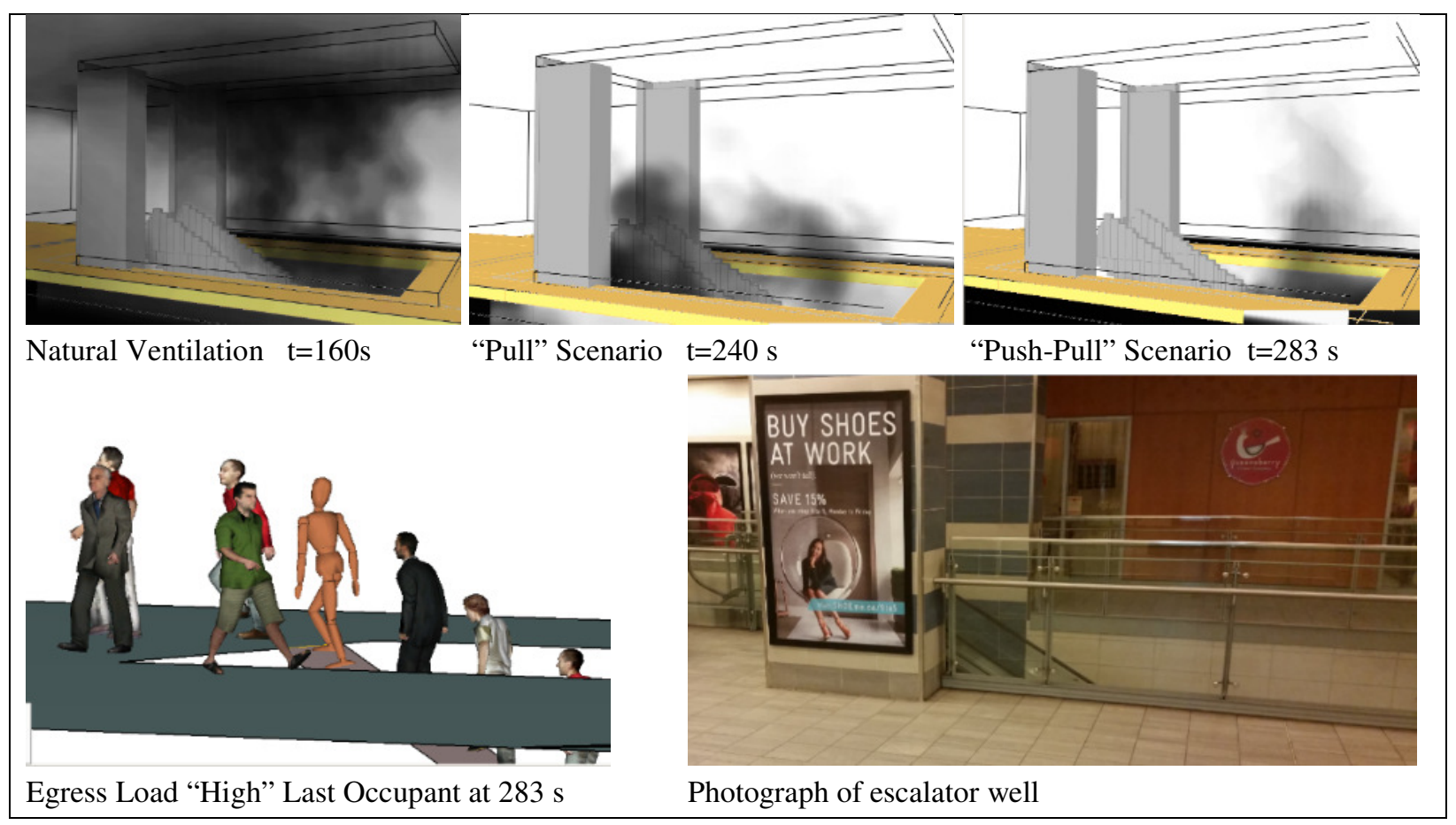

Figure 89 Escalator smoke spread and egress simulation 


\section{Chapter 8. Conclusion}

Performance based design is an iterative process that allows for the development of an optimal solution. The CFD and egress modeling provide valuable information regarding life safety within metro-stations. Egress modeling provides an indication of the inherit risk faced by passengers. The ability to determine RSET from egress modelling is significant in determining how much active fire protection is needed. The utilization of CFD smoke spread simulations allow us to determine if the ventilation systems can maintain tenability sufficient to meet this requirement.

\section{Effectiveness of Ventilation Strategies}

The hazards of fire development in metro-stations was made evident through the results of smoke spread simulations. Natural ventilation scenarios showed smoke infiltrate the entire platform area very quickly. For Union Station, this took just over 240 seconds and Yaletown Station was completely untenable by 190 seconds. The use of exhaust and supply ventilation strategies yielded significant increases to the tenability of the station. In some of the simulations, ventilation maintained tenability in areas of the platform for the duration of the simulation.

\section{Analysis of Egress}

The development of egress models help analyze the expected RSET for metro-stations. Knowing the time required for passengers to evacuate can allow us to value the risk of fires. Full capacity trains and platforms can result in long queues for stairs and slow egress. The longer duration puts passengers at severe risk. Tenability will be reduced from smoke and can make egress more challenging. Panic can result amongst high density crowds when forward movement is reduced. 
Egress modelling indicated significant risk exist for passengers in high load scenarios at Union Station's platform due to the limited channels for egress. Evaluation of the egress model can determine effectiveness of circulation, stair locations and obstacles. Union Station's platform showed significant issues surrounding the placement of stairs. Areas of platform served by only one stairway can result in occupants forming larger queues or searching for alternative exits. Obstacles such as turnstiles were observed to reduce the flow of occupants in egress simulations. Observing these simulations allows us to develop strategies to optimize designs.

\subsection{Recommendation and future research}

Further investigation of smoke spread simulations within metro-stations is needed. A large array of variables exist within simulations which need to be explored and understood in the early stages of practical CFD applications. Determination of criteria for the size and location of fire, ventilation strategies and occupant loading are expected to be investigated in greater detail.

Egress models have developed rapidly and are proving to be necessary tools for analysis of designs. The advancement of artificial intelligence into models can further enhance the realism of models. Recently, it has become possible to integrate CFD models with evacuation models. This can allow for tenability to influence the occupant behavior. The use of advanced pedestrian modeling software, such as Mott MacDonald's STEPS, can utilize FDS to provide real-time tenability feedback to the egress model (Sargant, Nightingale, Dinsdale-Young, \& Ganeshalingam, 2014). Through such approaches, tenability criteria, such as visibility, will affect the behavior and egress speed of evacuees in simulations. The advancements in egress modelling will allow for increased complexity to help better predict human behavior in building fires. 
The major objectives in this research is the evaluation of the hazards to occupants posed by metro-station fires, a study into the active measures of fire safety engineering and assessing the successfulness of such strategies for allowing occupants to safely evacuate. 


\title{
Appendix A
}

\section{A Three-layer Macro-Scale Model for Simulating the Combustion of Polyether Polyurethane Foam in CFD}

\begin{abstract}
This research investigates the development of numerical models in fire, smoke spread and evaluation of life safety. Development of numerical models allows for the prediction and analysis of hazards within the built environment. Such models can be applied in simulations and form the growing basis of performance based design in building engineering. The simulations utilize Fire Dynamics Simulator, a Computational Fluid Dynamics (CFD) model.

Polyether Polyurethane Foam (PPUF) is analyzed at various scales to determine its thermal decomposition characteristics. Material properties extracted from micro-scale experiments and decomposition behavior are combined to develop a PPUF fire model. The fire model is utilized to simulate PPUF burning in various arrangement and compared with experiments done by the National Research Council of Canada (NRC). The purpose of this paper is to improve the ability of the polyurethane fire model in numerical simulations.
\end{abstract}




\section{Appendix A}

\section{Nomenclature}

$\begin{array}{cll}\text { A } & \text { Pre-exponential factor } & \left(\mathrm{s}^{-1}\right) \\ \Delta \mathrm{H}_{\mathrm{c}} & \text { Heat of Combustion } & (\mathrm{kJ} / \mathrm{kg}) \\ \Delta \mathrm{H}_{\mathrm{r}} & \text { Heat of Reaction } & (\mathrm{kJ} / \mathrm{kg}) \\ \mathrm{C}_{\mathrm{p}} & \text { Specific heat } & (\mathrm{kJ} / \mathrm{kg} \mathrm{K}) \\ \mathrm{Ea} & \text { Activation energy } & (\mathrm{kJ} / \mathrm{mol}) \\ \mathrm{HR} & \text { Heat Release } & (\mathrm{MJ} \text { or kJ) } \\ \mathrm{HRR} & \text { Heat Release Rate } & (\mathrm{kW} \text { or } \mathrm{MW}) \\ \mathrm{k} & \text { Thermal Conductivity } & (\mathrm{W} / \mathrm{mK}) \\ \mathrm{K} & \text { Rate of reaction } & \left(\mathrm{s}^{-1}\right) \\ m_{f} & \text { Final specimen mass } & (\mathrm{kg}) \\ m_{i} & \text { Initial specimen mass } & (\mathrm{kg}) \\ \rho & \text { Density } & \left(\mathrm{kg} / \mathrm{m}^{3}\right) \\ \mathrm{q} & \text { Heat release } & (\mathrm{kJ} \text { or } \mathrm{MJ}) \\ \mathrm{Q} & \text { Heat Release Rate } & (\mathrm{kW} \text { or } \mathrm{MW}) \\ \mathrm{t} & \text { Time } & (\mathrm{s}) \\ \mathrm{T} & \text { Temperature } & \left(\mathrm{K} \text { or }{ }^{\circ} \mathrm{C}\right)\end{array}$

\footnotetext{
Abbreviations

CFD Computational Fluid Dynamics

DSC Differential Scanning Calorimetry

FDS Fire Dynamics Simulator

FTIR Transform Infra-Red Analyzer

NIST National Institute of Standards and Technology

NRC National Research Council of Canada

PPUF Polyether Polyurethane Foam

TDI Toluene Diisocyanate

TF French Tubular Furnace

TGA Thermo-Gravitational Analysis
} 


\section{Appendix A}

Flexible Polyether Polyurethane Foam (PPUF) is the dominant combustible constituent of upholstered furniture and is a common early fuel in residential fires. Upholstered furniture accounts for the majority of fire fatalities of all initial fuel sources in homes in the United States. It is highly combustible and can ignite at low temperature. The release of toxic gases such as hydrogen cyanide and formaldehyde create extremely hazardous environments for evacuating occupants. Its use is widespread and plays an expanding role in furnishings, equipment, and insulation. Effort to mitigate this hazard are evident through the extensive use and experimentation with fire retardants to lower the flame spread rate during combustion. However, the implementation, effectiveness and safety of such retardants limited (National Fire Protection Association, 2013). Some experiments demonstrate a decrease in approximately $25 \%$ heat release rate (Krämera, Zammarano, Linterisb, \& Gedde, 2010). A study by Ohlemiller noted the effects of typical fabric on fire retardant foam was equivalent to typical non-fire retardant foam (Krämera, Zammarano, Linterisb, \& Gedde, 2010). The hazard present from the use of polyurethane is still a prime concern in the built environment. Thus it is important to study the thermal degradation behavior of PUF and numerical models.

The properties of polyurethane foam derived from experiments can be synthesized into a fire model allowing the prediction of flame spread, heat release rate and other attributes. Numerical simulations conducted in this study utilized Fire Dynamics Simulator (FDS). The simulations replicate actual experiments in multiple scales, including furniture arrangements. Numerous PPUF fire experiments conducted by the National Research Council of Canada (NRC), the National Institute of Standards and Technology (NIST) and others, have allowed for validation of the polyurethane foam model. 


\section{Appendix A}

Describing the complex nature of PPUF requires analysis at different scales. At a molecular level, the decomposition of PPUF is able to be described thoroughly through thermal properties, kinetic parameters and gas-phase properties such as heat of combustion. However, the molecular scale description alone is insufficient for producing an accurate fire model. Due to the dynamic nature of PPUF foam, the physical behavior must be analyzed and accounted for. This physical behavior includes the melting and change in geometry and its impact to decomposition and combustion.

Early attempts in PPUF modelling were simplistic in nature, representing the foam as a homogenous fuel with decomposition governed by a single reaction. Such an approach disregards the liquid polyol byproduct which makes up the majority of the fuel. The inclusion of multi-step reaction allowed for the pyrolysis of foam into TDI and polyol. This approach has worked in micro-scale pyrolysis simulations, such as TGA. However, it strayed significantly from observations as it could not account of the liquid behavior of the polyol within the FDS framework (Meunders, et al., 2014). Attempting to address such complexities of the polyol byproduct has led to the development of creative strategies in modeling.

Advancement in PPUF modelling has sought to address the polyol complexities through the creative approaches in the fuel's representation. The two-layer model proposed by Prasad represents PPUF in TDI and polyol in separate layers (Prassad, et al., 2009). Analysis on PPUF

modelling for cone calorimeter experiments have been studied to great extent by Pau, identifying the benefits and drawbacks of multiple schemes developed to date (Pau, 2013). 


\section{Appendix A}

Recent advancement in micro-scale experiments have allowed for mapping of kinetic

parameters. Identification of reaction rates (Pau, Fleischmann, Spearpoint, \& Li, 2013) and

associated enthalpies have been explored (Pau, Fleischmann, Spearpoint, \& Li, 2014). The use of recent parameters and modeling approaches have allowed for the creation of the proposed three layer model. 


\section{Appendix A}

\section{Chapter 1. Physical and Chemical Attributes of Polyurethane Foam}

The properties of polyurethane foam derived from various experiments can be synthesized into a fire model allowing the prediction of flame spread, heat release rate and other fire properties. Numerical simulations conducted in this study utilized Fire Dynamics Simulator (FDS), a computational fluid dynamics (CFD) model of fire-driven fluid flow. The model synthesizes molecular and physical behavior learned through observations of thermal decomposition. The simulations reproduce actual experiments in multiple scales, including furniture arrangements. Varying polyurethane foam fire experiments conducted by the National Research Council of Canada (NRC), the National Institute of Standards and Technology (NIST) and others, has allowed for validation of the polyurethane foam model.

\subsection{Analysis of Molecular Properties}

The molecular properties of PPUF are well established through the analysis of cone and open calorimeter, Thermo-Gravitational Analysis (TGA), French Tubular Furnace (TF) with Fourier Transform Infra-Red Analyzer (FTIR) and Differential Scanning Calorimetry (DSC) were utilized to gather characteristics of combustion and pyrolysis which form the basis of the model. The analysis of data produced from these experiments allows for the development of equations to describe the decomposition under heat flux.

When subject to sufficient heat flux, PPUF is observed to undergo five major reactions which occur between $0^{\circ} \mathrm{C}-450^{\circ} \mathrm{C}$. In flaming combustion, PPUF decomposition occurs through pyrolysis. Oxidative reactions are limited due to the oxygen consumption by flames at the fuel surface. Oxidation reactions often plays a role in the early and decay stages of a fire, but are insignificant in PPUF decomposition when sustained flames are present (Pau, Fleishmann, Spearpoint, \& Li, 2014; Prassad, et al., 2009). 


\section{Appendix A}

\section{Oxidation Reactions}

$\mathrm{PPUF}+\mathrm{O}_{2}=$ Polyol $+\mathrm{OH}$

Polyol $+\mathrm{O}_{2}=\mathrm{Char}+\mathrm{OH}+\mathrm{H}_{2} \mathrm{CO}+\mathrm{CO}+\mathrm{CO}_{2}$

$\mathrm{Char}+\mathrm{O}_{2}=$ Residue $+\mathrm{OH}+\mathrm{H}_{2} \mathrm{CO}+\mathrm{CO}+\mathrm{CO}_{2}$

\section{Pyrolysis Reactions}

PPUF $=$ Polyol + TDI

Polyol $=\mathrm{H}_{2} \mathrm{O}+\mathrm{CH}_{4}+\mathrm{OH}+\mathrm{H}_{2} \mathrm{CO}$

The two constituents of PPUF are toluene diisocyanate (TDI) and polyether polyol. In the creation of polyurethane foam, these substances are mixed together with a blower agent to produce foam. In fire, PPUF pyrolysis results in the scission of TDI and polyol. The TDI is released as a combustible gas while the polyol product forms a liquid pool. The pyrolysis of polyol occurs at a higher temperature and produces a vast array of gases including methane, hydroxide, formaldehyde and water vapor (Figure 1-1).

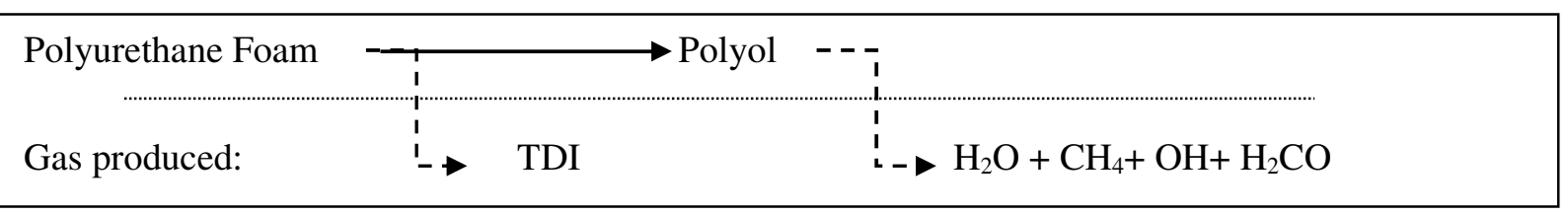

Figure 1-1 Polyurethane pyrolysis decomposition into polyol releases a variety of volatiles gases

Determining the pyrolysis rates and combustion properties are necessary for predicting the fire growth. The heat generated by the combustion will in turn increase the rate of pyrolysis, subject to environmental conditions (Figure 1-2). 


\section{Appendix A}
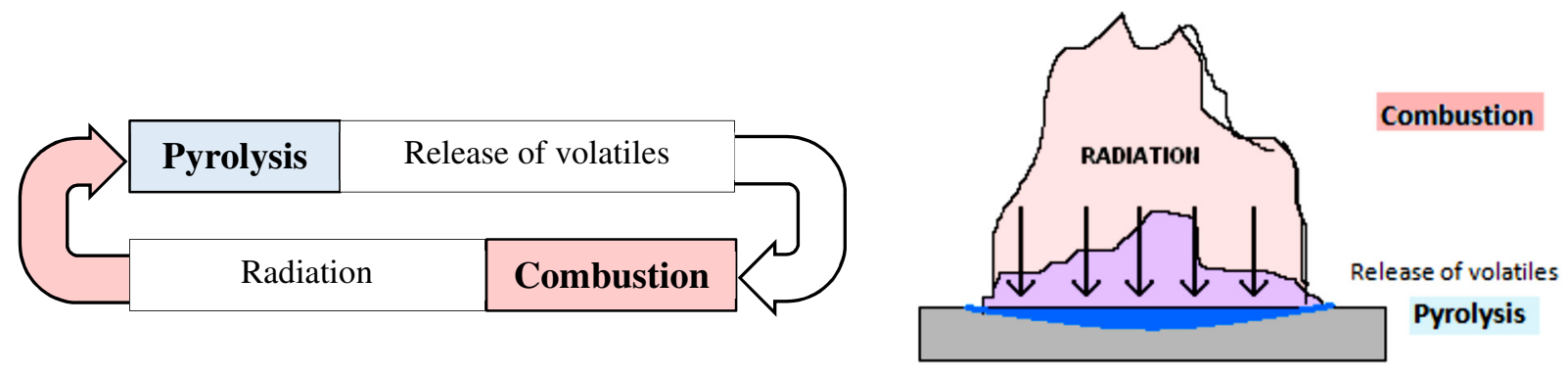

Figure 1-2 Pyrolysis reaction rates and combustion of volatiles are inter-reliant.

\subsection{Kinetic Properties of Polyurethane Foam}

Kinetic parameters can be determined from TGA, by gradually heating and measuring mass loss.

In a nitrogen environment, the mass loss rate consists of two peaks which identify distinct reactions; the pyrolysis of the virgin polyurethane foam (vPPUF) and the pyrolysis of the polyol. The decomposition of a fuel under a radiant heat flux can be described closely with Arrhenius equations, where decomposition rate is a function of temperature (McGrattan, 2015). TGA experiments from University of Edinburgh demonstrate the rate at which a sample of polyurethane foam decomposes (Figure 1-3). The reaction rates of different foams may vary in temperature range but generally adhere to the two peak profile.
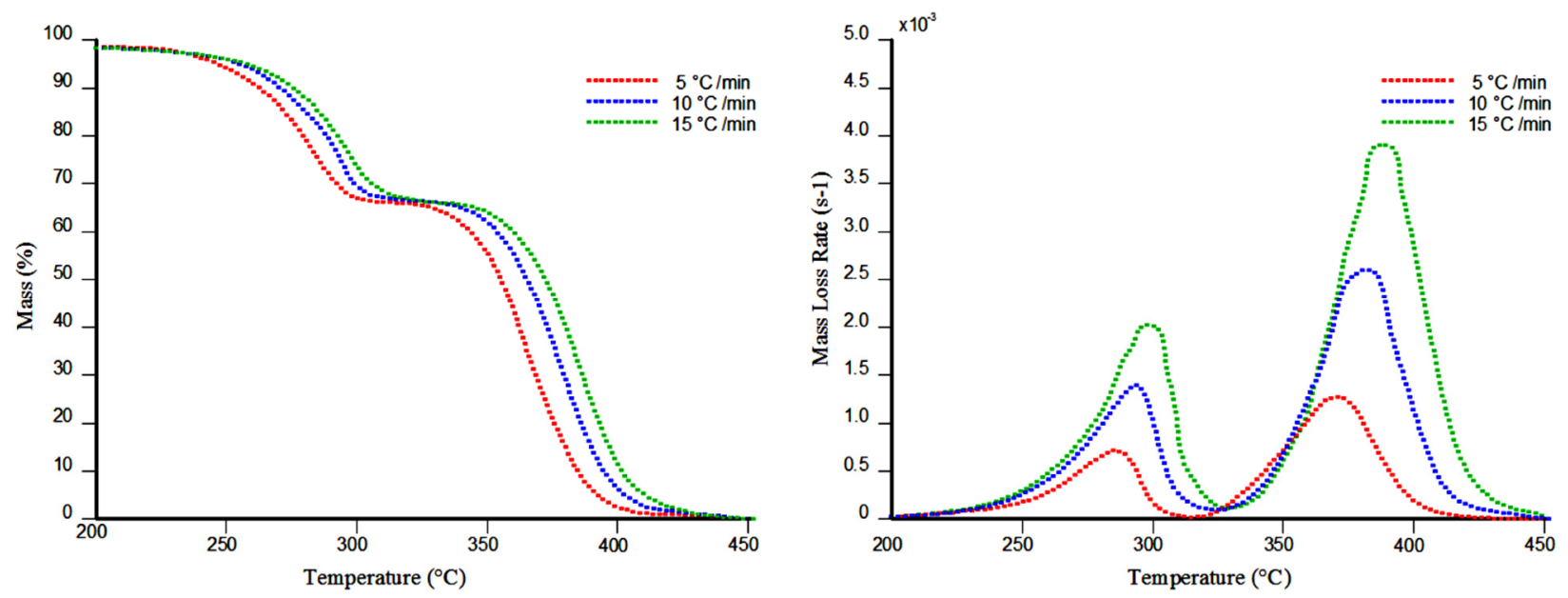

Figure 1-3 TGA Mass Loss Percentage and TGA Mass Loss Rates (Pau, Fleischmann, Spearpoint, \& Li, 2013) 


\section{Appendix A}

The mass loss rates observed under heating reveal PPUF composition to be approximately one third TDI and two thirds polyol. Under TGA, the pyrolysis of the virgin foam begins at temperatures approaching $250^{\circ} \mathrm{C}$ and is almost fully decomposed at $300^{\circ} \mathrm{C}$. The polyol requires further heating and begins pyrolysis at temperatures in excess of $325^{\circ} \mathrm{C}$. Estimating the kinetic parameters pre-exponential factor, $A$ and activation energy, $E$, can be determined using the TGA data (McGrattan, 2015):

$$
\begin{gathered}
K=A e^{-\frac{E a}{R T}} \\
\text { Where } \quad E=\frac{e r_{p}}{Y_{s}} \frac{R T^{2}}{\dot{T}} \quad: A=\frac{e r_{p}}{Y_{s}} e^{\frac{E a}{R T}}
\end{gathered}
$$

The endothermic reactions can be measured through DSC experiments. Enthalpy associated with the pyrolysis reactions are derived in a nitrogen environment (Figure 1-5). An array of DSC experiments on polyol conducted by Pau et al, demonstrated the convergence of enthalpy around 231 and $245 \mathrm{~J} / \mathrm{g}$ (Pau, 2013). The measurement of enthalpy for vPPUF decomposition converged between 800 and $1000 \mathrm{~J} / \mathrm{g}$. The measured enthalpy is sensitive to the applied heating rate and 


\section{Appendix A}

sample size. The numerical model utilizes reaction rates and enthalpy derived from TGA and DSC at analogous heating rates.
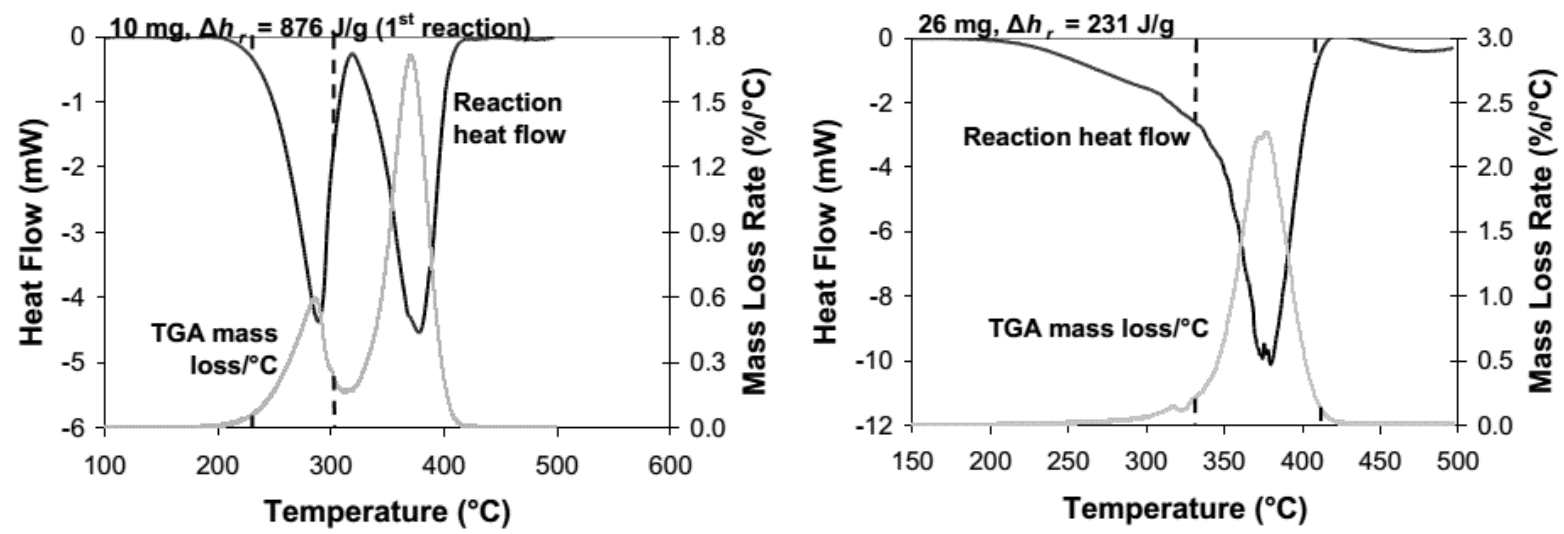

Figure 1-4 Heat of reaction for virgin PUF (left) and polyol (right) determined through DSC (Pau, Fleischmann, Spearpoint, \& Li, 2014)

Char can form in the burning of PPUF. In general, char can impact burning rates by effectively shielding unexposed fuel from decomposition. However, the amount produced may account for as little as 3\% total mass (Rein, Lautenberger, \& Fernandez-Pello, 2006). The charring is produced under oxidation rather than flaming conditions (Valencia, 2009) which is why the effect of char is omitted in the pyrolysis model. Additionally, due to the liquid nature of polyol, any char formed will likely be able to migrate and rotate from the surface due to liquid flow.

\subsection{Heat of Combustion of Polyurethane Foam}

The heat of combustion is the amount of heat released per unit mass of fuel. Literature regarding heat of combustion for PPUF varies widely from 20 to $40 \mathrm{MJ} / \mathrm{kg}$. The average value in many recent studies on flexible PPUF is approximately $26 \mathrm{MJ} / \mathrm{kg}$ (Robson, 2014; Valencia, 2009; Bwalya, et al., 2006; Bwalya, Lougheed, Kashef, \& Saber, 2007). The effective heat of combustion, $\Delta h_{c \text {,eff }}$, can be derived by calorimetry, measuring the heat produced per mass of consumed fuel (indicated by the difference in initial specimen mass, $m_{i}$ and final specimen mass, 


\section{Appendix A}

$m_{f}$ ). While this negates the heat of vaporization/reaction required to release volatiles, it gives substantiation for the effective heat of combustion used in the model.

$$
\Delta h_{c, \mathrm{eff}}=\frac{\sum \dot{q} \cdot \Delta t}{m_{i}-m_{f}}
$$

Use of material datasheets and calorimetry experiments determine TDI released to have a heat of combustion ranging between 25 and $31 \mathrm{MJ} / \mathrm{kg}$ (Bwalya, Lougheed, Kashef, \& Saber, 2007). Less information exist on the heat of combustion of Polyether Polyol. Manufacturer data provides limited detail regarding heat of combustion. Estimating the heat of combustion of polyol can be done by deducting the TDI heat of combustion from the heat of combustion for PPUF as a whole. A heat of combustion ranging between $24-26 \mathrm{MJ} / \mathrm{kg}$ was established by literature and estimates (Prassad, et al., 2009).

NIST experiments using micro-calorimetry determined the heat of combustion for PPUF to be 27.1 MJ/kg. The constituents TDI and polyol were found to have a heat of combustion of 28.8 $\mathrm{MJ} / \mathrm{kg}$ and 26.3 MJ/kg respectively (Prassad, et al., 2009). The heat of combustion for TDI and polyol may be impacted by the proportion of TDI and polyol used in the foam. Thus a higher content of polyol will reduce the heat of combustion per unit of mass and result in a larger polyol melt. The NRC experiments determined the heat release of numerous PPUF samples in cone and open calorimeter (Table 1-1).

Table 1-1 A comparison of heat release of PPUF in cone and open calorimeter experiments performed by the NRC (Bwalya, et al., 2006). Sample D-1* includes an aluminum foil pan to prevent migration of polyol.

\begin{tabular}{|c|c|c|c|c|c|c|c|}
\hline PUF Sample & $\underline{\text { Depth }(\mathbf{m m})}$ & $\underline{\text { Cone Calorimeter }}$ & $\underline{\text { Mass }(k g)}$ & $\underline{\text { Mass Loss (g) }}$ & $\underline{\text { HR }(M J)}$ & $\underline{\mathrm{MJ} / \mathrm{kg}}$ & $\underline{\text { Hceff }}$ \\
\hline $\bar{A}$ & 50 & Cone & $16.3(\mathrm{~g})$ & $\mathrm{n} / \mathrm{a}$ & 0.39 & 24.0 & $\mathrm{n} / \mathrm{a}$ \\
\hline $\mathrm{D}$ & 50 & Cone & $16.5(\mathrm{~g})$ & $\mathrm{n} / \mathrm{a}$ & 0.42 & 25.5 & $\mathrm{n} / \mathrm{a}$ \\
\hline $\mathrm{E}$ & 50 & Cone & $17.2(\mathrm{~g})$ & $\mathrm{n} / \mathrm{a}$ & 0.42 & 24.2 & $\mathrm{n} / \mathrm{a}$ \\
\hline & & & & & Average: & 24.62 & $\mathrm{n} / \mathrm{a}$ \\
\hline
\end{tabular}




\section{Appendix A}

\begin{tabular}{|c|c|c|c|c|c|c|c|}
\hline PUF Sample & $\underline{\text { Depth }(\mathbf{m m})}$ & Cone Calorimeter & $\underline{\text { Mass }(\mathrm{kg})}$ & $\underline{\text { Mass Loss }(\mathrm{g})}$ & $\underline{\text { HR }(M J)}$ & $\underline{\mathrm{MJ} / \mathrm{kg}}$ & $\underline{\text { Hceff }}$ \\
\hline $\bar{A}$ & 100 & Open & 1.178 & 1.055 & 35.10 & 29.8 & 33.3 \\
\hline D & 100 & Open & 1.245 & 1.165 & 38.80 & 31.1 & 33.3 \\
\hline D-1 & 150 & Open & 3.052 & 2.325 & 64.87 & 21.3 & 27.9 \\
\hline D-1* & 150 & Open & 2.933 & 2.635 & 76.74 & 26.2 & 29.6 \\
\hline $\mathrm{D}$ & 100 & Open & 2.973 & 2.902 & 78.07 & 26.1 & 26.9 \\
\hline D & 100 & Open & 5.840 & 5.510 & 142.00 & 24.3 & 25.8 \\
\hline $\mathrm{E}$ & 100 & Open & 1.240 & 1.025 & 34.50 & 27.8 & 33.7 \\
\hline \multirow[t]{2}{*}{ E } & 100 & Open & 3.005 & 2.720 & 90.60 & 30.2 & 33.3 \\
\hline & & & & & Average: & 27.12 & 30.4 \\
\hline
\end{tabular}

\subsection{Thermal Properties of Polyurethane Foam}

Thermal parameters of conductivity, specific heat and density have a significant effect on the burning of PPUF. The transfer and absorption of energy effect the spread of heat throughout the material. PPUF as a whole has low conductivity, generally ranging between 0.04 and 0.08 $\mathrm{W} / \mathrm{mK}$. The conductivity and heat capacity were found to increase approaching pyrolysis temperatures (Pau, 2013). The polyol conductivity was determined from manufacturer data and measurements from the hot disk method (Pau, 2013). However, only static values for conductivity and heat capacity were utilized to limit the model complexity (Table 1-2). A parametric study should be conducted to evaluate the influence the property may have.

\section{Summary of kinetic and material properties}

The molecular decomposition of PPUF is able to be described thoroughly through equations relating mass loss rate and material properties. However, the implementation is challenging because the physical form of the fuel changes vastly through burning. Consideration for the change in geometry, surface area, density and fuel migration needs to be contemplated in any attempt at creating a fire model. 


\section{Appendix A}

Table 1-2 A listing of key parameters gathered through literature and selected values for the numerical simulations.

\begin{tabular}{|c|c|c|c|c|}
\hline \multirow{3}{*}{ Property } & \multirow{2}{*}{\multicolumn{2}{|c|}{ virgin PPUF }} & \multirow[b]{2}{*}{ Polyol } & \\
\hline & & & & \\
\hline & Range & Selected & \multicolumn{2}{|l|}{ Selected } \\
\hline Density $\left(\mathrm{kg} / \mathrm{m}^{3}\right)$ & $\begin{array}{l}31.0 \text { (Bwalya, et al., } \\
\text { 2006) }\end{array}$ & 31.0 & $\begin{array}{l}800-1000 \text { (Prassad, et } \\
\text { al., 2009) }\end{array}$ & 1,000 \\
\hline & 1-2.4 (Czichos, Saito, & & 1.8-2.0 (International & \\
\hline Heat Capacity $(\mathrm{kJ} / \mathrm{kg} / \mathrm{K})$ & $\begin{array}{l}\text { Smith, \& Czichos, } \\
\text { 2011) }\end{array}$ & 2.0 & $\begin{array}{l}\text { Organization for } \\
\text { Standardization, 2007) }\end{array}$ & 1.8 \\
\hline Thermal Conductivity (W/m/K) & $\begin{array}{l}\text { 0.04-0.07 (Valencia, } \\
2009)\end{array}$ & 0.04 & $\begin{array}{l}\text { 0.12-0.15 (Valencia, } \\
\text { 2009) }\end{array}$ & 0.14 \\
\hline Reference Peak Temperature $\left({ }^{\circ} \mathrm{C}\right)$ & $\begin{array}{l}\text { 270-300 (Pau, } \\
\text { Fleischmann, } \\
\text { Spearpoint, \& Li, } \\
\text { 2014) }\end{array}$ & 295 & $360-400$ & 367 \\
\hline Activation Energy - E(kJ/mole) & & 182,000 & & 244,000 \\
\hline Pre-exponential factor - A (1/s) & & $3.32 \times 10^{14}$ & & $4.6 \times 10^{17}$ \\
\hline Heat of Reaction (J/g) & $\begin{array}{l}\text { Pyrolysis model } \\
\text { dependent }\end{array}$ & $\begin{array}{l}847[11] \\
\left(5^{\circ} \mathrm{C} / \mathrm{min}\right. \\
\left.\sim 290^{\circ} \mathrm{C} \text { peak }\right)\end{array}$ & $\begin{array}{l}\text { Pyrolysis model } \\
\text { dependent }\end{array}$ & $\begin{array}{l}231[11] \text { at }\left(5^{\circ} \mathrm{C}\right. \\
/ \min \\
\left.\sim 364^{\circ} \mathrm{C} \text { peak }\right)\end{array}$ \\
\hline Heat of Combustion (kJ/kg) & $\begin{array}{l}\text { 20,000-40,000 } \\
\text { (Ezinwa, 2009) }\end{array}$ & 27,000 & 24-26,500 (Pau, 2013) & 26,000 \\
\hline
\end{tabular}




\section{Appendix A}

\section{Chapter 2. Micro-Scale Physical Behavior}

The micro-scale behavior describes the foam collapse, melt and change in density. This is observed in all PPUF decomposition. Its significance to the fire model is described below.

\section{Polyol Byproduct}

PPUF will burn and form polyol which will collect at the surface of the foam. This polyol will accumulate and eventually form a pool that may burn. Observations of burning indicate polyol produced forms into "bead" like concentrations on the foam (Prassad, et al., 2009). Due to the high density difference, these beads initially occupy a small proportion of the surface area (Figure 1-5). This allows the vPPUF to continually burn as polyol is produced. However, as the accumulation of polyol continues, the burning of polyol will begin and transition to being the dominant fuel source.

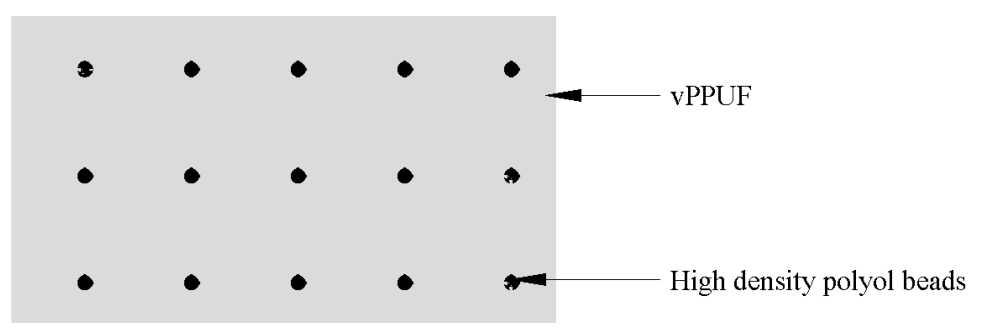

Figure 1-5 The pyrolysis of vPPUF results in the formation of polyol beads.

Current limitations in numerical simulations do not allow for representation of polyol beading and alternative methods to approach this problem have been developed. Some proposed methods for modeling PPUF represent the fuel into separate layers. Numerical simulations by Prassad represent vPPUF and polyol as separate layers, one burning after the other in conformance to observations (Prassad, et al., 2009).

\section{Density of Fuel}

PPUF is a low density material and the polyol byproduct is approximately 33 times as dense. The transition of burning from vPPUF to polyol carries in increase in thermal inertia, requiring 


\section{Appendix A}

energy to increase its surface temperature to support pyrolysis. In some scenarios this can lead extinguishment of the fire.

\subsection{The Numerical Model}

A challenge in modelling PPUF has been its representation of the polyol byproduct which tends to undergo decomposition after the majority of TDI has been combusted (Pitts, 2007). NIST Pyrolysis Model 4, developed by Prassad, accounts for this observed order by representing vPPUF and polyol in separate layers (Prassad, et al., 2009). Thus, when the vPPUF layer is consumed the polyol layer becomes exposed. The model has been used with some success in large scale simulations (Pau, 2013). However, an issue that often arises with the two-layer model is the failure for the polyol layer to burn, particularly in small scale simulations. In some scenarios, as the polyol layer becomes exposed, an insufficient amount of heat is available to sustain pyrolysis. This will result in a significant drop in HRR that leads to the extinction of the

fire. This occurs due to the large difference in thermo-physical properties, with polyol being over 30 times the density PPUF. As the polyol layer becomes exposed, a sudden trough in the HRR occurs in simulations to an extent not realized in cone calorimeter experiments. This discontinuity of burning between layers was similarly identified by Pau in numerical simulations seen in Figure 1-7 (Pau, 2013). 


\section{Appendix A}

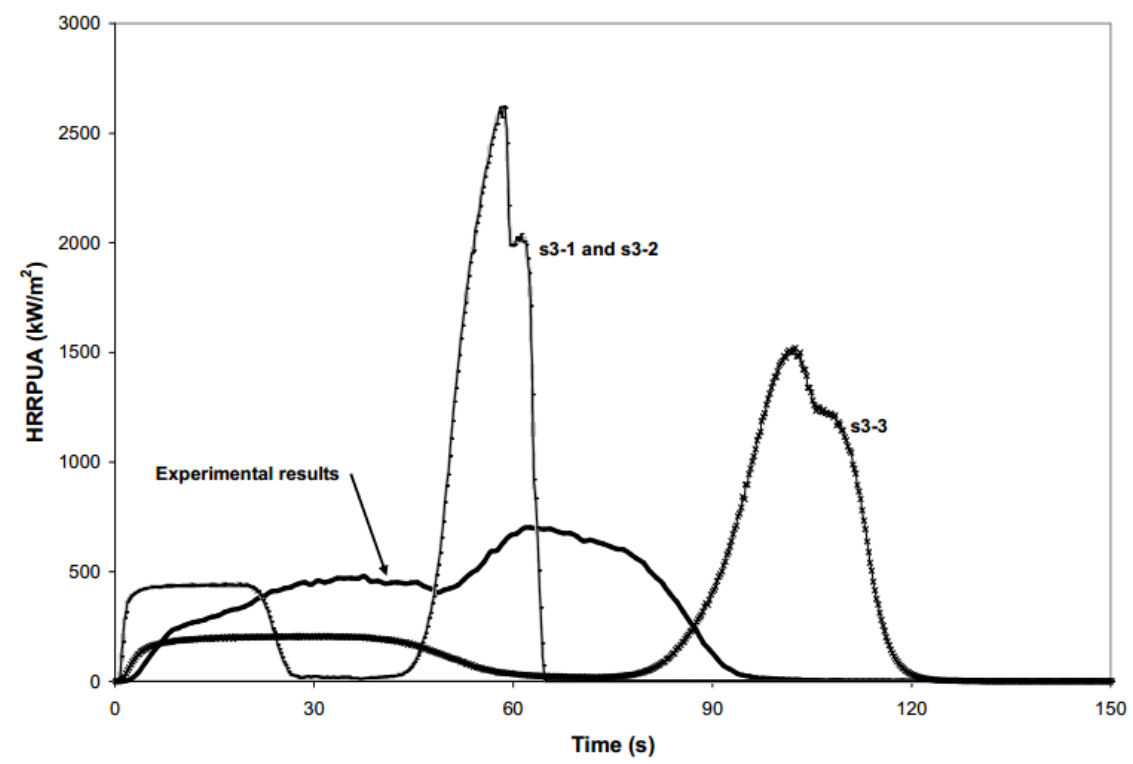

Figure 1-6 Comparison between numerical simulations and experimental cone calorimeter results. (Pau, 2013).

Recent studies have confirmed findings that the polyol produced stays on top of the foam surface. Observations and experiments noted that the production of polyol did not appear to infiltrate into the foam (Krämera, et al., 2010). While the polyol will occupy some surface area, the high density, liquid nature and uneven surface of the foam will limit the amount. A $50 \mathrm{~mm}$ thick PPUF slab will produce a $1 \mathrm{~mm}$ layer polyol. While the bulk of vPPUF is consumed in advance of polyol, it can be expected that some proportion of polyol will be consumed simultaneously with vPPUF.

As the majority of vPPUF is consumed and polyol becomes more abundant, an increase in the amount of polyol decomposition will occur. The model could incorporate an increasing concentration of polyol in a series of layers within the model. However, the complexity in implementing such a model will outweigh the benefits. The use of a single transition layer consisting of a mass fraction of vPPUF and polyol approximates the effect of increasing polyol 


\section{Appendix A}

combustion (Figure 1-7). However, the transition layer provides the function of allowing heat transfer between the layers.
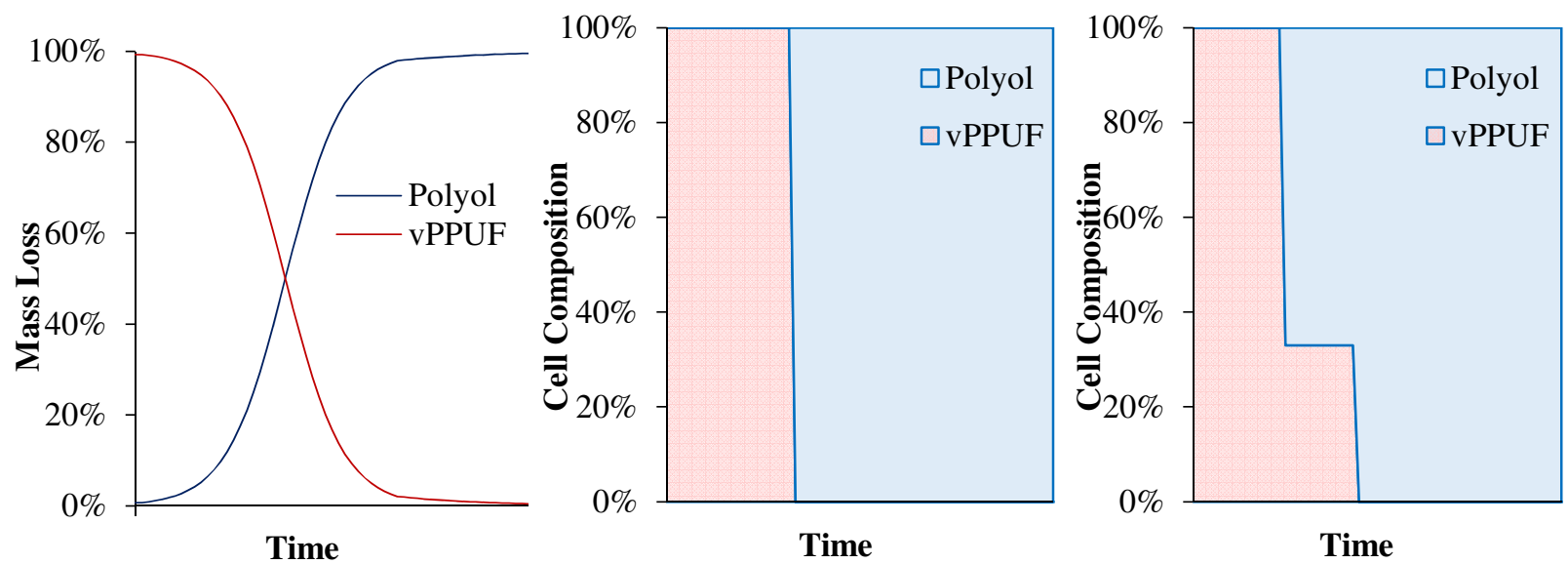

Figure 1-7 Fuel consumption transitions from vPPUF to Polyol (left) A transition phase results in burning of both fuels in varying proportions over time. The two-layer model does not permit burning of polyol until the PPUF layer is consumed (middle). The three-layer model implements a transition layer composed of both vPPUF and polyol.

The proposed model differs from the "two-layer models" by including a transitional layer which addresses the density issues mentioned previously. This concept interprets the observations in many cone calorimeter experiments which demonstrate a valley in HRR where the pyrolysis of vPPUF transitions to polyol (Figure 1-9). This transitional layer is composed of vPPUF and polyol (Figure 1-10). This concept reduces the sudden change of low density to high density fuel when polyol becomes exposed. 


\section{Appendix A}
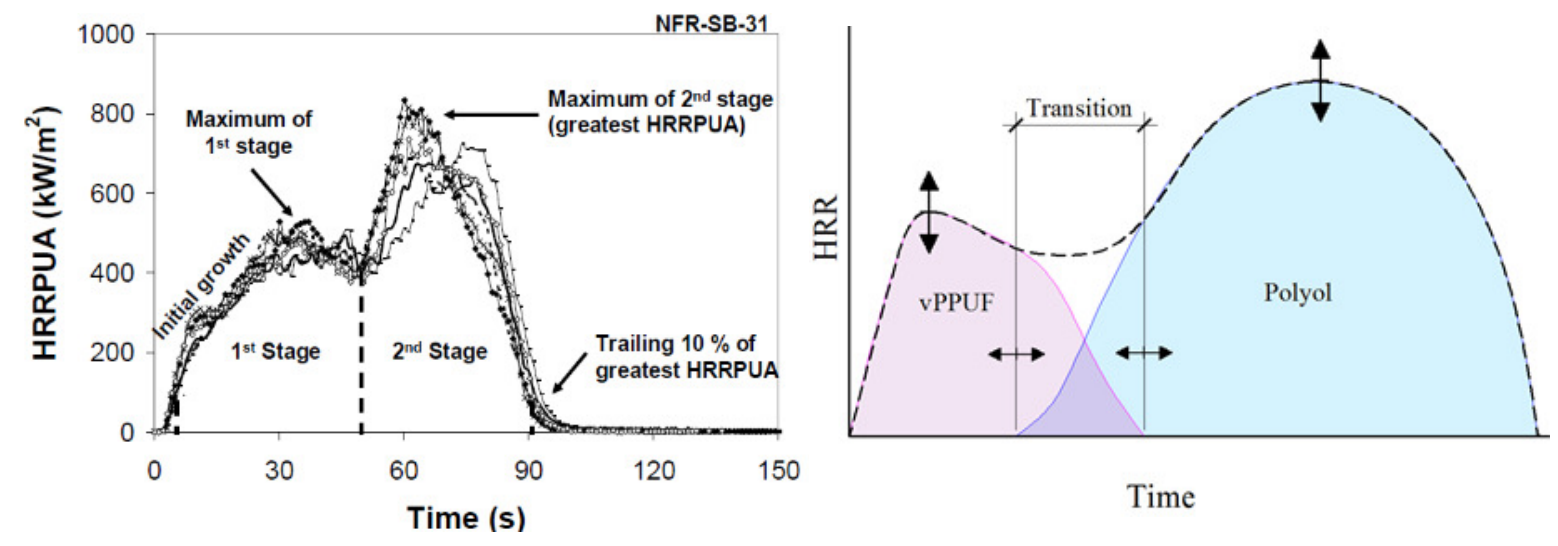

Figure 1-8 HRR Per Unit Area under a 50 kW cone calorimeter (Pau, 2013)
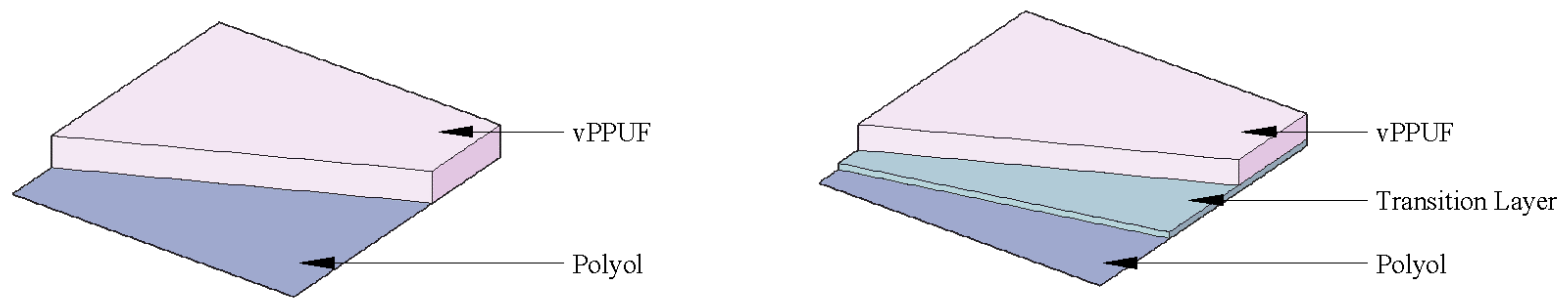

Figure 1-9 The two-layer polyurethane model developed by NIST (left) with a three-layer variation including transition layer of vPPUF and Polyol (right).

The transition layer is a mixture of vPPUF and polyol in a defined proportion. Various

proportions of each fuel and thickness of the layer itself were examined with numerical

simulations of cone calorimeters. Simulations were run to determine the transition layer's

optimal thickness and proportions fuel. A mass fraction of $8 \%$ vPPUF and $92 \%$ polyol with a

total density of $285 \mathrm{~kg} / \mathrm{m}^{3}$ was selected. In this model, the transition layer represent $28 \%$ of the total fuel mass (defined in Table 1-3). The density of this layer, $p$, was calculated from the mass fraction and density of each constituent, $i$ and $j$ in Equation 8.

$$
p=\left(\frac{Y_{i}}{p_{i}}+\frac{Y_{j}}{p_{j}}\right)^{-1}
$$




\section{Appendix A}

\subsection{Cone Calorimeter Simulation}

Numerical simulations of the two-layer and three-layer models were conducted using FDS to compare HRR and mass loss rates with cone calorimeter experiments. The PPUF samples measured $100 \mathrm{~mm} \times 100 \mathrm{~mm}$ with a thickness of $50 \mathrm{~mm}$ and were ignited with a various heat flux (Figure 1-11). The two-layer and three-layer model were simulated in a simple cone calorimeter experiment. A variety of grid sizes were simulated, from coarse $(20 \mathrm{~mm})$ to fine $(2.5$ $\mathrm{mm}$ ). The fine grid refinement incurred significant processing power and yielded similar results.
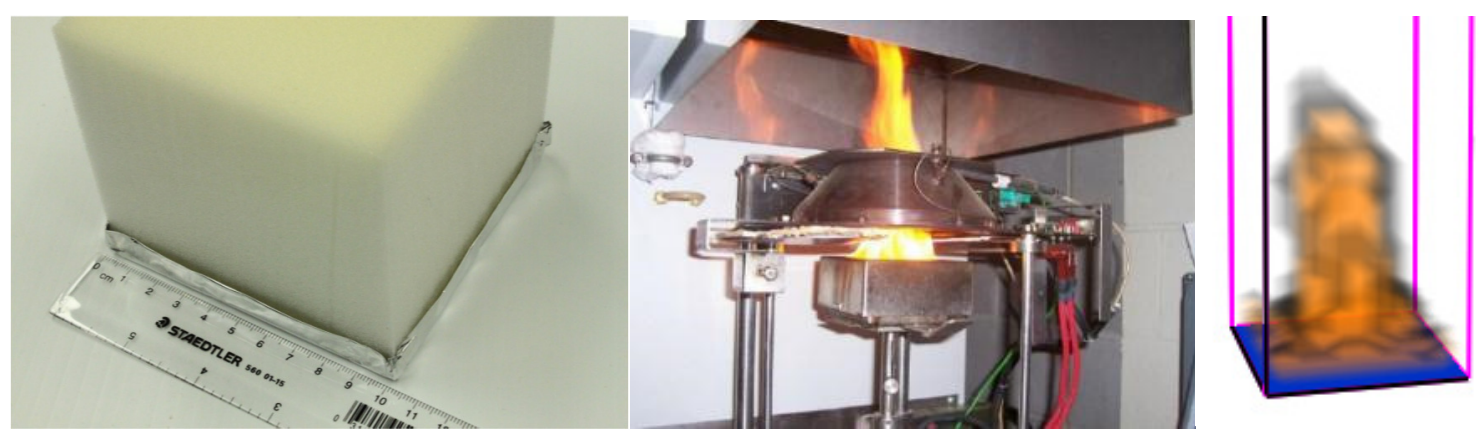

Figure 1-10 A PPUF sample (Robson, 2014), left, cone calorimeter experiment (Ezinwa, 2009), center, and replicated FDS simulation

\subsection{Parametric study of the transitional layer}

The transition layer is a mixture of vPPUF and polyol in a defined proportion. A parametric study was conducted to observe which formulations best maintained decomposition rates during the fuel transition phase. To evaluate the transition layers, the simulations subjected 15 grams PUFF samples to a constant heat flux of $45 \mathrm{~kW} / \mathrm{m}^{2}$. Pyrolyis simulations were run, with variations in both the transition layer's mass and mass fraction of vPPUF to polyol. The simulations were conducted in absence of oxygen, to clearly examine the effect on heat transfer between layers and pyrolysis rates. An initial criteria for the layer selected was the minimum layer mass that best maintains pyrolysis between the vPPUF and polyol layer. 


\section{Appendix A}

An array of simulations demonstrated the valley between vPPUF and polyol was limited as the transition layer mass approached $20-25 \%$ of the total fuel. This allowed for sufficient heat transfer to occur between the layers, sustaining pyrolysis. The ideal composition of the layer was observed to range between $88 \%-96 \%$ polyol (Figure 1-12).
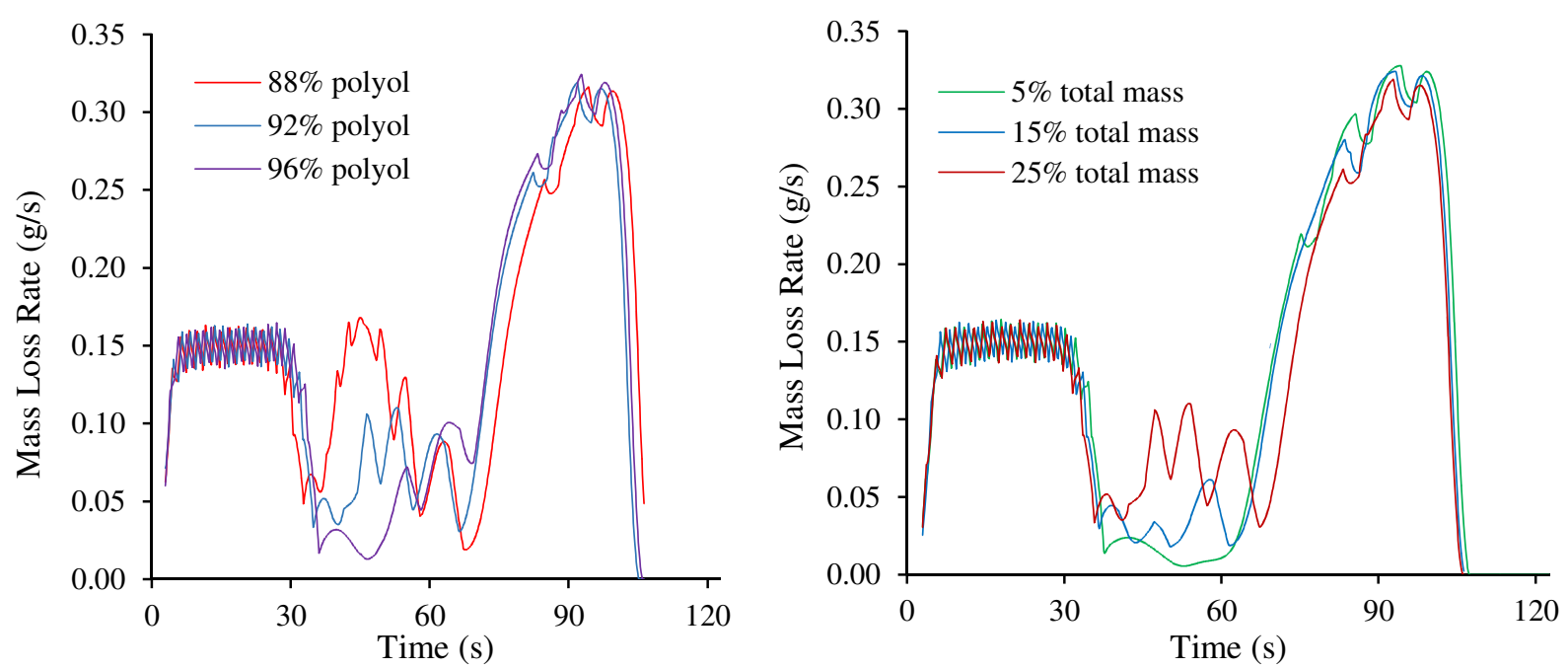

Figure 1-11. PPUF subjected to a $50 \mathrm{~kW}$ heat flux in pyrolysis simulations. This demonstrates the effect on mass loss rate for varying mass fractions of a transition layer $25 \%$ of the total mass, left, and pyrolysis simulations showing the effect of varying transition layer mass.

A mass fraction at the lower extent, $88 \%$ polyol, resulted in a drop in pyrolysis rates when the polyol layer became exposed. Conversely, a mass fraction of $96 \%$ polyol resulted in a drop in pyrolysis rates immediately after the vPPUF was consumed. As expected, a mass fraction of $92 \%$ resulted in minimizing drops in pyrolysis between the vPPUF and polyol layers.

The transition layer composed of $92 \%$ polyol with a total density of $285 \mathrm{~kg} / \mathrm{m}^{3}$ was selected. In this model, the transition layer represent $25 \%$ of the total PPUF mass. These proportions were utilized in all further simulations and the layer properties are identified in Table 1-3. 


\section{Appendix A}

Table 1-3 The representation of PPUF in the proposed two-layer and three-layer models

\begin{tabular}{|c|c|c|c|c|c|}
\hline \multirow{3}{*}{ Actual PPUF } & Layers & Material & Density $\left(\mathrm{kg} / \mathrm{m}^{3}\right)$ & Thickness (mm) & $\operatorname{Mass}(\mathrm{g})$ \\
\hline & Layer 1 & PUF & 31 & 50.00 & 15.50 \\
\hline & & & & 50.00 & 15.50 \\
\hline \multicolumn{6}{|l|}{ FDS Model } \\
\hline \multirow[t]{3}{*}{ Two-layer } & Layer 1 & TDI & 31 & 16.7 & 5.17 \\
\hline & Layer 2 & Polyol & 1000 & 1.03 & 10.33 \\
\hline & & & & & 15.50 \\
\hline \multirow[t]{3}{*}{ Three-layer } & Layer 1 & TDI & 31 & 15.54 & 4.70 \\
\hline & Layer 2 & $8 \%$ TDI, 92\% Polyol & 285 & 1.25 & 4.30 \\
\hline & Layer 3 & Polyol & 1000 & 0.65 & 6.50 \\
\hline
\end{tabular}

\subsection{Cone Calorimeter Results}

A comparison of the two-layer and three-layer models demonstrates a significant improvement to the burning behavior during the fuel transition. In the two-layer model, the HRR decreases dramatically as polyol is exposed (Figure 1-13). The three-layer model, exhibits continual burning during this phase. Under a $30 \mathrm{~kW}$ flux, the HRR does dip lower. The magnitude of this drop is greatly reduced when compared to the two-layer model.
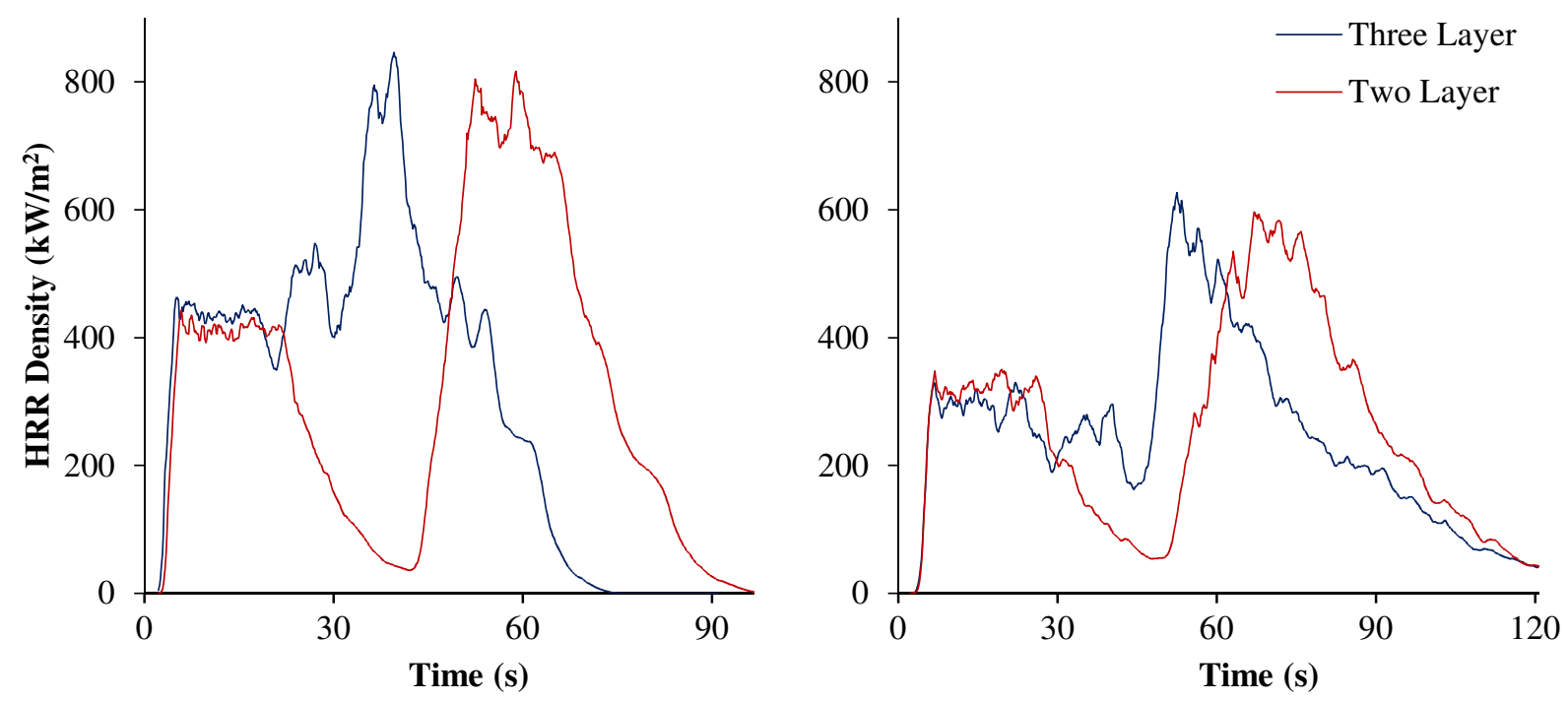


\section{Appendix A}

Figure 1-12 FDS cone calorimeter simulations of the two and three-layer models under $40 \mathrm{~kW}$ (left) and $30 \mathrm{~kW}$ (right) heat flux.

The results achieved by the cone calorimeter simulations were similar to other notable experiment by Pau, as seen in Figure 1-14 \& Figure 1-15. The HRR density of $300-500 \mathrm{~kW} / \mathrm{m}^{2}$ resulting from vPPUF burning phase was similar in experiment and simulations. The increase in HRR in the burning of polyol was consistent as well. Maximum HRR was found to be in general agreement with experiment results of $1,200 \mathrm{~kW} / \mathrm{m}^{2}$ and simulation of $1,050 \mathrm{~kW} / \mathrm{m}^{2}$ under a 60 $\mathrm{kW}$ heat flux.

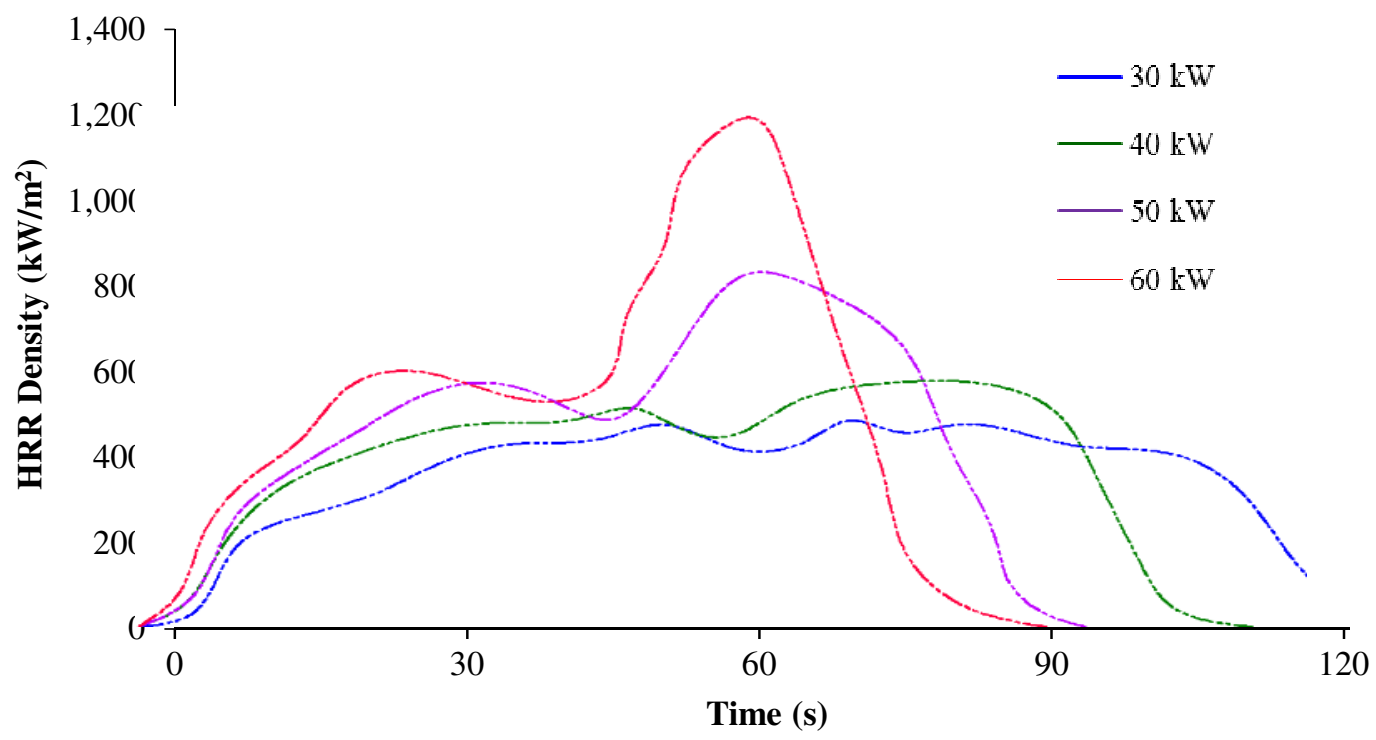

Figure 1-13 HRR density under heat flux at 30, 40, 50 and $60 \mathrm{~kW}$ (Pau, 2013) 


\section{Appendix A}

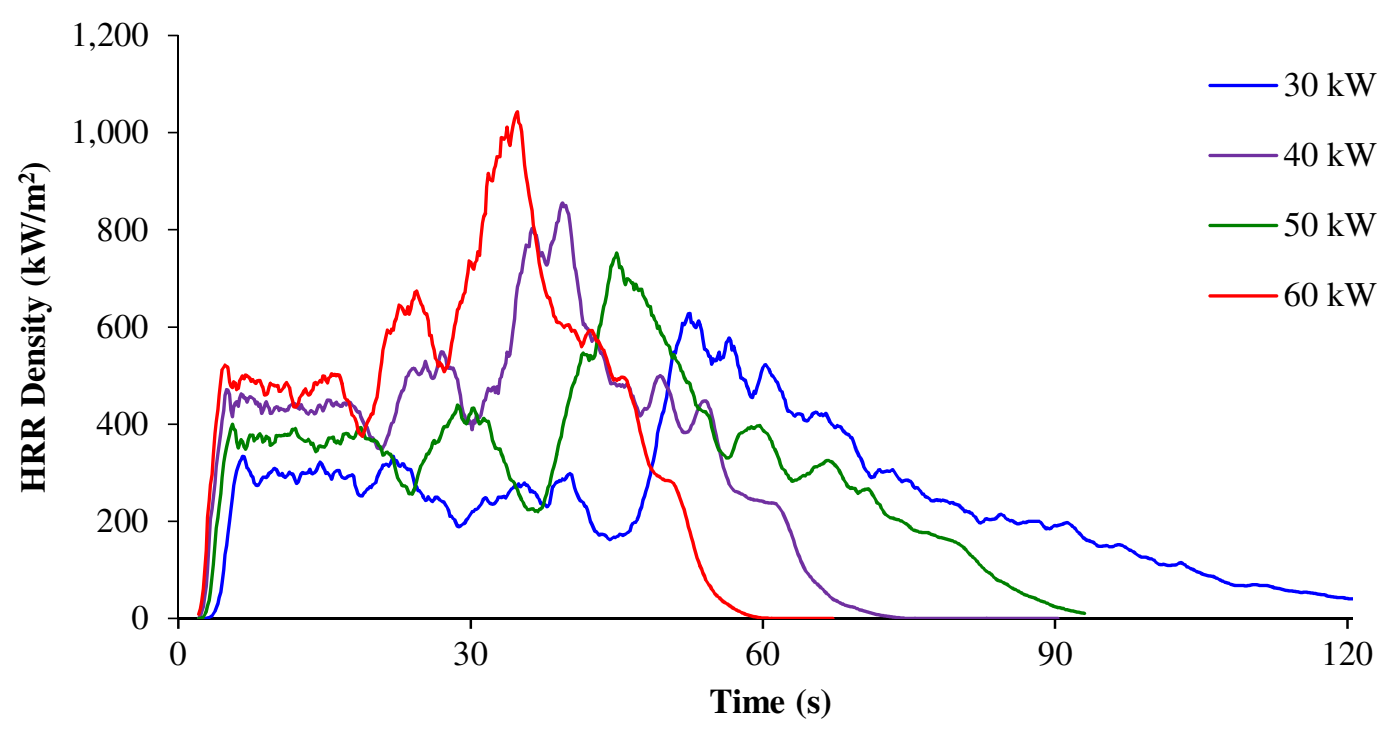

Figure 1-14 Simulation results from the three-layer model, showing the HRR density for heat flux at 30, 40,50 and $60 \mathrm{~kW}$

The duration of the burning was noticed to be somewhat reduced in the simulation as compared to the experiment (Figure 1-14 \& Figure 1-15). This may be partially accounted for difference in the onset of the heat flux in experiments versus simulation. A lag in the heat flux generally occurs as the cone calorimeter warms up, taking a number of seconds before a $100 \%$ flux is achieved. However, the flux applied in the numerical simulation is immediate. Thus, the burning does not follow the slow ramp up observed in the experiments.

Other explanations for the discrepancy between experiments and simulations can be attributed to the difficulty in replicating surface radiation in simulations. The melting in cone experiments results in an increasing distance between the radiation source and fuel surface (Pau, 2013). This is not captured in the simulations as the fuel surface is represented in 2-D and receives a constant heat flux throughout. As a result the distance between the fuel surface and the radiation source increases. The radiative distance does not change in the simulations, resulting in a higher heat 


\section{Appendix A}

flux. The effect of this may change in different cone calorimeters but studies have shown approximately a 6-8\% reduction in radiation flux when the surface is $50 \mathrm{~mm}$ further (Figure 1-16) (Babrauskas \& Grayson, 1990).

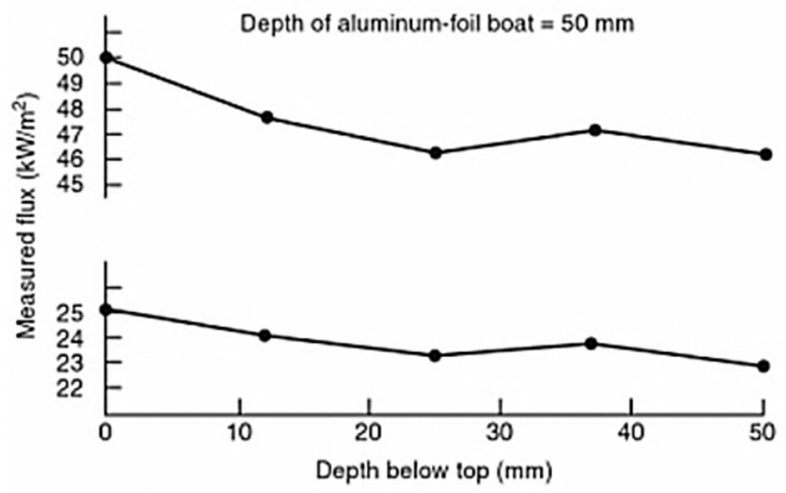

Figure 1-15 Measured flux at various positions below the top surface of a specimen (Babrauskas \& Grayson, 1990).

Boundary conditions play a significant role in the burning of polyol. The thermal properties of the backing substrate can influence the amount of heat transferred through and change the burning rate accordingly. Due to its higher conductivity and density compared to vPPUF, the transfer of heat from polyol to a defined backing can dramatically change burning behavior. Numerical simulations conducted by Pau demonstrate this influence a substrate has in its tendency to over-predict or under-predict HRR in the polyol phase (Pau, 2013). The influence of the backing and its effect on the HRR in the simulations conducted was significant. The conduction of heat into the gypsum substrate resulted in a lower peak HRR as seen in Figure $1-17$. 


\section{Appendix A}

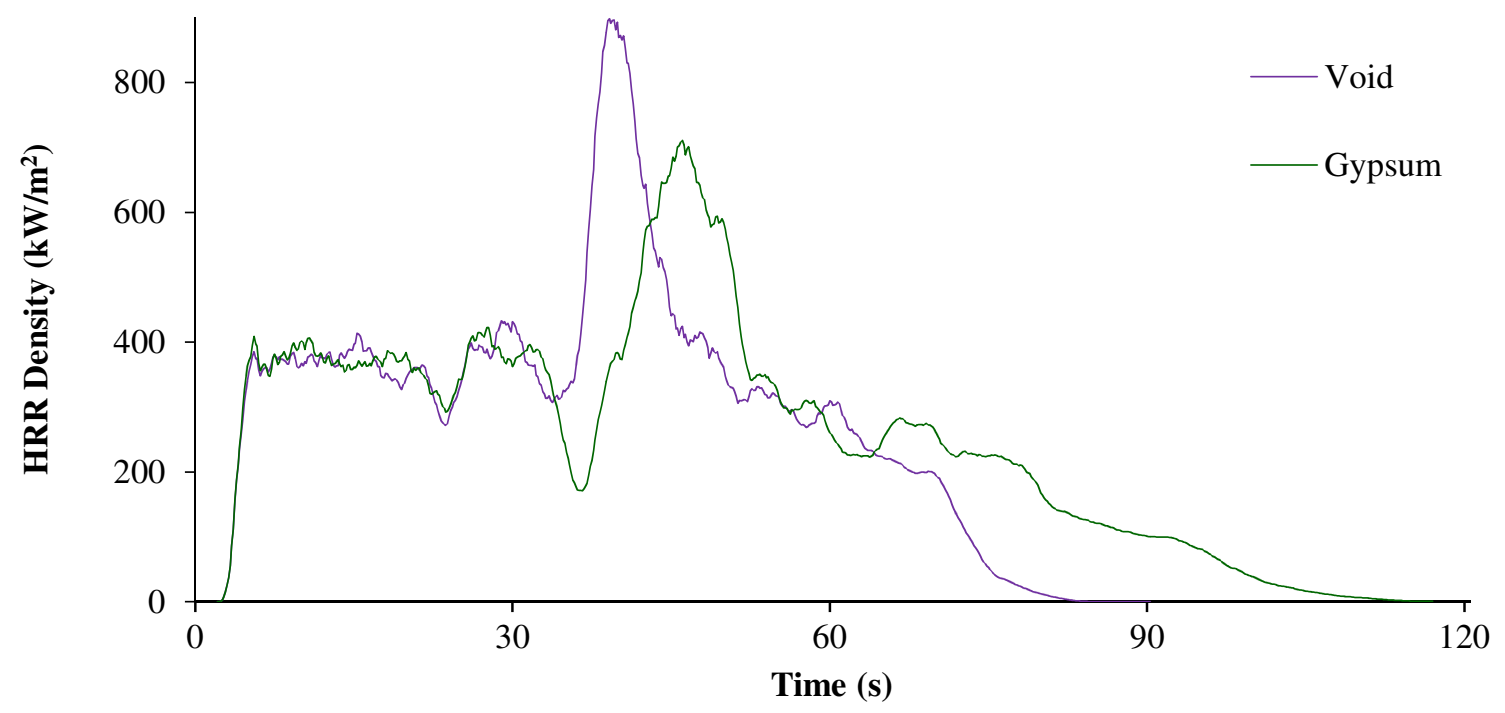

Figure 1-16 Boundary conditions and the impact on the HRR of polyol. 


\section{Appendix A}

\section{Chapter 3. Macro-Scale Physical Behavior}

The macro-scale behavior, describes the impact of fuel geometry and deformation that changes

the burning characteristics of PPUF. With migration of liquid fuel, the surface area may increase and potentially contribute feedback to the existing fire. These characteristics are identified by observing open calorimeter PPUF experiments. The burning of PPUF arranged in vertical and horizontal arrangements demonstrates the influence of polyol melt. In a series of experiments done by the NRC, mock-up sofas, consisting of a horizontal and vertical slab, were ignited by a $20 \mathrm{~kW}$ propane burner. The results of the "one-third" sofa experiment can be seen in Figure 1-18 and the observations are noted chronologically below:

- The fire begins spreading along the horizontal and vertical surfaces. The fire spreads quickest on the vertical surface, covering the entire surface area before it covers the entire horizontal surface. $(\mathbf{t = 6 0 s})$ At this stage, the dominant combustible is mainly TDI released from the collapsing vPPUF. Polyol beings to accumulate on the foam surface.

- $\quad(\mathbf{t = 1 2 0})$ The fire has spread to the entire foam surface. This represents the peak HRR with the fuel surface area being the highest. However, as the vertical foam burns quickly the reduction in this fuel surface results in a decline of HRR. Liquid polyol forms pools on the remaining vPPUF and begins to run off. A shift in combustibles from TDI to polyol begins as the foam is melted.

- $\quad(\mathbf{t = 1 8 0 )}$ With the majority of the vPPUF consumed, the liquid polyol pool spills over the remaining vPPUF.

- $\quad(\mathbf{t = 2 1 0})$ The burning polyol runoff forms a pool fire on the floor. This fire is beneath the original fuel location and increases the burning of remaining fuel.

- $\quad(\mathbf{t = 2 7 0 )}$ The fire surface area on the floor decreases as polyol is consumed. The fire decays with decreased heat and fuel, eventually smoldering.

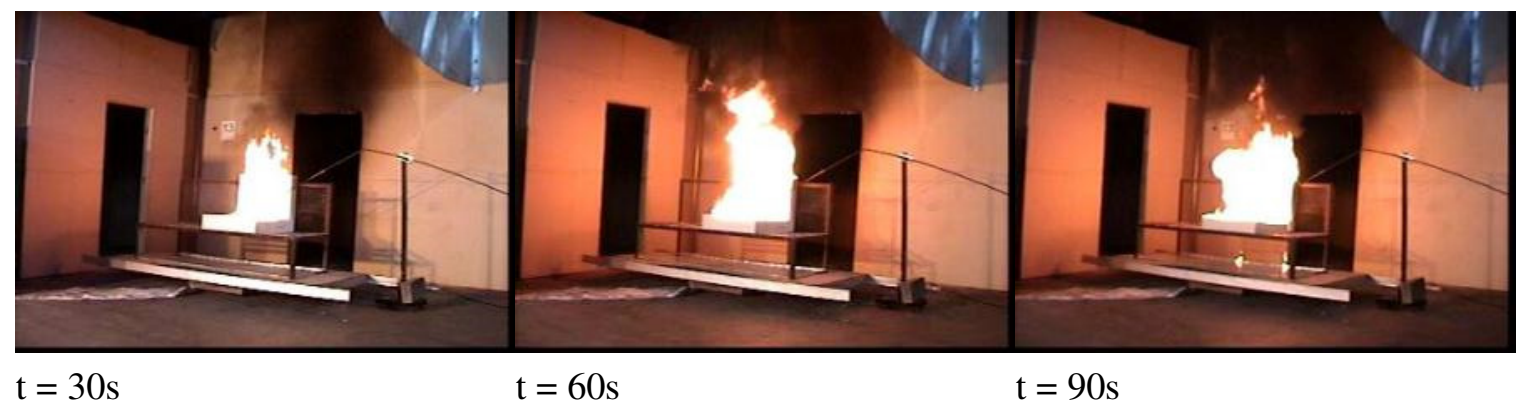




\section{Appendix A}

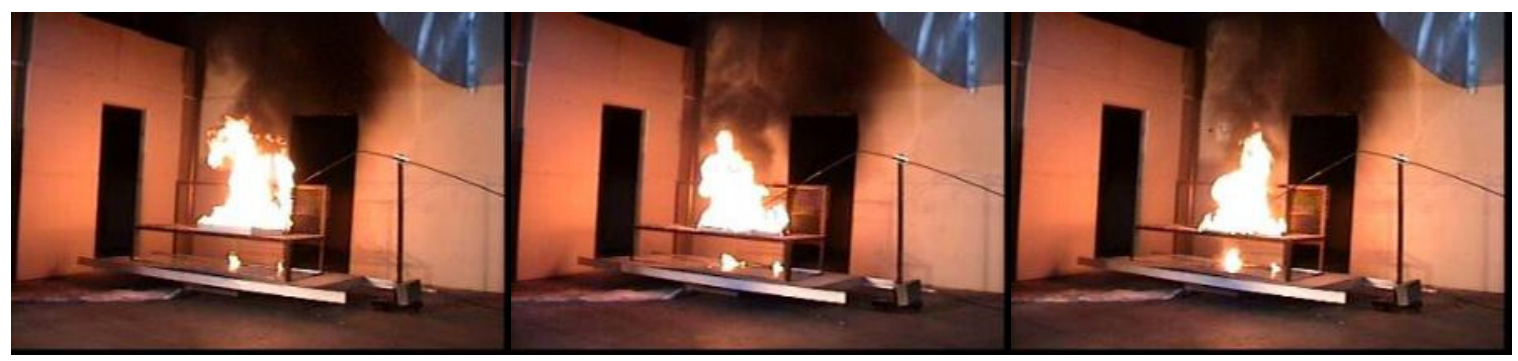

$\mathrm{t}=120 \mathrm{~s}$

$\mathrm{t}=150 \mathrm{~s}$

$\mathrm{t}=180 \mathrm{~s}$

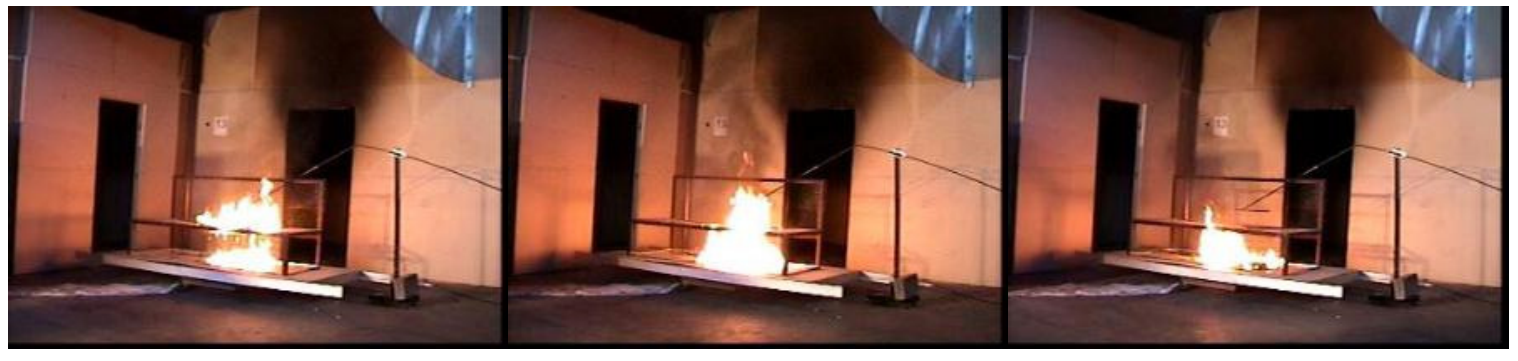

$\mathrm{t}=210 \mathrm{~s}$

$\mathrm{t}=240 \mathrm{~s}$

$\mathrm{t}=270 \mathrm{~s}$

Figure 1-17 Polyurethane Experiment in Open Calorimeter conducted by the NRC (Bwayla, 2008).

\section{Polyol Migration - Runoff}

The liquid polyol produced may pool or migrate from the location of the PPUF. Since polyol

represents approximately two-thirds of the combustible fuel, this is considered very important for accurate modeling. FDS cannot account for fuel migration or melting. However, some of these characteristics can be predicted and factored into the fire model. For horizontal PPUF slabs on a flat surface, the migration of polyol is limited. For PPUF elevated above the floor or in a vertical orientation, the migration can be significant. This too can be crudely predicted as the polyol flow will be dictated by gravity and polyol viscosity.

The available fuel area for a given time is difficult to predict, but can be estimated by observation of similar experiments. Recent work in Particle Finite Element Methods have begun to model the melt of polymers, but its implementation in fire modeling is still in early stages (Butler, 2009). Additionally, the polyol produced is subject to liquid flow and may migrate away from the fuel source depending on how the fuel is contained. Where the polyol ends up can affect 


\section{Appendix A}

the fire greatly. For instance, the polyol may burn and contribute radiation feedback to the existing fire (Pau, 2013). The orientation, whether vertical or horizontal, changes the migration of polyol. Vertical slabs allow the runoff of polyol which will collect at a horizontal surface (Figure 1-19).
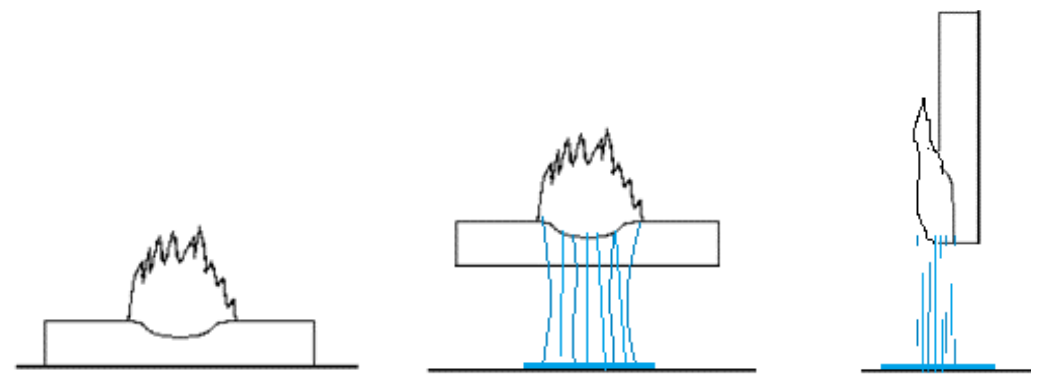

Figure 1-18 PPUF slab and polyol run off for horizontal slabs on grade (left), elevated slabs (middle) and vertical slabs (right).

\section{Polyol Migration - Distribution}

As a horizontal slab burns, the foam collapses forming a depression. The polyol liquid will accumulate and flow into the depressions. The result is that more polyol will be consumed at the point of ignition where the depression first forms. In FDS, the polyol fuel layer can only originate evenly distributed. Thus, the point of ignition may become exhausted early as no migration of polyol will occur in the fire model. In reality, the liquid nature of polyol allows distribution. This can be addressed in the model by increasing the polyol layer thickness in identified areas. While this misrepresents the actual amount of polyol, it serves to account for the distribution of polyol. In such a case, less polyol is consumed along the perimeter of the fire model and a decrease in polyol thickness can be implemented (Figure 1-20). 


\section{Appendix A}

Centre Ignition
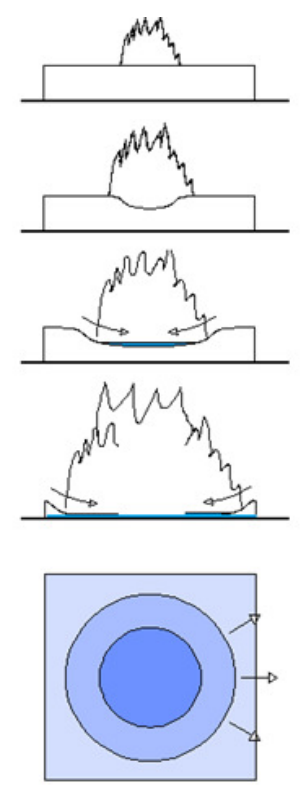

Edge Point Ignition
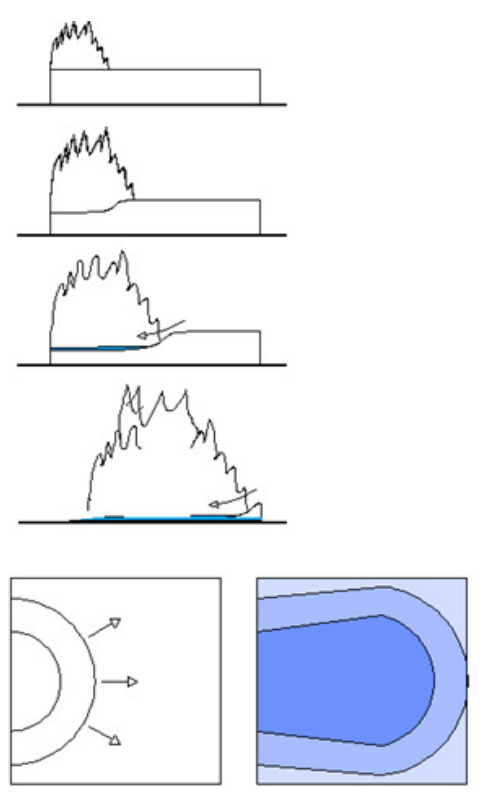

Change in polyol layer thickness

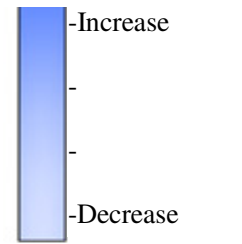

Figure 1-19 PPUF slab burning characteristics and the influence of polyol migration on horizontal slabs.

\section{Dynamic Fuel Surface Area}

The low density of PPUF translates to a rapid change of shape as the material is heated.

Representing an accurate model in FDS requires the ability to simulate the available surface area of fuel and its change over the duration of the fire. This characteristic cannot be fully considered in FDS simulations. The development and integration of Particle Finite Element Method in fire models such as FDS may be able to address the dynamic changing geometry. However, this is not available in FDS at the current time and the progression towards this ability is expected to be slow (Mcgratten, 2008).

\subsection{Numerical Simulations of PPUF Slabs}

The 3-layer model was simulated in FDS in horizontal fuel arrangements. The simulations were designed to replicate open calorimeter experiments (Figure 1-21). The PPUF slabs measured 600 $\mathrm{mm} \times 600 \mathrm{~mm}$ with a thickness of $100 \mathrm{~mm}$ and were ignited with a $19 \mathrm{~kW}$ burner. Sensitivity to 


\section{Appendix A}

the ignition location and resulting HRR has been noted in similar experiments (Ezinwa, 2009) and was also investigated for its impact on burning. Ignition at the center of the slab produces a faster fire growth rate compared to an edge point ignition. However, the fire behavior is affected by exhaustion of fuel in the center, resulting in a lower heat release and an accelerated decay (Figure 1-22).
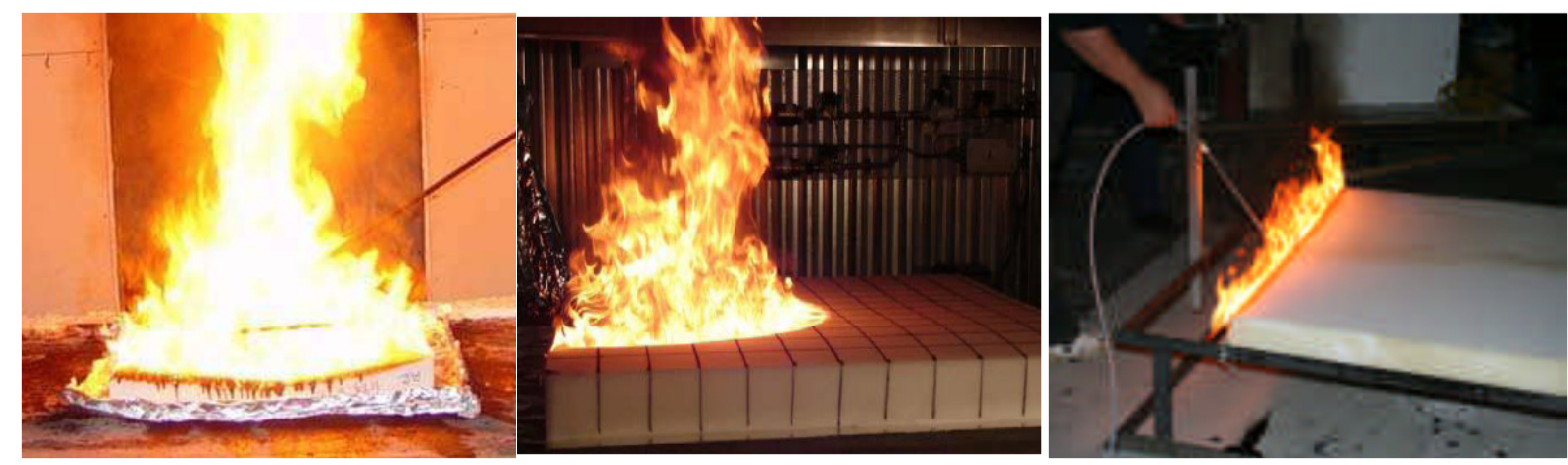

Figure 1-20 Open calorimeter experiment ignition locations center (left), edge point (middle) and edge line (right) (Bwalya, et al., 2006; Ezinwa, 2009).
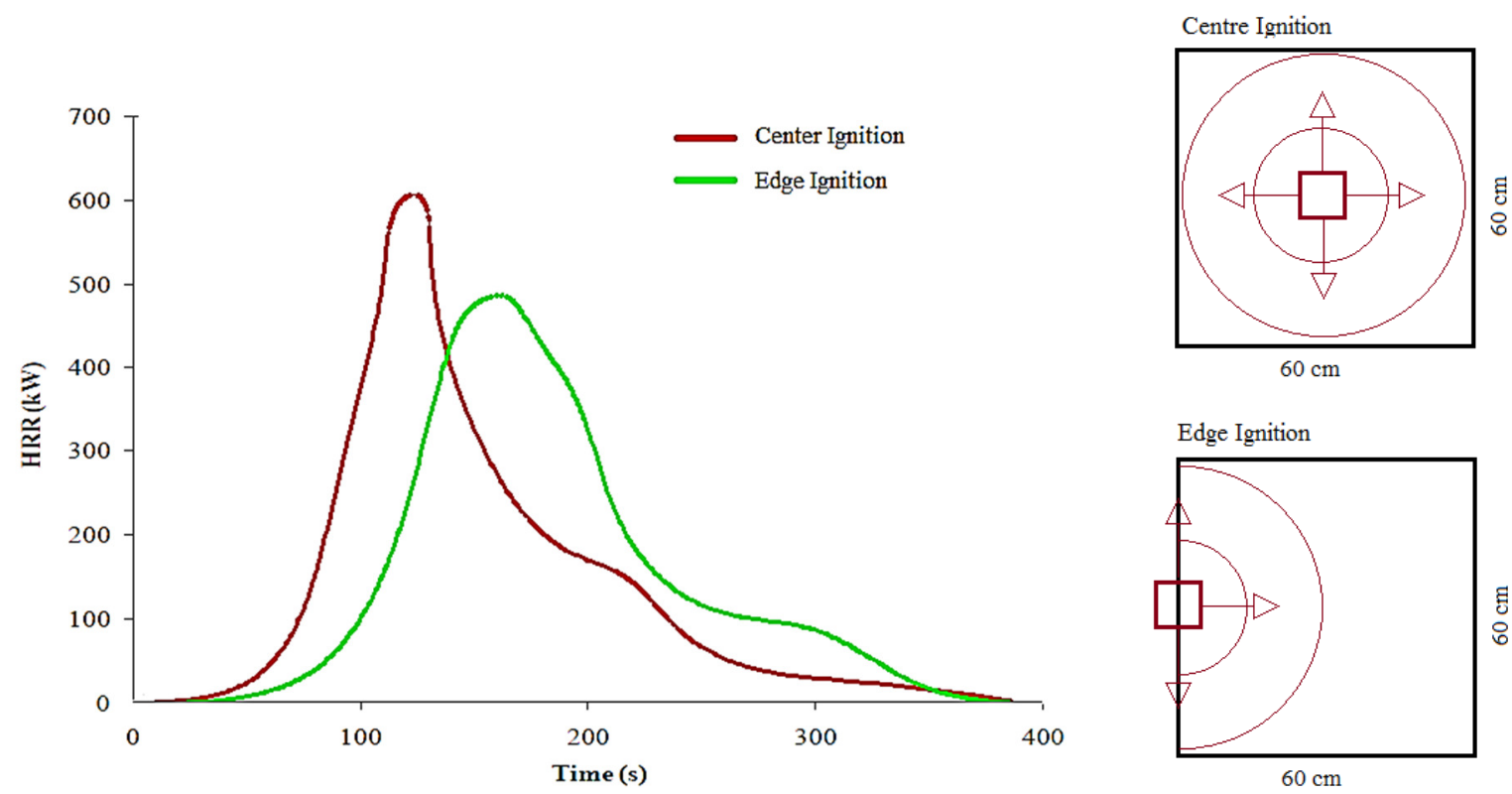

Figure 1-21 Comparison of HRR for center and edge-ignited PPUF slabs (Ezinwa, 2009), left, and schematic of flame spread over a center and edge ignited specimen

Table 1-4 PPUF composition in FDS for the two-layer and three-layer models

Layers Material

Density $\left(\mathrm{kg} / \mathrm{m}^{3}\right) \quad$ Thickness $(\mathrm{mm}) \quad$ Mass $(\mathrm{g})$ 


\section{Appendix A}

Actual PUF $\quad$ Layer $1 \quad$ PUF

FDS Model

Two-layer

\begin{tabular}{lll}
31 & 100.00 & 31.00 \\
\hline 100.00 & 31.00
\end{tabular}

\begin{tabular}{lll}
31 & 33.40 & 10.34 \\
1000 & 2.06 & 20.66 \\
\hline
\end{tabular}

Three-layer

\begin{tabular}{lll}
31 & 31.08 & 9.40 \\
285 & 2.50 & 8.60 \\
1000 & 1.30 & 13.00 \\
\hline
\end{tabular}

\subsection{Polyurethane Slab - Center Ignition}

The PPUF model ignited at the center of the slab and took approximately 160 seconds to reach peak HRR. As the fire consumes the vPPUF layer, the transitional layer is revealed and begins decomposition. The transitional layer is then consumed and reveals the final polyol layer which is heated and begins to be consumed at 80 seconds (Figure 1-23). This expands radially from the center and at 160 seconds a noticeable exhaustion of polyol in the center can be observed (where no burning is occurring), marking the fires decay. The FDS simulations demonstrated many of the characteristics observed from experiments. Comparisons with an infrared camera show an observable center burn-out noted indicating exhaustion of fuel in that area, similar to FDS results (Figure 1-24). 


\section{Appendix A}

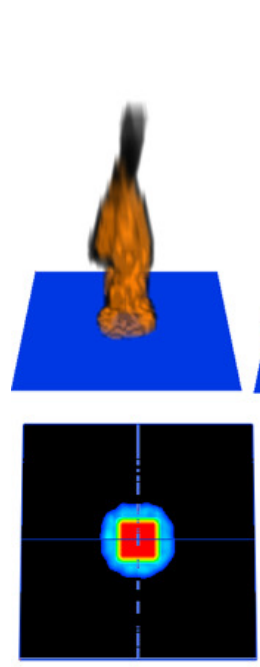

$0 \mathrm{~s}$
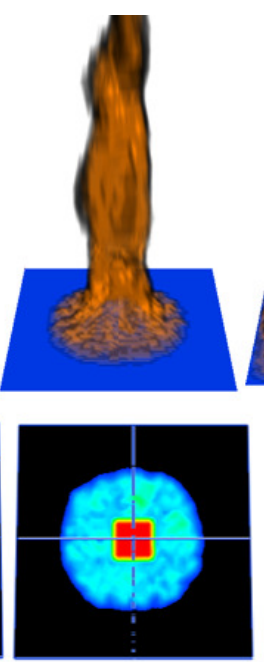

$40 \mathrm{~s}$
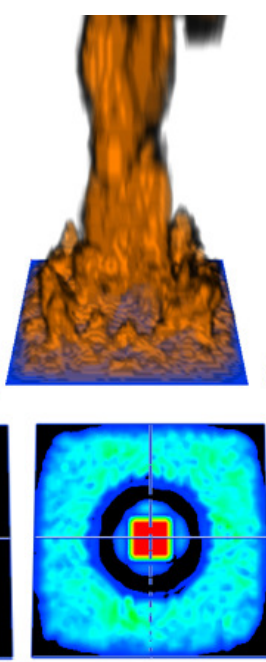

$80 \mathrm{~s}$
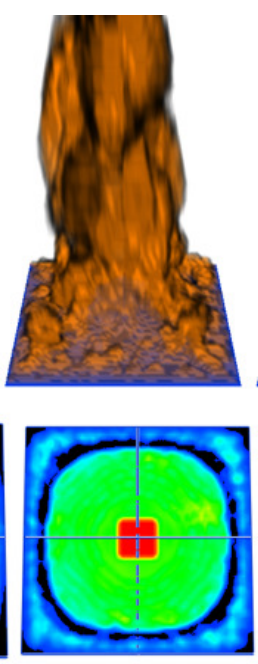

$120 \mathrm{~s}$
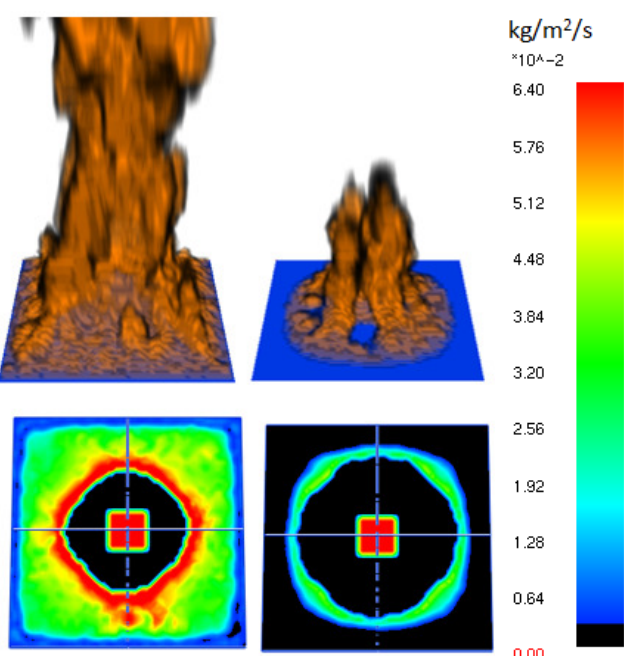

$160 \mathrm{~s}$

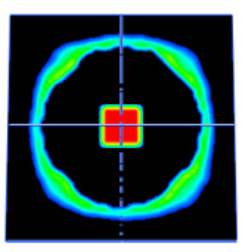

$200 \mathrm{~s}$

Figure 1-22 Simulation results of the two-layer model and its burning rate patter at given time intervals
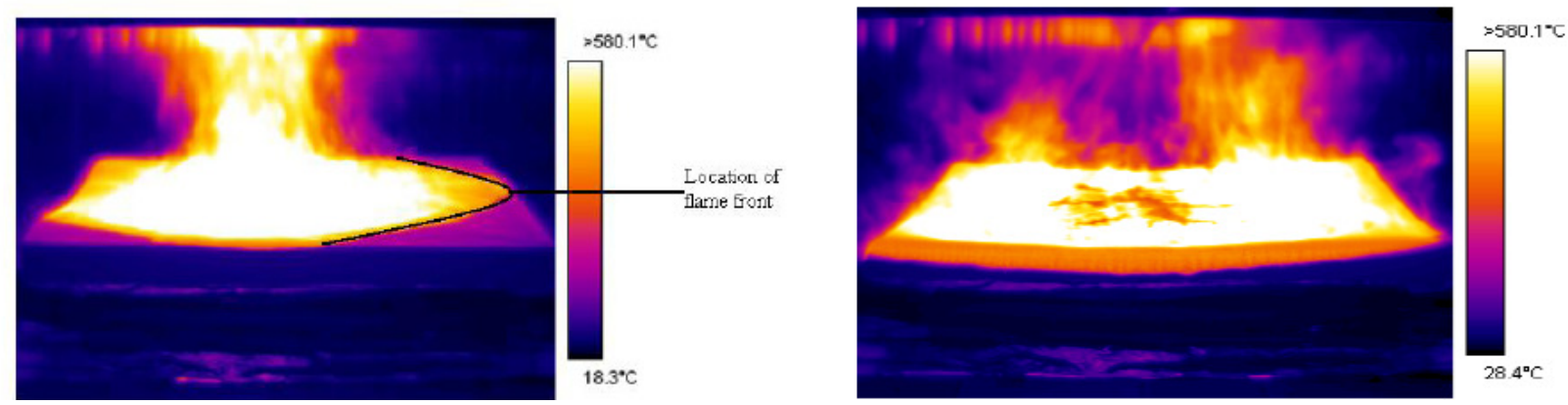

Figure 1-23 Similar independent experiment results on polyurethane slab burning with center ignition are seen with an IR camera. An observable center burn-out is noted on the image to the right, indicating exhaustion of fuel in that area, similar to FDS results (Ezinwa, 2009).

\subsection{Polyurethane Slab - Center Ignition Results}

The fire growth and peak HRR rate of the three-layer model was able to closely represent results from the NRC experiments (Figure 1-26). The peak HRR achieved was slightly lower than average results from multiple NRC experiments but demonstrated similar growth rates, reaching peak HRR at similar points in time. The total heat release was moderately less however. A significant reason for this is the models difficulty in replicating the fire decay. The exhaustion of polyol in the center of the model reduces the HRR. This intern results in a decrease of polyol 


\section{Appendix A}

decomposition and the fire declines rapidly. This problem is most pronounced in the center ignited experiment. This is investigated further by conducting a simulation where the ignition begins at the edge.

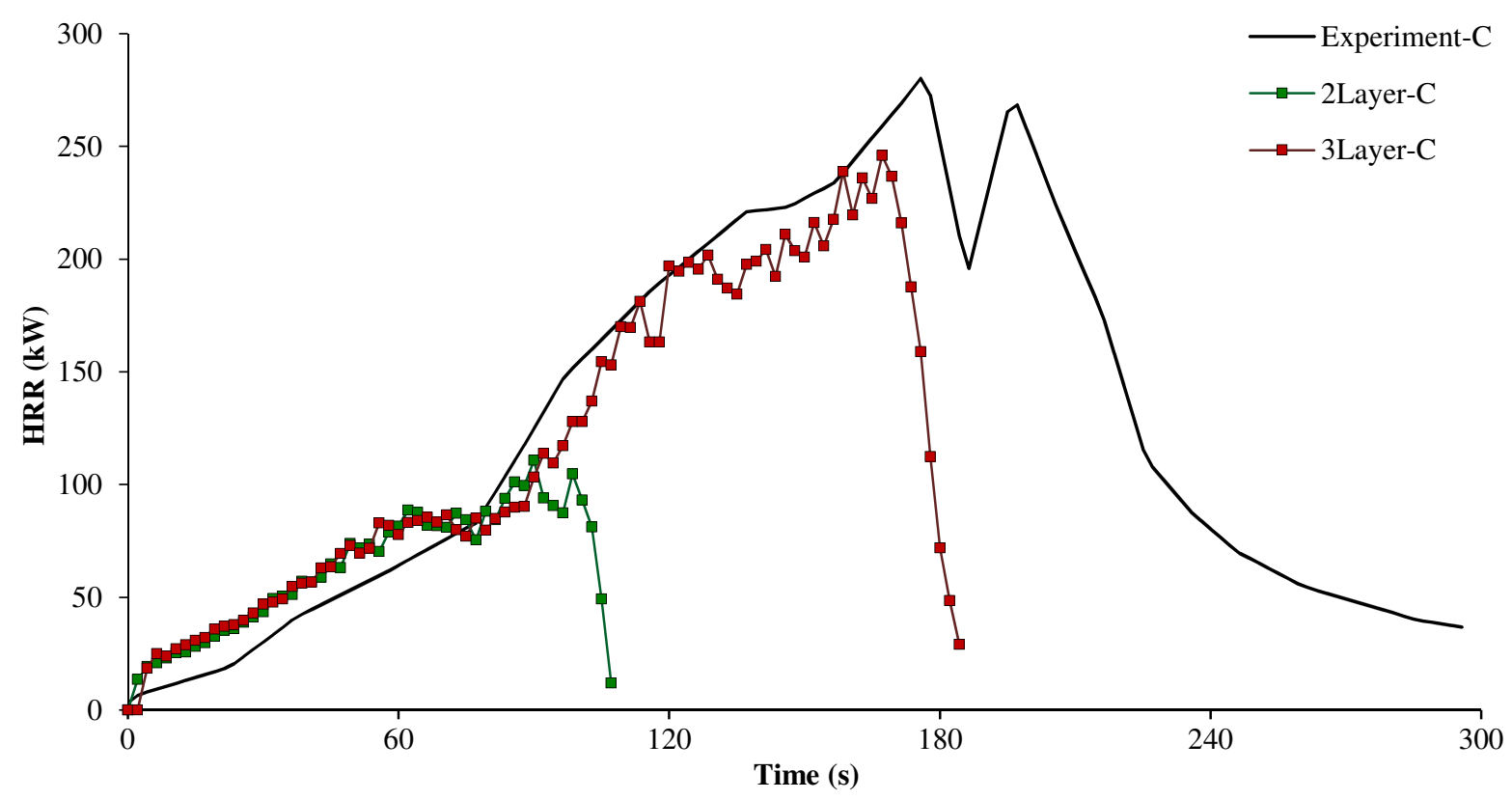

Figure 1-24 Comparison of HRR measured from NRC experiment (Experiment-C) and numerical simulations of the two-layer (2Layer-C) and three-layer models (3Layer-C)

\subsection{Polyurethane Slab - Edge Point Ignition}

A further simulation was conducted with the ignition location at the edge midpoint. The fire growth started slower as expected. It reached peak HRR at approximately 240 seconds, approximately 60 seconds after the center ignited simulation. While the exhaustion of polyol is also notable, it does not have as large of an effect on the fire duration as the fire travels directionally. Due to this, the exhausted fuel area is not at the center of the fire and does not affect the decomposition of remaining fuel as much, as seen in at 160 seconds in Figure 1-25. 


\section{Appendix A}

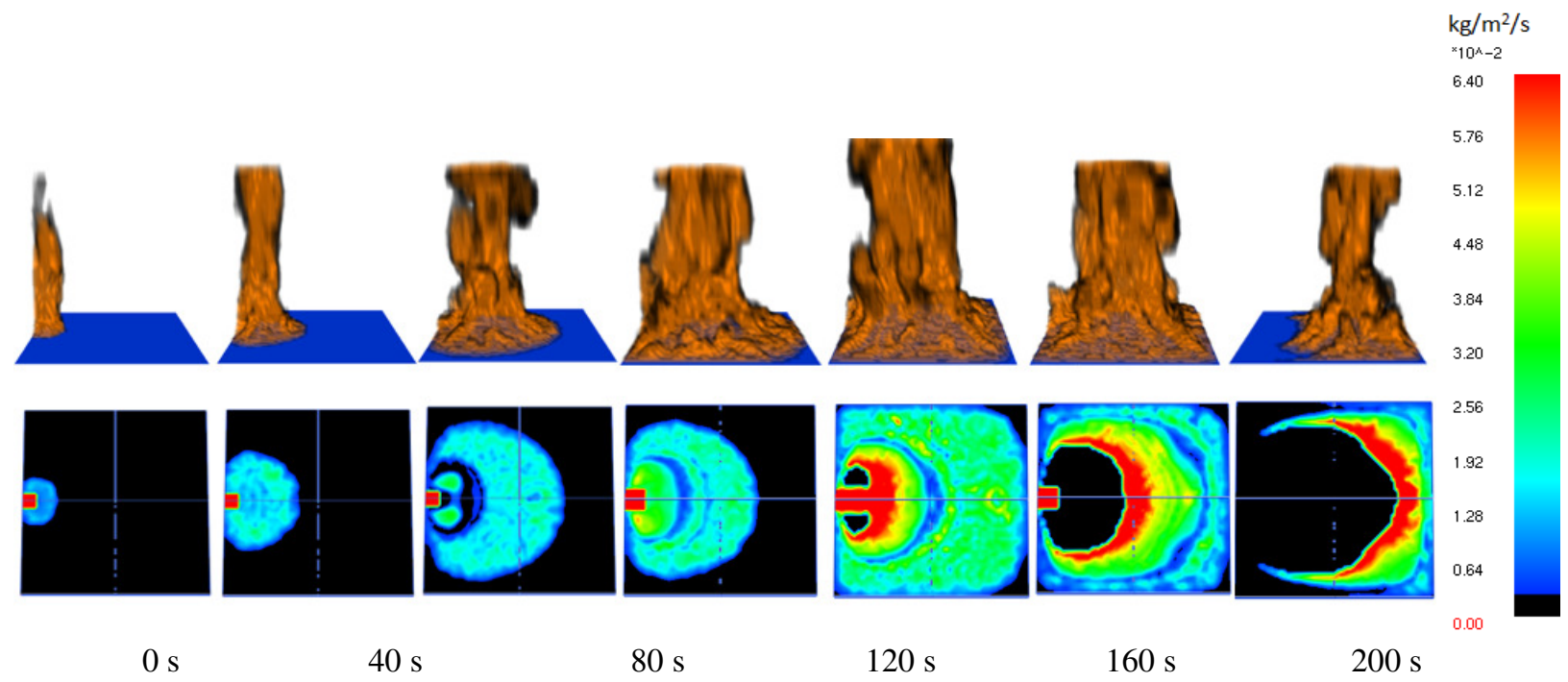

Figure 1-25 Simulation results of the two-layer model and its burning rate pattern at given time intervals

The vPPUF exist for a longer period of time and the total heat released is substantially greater.

These results prevent the decomposition of remaining polyol. Figure 1-25 shows how the central area becomes exhausted at approximately 200 seconds, coinciding with a quick decay in HRR. The HRR results from center and edge point ignition seen in Figure 1-26 are similar to actual experiments conducted, shown previously in Figure 1-21. 


\section{Appendix A}

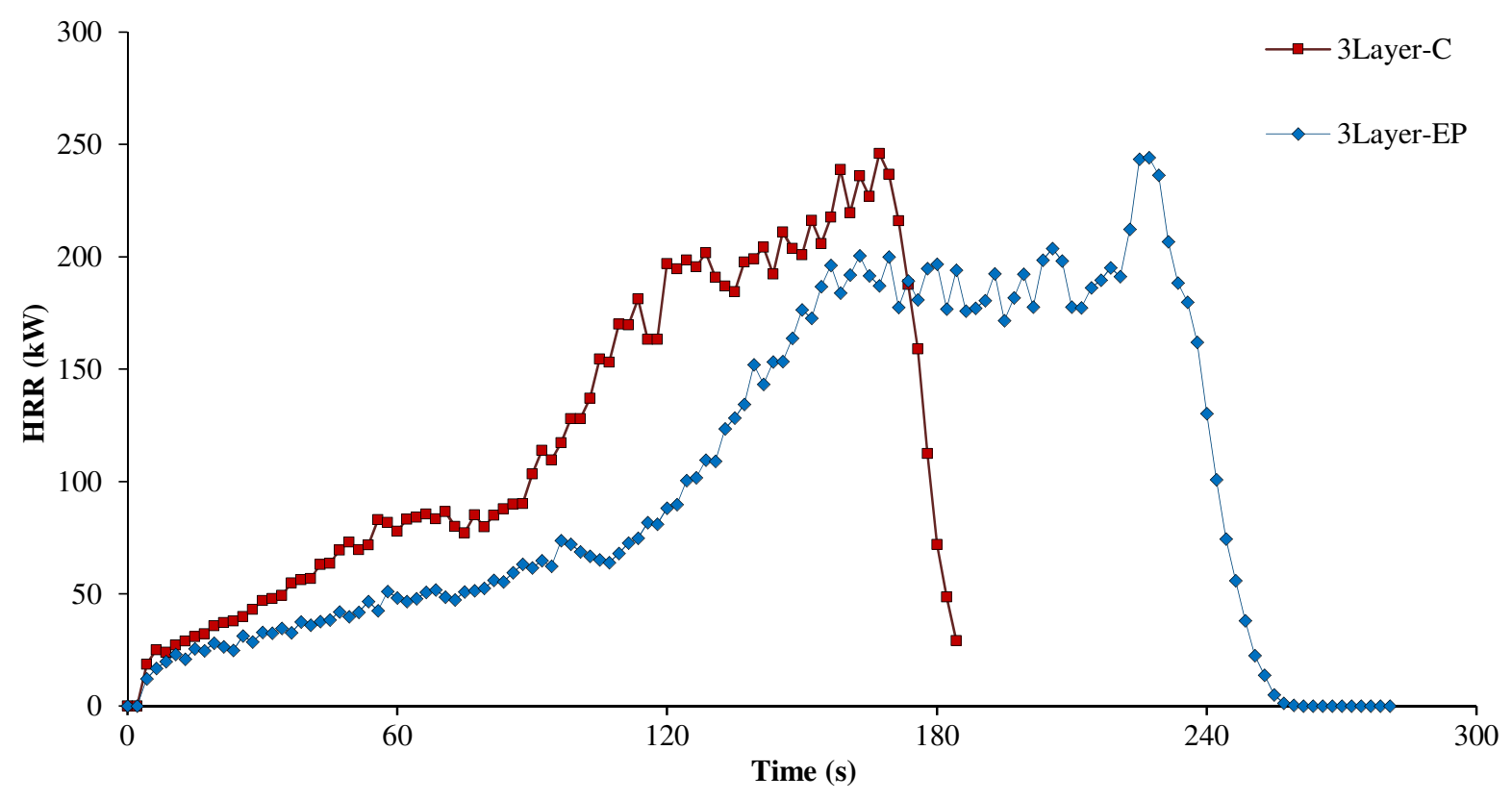

Figure 1-26 HRR results from numerical simulations of the three layer model for center (3Layer-C) and edge point ignitions (3Layer-EP)

The three-layer model can allow for close representation of the cone calorimeter experiments in regard to heat release rate across numerous heat flux. The inclusion of the transition layer, allows for combustion of both virgin foam and polyol to occur and for a gradual heat transfer to polyol. This model provides the basis for simulating fire behavior of polyurethane foam in larger scale simulations. The development of such framework models allows for classification of the potential fire hazards in built environments (Robson, 2014). The utilization of data/results gained from accurate small scale fire models can be implanted into larger scale CFD simulations at a decreased computational cost (Pau, 2013).

\subsection{Notable limitations}

As mentioned previously, the inability to simulate liquid fuel migration limits the ability to account for polyol flow. Due to this, a model which utilizes a uniform polyol layer may realize its fuel is consumed earlier at the origin of ignition compared to experiments. A current approach 


\section{Appendix A}

is to increase the polyol layer thickness to compensate. However, creating a model with multiple pre-defined polyol layers of specific thickness adds complexity when different geometries are modelled.

Creating a model to account for physical deformation and melting is required for further advancement of this model. Some work has been done to this accord, with the melting of horizontal and vertical polymer slabs experimented by Dr. Kathyrn Butler of NIST and International Center for Numerical Methods in Engineering (Butler, 2009). The synchronization of geometry changes and the fire model is a complex task, but not an impossible one. Current limitations will be overcome as the software and processing power increases.

The PPUF three-layer model has been tested for horizontal slabs. The thickness of the slabs tested during these studies commonly ranged between $50 \mathrm{~mm}$ and $100 \mathrm{~mm}$. Examining the impact of foam thickness is of interest for further study. It is assumed, that the transitional layer thickness would likely remain similar between a $100 \mathrm{~mm}$ slab and a thicker slab. The thickness of the transitional layer is only required acts as a sufficient heat transfer mechanism between vPPUF and polyol. Further experiments in burning of PPUF slabs of various thicknesses will allow for determining whether the transitional layer and its thickness are sufficient.

Variables in manufacturing and environmental conditions limit the ability for a general comparison between polyurethane foams and calorimetry experiments. The variety and type of commercially available polyurethane foams is vast, with varying thermo-physical properties affecting the burning rate and combustion products. This applies significantly to PPUF as the 


\section{Appendix A}

density for flexible foams can range between 15 to $130 \mathrm{~kg} / \mathrm{m}^{3}$ (Eurofoam, n.d.). Additives and fire retardants may result in a substantially reduced fire growth potential.

The humidity of the environment has a significant impact on burning due to PPUF's porous nature. A change in PPUF relative humidity from $20 \%$ to $80 \%$ in laboratory experiments, has been demonstrated to reduce the peak HRR by $10 \%$ (Robson, 2014). This will also have an effect on burning behavior and flame spread rate as well. A decrease in HRR will reduce the probability of polyol being completely consumed.

\subsection{Conclusions and Ongoing Work}

The difficulties encountered in numerical simulations due to the densities between the vPPUF and polyol layers can be overcome with the transition layer. The transition layer, allows for pyrolysis of polyol to occur by allowing sufficient heat transfer to the polyol layer. The composition of this layer was determined through parametric analysis of its mass and composition. Its use in the modelling of PPUF through the three-layer method can allow for close representation of horizontal slab experiments. Similarities in fire growth and peak size were observed between actual experiments.

This model provides the basis for simulating fire behavior of PPUF in larger scale simulations. The development of such framework models allows for classification of the potential fire hazards in built environments (Robson, 2014). The utilization of data/results gained from accurate small scale fire models can be implanted into larger scale CFD simulations at a decreased computational cost (Pau, 2013). The complex nature of the polyurethane foam and its polyol byproduct will still remain obstacles in the ability to predict fire growth. The advancement of numerical simulations and CFD is continual and limitations which currently prevent modeling of 


\section{Appendix A}

liquid and moving fuel will eventually be addressed. An analysis of foam orientations is being investigated to determine how variables related to polyol migration can be estimated and integrated into the model.

\section{References}

Babrauskas, V., \& Grayson, S. (1990). Heat release in fires. Taylor \& Francis.

Butler, K. (2009). A model of melting and dripping thermoplastic objects in fire. 11th international fire and materials conference, (pp. pp 341-352).

Bwalya, A., Carpenter, D. W., Kanabus-Kaminska, J. M., Lougheed, G. D., Su, J. Z., Taber, B. C., . . Thomas, J. R. (2006). Development of a Fuel Package for Use in the Fire Performance of Houses Project. Ottawa: National Research Council Canada.

Bwalya, A., Lougheed, G. D., Kashef, A., \& Saber, H. H. (2007). Survey Results of Combustible Contents and Floor Areas in Multifamily. Ottawa: National Research Council of Canada.

Bwayla, A. (2008, 10 14). Video of PPUF experiment.

Czichos, H., Saito, T., Smith, L., \& Czichos, H. (2011). Material-Environment Interactions. In Handbook of Metrology and Testing (p. 8). Berlin: Springer Science \& Business Media.

Eurofoam. (n.d.). Polyurethane foam types. (Eurofoam) Retrieved 2 5, 2015, from http://www.eurofoam.hu/habtipusok-en/technical-purpose-foams/1/

Ezinwa, J. U. (2009). Modeling full-scale fire test behavoir of polyurethane foams using cone calorimeter data (Unpublished masters thesis). University of Saskatchewan, Department of Mechanical Engineering. 


\section{Appendix A}

International Organization for Standardization. (2007, January 9). Building materials and products - Hygrothermal properties - Tabulated design values and procedures for determining declared and design thermal values. Retrieved 3 12, 2015, from http://www.iuav.it/Ateneo1/docenti/architettu/docenti-st/Fabio-Pero/materiali-/corsotecn1/_mat-_ISO_FDIS-10456--dati-materiali.pdf

Krämera, R., Zammarano, M., Linterisb, G., \& Gedde, T. (2010). Heat release and structural collapse of flexible polyurethane foam. Polymer Degradation and Stability, 95(6), Pages $1115-1122$.

McGrattan, K. K. (2015). Fire Dynamics Simulator(Version 5) User's Guide. NIST Special Publication 1019-5.

Mcgratten, K. (2008, 4 8). Coupling the Eulerian (FDS) and Lagrangian (PFEM) fluid solver. Retrieved from https://groups.google.com/forum/\#!topic/fds-smv/nh4OjO8fj_Q

Meunders, A., Baker, G., Arnold, L., Schroeder, B., Spearpoint, M., \& Pau, D. (2014). Parameter Optimization and Sensitivity Analysis for Fire Spread Modelling with FDS. Gold Coast, Australia: 10th International Conference on Performance-Based Codes and Fire Safety Design Methods.

National Fire Protection Association. (2013, September). Upholstered Furniture Flammability. Retrieved 4 12, 2015, from National Fire Protection Association: http://www.nfpa.org/ /media/Files/Research/NFPA\%20reports/Major\%20Causes/Uphols teredFurnitureWhitePaper.pdf

Pau, D. (2013). A Comparative Study on Combustion Behaviours of Polyurethane Foams with Numerical Simulations using Pyrolysis Models. Christchurch: Department of Civil and Natural Resources Engineering, University of Canterbury. 


\section{Appendix A}

Pau, D., Fleischmann, C., Spearpoint, M., \& Li, K. (2013). Determination of kinetic properties of polyurethane foam decomposition for pyrolysis modelling. Journal of Fire Science, 1-29.

Pau, D., Fleischmann, C., Spearpoint, M., \& Li, K. (2014). Sensitivity of Heat of Reaction for Polyurethane Foams. International Association for Fire Safety Science.

Pau, D., Fleishmann, C., Spearpoint, M., \& Li, K. (2014, June). Thermophysical properties of polyurethane foam and their melts. Fire and Materials, 38(4), 18.

Pitts, W. M. (2007). Ignition of Cellulosic Fuels by Heated and Radiative Surfaces. National Institute of Standards and Technology.

Prassad, K., Kramer, R., Marsh, N., Nyden, M., Ohlemiller, T., \& Zammarno, M. (2009). Numerical Simulation of Fire Spread on Polyurethane Foam Slabs. Fire Research Division. Gaithersburg: National Institute of Standards and Technology.

Rein, G., Lautenberger, C., \& Fernandez-Pello, C. (2006). Application of Genetic Algorithms and Thermogravimetry to Determine the Kinetics of Polyurethane Foam in Smoldering Combustion. Berkeley: Department of Mechanical Engineering, University of California.

Robson, L. D. (2014). Scalability of Cone Calorimter Test results for the prediction of full scale fire behavior of polyurethane foam. Saskatoon: University of Saskatchewan Department of Mechanical Engineering.

Valencia, L. B. (2009). Experimental and numerical investigation of the thermal de-composition of materials at three scales: application to polyether polyurethane foam used in upholstered furniture (Unpublished doctoral dissertation). École Nationale Supérieure de Mécanique et d'Aérotechnique, Chasseneuil-du-Poitou. 


\section{References}

Toronto Transit Commission. (2011, March 4). Toronto Transit Commission. Retrieved

November 1, 2014, from

http://www.ttc.ca/PDF/About_the_TTC/Union_Subway_Station/Union_Subway_Station _Presentation_March_4_2011.pdf

Blison, M., \& Marsico, S. (2014). Fixed Fire Fighting Systems in Road. Network, 16-18.

Bow, J. (2015, 6 25). The T-1 (Toronto) Series Cars. Retrieved from Transit Toronto: http://transit.toronto.on.ca/subway/5505.shtml

Brewer, R., \& Morrison, L. (2015). Fire Alarm Detection in High-Ceiling Rooms. 35th Annual Conference of the Canadian Nuclear Society. Saint John: Canadian Nuclear Society.

Bukowski, R. (2008). Emergency Egress from Buildings Part 1: History and Current Regulations for Egress Systems Design. Sky is the Limit (pp. 167-191). Auckland: Society of Fire Protection Engineers.

Butler, K. M., \& Mulholland, G. W. (2004). Generation and Transport of Smoke Components. Fire Technology(40), 149-176.

Chiam, B. H. (2005). Numerical Simulation of a Metro Train Fire. Department of Civil Engineering. Christchurch: University of Canterbury.

Choi, J., Hwang, H., \& Hong, W. (2011). Predicting the Probability of Evacuation Congestion Occurrence Relating to Elapsed Time and Vertical Section in a High-rise. Pedestrian and Evacuation Dynamics, 37-40.

Chow, W. K. (2004). Fire Safety of the Railway Systems. International Journal on Architectural Science, 5(2), 35-45. 
Chow, W. K. (2012). Concerns on estimating heat release rate of design fires in fire engineering approach. International Journal on Engineering Performance-Based Fire Codes, 11(1), 11-19.

Chow, W. K., Lam, K. C., Fong, N. K., Li, S. S., \& Gao, Y. (2011). Numerical Simulations for a Typical Train Fire in China. Modelling and Simulation in Engineering, 2011, 7.

Cox, G., Chitty, R., \& Kumar, S. (1989). Fire modelling and the King's Cross Fire Investigation. Fire Safety Journal(15), 103-106.

Crean, F. (2012). Tunnel Vision: An Investigation into the Toronto Transit Commission Second Exit Project at Donlands and Greenwood Stations. Toronto: Office of the Ombudsman.

Ferrazzini, M., Busslinger, A., \& Reinke, P. (2011). Smoke ventilation concepts of CEVA - an underground rail link with 4 stations. Dundee: BHR Group.

Hirschler, M. M. (2005). Critique of "ISO TS 13571 - 2002 - Life-threatening components of fire - Guidelines for the estimation of time available for escape using fire data". Mill Valley: GBH International.

Hong, W. (2004). The Progress and Controlling Situation of Daegu Subway Fire Disaster. 6th Asia-Oceania Symposium on Fire Science and technology, (pp. 28-46). Dague.

Kayili, S. (2005). CFD Simulation of Fire and Ventilation in the Stations of Underground Transportation Systems. Ankara: Middle East technical University.

Lee, S., \& Hong, S. (2006). An Experimental Study of the Effect of the Aspect Ratio on the Critical Velocity in Longitudinal Ventilation Tunnel Fires. Journal of Fire Science, 23, 119-139.

Li, Y. Z. (2014). Fire development in different scales of train carriages Draft. Fire Science proceedings of the eleventh international symposium. 
Li, Y. Z., \& Ingason, H. (2015). Fire-induced ceiling jet characteristics in tunnels under different ventilation conditions. Brandforsk: SP Technical Research Institute of Sweden.

Liu, Y. S. (2014). Smoke Management in Subway Stations Due to Train Arson Fire Scenario. Sixth International Symposium on Tunnel Safety and Security. Marseille,.

Lo, K. (2009). Skytrain- Hyundai Rotem.

Madrzykowski, D., Forney, G., \& Walton, W. (1999). Simulation of the Dynamics of a Fire in a Two-Storey Duplex. Gaithersburg, Maryland: National Institute of Standards and Technology (NIST).

McGrattan , K., \& Hamins, A. (2006). Numerical Simulation of the Howard Street Tunnel Fire. Fire Technology, 273-281.

McGrattan, K., Baum, H., Rehm, R., Mell, W., McDermott, R., Hostikka, S., \& Floyd, J. (2010). Fire Dynamics Simulator (Version 5) Technical Reference Guide, Volume 1: Mathematical Model. Gaithersburg, MD: National Institute of Standards and Technology.

National Fire Protection Association. (2008, February 8). Fire Dynamics Simulator Journal. Retrieved from National Fire Protection Association: http://www.nfpa.org/newsandpublications/nfpa-journal/2008/january-february2008/features/fire-dynamics-simulator/

National Fire Protection Association. (2009). NFPA 101, Life Safety code. Massachusetts: National Fire Proteection Association.

Poh, D. W. (2010). Tenability in Building Fires: Limits and Design Criteria. Industry Matters, pp. 24-26. 
Rhodes, N., McCulloch, M., \& Wong, H. (2008). Upgrading Toronto's University Subway Line Ventilation System. 4thInternational Conference 'Tunnel Safety and Ventilation. New York.

Sargant, T., Nightingale, S., Dinsdale-Young, O., \& Ganeshalingam, J. (2014). Evacuation modelling in road tunnel fire events, CFD influencing evacuation results. Fire and Evacuation Modeling Technical Conference, (pp. 1-20). Gaithersburg.

Schachenmayr, M. (1998). Application Guidelines. Parsons Brinckerhoff Quade \& Douglas, Inc. Singapore Civil Defence Force. (2012). Standard for Fire Safety in Rapid Transit Systems, 2012 Edition. Singapore.

Society of Fire Protection Engineers. (1998). SFPE Handbook of Fire Protection engineering. Massachusetts: National Fire Protection Association,. Society of Fire Safety. (2014). Practice Note for Tenability Criteria in Building Fires. Barton: The Society of Fire Safety.

Thunderhead Engineering. (2012). Pathfinder 2012 Technical Reference.

Toronto Transit. (2015, 04 02). TTC looks at installing safety screens on subway platforms. Retrieved from http://transit.toronto.on.ca/archives/data/200805231826.shtml Toronto Transit Commission. (2015, 6 12). TTC Planning Process and Principles. Retrieved from Toronto Transit Commission - TTC: https://www.ttc.ca/About_the_TTC/Projects/Second_Exit_Projects/Second_Exit_Plannin g/index.jsp

Translink. (2011). Millennium and Canada Line Station Counts Program. Vancouver: South Coast BC Transportation Authority. 
TransLink. (2015, 3 10). Improved interiors for the new SkyTrain cars. Retrieved from TransLink: https://buzzer.translink.ca/2009/05/improved-interiors-for-the-new-skytraincars/

White, N., Dowling, V., \& Barnett, J. (2005). Full-scale Fire Experiment on a Typical Passenger Train. Fire Safety Science - Proceedings of the eigth international symposium (pp. 11571168). Victoria: International Association for Fire Safety Science.

Wu, Y., \& Bakar, M. (2000). Control of smoke flow in tunnel fires using longitudinal ventilation systems - a study of the critical velocity. Fire Safety Journal(35), 363-390.

Yunlong, L., Cassady, S., Casey, J., \& Zlat, S. (2014). Smoke Management in Subway Stations Due to Train Arson Fire Scenario. Sixth International Symposium on Tunnel Safety and Security. Marseille,

Zhou, R., Zhang, W., Zhu, D., \& Zhao, D. (2013). Smoke Diffusion Research in Different Architectural Structure of Platform Layer with PSD in Subway Station Fires. International Journal of Advancements in Computing Technology, 5(1). 